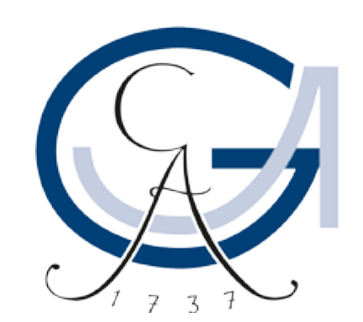

\title{
Biochemical characterization of presynaptic membrane protein complexes
}

\author{
Dissertation \\ for the award of the degree \\ “Doctor rerum naturalium” (Dr. rer. nat.) \\ of the Georg-August-Universität Göttingen \\ within the doctoral program Molecular Biology \\ of the Georg-August University School of Science (GAUSS) \\ submitted by \\ Momchil Nikolaev Ninov
}

born in

Pleven, Bulgaria

Göttingen 2015 


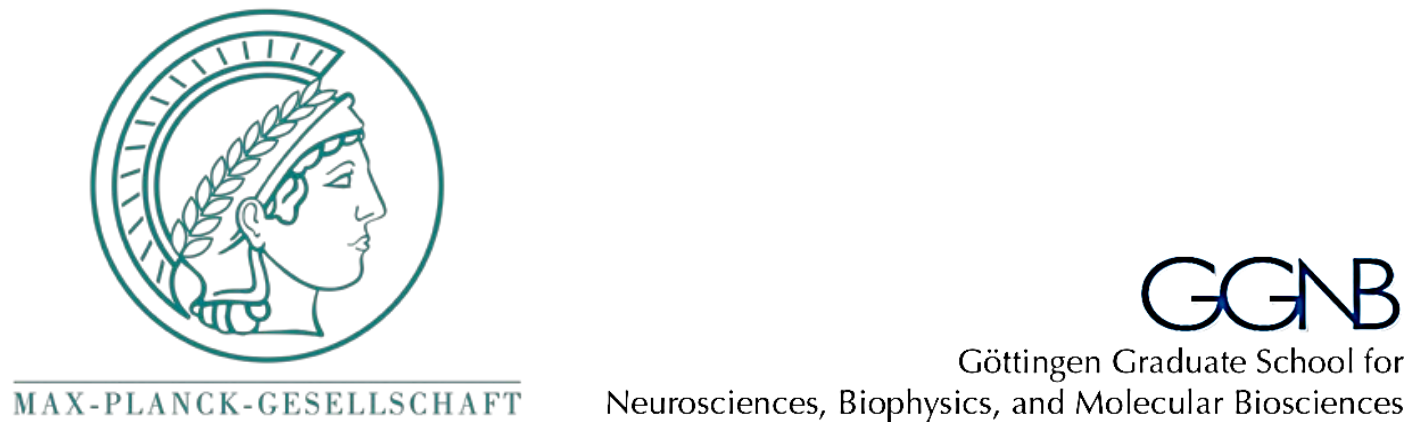

Göttingen Graduate School for Neurosciences, Biophysics, and Molecular Biosciences

\section{Members of the PhD Thesis Committee:}

\section{Prof. Dr. Reinhard Jahn (1 ${ }^{\text {st }}$ Reviewer and Supervisor $)$}

Department of Neurobiology, Max Planck Institute for Biophysical Chemistry, Göttingen Prof. Dr. Henning Urlaub (2 ${ }^{\text {nd }}$ Reviewer $)$

Research Group Bioanalytical Mass Spectrometry, Max Planck Institute for Biophysical Chemistry and Proteomics Core Facility, Institute of Clinical Chemistry, University Medical Center, Göttingen

Prof. Dr. Silvio Rizzoli

Department of Neuro- and Sensory Physiology, University Medical Center, Göttingen

\section{Further Members of the Examination Board}

\section{Prof. Dr. Nils Brose}

Department of Molecular Neurobiology, Max Planck Institute for Experimental Medicine, Göttingen

\section{Prof. Dr. Tobias Moser}

Research Group Synaptic Nanophysiology, Max Planck Institute for Biophysical Chemistry and Institute for Auditory Neuroscience, University Medical Center, Göttingen

\section{Prof. Dr. Jürgen Wienands}

Institute for Cellular and Molecular Immunology, University Medical Center, Göttingen 


\section{Declaration of Authorship}

Hereby, I declare, that I prepared this work entitled "Biochemical characterization of presynaptic membrane protein complexes” entirely on my own and that I have only used the sources and materials cited.

Göttingen, June 2015

/Momchil Ninov/ 


\section{Аз съм българче}

\section{/Иван Вазов/}

Аз съм българче и силна майка мене е родила; с хубости, блага обилна мойта родина е мила.

Аз съм българче. Обичам наште планини зелени, българин да се наричам първа радост е за мене.

Аз съм българче свободно, в край свободен аз живея, всичко българско и родно любя, тача и милея.

Аз съм българче и расна в дни велики, в славно време, син съм на земя прекрасна, син съм на юнашко племе. 


\section{Abstract}

At chemical synapses, synaptic vesicles, membrane-enclosed entities filled with neurotransmitters, undergo exocytosis at restricted areas of the presynaptic membrane called active zones (AZ). The core AZ proteins form a heterogeneous dynamic network in functional collaboration with many soluble and integral proteins. This network, called cytomatrix at the active zone (CAZ), represents a biochemical challenge due to its limited detergent solubilization. In addition, there is a big gap in the knowledge about the extractability of proteins associated with the presynaptic cytomatrix. Often, analyses focused on the extraction of a particular protein of interest and the identification of copurified proteins without any further validation of the findings. However, till date, no report has systematically investigated the solubilization of synaptic membranes by detergents. Our main goal was to characterize biochemically presynaptic membrane protein complexes. For this reason, I established a systematic protocol for non-denaturing solubilization of synaptic membranes. Moreover, the extractability of broad spectrum of presynaptic and postsynaptic proteins was assessed by immunoblots. The solubilization protocol considered experimental parameters like rotor type, centrifugation time as well as nature of the starting material. Interestingly, I found that the most proteins (integral, soluble and scaffolding) associated with the presynaptic CAZ were better extracted than the postsynaptic density-associated proteins. Importantly, for first time, a complete or partial extraction of very large cytomatrix proteins such as Piccolo and Bassoon using cholate, taurodeoxycholate and dodecyl- $\beta$-D-maltoside detergents was achieved. Moreover, the use of these detergents under optimized solubilization conditions allowed the extraction of all core AZ constituents as well as of many regulatory and scaffolding proteins, ion channels and receptors. Furthermore, I used density gradient centrifugation and size exclusion chromatography for separation of membrane-derived extracts. These results suggested possible preservation of protein-protein interactions during the solubilization process regardless of the used detergent. Additionally, in order to validate the established extraction protocol, I studied the presynaptic membrane protein syntaxin 1 in more detail. The target was immunoprecipitated from cholate extracts under two different conditions. The proteins, co-immunopurified with syntaxin 1, were analyzed by quantitative mass spectrometry. The use of stringent parameters in the statistical evaluation of the proteomics data allowed identification of 158 and 275 proteins above 
the threshold margin under high and low salt conditions, respectively. Both groups of proteins overlapped almost completely and emphasized the reproducibility of the data. In line with our goals, more than $95 \%$ of the identified proteins, that passed the filtering criteria, were membrane proteins. Many of these proteins were shown in earlier studies to interact directly with syntaxin 1 or form multimeric complexes with its participation. These results supported the idea of successful membrane protein extraction under preservation of protein-protein interactions. They also underline the usefulness of our protocol for the study of other presynaptic proteins and their complexes. 


\section{Contents}

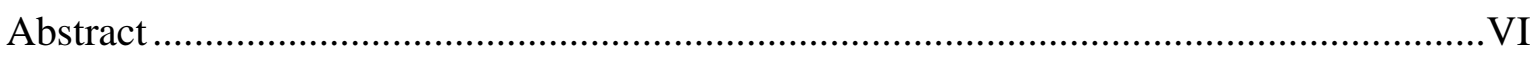

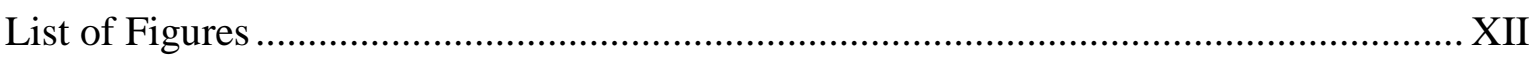

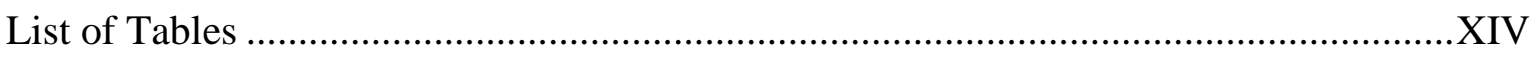

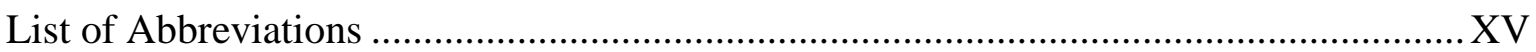

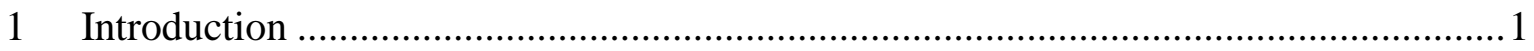

1.1 Aspects of structural and functional organization of the active zone .....................1

1.2 Molecular organization of the active zone ................................................................

1.2.1 Core active zone proteins............................................................................

1.2.1.1 RIM protein family members .....................................................................

1.2.1.2 UNC13/Munc13 protein family ……………………...............................

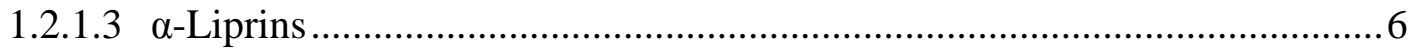

1.2.1.4 ELKS proteins - major structural organizers of the CAZ ..............................

1.2.1.5 RIM-binding proteins (RIM-BPs) .............................................................

1.2.2 Scaffolding proteins at the active zone .......................................................

1.2.3 Detergent classification...............................................................................11

1.2.4 Detergent's properties in solution.........................................................12

1.2.5 Use of detergents for membrane solubilization .............................................15

1.3 Affinity purification and quantitative proteomics...................................................17

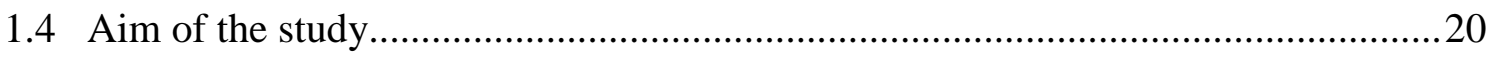

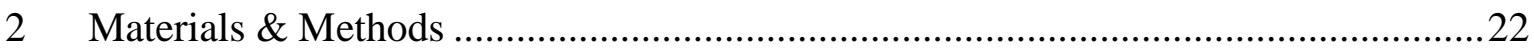

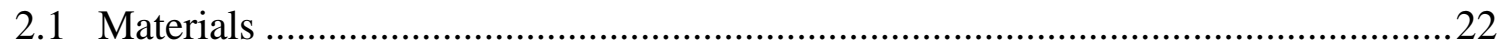

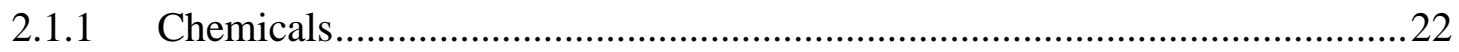

2.1.2 Commercial kits ............................................................................ 23

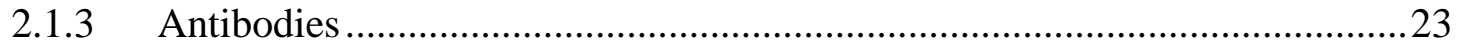

2.1.4 Buffers and media .....................................................................................29 


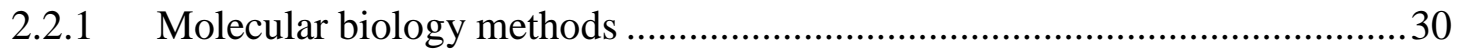

2.2.1.1 Protein concentration determination ...........................................................30

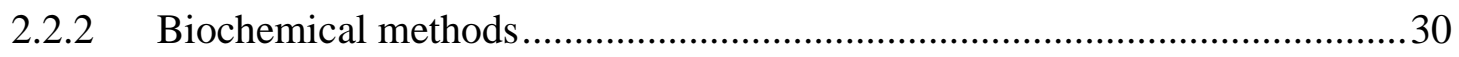

2.2.2.1 SDS-PAGE and Western blotting ..........................................................

2.2.2.2 Preparation of beads for immunoisolation .............................................. 31

2.2.2.3 Preparation of synaptosomes and LP1 fraction .......................................33

2.2.2.4 Proteolytic treatment ("shaving”) of synaptosomes ..................................35

2.2.2.5 Solubilization of synaptosomes and LP1 fraction...................................35

2.2.2.6 Sucrose density gradient centrifugation ...............................................36

2.2.2.7 Chromatographic fractionation of solubilized LP1 samples ......................36

2.2.3 Mass spectrometry methods................................................................... 37

2.2.3.1 On-beads-digestion of immunoprecipitates ............................................37

2.2.3.2 Protein digestion after denaturing elution from Eupergit C1Z beads .........37

2.2.3.3 In-gel digestion of proteins after SDS-PAGE ........................................38

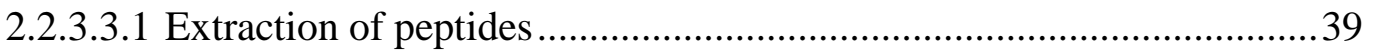

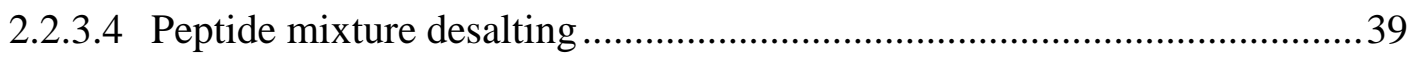

2.2.3.5 Mass spectrometry, data analysis and quantification ...............................39

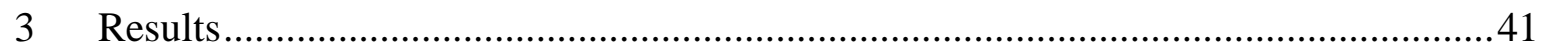

3.1 Protocol development for synaptosome solubilization and characterization of presynaptic protein complexes............................................................................. 41

3.1.1 Detergent screen for synaptosome solubilization .....................................4

3.1.2 Time- and detergent concentration-dependent solubilization........................52

3.1.3 New centrifugation protocol for solubilization experiments ........................54

3.2 Fractionation of LP1 extracts by sucrose density gradient centrifugation...............63

3.2.1 LP1 derived from non-treated synaptosomes ..........................................63

3.2.2 LP1 derived from synaptosomes subjected to limited proteolysis prior to lysis 
3.4 Immunoprecipitation of presynaptic membrane proteins under optimized extraction and centrifugation conditions..

3.4.1 Immunoprecipitation of stx 1A after cholate solubilization of LP1 fraction.81

3.5 Mass spectrometry ........ .85

3.5.1 Sample preparation for mass spectrometry .85

3.5.2 Study of the proteins co-immunoprecipitated with stx 1 by label-free quantitative proteomics . .88

3.5.2.1 Proteins co-purified with stx 1 under high salt conditions. .90

3.5.2.1.1 Synaptic vesicle proteins .91

3.5.2.1.2 SNAREs and trafficking proteins .92

3.5.2.1.3 Receptor, transporter and channel proteins .95

3.5.2.1.4 Adhesion and cell surface molecules. .98

3.5.2.1.5 Hypotethical and less characterized proteins. .99

3.5.2.1.6 Others .99

3.5.2.2 Proteins co-purified with stx 1 under low salt conditions 100

3.5.2.2.1 Synaptic vesicle proteins 102

3.5.2.2.2 SNAREs and trafficking proteins 103

3.5.2.2.3 Channels, receptors and transporter proteins.................................... 103

3.5.2.2.4 Cell surface and adhesion molecules ................................................ 105

3.5.2.2.5 Cytoskeleton proteins ................................................................... 105

3.5.2.2.6 Hypotethical and less characterized proteins....................................105

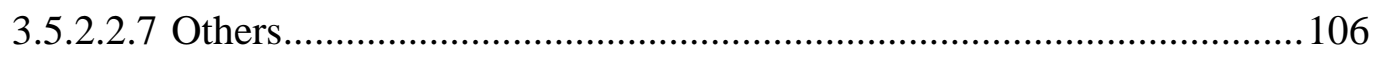

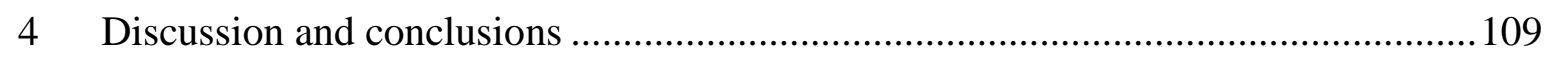

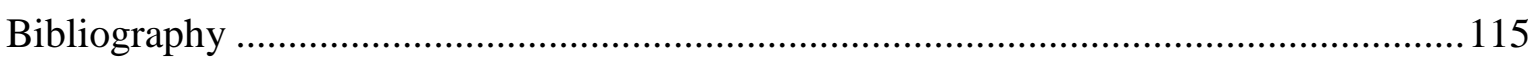

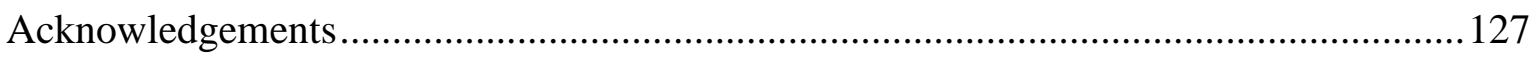

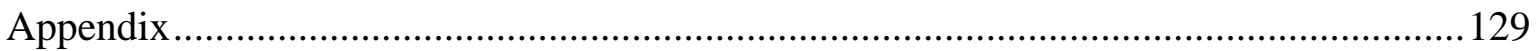

Curriculum Vitae 160 


\section{List of Figures}

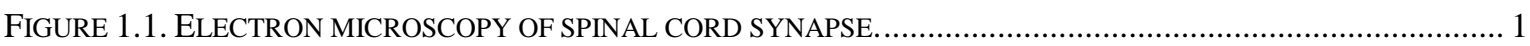

FIGURE 1.2. FUNCTIONAL ORGANIZATION OF CORE ACTIVE ZONE PROTEINS.................................................. 3

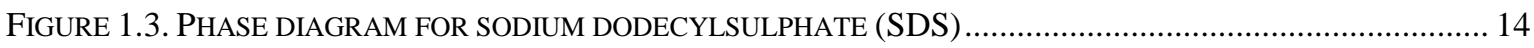

FIGURE 1.4. MECHANISM OF MEMBRANE SOLUBILIZATION BY DETERGENTS................................................... 16

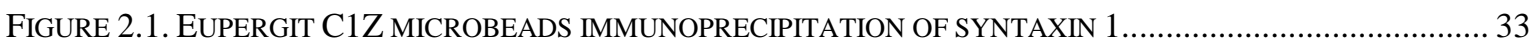

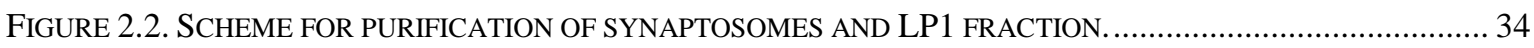

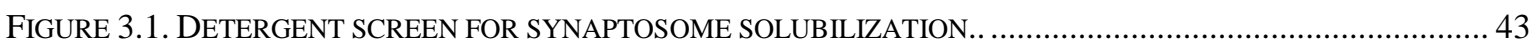

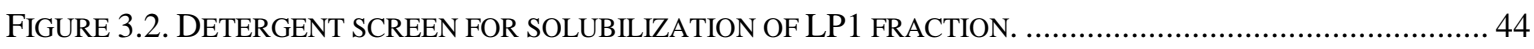

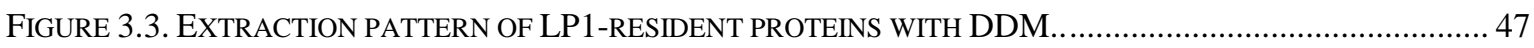

FIGURE 3.4. EXTRACTION PATTERN OF LP1-RESIDENT PROTEINS WITH TRITON X-100 …………....................... 48

FIGURE 3.5. EXTRACTION PATTERN OF LP1-RESIDENT PROTEINS WITH TDOC. ................................................ 49

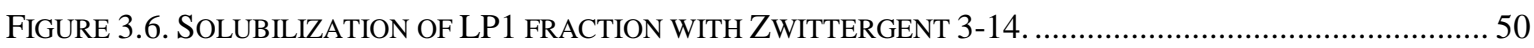

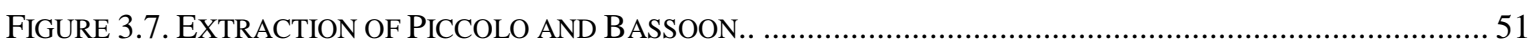

FIGURE 3.8. TIME- AND CONCENTRATION-DEPENDENT SOLUBILIZATION OF LP1 FRACTION................................ 53

FIGURE 3.9. EXTRACTION OF SV AND PLASMA MEMBRANE PROTEINS BY TDOC-SOLUBILIZATION OF LP1

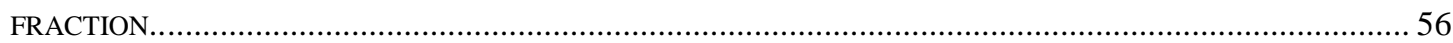

FIGURE 3.10. EXTRACTION OF ACTIVE ZONE, CAZ-ASSOCIATED AND POSTSYNAPTIC PROTEINS BY TDOC

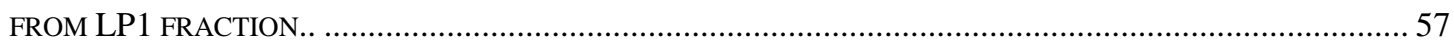

FIGURE 3.11. PROTEIN EXTRACTION PROFILE AFTER LP1 SOLUBILIZATION WITH CHOLATE............................... 59

FIGURE 3.12. PROTEIN EXTRACTION PROFILE AFTER LP1 SOLUBILIZATION WITH DDM. ........................................ 60

FIGURE 3.13. EXTRACTION OF SV AND PLASMA MEMBRANE PROTEINS FROM LP1 FRACTION WITH TRITON X100.

FIGURE 3.14. EXTRACTION OF ACTIVE ZONE, POSTSYNAPTIC AND PLASMA MEMBRANE PROTEINS FROM LP1

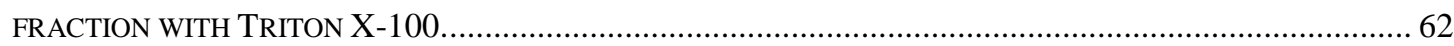

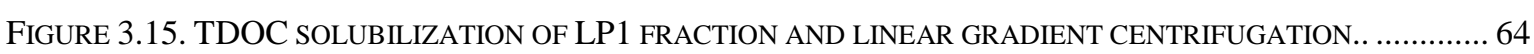

FIGURE 3.16. GRADIENT MEDIA SCREEN FOR LINEAR DENSITY CENTRIFUGATION AFTER SOLUBILIZATION OF

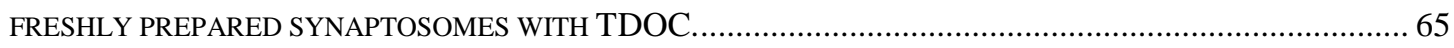

FIGURE 3.17. TDOC SOLUBILIZATION OF LP1 FRACTION AND EXTRACT SEPARATION BY $18 \mathrm{H}$ CENTRIFUGATION STEP AT $271000 \mathrm{G}$.

FIGURE 3.18. LP1 FRACTION ISOLATED FROM PROTEOLYTICALLY TREATED SYNAPTOSOMES WAS SOLUBILIZED WITH (A) TDOC, (B) TX-100 AND (C) ZWITTERGENT 3-14.

FIGURE 3.19. CHROMATOGRAPHIC SEPARATION OF CHOLATE-SOLUBILIZED LP1 FRACTION.............................. 71

FigURE 3.20. PROTEIN SEPARATION PROFILE AFTER CHOLATE SOLUBILIZATION OF LP1 FRACTION.................. 72

FIGURE 3.21. CHROMATOGRAPHIC SEPARATION OF PICCOLO AND BASSOON AFTER LP1 SOLUBILIZATION

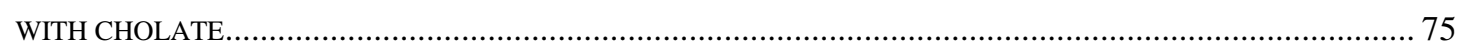

FIGURE 3.22. CHROMATOGRAPHIC SEPARATION OF TDOC-SOLUBILIZED LP1 FRACTION.................................. 77

FIGURE 3.23 CHROMATOGRAPHIC SEPARATION OF DDM-SOLUBILIZED LP1 FRACTION. .................................. 78

FigURE 3.24. IMMUNOISOLATION OF (A) STX1A AND (B) SYNCAM1/2/3 FROM CHOLATE-SOLUBILIZED LP1

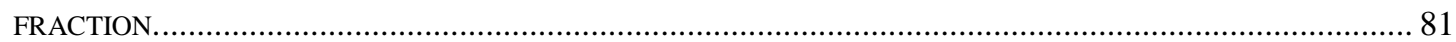

FIGURE 3.25. STX 1 IMMUNOPRECIPITATION FROM CHOLATE-SOLUBILIZED LP1 FRACTION USING HPC-1

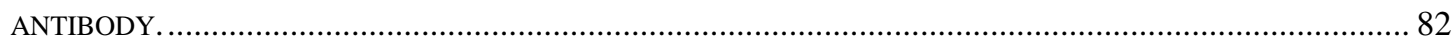

FIGURE 3.26. STX 1 IMMUNOPRECIPITATION FROM CHOLATE-SOLUBILIZED LP1 FRACTION WITH CL 78.2

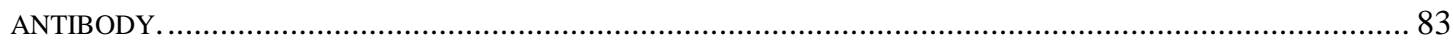

FIGURE 3.27. DIRECT APPROACH FOR IMMUNOISOLATION OF STX 1 WITH EUPRGIT C1Z-78.2 BEADS................ 84

FIGURE 3.28. SILVER STAINED SDS-PAGE GELS OF BEADS' SUPERNATANTS, TRYPSINIZED SAMPLES AND

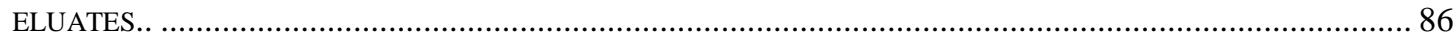

FIGURE 3.29. SILVER STAINING OF SDS-PAGE-RESOLVED PROTEINS FROM AN IP AND NEGATIVE CONTROL SAMPLE. 
FIGURE 3.30. VOLCANO PLOT REPRESENTING RESULTS FROM STX 1 IMMUNOPRECIPITATION WITH EUPERGIT C1Z-CL 78.2 BEADS UNDER HIGH SALT CONDITIONS...................................................................... 90

FIGURE 3.31. PROTEIN GROUPS AND NUMBER OF IDENTIFIED PROTEINS IN EACH GROUP STX1 IMMUNO-

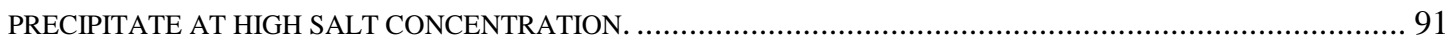

FIGURE 3.32. DISTRIBUTION OF SIGNIFICANTLY ENRICHED SV PROTEINS IN ANTI-STX 1 IPS. .......................... 92

FIGURE 3.33. DISTRIBUTION OF SIGNIFICANTLY ENRICHED SNARE AND TRAFFICKING PROTEINS IN STX 1 IP

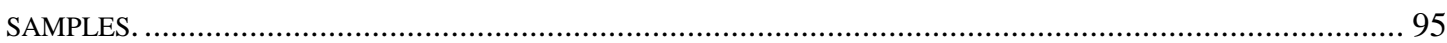

FIGURE 3.34. SIGNIFICANT AND FOLD-CHANGE ENRICHED TRANSPORTER, CHANNEL AND RECEPTOR PROTEINS

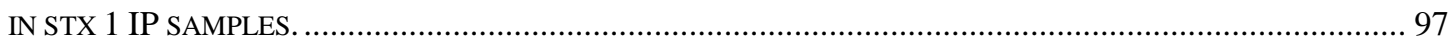

FIGURE 3.35. SIGNIFICANTLY AND FOLD-CHANGE ENRICHED CELL SURFACE AND ADHESION PROTEINS IN STX 1 IPS..

98

FIGURE 3.36. VOLCANO PLOT REPRESENTATION OF RESULTS FROM STX 1 IP WITH EUPERGIT C1Z-CL 78.2

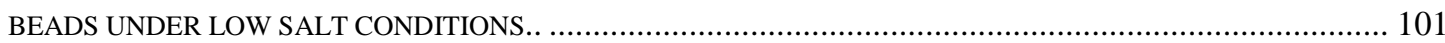

FIGURE 3.37. OVERLAP OF PROTEINS IDENTIFIED AS POSITIVE HITS UNDER LOW AND HIGH SALT IP CONDITIONS. 


\section{List of Tables}

TABLE 1.1. SUMMARY OF PROTEIN-PROTEIN INTERACTIONS BETWEEN CORE ACTIVE ZONE AND SCAFFOLDING PROTEINS.

TABLE 1.2. LIST OF DETERGENTS USED IN THE PRESENT STUDY AND SUMMARY OF THEIR MAIN

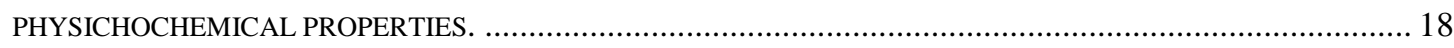

TABLE 2.1. LIST OF COMMERCIAL MATERIALS AND ALL DETERGENTS UTILIZED IN THIS STUDY......................... 22

TABLE 2.2. LIST OF ALL ANTIBODIES USED IN VARIOUS APPLICATIONS DURING THE STUDY.................................. 24

TABLE 2.3. RECIPES OF ALL IN-HOUSE PREPARED NON-COMMERCIAL SOLUTIONS AND BUFFERS. ...................... 29

TABLE 3.1. CENTRIFUGATION CONDITIONS USED IN PREVIOUS AND FOLLOWING EXPERIMENTS.......................... 55

TABLE 3.2. LIST OF IMMUNOPRECIPITATED PROTEINS AFTER LP1 SOLUBILIZATION WITH CHOLATE, DDM OR TDOC.

TABLE 3.3. SV PROTEINS IDENTIFIED AS SIGNIFICANTLY ENRICHED IN THE STX1 IP SAMPLES. ..........................93

TABLE 3.4. SNARES AND TRAFFICKING PROTEINS IDENTIFIED WITH HIGH SIGNIFICANCE AND FOLD-CHANGE

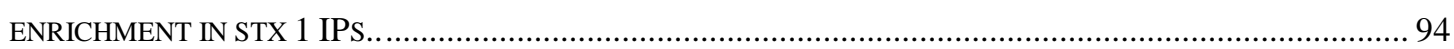

TABLE 3.5. RECEPTOR, TRANSPORTER AND CHANNEL PROTEINS IDENTIFIED WITH HIGH SIGNIFICANCE AND

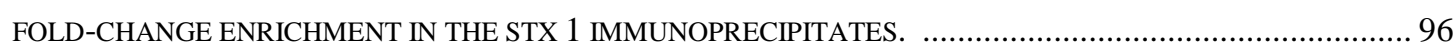

TABLE 3.6. ADHESION AND CELL SURFACE PROTEINS IDENTIFIED WITH HIGH SIGNIFICANCE AND FOLD-

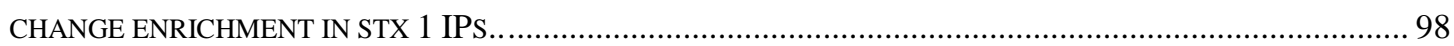

TABLE 3.7. HYPOTHETICAL OR POORLY CHARACTERIZED PROTEINS IDENTIFIED WITH HIGH SIGNIFICANCE AND FOLD-CHANGE ENRICHMENT IN THE STX 1 IPS.

TABLE 3.8. METABOLIC PROTEINS IDENTIFIED WITH HIGH SIGNIFICANCE AND FOLD-CHANGE ENRICHMENT IN

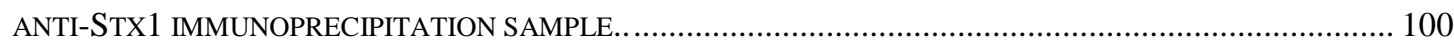

TABLE 3.9. SV PROTEINS ADDITIONALLY IDENTIFIED AS SIGNIFICANTLY ENRICHED UNDER LOW SALT

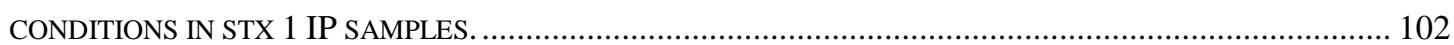

TABLE 3.10. SNARES AND TRAFFICKING PROTEINS ADDITIONALLY IDENTIFIED UNDER LOW SALT

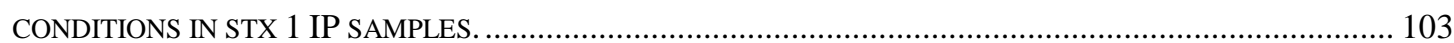

TABLE 3.11. RECEPTORS, CHANNELS AND TRANSPORTER PROTEINS ADDITIONALLY IDENTIFIED UNDER LOW

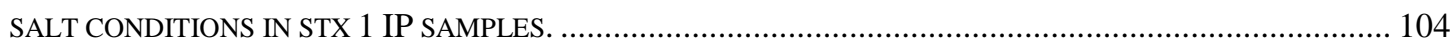

TABLE 3.12. CELL SURFACE AND ADHESION PROTEINS ADDITIONALLY IDENTIFIED UNDER LOW SALT

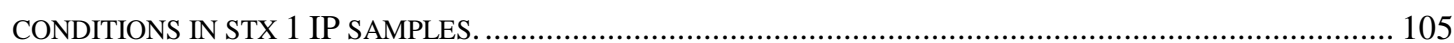

TABLE 3.13. HYPOTHETICAL OR POORLY CHARACTERIZED PROTEINS IDENTIFIED WITH HIGH SIGNIFICANCE AND FOLD-CHANGE ENRICHMENT IN STX 1 IP SAMPLES UNDER LOW SALT CONDITIONS

TABLE 3.14. METABOLIC PROTEINS ADDITIONALLY IDENTIFIED UNDER LOW SALT CONDITIONS IN STX 1 IP SAMPLES 


\section{List of Abbreviations}

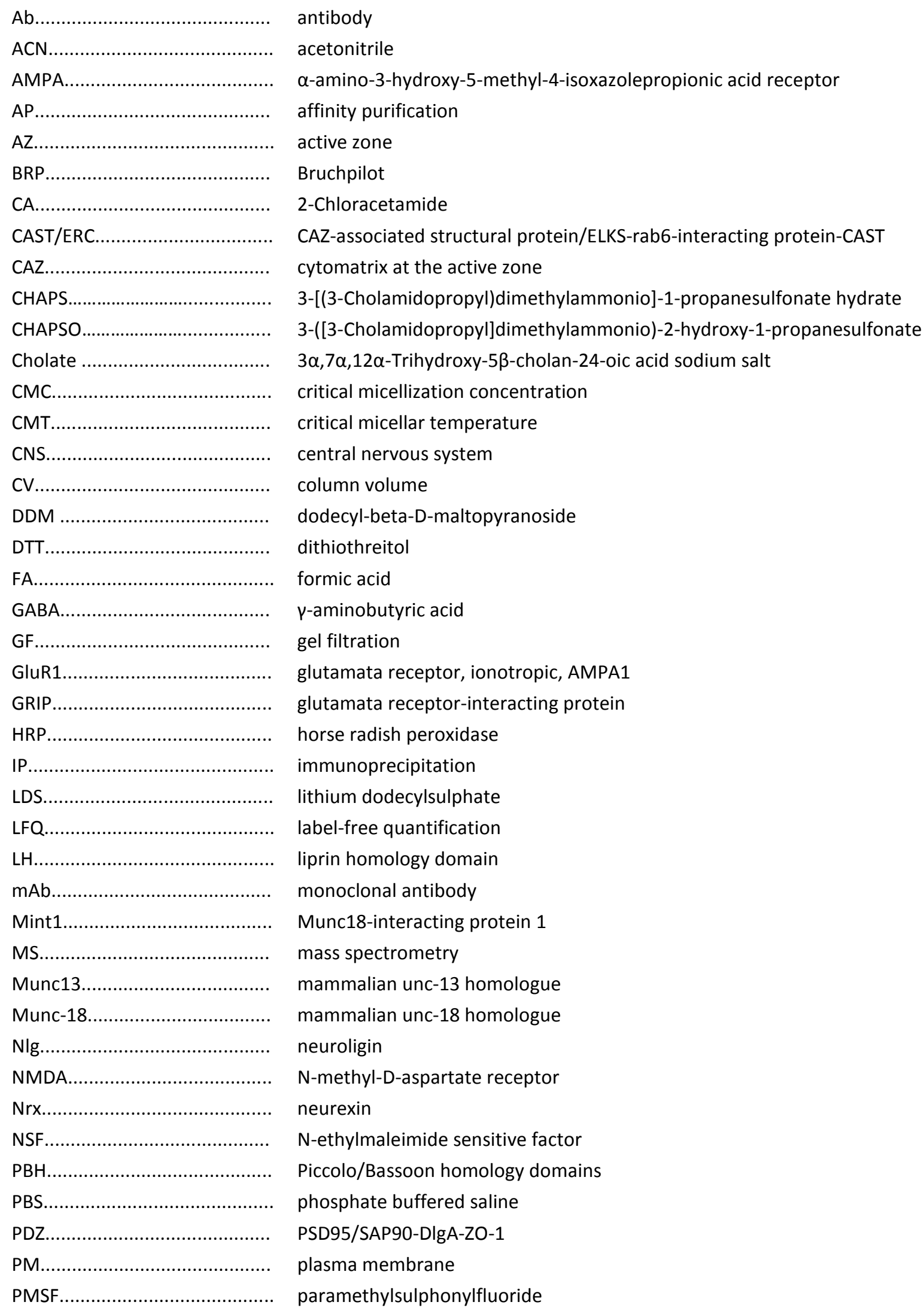


PRR.

PSD95.

RIM.

RIM-BP.

RT

SDS-PAGE

SEC

SNAP-25

SNARE.

Stx 1.

SV.

Syb 2

Syt-1

Taurodeoxycholate

TBST.

TEMED.

UPS2

VGCC.

WB

ZF. proline-rich region

postsynaptic density protein 95

Rab3 interacting molecule

Rab3 interacting molecule-binding protein

room temperature

sodium dodecylsulphate polyacrylamide gel electrophoresis

size exclusion chromatography

synaptosomal-associated protein 25

soluble NSF attachment protein

syntaxin 1

synaptic vesicle

synaptobrevin 2

synaptotagmin-1

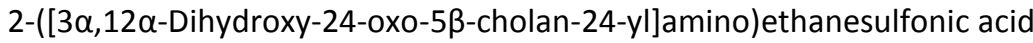
Tris-buffered saline with Tween 20

$N, N, N^{\prime}, N^{\prime}$-Tetramethylethan-1,2-diamin

universal protein standard mixture

voltage-gated calcium channel

Western blot

zinc finger domain 



\section{Introduction}

\subsection{Aspects of structural and functional organization of the active zone}

Synapses are specialized intercellular junctions between neurons or neurons and other excitable cell types and are defined as electrical or chemical depending on the mechanism of signal propagation. Electrical synapses have the characteristics of gap junctions between neurons and allow direct (bidirectional) propagation of the electrical stimulus. Interestingly, electrical synapses were recently reported to interconnect inhibitory interneurons in the neocortex and are involved in synchronizing neuronal activity [1-3]. In contrast to them, at chemical synapses (from now on termed only synapses) a signal discontinuity occurs. When an action potential arrives at the synapse, voltage-gated $\mathrm{Ca}^{2+}$ channels (VGCC) open and local increase in $\mathrm{Ca}^{2+}$ concentration triggers exocytosis of neurotransmitter-filled synaptic vesicles (SVs) $[4,5]$. Released inhibitory and/or excitatory neurotransmitters pass the synaptic cleft and bind to receptors on the postsynaptic reception site, initiating a cascade of intracellular signaling events. A typical feature of synapses in the central nervous system (CNS) is their morphological and functional asymmetry. At ultrastructural level, pre- and postsynaptic specializations are precisely opposed to each other and are characterized by electron-dense thickening of the membranes [6, 7] (Figure 1.1).
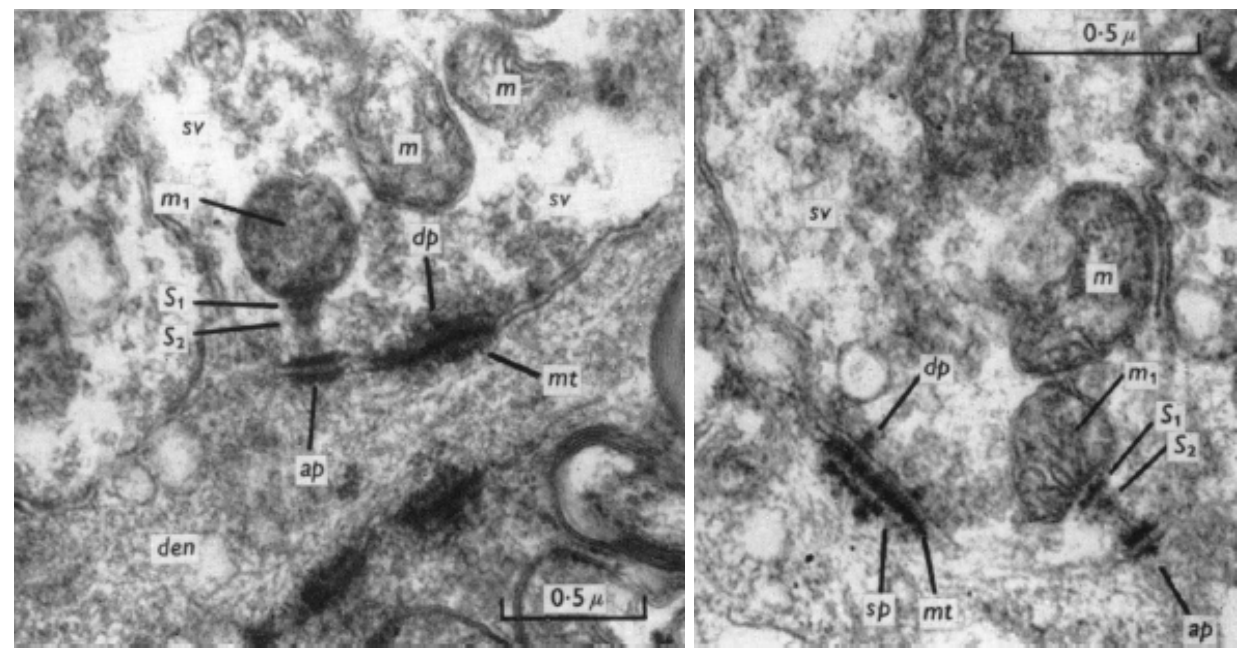

Figure 1.1. Electron microscopy of spinal cord synapse. Pre- and postsynapse show electron-dense and thickened membrane regions after phosphotungstic acid staining. mt: membrane thickening, ap: attachment plaque, sv: synaptic vesicle, den:dendrite, dp: presynaptic dense projection, m: mitochondrium, sp: subsynaptic particles, s: striation in dense zone. Image modified from [6]. 
The fusion of SVs is limited only to a small portion of the presynaptic membrane that contains the electron-dense material and is termed "active zone" [8]. At vertebrates' CNS synapses, active zones are disc-like structures with diameter of 0.2-0.5 $\mu \mathrm{m}$ and consist of two major parts: the presynaptic active zone membrane and the associated cytoskeletal matrix, called cytomatrix assembled at the active zone (CAZ) or presynaptic grid [9]. In electron micrographs of chemically fixed and stained synapses, CAZ appears as an array of electron-dense pyramidically shaped particles, that extend $\sim 50 \mathrm{~nm}$ into the cytoplasm and are connected by a network of cytoskeletal fibrils [6, 10-12]. Electron microscopy combined with immunolabeling suggested that the two major AZ proteins Munc13 and RIM localize between the dense projections proximal to the plasma membrane [13]. Interestingly, these electron-dense projections are missing in unfixed and unstained cryo-electron microscopy studies of the synapses. The only visible structures are SVs and connecting filaments. The latter ones either connect SVs to each other or to the active zone membrane $[14,15]$.

Moreover, in a functional perspective, active zones are the sites of action potentialencoded signal transformation and transmission. The CAZ at the presynaptic active zone is involved in four main steps in the neurotransmitter release [16]. First, active zones are the sites of synaptic vesicle docking and priming. These two steps, recently shown to be the morphological and functional elements of the same process [17], are dependent on the regulated assembly of evolutionary conserved proteins. The core constituents of CAZ protein complex are the proteins Munc13, RIM, RIM-BPs, ELKS and liprins. Interestingly, the main components of the release machinery - members of the soluble NSF-attached protein receptor (SNARE) family and Sec1p/Munc18-like (SM) proteins are not selectively enriched in the active zone [5, 18-20]. Second, active zone proteins recruit in an activitydependent manner VGCCs and thus ensure fast excitation-release coupling [11]. Third, active zones contribute to the precise localization of the presynaptic release machinery opposite to the postsynaptic site via binding to cell adhesion and surface molecules. And last but not least, active zones mediate short and long term plasticity either by direct excitation response or indirectly by recruitment of proteins to the release sites. 


\subsection{Molecular organization of the active zone}

The protein components of the active zone form a detergent insoluble matrix that is heterogeneous and difficult to purify. However, some protein interactions were identified in small protein-protein interactions studies, antibody and yeast two-hybrid system screens and genetic mutation experiments in Drosophila melanogaster and/or Caenorhabditis elegans. The studies suggest that the multidomain proteins - Munc13, RIM, RIM-BPs, liprins and ELKS - form the core regulatory protein complexes at the vertebrate active zone (Figure 1.2). These proteins are encoded by multiple genes in vertebrates, from which distinct protein isoforms and splice variants are expressed.

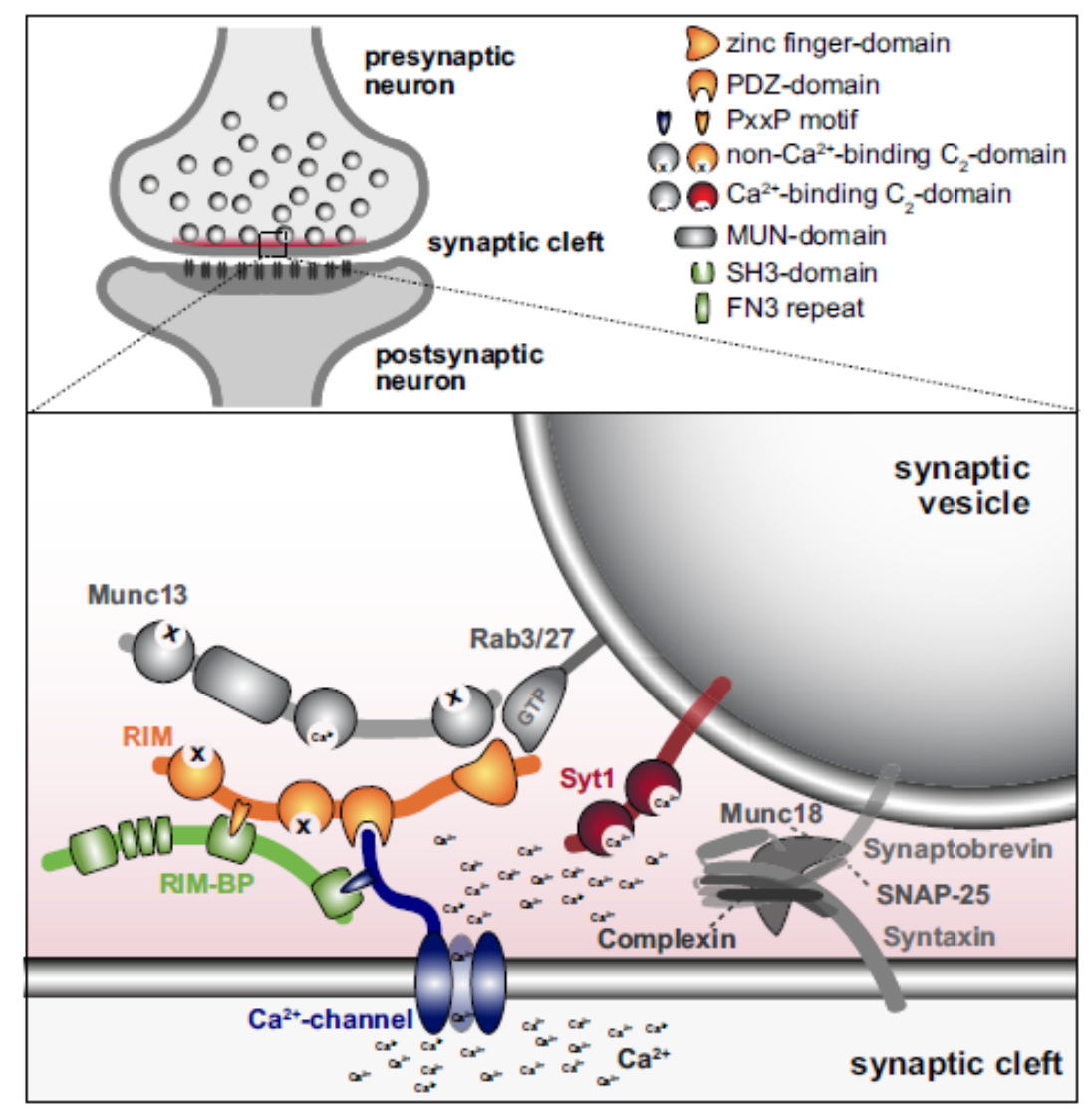

Figure 1.2. Functional organization of core active zone proteins. AZ-resident proteins form protein complexes that regulate SV docking and priming and recruit VGCCs to the release sites, thus coupling excitation and release machineries. Spatial and temporal regulation of neurotransmission is achieved by controlled protein association into complexes differing in their stoichiometries and AZ positioning. Image modified from [11]. 
These core five classes of proteins together with the largest AZ specific residents Bassoon and Piccolo/Aczonin are interconnected into complex machinery, which governs synaptic transmission in cooperation with cell adhesion and cytoskeleton elements. The AZ proteins and their known protein-protein are discussed in more detail and summarized below.

\subsubsection{Core active zone proteins}

\subsubsection{RIM protein family members}

Invertebrates possess one gene for RIM (Rab3-interacting molecule, [21]) homologue UNC10. In contrast, in vertebrates four RIM genes encode for seven isoforms and splice variants: RIM1 $\alpha$ and $\beta, \operatorname{RIM} 2 \alpha, \beta$ and $\gamma, \operatorname{RIM} 3 \gamma$ and RIM4 $\gamma$. Only the two isoforms RIM1 $\alpha$ and RIM2 $\alpha$ contain all five distinct protein domains: N-terminal zinc finger domain surrounded by $\alpha$-helices, central PDZ (ㅁD95/SAP90-DlgA-ZO-1) domain, two $\mathrm{C} 2$ domains (C2A and $\mathrm{C} 2 \mathrm{~B}$ ) and conserved proline-rich region (PRR) in the linker sequence between C2A and C2B [22]. RIM1 and RIM2 genes encode the two isoforms RIM1 $\alpha$ and RIM2 $\alpha$, which contain the five structural domains. RIM1 gene contains a single additional internal promoter driving the expression of RIM1 $\beta$ that lacks the Nterminal $\alpha$-helix [23]. The RIM2 gene has two internal promoters leading to the expression of N-terminal domain-missing RIM2 $\beta$ [22] and RIM2 $\gamma$ isoform consisting only of short unique sequence followed by C2B domain [24]. RIM3 and RIM4 genes encode RIM3 $\gamma$ and RIM4 $\gamma$, respectively, which have the same domain structure as RIM2 $\gamma$. RIM proteins emerged as main organizers of the $\mathrm{AZ}$ and genetic experiments revealed their implication in SV docking and priming [25-31], $\mathrm{Ca}^{2+}$ channel tethering to the $\mathrm{AZ}[11,26]$ and synaptic plasticity [28, 32]. RIM proteins fulfill these functions through versatile protein-protein interactions with the other constituents of the AZ. The N-terminal zinc domain of RIM1/2 binds to C2A domain of Munc13-1 and ubMunc13-2 [33-35]. Munc13 forms C2A domaindependent homodimers that can be disrupted by the Munc13-RIM protein-protein interaction [35]. In addition, the zinc finger domain-surrounding $\alpha$-helices bind to Rab3 and Rab27 GTPases in a GTP-dependent manner to recruit SVs to the release sites [21, 24, 36]. Furthermore, the central PDZ domain of RIMs binds directly to the C-terminal tails of P/Q- and N-type VGCC, thus increasing their density at the AZ [11] and to a C-terminal putative sequence of ELKS/CAST proteins [37]. Loss of the PDZ domain was shown to 
desynchronize release and increase the $\mathrm{Ca}^{2+}$ ion concentration requirement for $\mathrm{Ca}^{2+}$ dependent release of neurotransmitter [11]. N- and P/Q-type VGCC are tethered to the AZ not only by direct interaction with RIM, but also via RIM-BPs. SH3 domains of RIM-BPs bind to the PRR of RIMs and the cytoplasmic tails of VGCCs $[11,38]$. The C2 domains of RIMs bind synaptotagmin-1 (syt-1) and liprins, but also the plasma membrane Q-SNARE SNAP-25 [28, 39]. Furthermore, RIMs can associate via their C2 domains in a $\mathrm{Ca}^{2+}$ independent manner to $\alpha 1 \mathrm{~B}$ pore-forming subunit (Cav2.2) of N-type VGCC [39]. Thus, this class of proteins regulates different steps in SV exocytosis by a broad spectrum of protein-protein interactions.

\subsubsection{UNC13/Munc13 protein family}

The unc-13 gene encodes a protein whose mutation caused uncoordinated movements in C. elegans and was discovered in the early seventies [40]. The analysis of the mammalian homologs of unc-13 (Munc13) revealed their essential function for SV priming [41, 42]. Mammals possess five Munc13 genes from which six large proteins are expressed. Munc13-1, -2 and -3 genes encode proteins primarily expressed in the brain. However, Munc13-2 gene has two promoters driving the expression of ubiquitously expressed ubMunc13-2 protein and less abundant brain-specific bMunc13-2 isoform. Munc13-4 and BAP3 genes encode proteins expressed mainly outside of the brain [42, 43]. The common structure of Munc13 proteins consists of N-terminal C2A domain, followed by long sequence bearing a calmodulin-binding domain, C1 and C2B domains and Cterminal MUN and C2C domain. The ubMunc13-2 and Munc13-1 proteins contain all described domains, whereas in bMunc13-2 and Munc13-3 the $\mathrm{Ca}^{2+}$-independent $\mathrm{C} 2 \mathrm{~A}$ domain is replaced by a long $\mathrm{N}$-terminal sequence upstream the $\mathrm{C} 1$ domain. The short proteins Munc13-4 and BAP3 possess only C2B, MUN and C2C domains [43]. In a functional context, the MUN domain is the structural entity responsible for the priming activity of Munc13 proteins [44, 45]. In addition, a recent report suggested that a weak interaction of MUN domain with SNARE motif of syntaxin 1 in the closed syntaxin 1Munc18 complex helps syntaxin 1 opening and SNARE complex assembly [46]. At a molecular level, Munc13 interacts with several proteins: with RIM [33, 35], calmodulin [47], spectrin [48], syntaxin 1 [49], Munc18 [46] and double C2 domain protein (DOC2 $\alpha$ ) [50]. No functions and interactions are known up to date for the C2C domain of Munc13 proteins. 


\subsubsection{3 $\alpha$-Liprins}

Liprins (for LAR-interaction proteins) were originally identified as interaction partners of LAR-type (leukocyte common antigen related) receptor proteins with tyrosine phosphatase activity [51, 52]. In vertebrates, no studies on $\alpha$-liprin functions exist, however, studies in C. elegans confirmed protein's localization (encoded by syd-2 gene, for synaptic defect) at presynaptic termini and its importance for active zone formation, cell adhesion and cell migration during development [53, 54]. $\alpha$-liprins exist in four homologous forms composed of N-terminal coiled-coil domain, containing "liprinhomology domains” LH1 and LH2 [55], and three C-terminal SAM domains. As the other AZ proteins, liprins participate in multiple protein-protein interactions. The N-terminal half of the proteins containing the LH1 domain can bind to itself and results in homodimers [55]. ELKS/CAST protein and RIMs compete for binding to liprins via their coiled-coil domains or C2B domain, respectively [28]. It was suggested that the interaction with ELKS recruits liprins to the active zone [56, 57]. In addition, $\alpha$-liprins can form complexes with MAGUK family protein member CASK [58], but also can bind via their C-terminal SAM domains to $\beta$-liprins to form heterodimers [51, 59].

\subsubsection{ELKS proteins - major structural organizers of the CAZ}

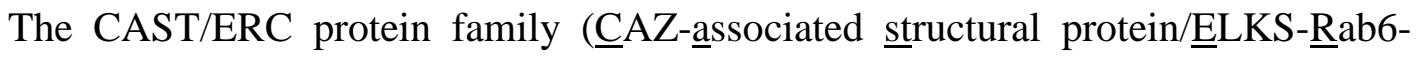
interacting protein-CAST) consists of conserved proteins from worms to mammals, expressed from two genes: CAST1/ERC2 and ERC1. ERC1 gene undergoes alternative splicing resulting in the expression of two proteins diverging in their C-termini: brainspecific ERC1b and ubiquitously expressed ERC1a isoforms [37, 60, 61]. CAST1/ERC2 and ERC1b isoforms are localized at the AZ. ELKS consist mainly of three coiled-coil sequences. These sequences can serve as platform for self/homo-oligomerization and heterocomplex formation. The C-termini of the proteins bear IWA amino acid sequence motif and resemble canonical PDZ recognition sequences for interaction with RIM1 $\alpha$ [37, 60, 62]. The C-terminal motif probably binds also other PDZ domain-containing proteins as reported for syntenin-1 [63]. The first of three coiled-coil sequence domains is involved homodimerization of the proteins, whereas second and third coiled-coil regions interact with Piccolo/Basson and Munc13-1, respectively (for review and references [62]). 
Furthermore, CAST/ERCs interact with liprins [57] and have been recently identified as a component of large interaction complex assemblied at the AZ [64]. Recently, a homologue of the human and C. elegans ELKS/CAST/ERC proteins, called Bruchpilot (BRP), was identified in Drosophila melanogaster as a crucial structural component of the AZ with Cterminal structural similarity to multifunctional cytoskeleton proteins [65]. Furthermore, the protein is a constituent of donut-shaped structures localized at the AZ of neuromuscular junctions in Drosophila and is required for $\mathrm{Ca}^{2+}$ channel clustering, evoked neurotransmitter release and short-term plasticity $[65,66]$. In addition, it was shown that brp mutants lose their electron-dense projections of the AZ cytomatrix (T-bars) [66] and that a functional collaboration between synaptotagmin and BRP is a prerequisite for AZ differentiation [67].

\subsubsection{RIM-binding proteins (RIM-BPs)}

In vertebrates, three RIM-BP genes encode large scaffolding proteins consisting of three SH3 and three fibronectin III (FNIII) domains. These proteins were identified as interactors of VGCC of N-, P/Q- and L-type and of RIM proteins [24, 68]. The SH3 domains of RIM-BPs bind to the PRR between C2A and C2B domains of RIMs. The two classes of proteins are highly expressed in the brain and form tight complexes. The formation of RIM-RIM-BP complex, the direct interactions between PDZ domain of RIM with N- and P/Q-type VGCC [11, 24] and between RIM-BPs and VGCC [68] suggest a role of RIM-BPs for VGCC recruitment to the sites of release. This suggestion was confirmed recently by Liu et al. showing disruption of VGCC localization to the AZ in Drosophila carrying mutated RIM-BP gene, as well as impairment of AZ formation [69].

\subsubsection{Scaffolding proteins at the active zone}

Piccolo/Aczonin [70, 71] and Bassoon [72] are the two largest scaffolding proteins at the AZ with molecular weight of $530 \mathrm{kDa}$ dn $420 \mathrm{kDa}$, respectively. Partial knockout of Bassoon impairs exocytosis and leads to partial lethality [73], in contrast to Piccolo, the deletion of which does not severely affect survival of cultured neurons [74]. However, partial deletion of both proteins disrupts SV clustering, indicating a possible role in 
organizing the SV pools at the presynaptic site [74]. Piccolo and Bassoon share regions of sequence similarity called Piccolo/Basson homology (PBH) domains. Three of the PBH domains contain coiled-coil regions termed CC1, CC2 and CC3. Within the first PBHs, two zinc finger domains (ZF) with limited homology to ZF domains of RIM $\alpha$ isoforms are located. The ZF domains of Piccolo can bind PRA1 (prenylated Rab acceptor), interacting with synaptobrevin 2 (syb 2) as well as with Rab3 [71]. Piccolo contains also PRR Nterminally, which is absent in Bassoon. This PRR interacts with F-actin binding proten 1 (Abp1). Piccolo contains also unique PDZ and C2A and C2B domains, absent in Bassoon, but resembling the RIM domains. Interestingly, C2A shows high specific binding for $\mathrm{Ca}^{2+}$ at low affinity [75]. In addition, Piccolo is expressed in multiple alternative spliced variants [76, 77]. It can bind L-type VGCC and RIM2 and can form homodimers via its C2 domains [78], whereas its CC3 and PDZ domains interact with ELKS and cAMP-GEFIII, respectively [78, 79]. The interaction with ELKS proteins is preserved also for Bassoon, explained by the homology of the CC3 domains [79].

In addition to the described interactions between core AZ constituents and Piccolo and Bassoon (see Table 1.1), additional interconnections between other known synaptic proteins contribute to neurotransmission regulation and SV exocytosis. Although they are not classified as core AZ residents, the Velis (MALS/Lin-7), CASK and Mint proteins form complexes with variable stoichiometry and composition. These assemblies were reported to regulate exocytosis and $\mathrm{AZ}$ development and to link intracellular protein complexes with synaptic junctions [58, 80-82]. The functional and structural relevance of cell adhesion and cytoskeleton molecules for synaptic transmission and exocytosis remain elusive and is reviewed elsewhere (for references see [16, 83-85]). 
Table 1.1. Summary of protein-protein interactions between core active zone and scaffolding proteins.

\begin{tabular}{|c|c|c|}
\hline Protein & Interaction partners & Reference \\
\hline \multirow{5}{*}{ ELKS (CAST/ERC) } & Bassoon, Piccolo & [79] \\
\hline & $\alpha$-liprins & [57] \\
\hline & RIM1 $\alpha$ & [60] \\
\hline & Munc13 & {$[37,62,64]$} \\
\hline & Syntenin-1, Rab6-GTP & {$[63,86]$} \\
\hline \multirow{8}{*}{ Liprins } & ELKS & {$[56,57]$} \\
\hline & KIF1A & [87] \\
\hline & LAR-type tyrosine phosphatase & {$[51,52,88]$} \\
\hline & GRIP & [89] \\
\hline & Liprins & {$[51,55]$} \\
\hline & GIT1 & [90] \\
\hline & CASK & [58] \\
\hline & RIMs & [28] \\
\hline \multirow{9}{*}{ RIMs } & Munc13 & [33-35] \\
\hline & Rab3, Rab27 & {$[21,24,36]$} \\
\hline & RIM-BPs & [24] \\
\hline & N- and P/Q-type VGCCs & {$[11,39]$} \\
\hline & $\alpha$-liprin & [28] \\
\hline & synaptotagmin-1 & {$[28,39]$} \\
\hline & ELKS & {$[37,60]$} \\
\hline & SNAP25 & [39] \\
\hline & Piccolo & [78] \\
\hline \multirow{2}{*}{ RIM-BPs } & N-, P/Q- and L-type VGCC & [68] \\
\hline & RIMs & [24] \\
\hline
\end{tabular}




\begin{tabular}{|c|c|c|}
\hline \multirow{7}{*}{ Munc13 } & RIMs & {$[33]$} \\
\hline & Calmodulin & [47] \\
\hline & $\mathrm{DOC} 2 \alpha$ & [50] \\
\hline & Syntaxin-1 & [49] \\
\hline & SNARE/Munc18 assembly & {$[46]$} \\
\hline & Diacylglycerol & {$[91]$} \\
\hline & spectrin & [48] \\
\hline \multirow{5}{*}{ Piccolo } & Abp1 & {$[92]$} \\
\hline & PRA1 & {$[71]$} \\
\hline & L-type VGCC & {$[78]$} \\
\hline & ELKS & [79] \\
\hline & RIM & [78] \\
\hline Bassoon & ELKS & [79] \\
\hline \multirow{4}{*}{ CASK } & $\alpha$-Liprins & {$[58,59]$} \\
\hline & CASKIN & {$[80]$} \\
\hline & Mint & {$[80,93]$} \\
\hline & SynCAM & [94] \\
\hline
\end{tabular}

The major goal of our study was the development of a protocol for extraction of integral protein complexes from synaptic membranes. The focus was set specifically on presynaptic cytomatrix-associated proteins. This required the use of detergents with high extraction affinity towards the proteins of interest under preservation of their proteinprotein interactions and native structure. However, though membrane mimetics are essential component of daily biochemical work, detergents' use is not trivial due to their complex physicochemical properties in solution. Therefore, in the following section, an afford was made to summarize the most important aspects, which need to be considered when using detergents for membrane solubilization and protein extraction. 


\subsubsection{Detergent classification}

Nowadays, a large number of detergents are commercially available. Often, the same detergents are available under different commercial names based on their purity degree or production source. These facts, together with the patent protection of the products, restrain transparency and hinder comparison of experimental results.

Detergents are amphipathic (amphiphilic) molecules containing both hydrophobic and polar (hydrophilic) structural entities. The chemical nature of these entities varies broadly and their combination diversifies the available detergent structures. Nevertheless, detergents can be classified based on 1) the charge and/or nature of their polar (head) groups and 2) the flexibility and chemical nature of their hydrophobic portion. According to the chemistry of their hydrophilic head group detergents are classified as ionic, nonionic and zwitterionic.

Ionic detergents contain head groups with a net positive or negative charge. The widely used sodium dodecylsulphate (SDS) contains a negatively charged sulphate group whereas trimethyl-amonium bromide (CTAB) represents an amine based quaternary detergent. In addition, the hydrophobic portion of the molecules can contain a hydrocarbon aliphatic chain like in SDS and CTAB or rigid sterane non-aromatic element like in sodium deoxycholate (DOC). The latter one is also considered as bile acid detergent. Anionic detergents can be bile acid salts with rigid hydrophobic portion of the molecule (cholic, taurodeoxycholic or deoxycholic acids). In addition to their aliphatic carboxylate (anionic) groups, the sterane ring of the bile acid derivatives carries hydroxyl groups. Thus, the structural complexity disables a strict definition of a polar head group. Generally, dihydroxy bile acid detergents (taurodeoxycholic and deoxycholic acid derivatives) are more effective than trihydroxy bile acids (e.g. sodium cholate) in membrane solubilization and disruption of protein-protein interactions. However, trihydroxy bile acids are milder in nature and preferable for use.

Nonionic detergents contain hydrophilic head groups composed either of polyoxyethylene chains as in the Brij and Trition detergent series or of glycosidic groups (sugars) as in octyl glucoside or dodecyl maltoside. In general, these detergents are considered non-denaturing, mild and efficient in breaking lipid-lipid and lipid-protein interactions and preserving protein-protein interactions. Thus, they are widely used in membrane biochemical studies and for isolation of protein complexes. However, the Triton 
class and NP-40 detergents contain aromatic rings in their hydrophobic portions, which might be limiting for their application. The absorbance at $280 \mathrm{~nm}$ and $254 \mathrm{~nm}$ interferes with spectrophotometric detection of proteins. For this reason, alkyl glycosides (containing sucrose, maltose or glucose polar head group) are preferred. Additionally, the attachment of alkyl chains to the sugar moieties can be achieved synthetically, however racemic mixtures are formed without the use of heterogeneous (surface) catalysis and the separation of stereoisomers increases the costs. A great advantage of this method is the resulting structural diversity encoding different physicochemical properties, which can be explored in membrane solubilization studies.

Zwitterionic detergents are special because they combine properties of ionic and nonionic detergents. They resemble nonionic detergents in the net molecules charge lacking electrophoretic mobility and conductivity and are suitable for ion-exchange chromatography. In line with ionic detergents, they are efficient in breaking protein-protein interactions. However, intraclass differences are observed. The detergents CHAPS and CHAPSO, being zwitterionic with rigid sterane structure, are less denaturing than the Zwittergent 3-X series.

\subsubsection{Detergent's properties in solution}

Detergents are also known as tensides, soluble amphiphiles, soaps (usually the metal salts of long-chain fatty acids) or surfactants. The latter term is a contraction of the word “surface-active agent” [95]. This term emphasizes an important physicochemical property of detergents. When small quantities of the compounds are dissolved in water, they reduce interfacial surface tension by adsorbing to the surface. They align in a monolayer at the water-air or water-organic phase with their hydrophobic portion in the air or organic phase and the polar groups pointing towards the water phase. The monomers, which are not involved in the monolayer formation at the phase interface, are dissolved as monomers in the water solution. However, detergents exhibit self-aggregation properties and thus the described situation exists only at low detergent concentrations [96]. Above a broad threshold concentration range, called critical micellization concentration (CMC), micelles are formed [96]. Micelles are defined as thermodynamically stable colloidal non-covalent aggregates, which are spontaneously formed by amphiphilic compounds above a narrow concentration range (CMC) [97]. This means that above CMC, hydrophobic interactions 
force assembly of the hydrophobic portions of the detergent molecules in order to avoid contact with water, whereas the polar groups are exposed to the water environment [98]. Furthermore, from an application point of view, detergent solutions above the CMC values will be composed of micelles in equilibrium with the monomer. Increasing the detergent concentration above the CMC increases the micelle concentration, whereas the monomer concentration in the solution remains constant and equals the CMC $[99,100]$. In addition, micelles are not static, but dynamic structure. This means that detergent monomers within the micelles are in constant exchange with monomers from the solution. Importantly, the solubilization properties of detergents are dependent on the formation of micelles in solution. The CMC of given detergents can be affected by few different factors: the hydrophobic and hydrophilic groups of the detergent molecules as well as the addition of electrolytes to the detergent solution [101]. In general, detergents with ionic head groups have higher CMC values than ones with nonionic head structure. This is due to electrostatic repulsion of the groups of neighbouring detergent molecules [101]. Additionally, zwitterionic head group-contaning detergents have smaller CMCs than ionic ones. Moreover, an extension of the alkyl chain (for straight alkyl chain containing detergents) of a detergent halves the CMC of the detergent [101]. The effect of electrolytes on the CMC of detergents is more pronounced for ionic detergents. Addition of dissociative electrolytes (e.g. $\mathrm{NaCl}$ ) shields the ionic groups of detergents and reduces their repulsion, thus decreasing the CMC $[101,102]$. Decrease in the CMC is observed also for nonionic detergents like Triton X-100 and glucosides. However, this effect is dependent on the nature of the electrolyte. $\mathrm{Cl}^{-}$ions are highly hydrated and salt out the hydrophobic moieties of detergents, decreasing their CMC. An opposite effect results from the addition of ions with high radius:charge ratio (i.e. $\mathrm{I}^{-}$and $\mathrm{SCN}^{-}$) $[101,103,104]$.

Generally, the detergent micellar size is defined by the molecular weight of the monomer and/or the aggregation number of the detergent. The aggregation number $(\mathrm{N})$ is the number of monomers assembled in a micelle. The higher $\mathrm{N}$, the greater is the detergent micellar weight. However, this number is dependent on the nature of the detergent and is not constant. It varies and for some detergents and might exhibit a concentration dependence [105]. Most detergents with biochemical applications have $\mathrm{N}=\sim 50$ to 100 . Exceptions represent the bile acid detergents with $N ~ 10[100,106]$.

Few factors affect the detergent performance in experiments: temperature, $\mathrm{pH}$, ionic strength, detergent concentration and the presence of salts in the solutions, as well as the 
purity of the detergents. $\mathrm{pH}$ is most important when working with detergents other than nonionic ones. Anionic detergents remain soluble at $\mathrm{pH}$ greater than the $\mathrm{pKa}$ value of their ionizable group, i.e. they precipitate when the $\mathrm{pH}$ is lowered under the $\mathrm{pKa}$ value. The opposite is valid for catioinic detergents (e.g. primary, secondary and ternary amines) - pH lower than the pKa value is required. This is a noteworthy remark because some bile acid detergents as sodium deoxycholate and its derivates undergo gelation at pHs higher than their pKa’s [96]. Importantly, each detergent has a characteristic phase diagram describing its behavior in solution dependent on concentration and temperature. This behavior is exemplified by a SDS phase diagram (Figure 1.3). A phase diagram shows under which conditions the detergent exists in a crystalline form, as micelles or monomer. The line between the crystalline and the micelle phases defines the critical micellar temperature (CMT). Practically, this means that detergent solubilization, which is dependent on the micelle formation, will only occur above temperature higher than the CMT. In addition, at a characteristic temperature higher than the CMT, called cloud point (not shown in the diagram), the detergent solutions undergo a phase separation to yield a detergent-rich and aqueous layers. This is a phenomenon characteristic for polyoxyethylene detergents and results from dehydration of the polyoxyethylene groups and formation of giant micelles [107]. The exploitation of the cloud point has been described earlier and enables the concentration of solubilized integral proteins [108, 109] The horizontal line between the monomer and micelle phases represents the concentration range above which a micellization takes places. In addition as shown in the diagram, the Krafft point is the CMT at the CMC value (for reviews and more references see [95, 96, 99]).

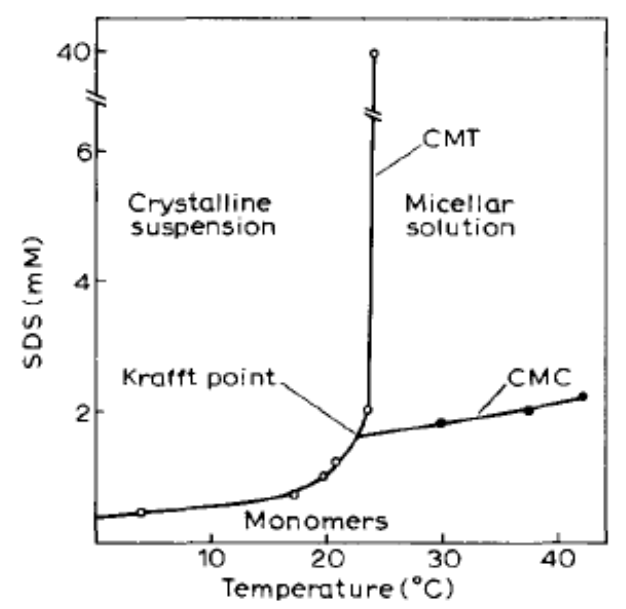

Figure 1.3. Phase diagram for sodium dodecylsulphate (SDS). The phase diagram shows the concentration and temperature dependent behavior of a detergent in solution on the example of SDS. Diagram modified from [95]. 


\subsubsection{Use of detergents for membrane solubilization}

The majority of detergents are used for isolation and study of membrane proteins and their interactions. Importantly, from a definition point of view, the stage at which biological membranes lose their lamellar integrity and break down in their constituents is called "solubilization". This definition is determined empirically and is usually based on decrease of the turbidity of a membrane solution, increase in non-sedimentable material and disappearance of the intact membrane structures as observed in electron microscopy $[95,96]$. The mechanisms of detergent interaction with biological membranes do not follow general rules. However on molecular level the solubilization of membranes by detergents and the extraction of proteins are thought to take place in three different steps (Figure 1.4) [95]. Moreover, when membranes are solubilized, every step of the process follows the laws of equilibrium thermodynamics [95]. The first step occurs at low detergent concentrations and is characterized by incorporation of detergent monomers into the lipid bilayer of the membrane. Second, further increase in detergent concentration leads to saturation of the membrane bilayer and its destabilization. This step is followed by membrane disintegration, termed "lysis" or "solubilization". Membrane solubilization is accompanied by formation of four different types of micelles in the solution: lipiddetergent mixed micelles, detergent micelles, lipid-detergent-protein mixed micelles and protein-detergent mixed micelles (see Figure 1.4). 


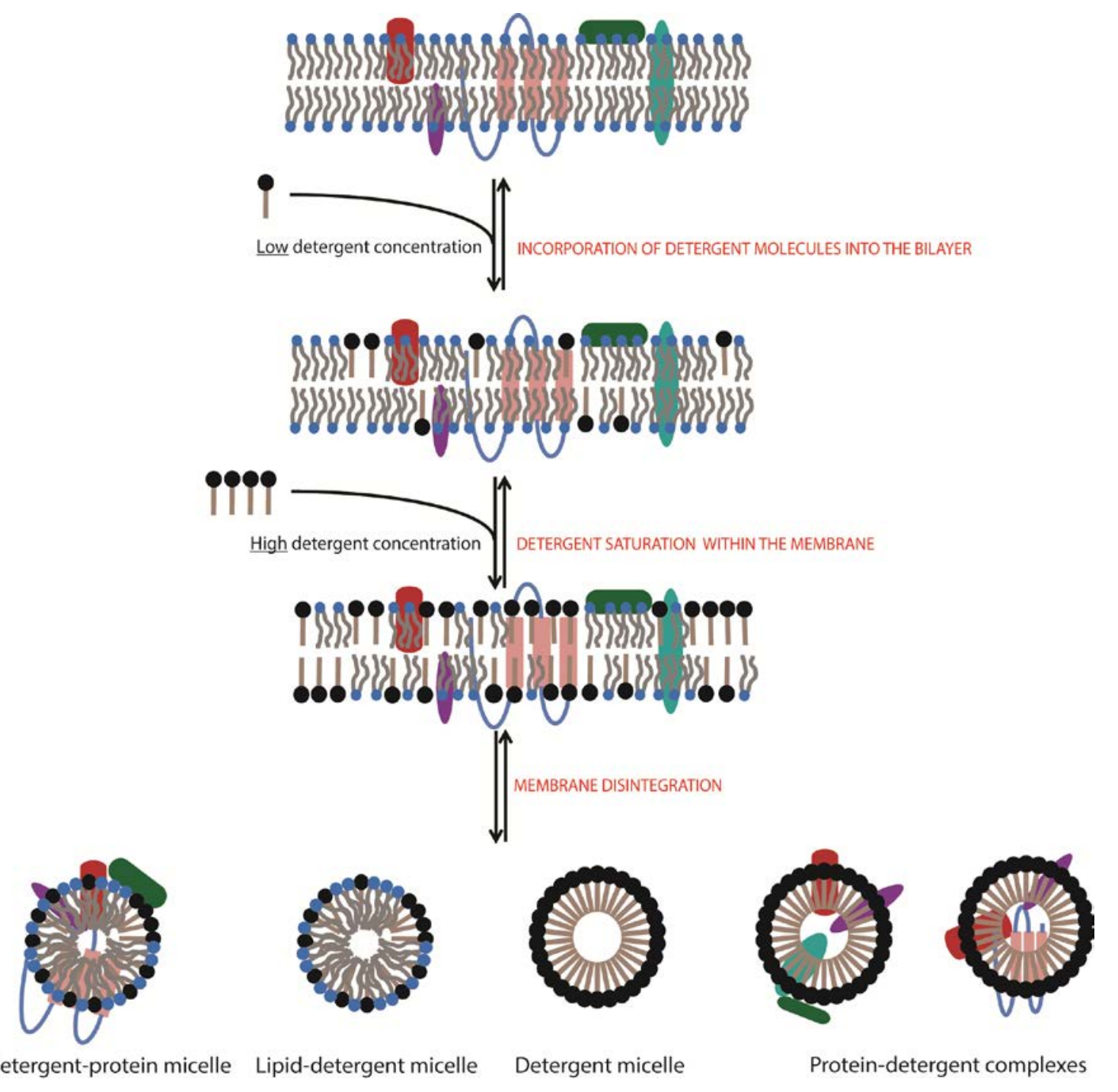

Figure 1.4. Mechanism of membrane solubilization by detergents. Membrane solubilization takes place in three steps. First, at low detergent concentrations, detergent monomers incorporate into the membrane lipid bilayer. Increase in the detergent concentration leads to membrane saturation and destabilization followed by disintegration and breakdown of the lamellar membrane structure (detergent monomers:black head groups; lipids: blue head groups; peripheral and integral proteins: green, pink, violet, red and cyan colored).

For the isolation of integral and peripheral protein complexes from synaptic membranes, detergents from different classes and with different physicochemical characteristics were used and are listed below (see Table 1.2, data summarized from Sigma Aldrich and Calbiochem catalogues). 


\subsection{Affinity purification and quantitative proteomics}

Different approaches can be used for characterization of protein complexes and protein-protein interactions. First, protein interaction maps were described for the budding yeast Saccharomyces serevisiae using yeast two-hybrid (Y2H) system [110-113]. Although the strength of the method was proved over the years, the rate of false positives and the verification of the data limited the use of this time-consuming approach. In recent years, the combination of affinity purification with mass spectrometry (AP-MS) advanced our knowledge about protein interactomes among species [114]. One advantage of AP-MS over $\mathrm{Y} 2 \mathrm{H}$ is the control of experimental conditions (near physiological) which can be determined and optimized by the researcher. However, two major problems accompany AP-MS. First, mass spectrometry identification of proteins is usually performed in a nonquantitative manner. This makes it difficult to distinguish true interaction partners from background proteins binding to the affinity matrix and resulting in high false positive rates. Second problem is the use of overexpressed tagged proteins for immunoisolations due to limited availability of good antibodies. This might cause artefacts in protein localization and interactions. Importantly, the combination of AP-MS approach with quantitative proteomic techniques allows elucidating dynamic changes in protein complex compositions [114-119]. The most of the quantitative techniques developed in the last two decades relied on the use of chemical or metabolic labeling [120]. They allow distinguishing between true protein interactors and background proteins but also restrain experimentalists due to high costs and the dependence on labeling efficiency which varies between experiments [120].

Proteomic analysis of membrane proteins and their associated assemblies represents a special case of interactome mapping with major experimental and technical challenges. First milestone is the efficient solubilization of the membrane proteins under preservation of their interaction partners. Mild extraction conditions might advance the number of identified associated proteins but also increase the background proteins detected. Solubilization often is seen as compromise between efficient extraction and protein-protein interaction preservation. 
Table 1.2. List of detergents used in the present study and summary of their main physichochemical properties.

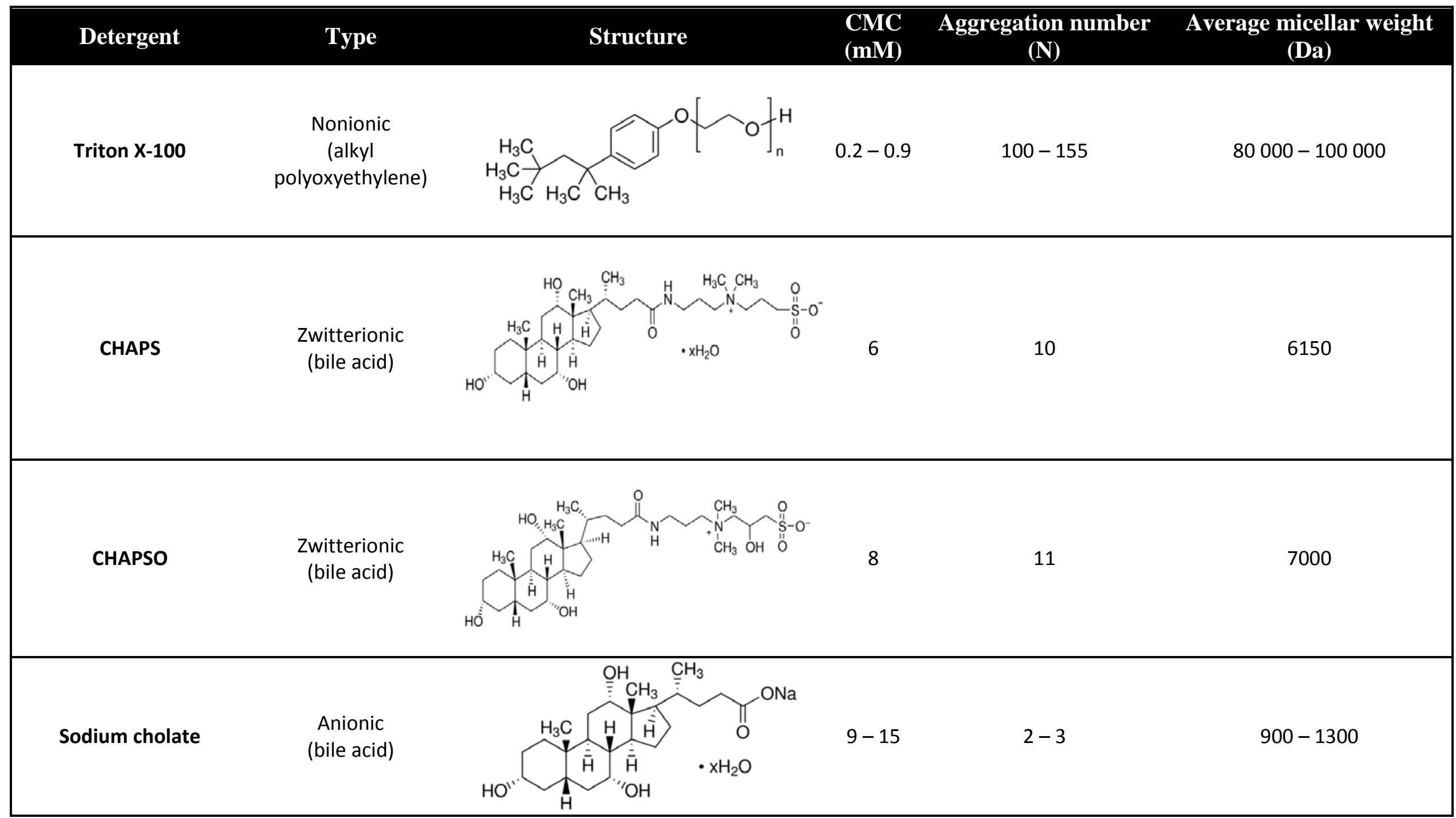




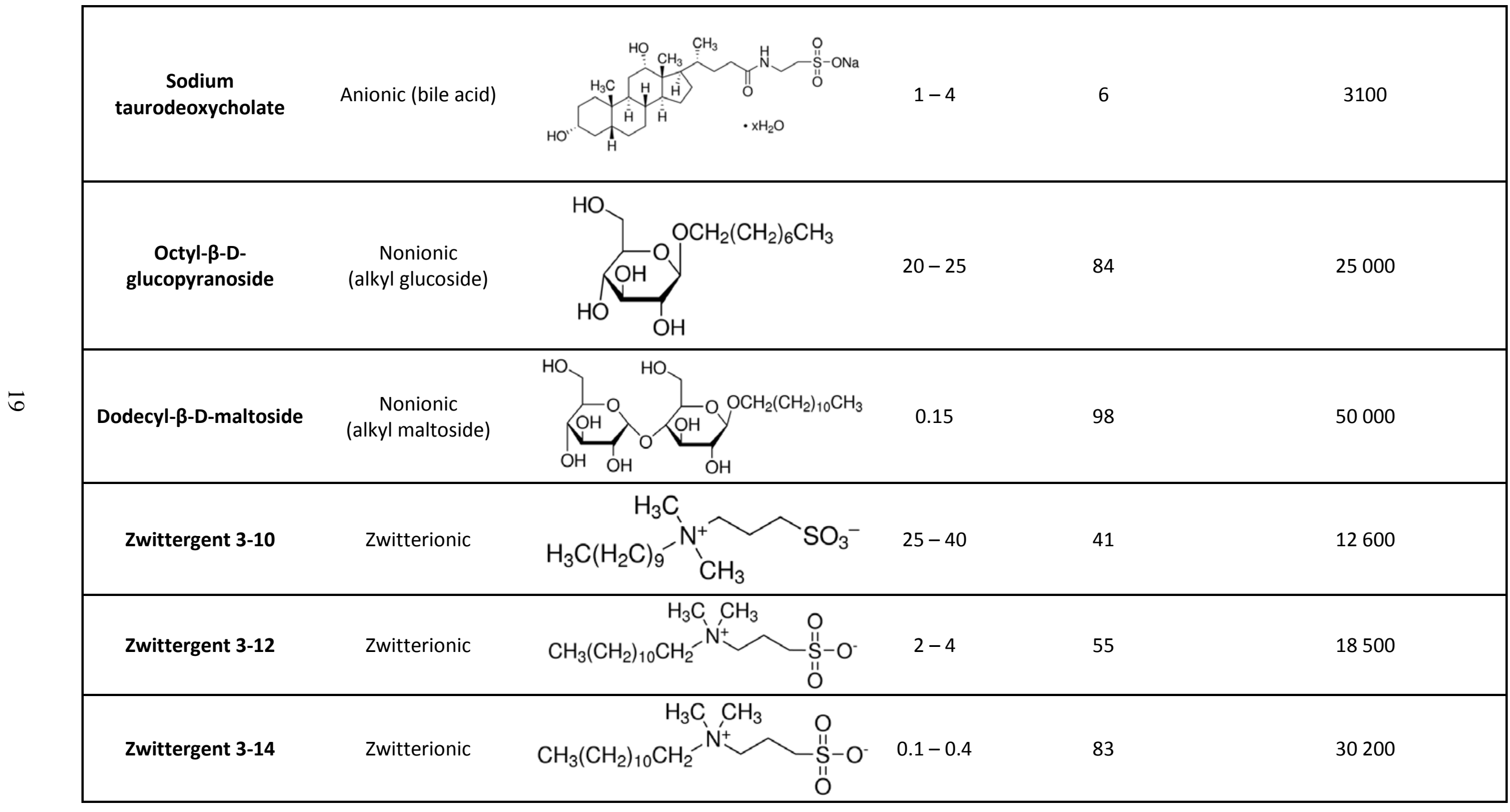


Second, the limited availability of antibodies capable of isolating the membraneanchored or membrane embedded target proteins under the solubilization conditions hinders biochemists. Finally, often the low number of tryptic peptides obtained after digestion of isolated proteins, together with their hydrophobic character constrain the reliable identification of less abundant and smaller proteins.

However, in recent years few studies reported successful identification of auxiliary subunits and regulatory proteins of ion channels and transmembrane proteins [121-128]. Some of these studies revealed the architecture and diversity of AMPA receptor proteome during development in different brain regions [126, 129] or identified cornichon proteins as novel auxiliary subunits of AMPARs [127]. Furthermore, the proteome of Cav2 channel family was recently reported and showed that more than 200 proteins are assembled in complexes with distinct stability and abundance in the mammalian brain. Although this study failed in deciphering the proteome of VGCC subtypes, it showed that label-free quantification (LFQ) can advance our knowledge about membrane protein-protein interactions. The LFQ method relies on spectral counts (limited by saturation and ion suppression effects), peak volume integration by correlation-based method or most applicably - on signal integration of peptide intensities (for reviews on LFQ see [119, 130132]). Interestingly, the quantification of SV proteins by time- and cost-consuming Western blotting was also validated using LFQ proteomics by Takamori et al. [133]. Moreover, the group of Fakler et al. identified novel interaction candidates and confirmed known interactions using the LFQ AP-MS strategy as exemplified on voltage-gated potassium channel Kv1.1 [134]. Interestingly, the LFQ approach was successfully used not only for synaptic membrane protein-protein interaction discovery [121, 122, 125, 135], but also when applied to chromatin-associated and anaphase-promoting protein complexes $[136,137]$.

\subsection{Aim of the study}

Biological membranes are the physical and physiological barriers that functionally and morphologically define biological entities like cells, intracellular compartments, organelles and also synaptosomes - re-sealed nerve terminals [138]. Synaptosomes possess membrane-dependent functional integrity (and preserved biological activity) and structural asymmetry. Importantly, their functionality is governed by multiple transmembrane and peripheral proteins with their extra- and intra-cellular protein interactions. 
The structural features of the highly specialized synaptosomal membrane present major experimental challenges for its study - (1) extraction and preservation of integral proteins and their complexes in a native state using membrane mimetics (e.g. detergents), (2) biochemical separation and component identification of such complexes (3) deciphering the biological meaning behind the molecular interplay of protein complex constituents. Three main difficulties accompany the isolation of native integral and/or peripheral protein complexes from synaptosomes and synaptosomal membrane subfractions (e.g. LP1 fraction, [139]) and were addressed in our study. First, little is known about the extractability of synaptic proteins and the preservation of their proteinprotein interactions upon use of detergents. Therefore, I aimed on screening different classes detergents for their solubilization properties focusing on the extraction of presynaptic proteins. A main goal was the extraction of presynaptic integral and large scaffolding proteins in a native form. Second, there are technical limitations to separate protein complexes in the molecular weight range of few hundred kilodaltonds (kDA) to megadaltons (MDa). For his reason, I analyzed the usefulness of gradient centrifugation and size exclusion chromatography for separation of membrane-derived extracts upon preservation of protein-protein interactions. Third, up to date no systematic study evaluated the effect of the centrifugation step post-solubilization on the protein composition of the extracts. Thus, a semi-quantitative immunoblotting was performed in order to assess the extractability of synaptic proteins under two different centrifugation conditions. Additionally, in the context of synaptic membrane research and interactomics, I validated the efficiency of the newly developed protocol as follows. I screened different affinity matrices and available antibodies against syntaxin 1 in order to find best immunoprecipitation conditions for the target protein. LFQ AP-MS in combination with a recently developed method for data analysis and presentation (volcano plotting) was used to separate unspecifically bound proteins from true positive hits under stringent statistical filtering conditions. Importantly, the tandem use of non-denaturing protein extraction and LFQ AP-MS should provide a universal protocol for the isolation of membrane proteins and their protein interacting partners while keeping the number of target-nonspecific binding proteins low. 


\section{Materials \& Methods}

\subsection{Materials}

\subsubsection{Chemicals}

All commercial chemicals such as salts, solvents and detergents used were of highest analytical purity grade. Unless indicated differently, the chemicals, kits and buffers were purchased either from Glycon GmbH (Luckenwalde, Germany), Merck, Calbiochem (Darmstadt, Germany), Boehringer (Mannheim, Germany), Sigma Aldrich (Steinheim, Germany), Roth (Karlsruhe, Germany), Fluka (Buchs, Germany), Roche (Basel, Germany), Promega (Madison, USA), Waters (Milford, USA), Invitrogen (Carlsbad, USA), Expedeon (Cambridge, UK), Stratagene (Santa Clara, USA) or Pierce/Thermo Scientific (Waltham, MA USA). Other used materials and all detergents are listed below separately in Table 2.1.

Table 2.1. List of commercial materials and all detergents utilized in this study.

\begin{tabular}{|ll|}
\hline Material/Detergent & Source \\
\hline Eupergit C1Z beads & Roehm Pharma \\
\hline Dynabeads ${ }^{\circledR}$ Protein A & Invitrogen Life technologies \\
\hline Dynabeads ${ }^{\circledR}$ Protein G & Invitrogen Life technologies \\
\hline Triton X-100 & Merck \\
\hline Dodecyl-beta-D-maltopyranoside & Glycon \\
\hline Octyl-beta-D-glucopyranoside & Anatrace \\
\hline Sodium taurodeoxycholate & Calbiochem \\
\hline Sodium cholate & Sigma Aldrich \\
\hline Tween 20 & Sigma Aldrich \\
\hline Zwittergents (3-10, 3-12, 3-14) & Calbiochem \\
\hline CHAPS & Sigma-Aldrich \\
\hline CHAPSO & Sigma-Aldrich \\
\hline Igepal CA 630 & Sigma Aldrich \\
\hline CompleXiolyte 114 and 91 & Logopharm GmbH \\
\hline (CL91, CL114) & Pierce (Thermo Scientific) \\
\hline Protein A & \\
\hline
\end{tabular}




\begin{tabular}{|ll|}
\hline Protein G & Pierce (Thermo Scientific) \\
\hline Superdex 200 10/300 GL & GE Healthcare \\
\hline Superose 6 10/300 GL & GE Healthcare \\
\hline $\begin{array}{l}\text { Universal protein standard } \\
\text { (UPS2) }\end{array}$ & Sigma Aldrich \\
\hline ReproSil C18-AQ & Dr. Maisch \\
\hline
\end{tabular}

\subsubsection{Commercial kits}

Kits were purchased and used according to manufacturer's instructions - Western Lightening TMPlus-ECL for Chemoluminescence detection (Perkin Elmer), Pierce BCA Protein assay for protein quantification in a 96-well plate format (Thermo Fisher) [140], NucleoBond ${ }^{\circledR}$ Xtra Midi (Macherey-Nagel) for plasmid DNA isolation, Silver stain (Life Technologies), Simply stain Blue (Invitrogen), Pierce $660 \mathrm{~nm}$ protein assay (Pierce), DC protein assay (Bio-rad)

\subsubsection{Antibodies}

Antibodies used in this study are listed in Table 2.2 and were either produced in our laboratory or commercially purchased at Abcam (Cambridge, UK), BioRad (Hercules, CA, USA), Jackson Immunoresearch Europe (Newmarket, UK), NeuroMab (Davis, USA) or Synaptic Systems GmbH (Göttingen, Germany). 
Table 2.2. List of all antibodies used in various applications during the study.

\begin{tabular}{|lllll|}
\hline Antigen & Epitope & Antibody specification & Application & Source \\
\hline Synaptobrevin 2 & $\begin{array}{l}\text { SATAATVPPAAPAGEG } \\
\text { (aa 2-17) }\end{array}$ & $\begin{array}{l}\text { Cl 69.1, mouse monoclonal } \\
\text { IgG1 }\end{array}$ & WB (1:1000) & $\begin{array}{l}\text { Synaptic systems } \\
\text { (cat. \#104211) }\end{array}$ \\
\hline Synaptophysin & Cytoplasmic tail & Cl 7.2, mouse monoclonal & WB (1:1000) & $\begin{array}{l}\text { Synaptic systems } \\
\text { (cat. \#101011) }\end{array}$ \\
\hline Synaptotagmin-1 & C-terminal part (aa 80-421) & $\begin{array}{l}\text { Cl 41.1, mouse monoclonal } \\
\text { IgG2a }\end{array}$ & WB (1:1000) & $\begin{array}{l}\text { Synaptic systems } \\
\text { (cat. \#105011) }\end{array}$ \\
\hline Synaptotagmin 2 & aa 1-11 in lumenal domain & Polyclonal rabbit, antiserum & WB (1:1000) & $\begin{array}{l}\text { Synaptic systems } \\
\text { (cat. \#105222) }\end{array}$ \\
\hline Syntaxin 1A & N-terminal part of rat & Cl 78.3, mouse monoclonal & WB (1:1000), & $\begin{array}{l}\text { Synaptic systems } \\
\text { (cat. \#110 111) }\end{array}$ \\
\hline Syntaxin 1A & IgG2a & IP & $\begin{array}{l}\text { Synaptic systems } \\
\text { (cat. \#110 001) }\end{array}$ \\
\hline Ryntaxin 1 & N-terminal part of rat & Cl 78.2, mouse monoclonal & IP & $\begin{array}{l}\text { Synaptic systems } \\
\text { (cat. \#107111) }\end{array}$ \\
\hline syntaxin 1 & IgG1 & Cl 42.2, mouse monoclonal & WB (1:1000) & W-terminal part of the \\
molecule (aa 191 - 220) & IgG2b & Polyclonal rabbit IgG & WB (1:1000) & $\begin{array}{l}\text { Synaptic systems } \\
\text { (cat. \#121002) }\end{array}$ \\
\hline
\end{tabular}




\begin{tabular}{|c|c|c|c|c|}
\hline V-ATPase & $\begin{array}{l}\text { FSFEHIREGKFDE } \\
\text { (826-838 in rat) }\end{array}$ & Polyclonal rabbit antiserum & WB (1:1000) & $\begin{array}{l}\text { Synaptic systems } \\
\text { (cat. \#109002) }\end{array}$ \\
\hline Bassoon & $\begin{array}{l}\text { C-terminal part of the } \\
\text { protein (last } 330 \mathrm{aa)}\end{array}$ & mouse monoclonal IgG2b & WB (1:1000) & $\begin{array}{l}\text { Synaptic systems } \\
\text { (cat. \#141021) }\end{array}$ \\
\hline Piccolo & aа $4439-4776$ & $\begin{array}{l}\text { Polyclonal rabbit, affinity } \\
\text { purified IgGs }\end{array}$ & WB (1:1000) & $\begin{array}{l}\text { Synaptic systems } \\
\text { (cat. \# 142003) }\end{array}$ \\
\hline CASK & aa $1-337$ & Polyclonal rabbit antiserum & WB (1:1000) & $\begin{array}{l}\text { Synaptic systems } \\
\text { (cat. \#150002) }\end{array}$ \\
\hline CASK & aa $318-415$ & $\begin{array}{l}\text { Cl K56A/50, Mouse mono- } \\
\text { clonal IgG1 }\end{array}$ & WB (1:1000) & NeuroMab \\
\hline CASKIN1 & aa $1416-1430$ & $\begin{array}{l}\text { Polyclonal rabbit, affinity } \\
\text { purified }\end{array}$ & $\begin{array}{l}\text { WB (1:1000), } \\
\text { IP }\end{array}$ & $\begin{array}{l}\text { Synaptic systems } \\
\text { (cat. \# 185003) }\end{array}$ \\
\hline ERCs (1b/2) & $\begin{array}{l}\text { CDQDEEEGIWA (aa } 939- \\
948 \text { ) }\end{array}$ & $\begin{array}{l}\text { Polyclonal rabbit, affinbity } \\
\text { purified }\end{array}$ & $\begin{array}{l}\text { WB (1:1000), } \\
\text { IP }\end{array}$ & $\begin{array}{l}\text { Synaptic systems } \\
\text { (cat. \# 143003) }\end{array}$ \\
\hline Liprin- $\alpha 3$ & aа 463 - 604 & $\begin{array}{l}\text { Polyclonal rabbit, } \\
\text { antiserum }\end{array}$ & $\begin{array}{l}\text { WB (1:1000), } \\
\text { IP }\end{array}$ & $\begin{array}{l}\text { Synaptic systems } \\
\text { (cat. \# 169102) }\end{array}$ \\
\hline Mint1 & aa $2-265$ & $\begin{array}{l}\text { Polyclonal rabbit, affinity } \\
\text { purified }\end{array}$ & $\begin{array}{l}\text { WB (1:1000), } \\
\text { IP }\end{array}$ & $\begin{array}{l}\text { Synaptic systems } \\
\text { (cat. \#144103) }\end{array}$ \\
\hline Munc13-1 & aa $3-317$ & $\begin{array}{l}\text { Polyclonal rabbit, affinity } \\
\text { purified }\end{array}$ & $\begin{array}{l}\text { WB (1:1000), } \\
\text { IP }\end{array}$ & $\begin{array}{l}\text { Synaptic systems } \\
\text { (cat. \# 126103) }\end{array}$ \\
\hline
\end{tabular}




\begin{tabular}{|c|c|c|c|c|}
\hline Munc13-1 & aa $3-317$ & Polyclonal rabbit antiserum & WB (1:1000) & $\begin{array}{l}\text { Synaptic systems } \\
\text { (cat. \# 126102) }\end{array}$ \\
\hline RIM1/2 & $\begin{array}{l}\text { aa } 1-466, \text { Zn-finger } \\
\text { domain }\end{array}$ & Polyclonal rabbit & $\begin{array}{l}\text { WB (1:1000), } \\
\text { IP }\end{array}$ & $\begin{array}{l}\text { Synaptic systems } \\
\text { (cat. \# 140203) }\end{array}$ \\
\hline Velis (1/ 2/ 3) & N.A. & $\begin{array}{l}\text { Polyclonal rabbit, affinity } \\
\text { purified }\end{array}$ & $\begin{array}{l}\text { WB (1:1000), } \\
\text { IP }\end{array}$ & $\begin{array}{l}\text { Synaptic systems } \\
\text { (cat. \# 184003) }\end{array}$ \\
\hline Velis (1/ 2/ 3) & N.A. & Polyclonal rabbit antiserum & WB (1:1000) & $\begin{array}{l}\text { Synaptic systems } \\
\text { (cat. \# 184002) }\end{array}$ \\
\hline Beta-actin & aa $2-16$ & Polyclonal rabbit & WB (1:3000) & $\begin{array}{l}\text { Synaptic systems } \\
\text { (cat. \#251003) }\end{array}$ \\
\hline Alpha-tubulin & $\begin{array}{l}\text { SEAREDMAALEKDYEEV } \\
\text { (aa } 419-435 \text { ) }\end{array}$ & $\begin{array}{l}\text { Cl 3A2, Mouse monoclonal } \\
\text { IgG1 }\end{array}$ & WB (1:3000) & $\begin{array}{l}\text { Synaptic systems } \\
\text { (cat. \#302211) }\end{array}$ \\
\hline $\begin{array}{l}\mathrm{Ca}^{2+} \text { channel } \\
\mathrm{N} \text {-type }\end{array}$ & $\begin{array}{l}\text { aa } 2074-2314 \text { of } \mathrm{Ca}^{2+}- \\
\text { channel } \alpha-1 \mathrm{~B} \text { subunit }\end{array}$ & $\begin{array}{l}\text { Polyclonal rabbit, affinity } \\
\text { purified }\end{array}$ & WB (1:500) & $\begin{array}{l}\text { Synaptic systems } \\
\text { (cat. \# 152303) }\end{array}$ \\
\hline $\begin{array}{l}\mathrm{Ca}^{2+} \text { channel } \\
\mathrm{N} \text {-type }\end{array}$ & Synprint site & Polyclonal rabbit & WB (1:1000) & In-house-made \\
\hline $\begin{array}{l}\mathrm{Ca}^{2+} \text { channel } \\
\text { P/Q-type }\end{array}$ & aa 856 - 888 & $\begin{array}{l}\text { Polyclonal rabbit, affinity } \\
\text { purified }\end{array}$ & WB (1:500) & $\begin{array}{l}\text { Synaptic systems } \\
\text { (cat. \# 152103) }\end{array}$ \\
\hline ZnT3 & aа 2 - 75 & Polyclonal rabbit antiserum & WB (1:1000) & $\begin{array}{l}\text { Synaptic systems } \\
\text { (cat. \#197003) }\end{array}$ \\
\hline
\end{tabular}




\begin{tabular}{|c|c|c|c|c|}
\hline VGLUT1 & N.A. & $\begin{array}{l}\text { Polyclonal rabbit, affinity } \\
\text { purified }\end{array}$ & WB (1:2000) & $\begin{array}{l}\text { In-house-made, } \\
\text { Shigeo 03, \#77 and \#78 }\end{array}$ \\
\hline Gephyrin & aa $294-736$ & Polyclonal guinea pig & WB $(1: 1000)$ & $\begin{array}{l}\text { Synaptic systems } \\
\text { (cat. \#147004) }\end{array}$ \\
\hline Homer1 & aa 1 - 186 & Polyclonal rabbit antiserum & WB $(1: 1000)$ & $\begin{array}{l}\text { Synaptic systems } \\
\text { (cat. \#160002) }\end{array}$ \\
\hline PSD95 & aа 77-299 & $\begin{array}{l}\text { Cl K28/43,Mouse mono- } \\
\text { clonal, IgG2a }\end{array}$ & WB $(1: 1000)$ & NeuroMab \\
\hline GABAR & N.A. & Polyclonal rabbit, antiserum & WB $(1: 1000)$ & In-house-made \\
\hline $\begin{array}{l}\text { NMDAR1 } \\
\text { (GluN1) }\end{array}$ & aa $660-811$ & $\begin{array}{l}\text { Cl. } 54.2 \text { (M68), mouse } \\
\text { monoclonal, IgG2b }\end{array}$ & WB $(1: 1000)$ & $\begin{array}{l}\text { Synaptic systems } \\
\text { (cat. \#114011) }\end{array}$ \\
\hline Neuroligin $1 / 2 / 3 / 4$ & aa $1-695$ & $\begin{array}{l}\text { Cl 4F9, Mouse monoclonal, } \\
\text { IgG2a }\end{array}$ & WB $(1: 1000)$ & $\begin{array}{l}\text { Synaptic systems } \\
\text { (cat. \#129011) }\end{array}$ \\
\hline SynCAM 1/2/3 & C-terminal region & Polyclonal rabbit & WB (1:1000) & Abcam \\
\hline SynCAM 1/2/3 & aa $436-446$ of SynCAM 1 & $\begin{array}{l}\text { Polyclonal rabbit, affinity } \\
\text { purified }\end{array}$ & IP & $\begin{array}{l}\text { Synaptic systems } \\
\text { (cat. \#243003) }\end{array}$ \\
\hline Mouse IgG & N.A. & $\begin{array}{l}\text { ChromPure mouse IgG, } \\
\text { whole molecule }\end{array}$ & IP & $\begin{array}{l}\text { Jackson Research } \\
\text { (cat. \# 015-000-003) }\end{array}$ \\
\hline Rabbit IgG & N.A. & $\begin{array}{l}\text { ChromPure rabbit IgG, whole } \\
\text { molecule }\end{array}$ & IP & $\begin{array}{l}\text { Jackson Research } \\
\text { (cat. \# 011-000-003) }\end{array}$ \\
\hline
\end{tabular}




\begin{tabular}{|lllll|}
\hline $\begin{array}{l}\text { Mouse IgG } \\
\text { (HRP-labeled) }\end{array}$ & N.A. & Goat anti-mouse IgG (H+L) & WB (1:2000) & BioRad \\
\hline $\begin{array}{l}\text { Rabbit IgG } \\
\text { (HRP-labeled) }\end{array}$ & N.A. & Goat anti-rabbit IgG (H+L) & WB (1:2000) & Biorad \\
\hline $\begin{array}{l}\text { Guinea pig IgG } \\
\text { (HRP-labeled) }\end{array}$ & N.A. & Goat anti-guinea pig IgG & WB (1:2000) & $\begin{array}{l}\text { Immunoresearch } \\
\text { (cat. \# 106-035-003) }\end{array}$ \\
\hline
\end{tabular}




\subsubsection{Buffers and media}

The compositions of all the buffers, media and different solutions utilized in the working process are listed in Table 2.3.

Table 2.3. Recipes of all in-house prepared non-commercial solutions and buffers.

\begin{tabular}{|c|c|}
\hline Buffer/Media (1x) & Composition \\
\hline Phosphate buffered saline (PBS) & $\begin{array}{l}137 \mathrm{mM} \mathrm{NaCl}, 2.7 \mathrm{mM} \mathrm{KCl}, 8.1 \mathrm{mM} \mathrm{Na}_{2} \mathrm{HPO}_{4} \text {, } \\
1.47 \mathrm{mM} \mathrm{KH}_{2} \mathrm{PO}_{4}, \mathrm{pH} 7.4\end{array}$ \\
\hline high-salt PBS & $\begin{array}{l}400 \mathrm{mM} \mathrm{NaCl}, 2.7 \mathrm{mM} \mathrm{KCl}, 8.1 \mathrm{mM} \mathrm{Na}_{2} \mathrm{HPO}_{4} \text {, } \\
1.47 \mathrm{mM} \mathrm{KH}_{2} \mathrm{PO}_{4}, \mathrm{pH} 7.4\end{array}$ \\
\hline $\begin{array}{l}\text { Tris-buffered saline with Tween } \\
20 \text { (TBST) }\end{array}$ & $\begin{array}{l}15 \text { mM Tris-HCl, pH 7.4, } 150 \text { mM NaCl, } 0.5 \% \\
(\mathrm{v} / \mathrm{v}) \text { Tween } 20\end{array}$ \\
\hline SDS running buffer & $\begin{array}{l}25 \mathrm{mM} \text { Tris-HCl, } 192 \mathrm{mM} \text { Glycine, } 0.1 \% \text { (w/v) } \\
\text { SDS }\end{array}$ \\
\hline Tris MOPS SDS running buffer & $\begin{array}{l}50 \mathrm{mM} \text { MOPS , } 50 \mathrm{mM} \text { Tris base, } 0.1 \%(\mathrm{w} / \mathrm{v}) \\
\text { SDS, } 1 \text { mM EDTA, pH } 7.7\end{array}$ \\
\hline Transfer buffer & $\begin{array}{l}200 \text { mM Glycine, } 25 \text { mM Tris, pH 7.5, } 20 \text { \% 2- } \\
\text { propanol or } 20 \% \text { ethanol }\end{array}$ \\
\hline Homogenization buffer & $320 \mathrm{mM}$ sucrose, 5 mM HEPES, pH 7.4 \\
\hline Low-salt IP washing buffer & 1\% Cholate/ PBS, pH 7.4 \\
\hline High-salt IP washing buffer & 1\% Cholate/ high-salt PBS, pH 7.4 \\
\hline Antibody dialysis buffer & $150 \mathrm{mM} \mathrm{NaCl} / \mathrm{H}_{2} \mathrm{O}, \mathrm{pH} 7.4$ \\
\hline $\begin{array}{l}\text { Äkta - Gel filtratration (Superose } \\
6 \text { 10/300 GL) buffer }\end{array}$ & 1\% detergent/PBS, pH 7.4 \\
\hline $\begin{array}{l}\text { Äkta - Superdex } 200 \text { 10/300 GL } \\
\text { buffer }\end{array}$ & $150 \mathrm{mM} \mathrm{NaCl} / \mathrm{H}_{2} \mathrm{O}$ \\
\hline Digestion buffer 1 & $\begin{array}{l}\text { For } 120 \mu \mathrm{l}-15 \mu \mathrm{l} \text { of trypsin (Roche, } 0.1 \mu \mathrm{g} / \mu \mathrm{l}) \text {, } \\
50 \mu \mathrm{l} \text { of fresh } 100 \mathrm{mM} \mathrm{NH}_{4} \mathrm{HCO}_{3}, 5 \mu \mathrm{l} \text { of } 100 \mathrm{mM} \\
\mathrm{CaCl}_{2}, 50 \mu \mathrm{l} \text { of } \mathrm{H}_{2} \mathrm{O}\end{array}$ \\
\hline Digestion buffer 2 & $\begin{array}{l}\text { For } 105 \mu \mathrm{l}-50 \mu \mathrm{l} \text { of fresh } 100 \mathrm{mM} \mathrm{NH} \mathrm{HCO}_{3}, 5 \\
\mu \mathrm{l} \text { of } 100 \mathrm{mM} \mathrm{CaCl}_{2}, 50 \mu \mathrm{l} \text { of } \mathrm{H}_{2} \mathrm{O}\end{array}$ \\
\hline Blocking buffer & 5\% non-fat milk in TBST \\
\hline
\end{tabular}




\subsection{Methods}

\subsubsection{Molecular biology methods}

\subsubsection{Protein concentration determination}

Protein concentration was determined using Pierce ${ }^{\mathrm{TM}}$ BCA, Pierce ${ }^{\mathrm{TM}} 660 \mathrm{~nm}$ or $\mathrm{DC}^{\mathrm{TM}}$ Protein Assay (Bio-Rad) commercial kits. Commercially available BSA (Pierce) or IgG solutions (Bio-rad) were used as standards. Dilutions of BSA and/or IgG standards (according to manufacturer's manual) and samples (5x,10x and $15 x)$ were prepared in duplicates with either $20 \mathrm{mM}$ Tris $\mathrm{pH} 8.0$ (Pierce BSA, Pierce $660 \mathrm{~nm}$ protein assay) or $2 \% \mathrm{SDS} / \mathrm{H}_{2} \mathrm{O}$ as diluent (DC Protein Assay, Bio-rad).

Concentration of IgGs was determined as well with Nanodrop ND-1000 (Thermo Scientific) in a IgG calculation mode.

\subsubsection{Biochemical methods}

\subsubsection{SDS-PAGE and Western blotting}

Prior to immunoblot analysis, proteins with a molecular weight $<130 \mathrm{kDa}$ were separated on denaturing $10 \%$ Tris SDS polyacrylamide gels by electrophoresis, as previously described [141, 142]. Resolving gel (final concentration of 10\% bis-acrylamide, $375 \mathrm{mM}$ Tris $\mathrm{pH}$ 8.8, 0.1\% SDS) and stacking gel (final concentration of $3.75 \%$ bisacrylamide, $125 \mathrm{mM}$ Tris $\mathrm{pH}$ 6.7, 0.1\% SDS) were polymerized by addition of TEMED (catalyst) and ammoniumperoxodisulphate (polymerization initiator) in final concentrations of $0.1 \%$. If not indicated differently, samples were boiled at $95^{\circ} \mathrm{C}$ for $5 \mathrm{~min}$ in 4x Laemmli sample buffer adjusted accordingly to final concentrations of $62.5 \mathrm{mM}$ Tris $\mathrm{pH}$ 6.8, $10 \%$ sucrose or glycerol, $4 \%$ SDS or LDS, 5\% beta-mercaptoethanol and $0.02 \%$ bromphenol blue. Separation was performed in a continuous Tris-Glycine buffer system, composed of $190 \mathrm{mM}$ Tris, $25 \mathrm{mM}$ glycine, 0.1\% SDS. For analysis of large proteins $>130$ $\mathrm{kD}$ and mass spectrometry, precast mini NUPAGE ${ }^{\circledR}$ Bis-Tris, Tris glycine or Expedeon SDS-PAGE 4-12\% gradient gels were used. NUPAGE ${ }^{\circledR}$ Bis-Tris and Expedeon SDSPAGE gels were run with Tris MOPS SDS running buffer (50 mM MOPS, $50 \mathrm{mM}$ Tris base, $0.1 \%$ SDS, 1 mM EDTA, pH 7.7) while Tris Glycine gel system operates only with 
Tris-Glycine SDS PAGE running buffer (25 mM Tris base, $192 \mathrm{mM}$ Glycine, 0.1\% SDS, $\mathrm{pH}$ 8.3).

Western blotting was performed as described by [143]. Proteins were transferred in wet mode using a Tris glycine transfer buffer (200 mM glycine, $25 \mathrm{mM}$ tris, 0.04\% SDS, $20 \%$ ethanol). Small proteins $<130 \mathrm{kDa}$ were transferred at $200 \mathrm{~mA}$ for $2 \mathrm{~h}$ at RT or at $4^{\circ} \mathrm{C}$. Large proteins $>130 \mathrm{kDa}$ (e.g. Piccolo and Bassoon) were transferred over night for at least $16 \mathrm{~h}$ at $4^{\circ} \mathrm{C}$ with a pre-cooled transfer buffer composed of $200 \mathrm{mM}$ glycine, $25 \mathrm{mM}$ Tris, $0.04 \%$ SDS, $20 \%$ isopropanol at $400 \mathrm{~mA}$ on a magnetic stirrer. After transfer, membranes were either stained with Ponceau S (0.1\% (w/v) Ponceau S in 5\% (v/v) acetic acid) prior to blocking to make gel lanes visible for cutting or proceeded directly to blocking with 5\% non-fat milk powder in TBST (50 mM Tris, $150 \mathrm{mM} \mathrm{NaCl,} \mathrm{0.05 \%}$ Tween-20, pH 7.6) for 20-30 min. Primary antibodies in the above indicated dilutions (see 2.1.3) were incubated with the membranes overnight at $4^{\circ} \mathrm{C}$ and collected for reuse. The membranes were washed three times, 5 min each with TBST prior to incubation with HRPconjugated secondary antibodies (1:2000 dilution) in blocking buffer for $1 \mathrm{~h}$ at RT upon constant shaking, followed by three washing steps (10 min each). Western blots were developed using Super Signal West Pico kit (Thermo Scientific) and protein bands were visualized by using chemiluminescence detection on FUJIFILM Luminescent Image Analyzer LAS-1000.

For dot blots, $2 \mu \mathrm{l}$ of sample were spotted on a nictrocellulose membrane, which was dried for $5 \mathrm{~min}$. The membrane was then blocked for $10 \mathrm{~min}$ at room temperature in blocking buffer and probed with primary antibodies (monoclonal $\alpha$-synaptophysin, Cl 7.2 and monoclonal $\alpha$-PSD95, $\mathrm{Cl} \mathrm{K28/43)} \mathrm{for} \mathrm{15-30} \mathrm{min.} \mathrm{After} \mathrm{washing} \mathrm{of} \mathrm{the} \mathrm{membrane} 3$ times for 3-5 min each with blocking buffer, the blot was incubated with secondary HRPconjugated antibody for $15 \mathrm{~min}$, followed by 3 washing steps for 5 min each with TBST. Dot blot was developed as indicated above by chemiluminescence.

\subsubsection{Preparation of beads for immunoisolation}

Dynabeads ${ }^{\circledR}$ Protein A and/or Protein $G$ magnetic beads (30 mg/mL, binding capacity of 8 ug human IgG/mg beads, Life Technologies) were used according to manufacturer's manual. Briefly, $50 \mu \mathrm{l}$ bead slurry ( $50 \%$ beads) were washed 3 times for 5 10 min each with IP buffer (1\% Cholate/1x PBS or $1 \mathrm{x}$ high-salt PBS) at $4^{\circ} \mathrm{C}$ and supernatants were discarded. After the last washing step, at least $15 \mu \mathrm{g}$ of antibodies or 
whole IgG fractions $(\mathrm{H}+\mathrm{L})$ from pre-immunized animals were allowed to bind to the Protein A/G-coupled magnetic Dynabeads ${ }^{\circledR}$ for $40 \mathrm{~min}$ at $4^{\circ} \mathrm{C}$ (rotating). Unbound antibody was removed with the supernatant. Samples were added to the beads and rotated at $4^{\circ} \mathrm{C}$ for $2 \mathrm{~h}$, followed by 4 washing steps of 15 min each with either $1 \%$ cholate/PBS or $1 \%$ cholate/high-salt PBS. After the final washing, beads were boiled in $50 \mu \mathrm{l} 4 \mathrm{x}$ LDS sample buffer at $70^{\circ} \mathrm{C}$ for $15 \mathrm{~min}$.

Conjugation of monoclonal syntaxin 1a ( $\mathrm{Cl} \mathrm{78.2)} \mathrm{antibody} \mathrm{(mouse} \mathrm{ascites),} \mathrm{pre-}$ immunized rabbit anti-mouse, mouse or rabbit IgGs $(\mathrm{H}+\mathrm{L})$ to Eupergit C1Z beads was done as described earlier [144]. Prior to coupling, syntaxin 1a antibody (purified on Superdex 200 10/300 GL in $150 \mathrm{mM} \mathrm{NaCl}$ ) and IgGs were dialyzed (MWCO 10K) against $\mathrm{H}_{2} \mathrm{O}$ or $150 \mathrm{mM} \mathrm{NaCl}$ for 4 days with at least 7 changes. After dialysis, the solution was centrifuged for $15 \mathrm{~min}$ at $10 \mathrm{000 \textrm {g }}$ in a bench centrifuge, supernatant used for coupling after determination of the antibody concentration. Eupergit C1Z beads were washed twice by vigorous vortexing in $\mathrm{H}_{2} \mathrm{O}$ and applying ultrasonication for 2 min. Beads were centrifuged at $1300 \mathrm{~g}$ for $6 \mathrm{~min}$ and resuspended in the antibody solution with concentration of at least $1 \mathrm{mg} / \mathrm{mL}$, vortexed vigorously and rotated for $8 \mathrm{~h}$ at $21^{\circ} \mathrm{C}$. A ratio of $1 \mathrm{mg}$ antibody to 100 mg of beads was used. After coupling, the beads were centrifuged at $1300 \mathrm{~g}$ for $6 \mathrm{~min}$ and remaining reactive sites were quenched with $1 \mathrm{M}$ glycine $/ \mathrm{H}_{2} \mathrm{O}$ for $8 \mathrm{~h}$ or overnight. The antibody solution was collected in order to assess coupling efficiency. The beads were washed 3 times by vigorous vortexing with alternating $0.1 \mathrm{M}$ potassium acetate, $0.5 \mathrm{M}$ $\mathrm{NaCl}$ at $\mathrm{pH} 4.5$ and $0.1 \mathrm{M}$ Tris, $0.5 \mathrm{M} \mathrm{NaCl}$ at $\mathrm{pH} 8.0$ (in total 6 washes). Finally, the beads were washed once with $1 \mathrm{x}$ PBS, resuspended 4x of their dry volume (assuming 100 mg correspond to $100 \mathrm{ul}$ ) in 1x PBS (e.g. $100 \mathrm{mg}$ beads in a total volume of $400 \mu \mathrm{l}$ ) and frozen at $-80^{\circ} \mathrm{C}$ until usage without loss of activity (Figure 2.1 ). 
A.

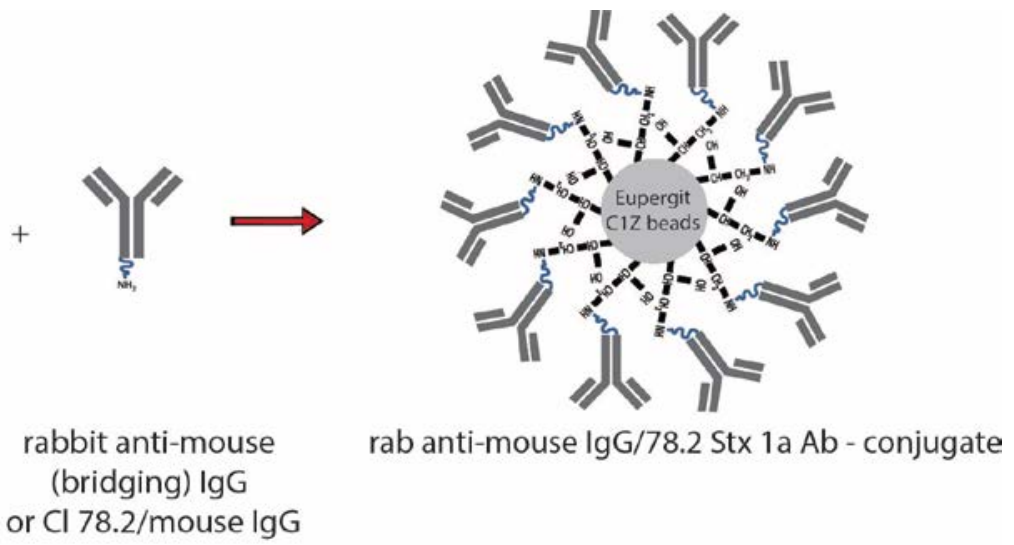

B.
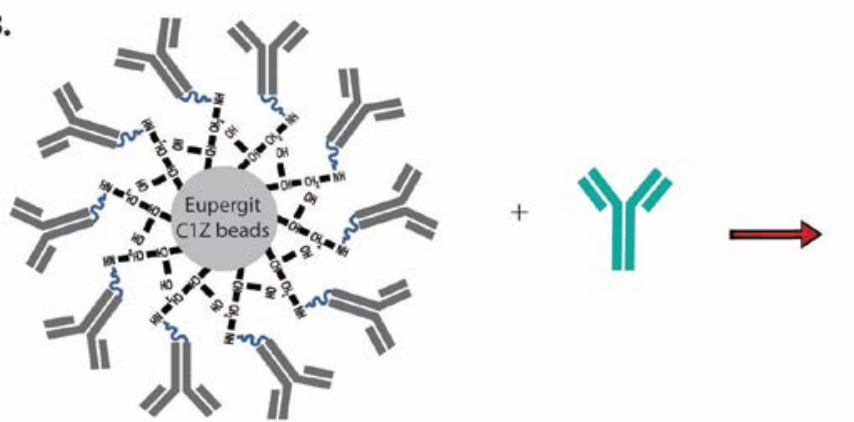

rabbit anti-mouse (bridging) IgG conjugate

mouse anti-Stx1a (Cl 78.3) or mouse lgG

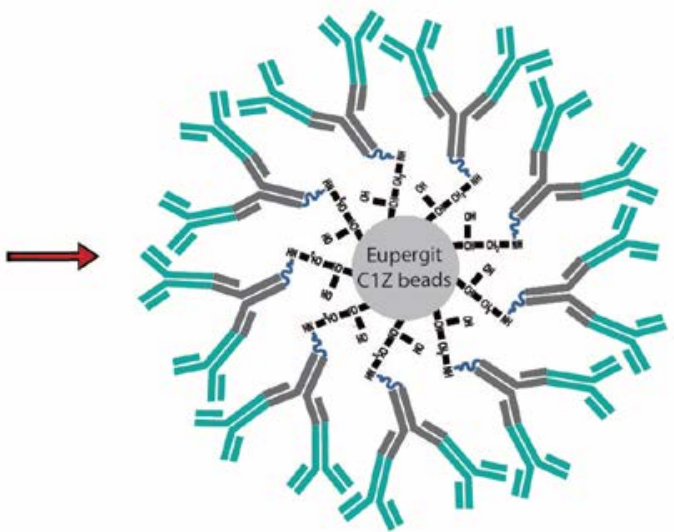

mouse anti-Stx1a $(\mathrm{Cl} 78.3) /$ mouse lgG conjugate

Figure 2.1. Eupergit C1Z microbeads-mediated immunoprecipitation of syntaxin 1. In a direct approach (A) anti-syntaxin 1 antibody ( $\mathrm{Cl}$ 78.2, subtype IgG1 ) or mouse IgGs (control) were directly coupled to the beads via epoxy groups to the surface of the matrix. The resulting conjugates were used for immunoprecipitations from pre-cleared solubilized LP1 fractions. In the second, indirect (B) approach, a twostep protocol was used, as direct coupling of syntaxin 1a-specific antibody ( $\mathrm{Cl}$ 78.3, subtype IgG2a) was not possible. In the first step, beads were coupled with bridging rabbit anti-mouse IgGs in order to obtain an immnoreactive matrix. In the second step, the matrix was incubated over night at $4^{\circ} \mathrm{C}$ either with $\mathrm{Cl} 78.3$ antibody or mouse IgGs (control). The resulting conjugate was used for the immunoprecipitations.

\subsubsection{Preparation of synaptosomes and LP1 fraction}

Synaptosomal subfractionation was performed as previously described [145]. Briefly, 12 six-week-old rats were sacrificed and cortices and cerebellum dissected. Samples were divided in two and each half was homogenized in $60 \mathrm{ml}$ homogenization/sucrose buffer (320 mM sucrose, 5 mM HEPES, pH 7.4) supplemented with PMSF $(0.2 \mathrm{mM}$ in $100 \%$ ethanol) and pepstatin $(1 \mu \mathrm{g} / \mu \mathrm{l})$ in a glass-Teflon homogenizer with 9 strokes at $9000 \mathrm{rpm}$. Homogenate (BH) was cleared from cell debris and nuclei at $5000 \mathrm{rpm}$ for $2 \mathrm{~min}$ in a SS34 rotor (Beckmann). Supernatant (S1) was recentrifuged at $11000 \mathrm{rpm}$ for $12 \mathrm{~min}$ in the same rotor to obtain a cytosolic fraction (S2) 
and a crude synaptosomal fraction (P2). Synaptosomes were carefully resuspended with homogenization buffer in a total volume of $36 \mathrm{~mL}$ using pre-cut $1 \mathrm{~mL}$ tips and avoiding the brownish part of the pellet, which represents a mitochondrial contamination. $3 \mathrm{~mL}$ of synaptosomes were layered on a discontinuous Ficoll gradient (Ficoll dissolved in prefiltered homogenization buffer), composed of $4 \mathrm{~mL}$ 13\% Ficoll, $1 \mathrm{~mL} \mathrm{9 \%} \mathrm{Ficoll} \mathrm{and} 4 \mathrm{~mL}$ 6\% Ficoll. Gradients were centrifuged in a swing-out SW41 rotor (Beckmann) at 22500 rpm for 35 min and the band from the 13\% and 9\% Ficoll interface was collected (Figure 2.2).

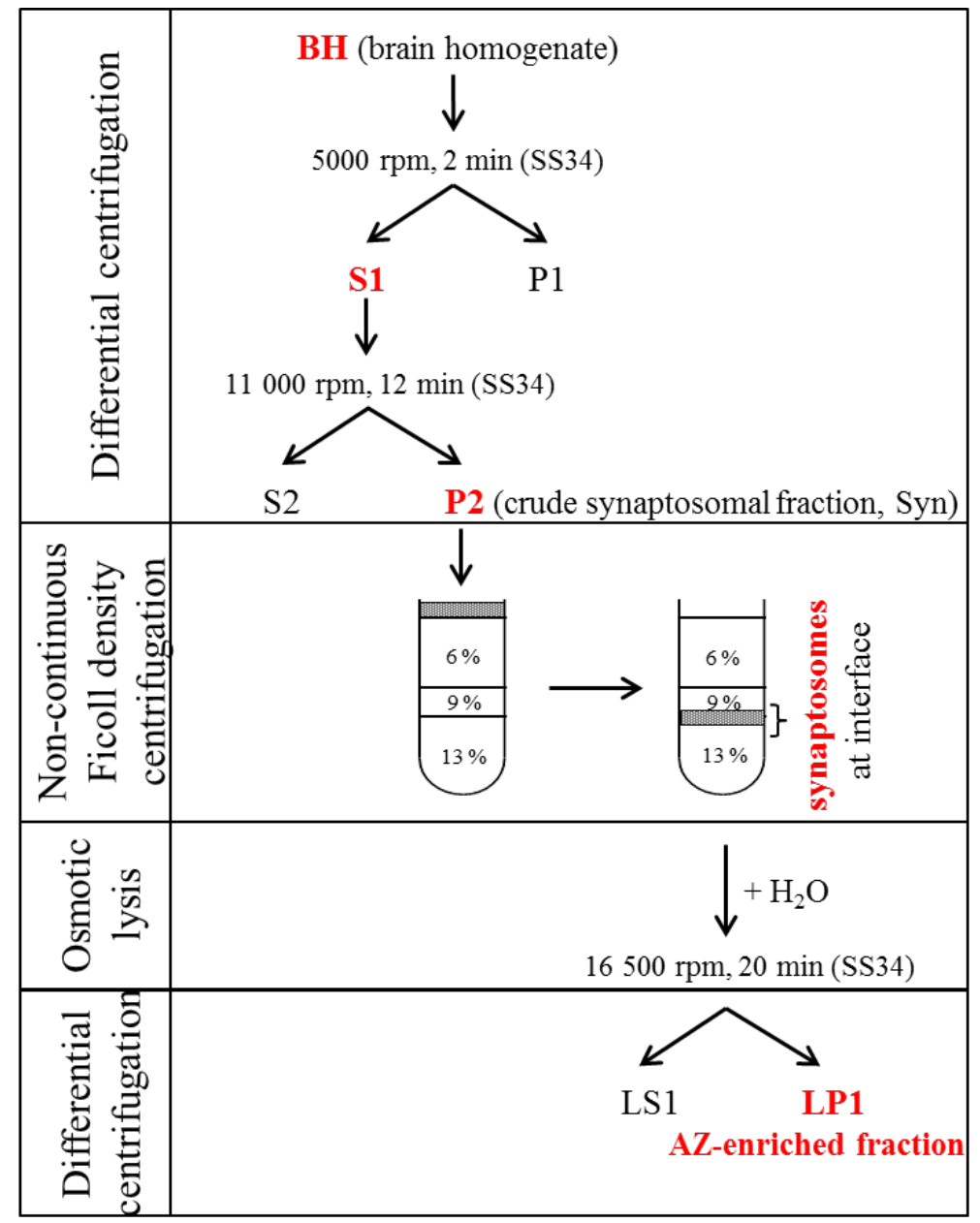

Figure 2.2. Scheme for purification of synaptosomes and LP1 fraction. The procedure of synaptosomal and LP1 preparation consists of steps of differential and non-continuous density gradient, followed by hypoosmotic lysis of synaptosomes resulting in release of soluble protein contents and SVs as well as AZenriched presynaptic membrane fraction (LP1). 
Bands from 6 gradients were pooled together, diluted for washing with $35 \mathrm{~mL}$ of fresh homogenization buffer supplemented with protease inhibitors and centrifuged at 11 $000 \mathrm{rpm}$ for $12 \mathrm{~min}$ in a SS34 fixed-angle rotor. Pellets were resuspended in $4 \mathrm{~mL}$ sucrose buffer, $36 \mathrm{~mL}$ of ice-cold water were added and synaptosomes were osmotically lyzed with 3 strokes of max speed in a glass-Teflon homogenizer, followed by immediate addition of protease inhibitors (PMSF and pepstatin) and $200 \mu \mathrm{l}$ of 1 M HEPES-NaOH pH 7.4 (1:200 stock solution. The pellet after lysis (LP1), containing mainly active zone (AZ)-enriched presynaptic membranes with docked vesicles attached to a portion of PSD, was isolated in a centrifugation step of $16500 \mathrm{rpm}$ for $20 \mathrm{~min}$ in a SS34 rotor and resuspended in a volume of 5-6 mL. The protein concentration was determined using BCA assay.

\subsubsection{Proteolytic treatment ("shaving”) of synaptosomes}

Five to ten mg of synaptosomes were proteolytically treated with sequencing grade trypsin (Roche) as described earlier [146]. In brief, synaptosomes were resuspended in 20 to $40 \mathrm{~mL}$ homogenization buffer $\left(\mathrm{pH} 8.0\right.$ at $\left.30^{\circ} \mathrm{C}\right)$ and 500 to $1000 \mu \mathrm{l}$ trypsin $(0.1 \mathrm{mg} / \mathrm{mL}$ in $1 \mathrm{mM} \mathrm{HCl}$, final ratio of protein:protease $=100: 1$ ) were added. Synaptosomes were moderately shaken in a water bath at $30^{\circ} \mathrm{C}$ for $30 \mathrm{~min}$ and the trypsinization was terminated with 20 to $40 \mu$ l Pefabloc (400 mM 1:1000 stock solution in $d_{d d H_{2}} \mathrm{O}$ ). The trypsinized synaptosomes were isolated by differential centrifugation in a SS34 rotor for 5$8 \mathrm{~min}$ at $8700 \mathrm{~g}$ followed by a washing step with homogenization buffer ( $\mathrm{pH}$ 7.4) containing $400 \mu \mathrm{M}$ Pefabloc inhibitor. The pellet was taken up in the respective volume of homogenization buffer for further experiments.

\subsubsection{Solubilization of synaptosomes and LP1 fraction}

The synaptosomes and the LP1 fraction were solubilized in detergent/PBS at protein: detergent ratios ranging from 1:10 to 1:30 for all initial experiments. The samples for fractionation by gel filtration, immunoprecipitations and mass spectrometry were solubilized at a protein:detergent ratio of 1:10.The protein content was determined using commercially available kits (Pierce BCA protein assay). The desired amount of protein was directly added to the ice-cold PBS ( $\mathrm{pH} 7.4$ )/detergent solution and the final volume 
(1mL for S140AT4 rotor and 3mL for TLA100.3 rotor) was adjusted by addition of icecold PBS. The samples were rotated for $5-30 \mathrm{~min}$ at $4^{\circ} \mathrm{C}$ and pre-cleared by ultracentrifugation at $100000 \mathrm{~g}$ for $20 \mathrm{~min}$ either in a S140AT4 rotor (Sorvall) or a TLA100.3 rotor (Beckmann). The pellets containing insolubilized material were resuspended in PBS buffer in $1 / 4$ of the supernatant volume and frozen at $-20^{\circ} \mathrm{C}$ until use.

\subsubsection{Sucrose density gradient centrifugation}

Sucrose density gradients were prepared in SW41 rotor tubes using preprogrammed settings on a Bio-comp gradient master mixer B107-202M. Fresh solutions of sucrose in PBS ( $\mathrm{pH} 7.4$ at $4^{\circ} \mathrm{C}$ ) with $1 \%$ detergent were used in all experiments. Using a Minipuls 3 peristaltic pump (MP3 drive Unit 0.01 TO 48 RP, Gilson), $500 \mu$ l fractions of the gradients were collected on ice starting from high density.

\subsubsection{Chromatographic fractionation of solubilized LP1 samples}

After solubilization of the LP1 fraction, the pre-cleared supernatant was subjected to further fractionation by gel filtration chromatography on a Superpose 6 10/300 GL column usingan automated Äkta system (Äkta purifier, GE Healthcare). Prior to size exclusion chromatography, the sample was cleared at $100000 \mathrm{~g}$ for $20 \mathrm{~min}$ in a TLA100.3 rotor. Degassed 1\% (w/v) detergent/PBS pH 7.4 was used to pre-equilibrate the column with $4 \mathrm{CV}$ and as mobile phase. The protein-detergent complexes were eluted at a flow rate of $0.4 \mathrm{~mL} / \mathrm{min}$ and the elution profile was monitored at $280 \mathrm{~nm}$. Fractions of $500 \mu \mathrm{l}$ were collected using a fraction collector (Fraction Collector Frac-900). The separation reproducibility was evaluated by western blotting. The remaining volume of each fraction was used for immunoprecipitations with Dynabeads Protein A/Protein G or antibodycoupled Eupergit C1Z beads. 


\subsubsection{Mass spectrometry methods}

\subsubsection{On-beads-digestion of immunoprecipitates}

Affinity enrichment of syntaxin 1 and syntaxin-binding proteins for mass spectrometry was performed using Eupergit C1Z beads coupled covalently either to syntaxin 1 antibody (Cl 78.2) or to bridging polyclonal rabbit-anti mouse IgGs. When bridging IgGs were used, beads were incubated overnight rotating at $4^{\circ} \mathrm{C}$ with an excess of syntaxin1a antibody ( $\mathrm{Cl}$ 78.3). The immunoprecipitates were digested with trypsin directly on the beads following a new optimized version of a standard protocol [147] for digestion in the presence of detergent. Briefly, 1\% Rapigest SF (Waters) were added to the beads, which were vigorously vortexed, spun down and incubated for $15 \mathrm{~min}$ at $60^{\circ} \mathrm{C}$, upon shaking on a Thermomixer (ThermoMixer C, Eppendorf). $10 \mathrm{mM}$ DTT (same volume as $1 \%$ Rapigest SF) was added and the beads further incubated for $30 \mathrm{~min}$ at $60^{\circ} \mathrm{C}$, upon shaking, followed by addition of $20 \mathrm{mM}$ 2-Chloracetamide (CA). The incubation was continued at $37^{\circ} \mathrm{C}$ for $30 \mathrm{~min}$. The samples were diluted with freshly prepared $50 \mathrm{mM}$ $\mathrm{NH}_{4} \mathrm{HCO}_{3}$ to a final concentration of Rapigest $=0.1 \%$ and $5 \mu \mathrm{l}(0.1 \mu \mathrm{g} / \mu \mathrm{l})$ of sequencing grade modified trypsin (Promega) were added and mixed by vortexing. The samples were spun down and digested for $16 \mathrm{~h}$ at $37^{\circ} \mathrm{C}$. After digestion, $100 \%$ formic acid (FA) (1 $\mu \mathrm{l}$ $100 \% \mathrm{HCOOH}$ per $10 \mu \mathrm{l}$ of $1 \%$ Rapigest SF) was added to the samples to cleave Rapigest $\mathrm{SF}$ and inactivate the trypsin. The beads were incubated for $1 \mathrm{~h}$ at $37^{\circ} \mathrm{C}$, and centrifuged for $30 \mathrm{~min}$ at maximal speed (14 $800 \mathrm{rpm}$ ) in a bench centrifuge. The supernatant containing protein peptides was collected and dried in a speed-vac system (SpeedVac concentrator Savant SPD121P supplied with refrigerated Vapor Trap RVT5105, Savant and Vacuum Pump OFP400, Thermo Scientific).

\subsubsection{Protein digestion after denaturing elution from Eupergit C1Z beads}

In order to compare efficiencies of trypsin digestion after the elution from the immunobeads, in-gel-digestion and direct on-beads-digestion, immunoprecipitates from Eupergit C1Z beads (coupled to bridging anti-mouse IgGs and incubated with syntaxin 1 antibody $\mathrm{Cl} 78.3$ ) were eluted by addition of $50 \mu \mathrm{l}$ of $2 \% \mathrm{SDS} / \mathrm{H}_{2} \mathrm{O}$ and incubation at $65^{\circ} \mathrm{C}$ for $15 \mathrm{~min}$. Eluted proteins were precipitated by addition of the 4 fold volume of ice-cold acetone $(200 \mu \mathrm{l})$ and stored overnight at $-20^{\circ} \mathrm{C}$. Afterwards, the proteins were pelleted by 
centrifugation in a table-top centrifuge at maximal speed for $30-40 \mathrm{~min}$ at $4^{\circ} \mathrm{C}$. The acetone was completely removed and the pellets were dried at room temperature for 15-45 min until residual acetone was evaporated. The dried samples were trypsinized as described (see 2.2.3.1).

\subsubsection{In-gel digestion of proteins after SDS-PAGE}

In-gel digestion of proteins after SDS-PAGE followed by Coomassie staining and extraction of peptides from gel pieces were performed as described [148]. Briefly, every lane of stained SDS-PAGE gels was cut in 24 small pieces of equal size. The gel pieces were washed with $150 \mu \mathrm{l} \mathrm{H}_{2} 0$ by incubation in a thermomixer for $5 \mathrm{~min}$ at $26^{\circ} \mathrm{C}, 1050 \mathrm{rpm}$. The pieces were centrifuged and the excess liquid removed. The samples were dehydrated with $150 \mu \mathrm{l}$ acetonitrile, shaking at $1050 \mathrm{rpm}$ for $15 \mathrm{~min}$ at $26{ }^{\circ} \mathrm{C}$ and the supernatant removed after spinning down. To assure full drying, the samples were additionally subjected to speed vacuum for at least 5 min. To reduce disulfide bridges, the gel cut-outs were supplied with $100 \mu \mathrm{l}$ of $10 \mathrm{mM}$ DTT/100 mM NH $\mathrm{mCO}_{3}$ and shaken for $50 \mathrm{~min}$ at 56 ${ }^{\circ} \mathrm{C}$. The gel pieces were spun down, excess liquid was discarded and dehydrated again with $150 \mu \mathrm{l}$ of acetonitrile for $15 \mathrm{~min}$ at $26^{\circ} \mathrm{C}$ at $1050 \mathrm{rpm}$. The dehydrating agent was removed and alkylation of reduced cysteine residues was performed using $100 \mu \mathrm{l}$ of $55 \mathrm{mM}$ iodoacetamide $/ 100 \mathrm{mM} \mathrm{NH}_{4} \mathrm{HCO}_{3}$ for $20 \mathrm{~min}$ at $26^{\circ} \mathrm{C}, 1050 \mathrm{rpm}$. The gel pieces were spun down and incubated for $15 \mathrm{~min}$ at $26^{\circ} \mathrm{C}, 1050 \mathrm{rpm}$ in $150 \mu \mathrm{l}$ of $100 \mathrm{mM} \mathrm{NH}_{4} \mathrm{HCO}_{3}$ ,after the excess liquid was removed,, followed by addition of $150 \mu \mathrm{l}$ of acetonitrile and further incubation under the same conditions for 20 more minutes. The gel pieces were pelleted and shaken (1050 rpm) in $150 \mu \mathrm{l}$ of acetonitrile for $15 \mathrm{~min}$ at $26^{\circ} \mathrm{C}$ after removal of the supernatant. The acetonitrile was discarded and the gel stripes dried for 5-10 min in a vacuum centrifuge. After rehydration at $4^{\circ} \mathrm{C}$ in a few microliters of digestion buffer 1 (see Table 2.3) for 30-45 min (after approx. 15 min the samples were checked and more buffer was added in case the liquid was completely absorbed by the gel pieces). 10-20 $\mu \mathrm{l}$ of digestion buffer 2 (see Table 2.3) were added to cover the gel pieces and keep them wet during the trypsinization. The samples were incubated over night for max. $16 \mathrm{~h}$ at $37^{\circ} \mathrm{C}$. 


\subsection{Extraction of peptides}

The peptide mixtures from the digested proteins were extracted as following.10-15 $\mu \mathrm{l}$ of $\mathrm{H}_{2} \mathrm{O}$ were added to the digest (the samples should be completely covered with liquid). The samples were shortly spun down and incubated for $15 \mathrm{~min}$ at $37^{\circ} \mathrm{C}$ shaking at $1050 \mathrm{rpm} .50 \mu \mathrm{l}$ of acetonitrile were added and further incubated for $15 \mathrm{~min}$. The gel pieces were removed by centrifugation and the supernatant containing the peptides was collected in protein LoBind Eppendorf tubes. $50 \mu \mathrm{l}$ of 5\% (v/v) $\mathrm{HCOOH}$ were added to the gel pieces and incubation was continued for $15 \mathrm{~min}$ at $37^{\circ} \mathrm{C}$ and $1050 \mathrm{rpm}$. The stripes were shortly centrifuged and $50 \mu \mathrm{l}$ of acetonitrile were added and incubated for further 15 min. The gels were finally removed by centrifugation, the supernatant was collected and both extracts were pooled and dried under speed-vacuum (approx.. 1 1⁄2 h).

\subsubsection{Peptide mixture desalting}

The peptide mixture was preceded to desalting using StageTips (using gel loading tips and Empore C18 discs) [149]. In brief, speed-vacuum dried peptide mixtures were dissolved in $40 \mu \mathrm{l}$ of $0.5 \% \mathrm{HCOOH}$, vortexed, spun down, sonicated for $2 \mathrm{~min}$ and centrifuged at maximal speed in a table top centrifuge for $40 \mathrm{~min}$ at $4^{\circ} \mathrm{C}$. During centrifugation 2 C18 desalting discs were excised and packed on a $10 \mu$ l pipetting tip. The columns were equilibrated using a bench centrifuge (5min, $2000 \mathrm{rpm}$ ) by washing once with $25 \mu \mathrm{l}$ of $100 \%$ methanol, followed by one washing step with $80 \%$ acetonitrile ( $25 \mu \mathrm{l})$ and three washings with $0.5 \% \mathrm{HCOOH}(25 \mu \mathrm{l}$ each). After the last washing step, the dissolved peptides were loaded on the columns, centrifuged for $8 \mathrm{~min}$ at $2000 \mathrm{rpm}$ and washed as described above at least three times with $0.5 \% \mathrm{HCOOH}$. Collecting vials were exchanged for $1.5 \mathrm{~mL}$ MS grade Protein LoBind tubes (Eppendorf) and desalted peptides were eluted three times with $25 \mu \mathrm{l}$ of $80 \%$ acetonitrile each. Samples were speed-vacuum dried and stored at $-80^{\circ} \mathrm{C}$ until measurements.

\subsubsection{Mass spectrometry, data analysis and quantification}

The samples were dissolved in $20 \mu \mathrm{l} 5 \%(\mathrm{v} / \mathrm{v})$ acetonitrile and 1\% (v/v) formic acid and analyzed in two technical replicates on a Q Exactive Plus Hybrid Quadrupole-Orbitrap Mass Spectrometer coupled to Dionex UltiMate ${ }^{\circledR} 3000$ RSLCnano system (Thermo Scientific). In the nano-LC system (equipped with in-house made ReproSil C18-AQ 5 u, 
pre-column - $30 \mathrm{~mm}$ in length, inner diameter $150 \mu \mathrm{m}$ and C18 (1.9 u) separation column $30 \mathrm{~cm}$ in length, inner diameter $75 \mu \mathrm{m}$ ), peptides were separated at a flow rate of 300 $\mathrm{nL} / \mathrm{min}$ on a $8-45 \%$ mobile phase $\mathrm{B}$ ( $80 \%$ acetonitrile, $0.15 \%$ formic acid) gradient with a duration of $118 \mathrm{~min}$. Eluting peptides were analyzed on-line in the MS scan range 350$1600 \mathrm{~m} / \mathrm{z}$ (TopN 20 fragmentation mode, isolation window set at $2.0 \mathrm{~m} / \mathrm{z}$, NCE 30). The acquired data was analyzed using MaxQuant (version 1.3.0.5) with Andromeda search engine and data search was against SwissProt $R$. norvegicus database and UPS2 protein database (in case of iBAQ measurements) [150]. iBAQ values for protein quantification were obtained as recently described [151]. 


\section{Results}

\subsection{Protocol development for synaptosome solubilization and characteriza- tion of presynaptic protein complexes}

\subsubsection{Detergent screen for synaptosome solubilization}

First studies with detergent on isolated nerve terminals were conducted by de Robertis and co-workers [152, 153] and followed up by Taylor and Bloom [153-155]. They discovered that Triton X-100 solubilizes synaptsosomal membranes releasing membrane-bound enzymes of interest. This process involved a post-solubilizational centrifugation step at $100000 \mathrm{~g}$ for $60 \mathrm{~min}$ which led to the isolation of a detergentresistant residue (pellet). The pellet was considered to represent a junctional complex, comprised of membranes and underlying proteinaceous network. Since then, also the terms supernatant (S) and pellet (P) became conventional in detergent trials to describe detergentsoluble and resistant fraction, respectively. Few years later, Cotman et. al. [156] showed that N-lauroyl sarcosinate treatment of synaptosomes results in the isolation of postsynaptic densities, free of junction-flanking membranes and presynaptic structures. The results from these initial studies suggested differential solubilization of synaptosomes by different detergents. They also emphasized weak points in the application of Triton X100 that was not able to completely solubilize presynaptic membranes $[157,158]$.

Up to date, only few reports addressed the extractability of individual synaptosomal membrane proteins and their complexes by different detergents [64, 126, 127, 129, 135, 159, 160]. Moreover, they did not report an extensive detergent screen and did not provide an overview on the extractability of synaptic proteins. Rather, the authors focused on the extraction of one particular protein and relied on co-solubilization of its interaction partners.

Our major goal was isolation and characterization of presynaptic protein complexes. As a first step in our protocol, an advanced detergent screen was performed on synaptosomes and LP1 fraction in order to analyze the extractability of proteins associated either with the presynaptic active zone or with the postsynaptic density.

Synaptosomes represent resealed pinched-off nerve terminals and thus contain the proteins required for SV exocytosis and regulation of neurotransmitter release [138]. Some 
of these proteins are core AZ constituents (e.g. Munc13 and ERC1b/2), AZ-associated (e.g. Munc-18) or plasma membrane proteins (e.g. SNAP-25 and syntaxin 1A). In addition, large portion of the proteins involved in neurotransmission are integral and represent transporter proteins, channels, receptors as well as SNAREs, often regulated by proteinprotein interactions with peripheral proteins. These protein groups are present also in the membrane-enriched LP1 fraction which is obtained by centrifugation after a hypotonic osmotic lysis of synaptosomes [139] (Figure 2.2). LP1 could be used as an alternative starting material to synaptosomes in the solubilization tests. It has the advantage of containing less soluble proteins compared to intact synaptosomes, but is enriched in core $\mathrm{AZ}$ and AZ-associated proteins as well as presynaptic membrane proteins (mainly ion channels, transporter proteins and receptors) which are in the focus of our study. In the performed screen, the extraction properties of different detergents (see Table 1.2) were analyzed by immunodetection of proteins in pellet (P) and supernatant (S) fractions. These two fractions were obtained after the solubilization of freshly prepared synaptosomes and LP1 fraction (see section 2.2.2.5) followed by pre-centrifugation for $20 \mathrm{~min}$ at $100000 \mathrm{~g}$ in S140AT4 rotor. The $g$ force factor for the pre-centrifugation step was adopted from the published studies. Considering the clearing factor $k$ of the used rotors in former studies and our rotor (S140AT4), the centrifugation time was adjusted. Same amount of protein from the pellet and supernatant was resolved by SDS-PAGE and probed for the protein distribution by Western blotting (Figure 3.1 and Figure 3.2). 


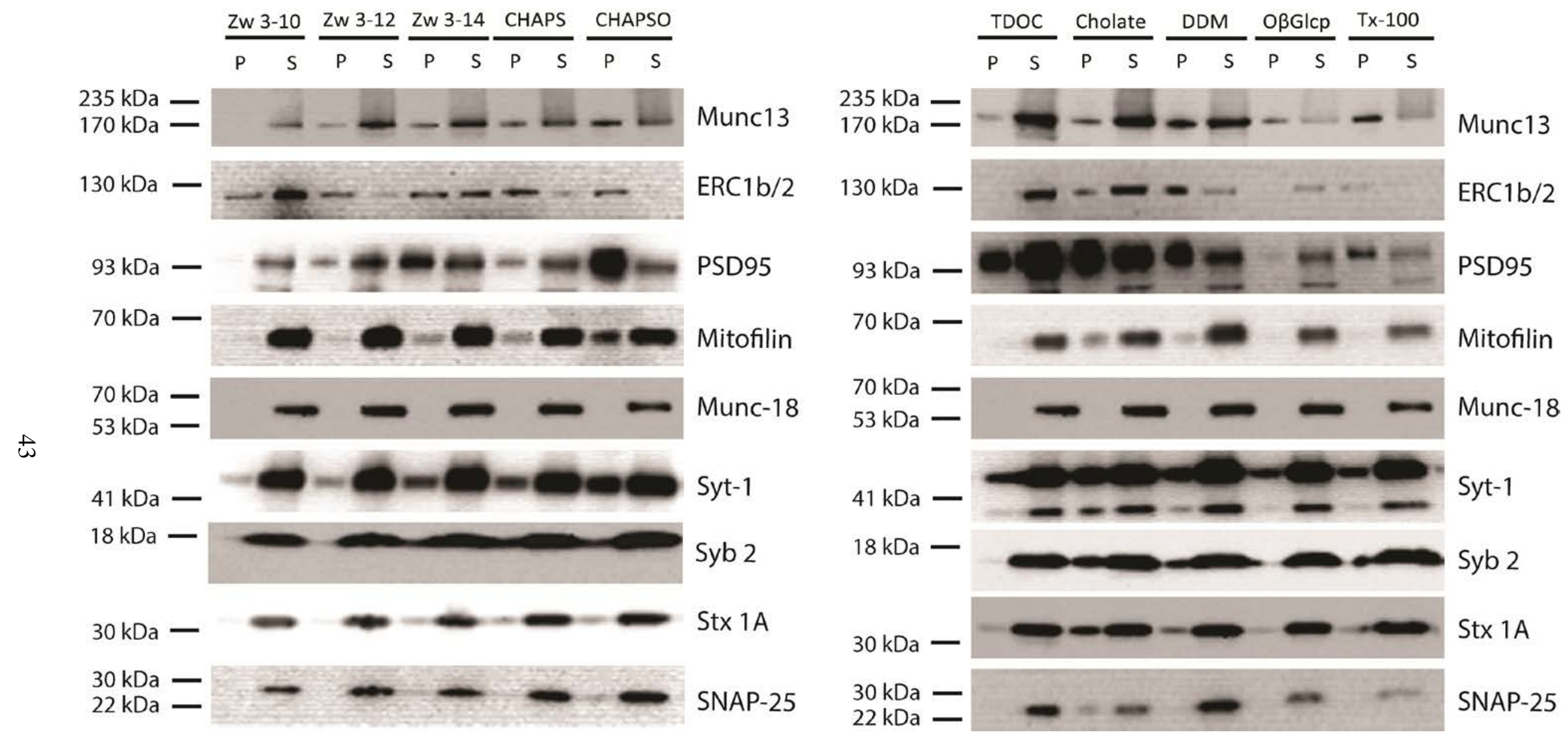

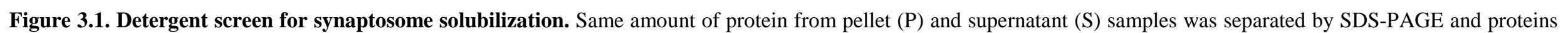

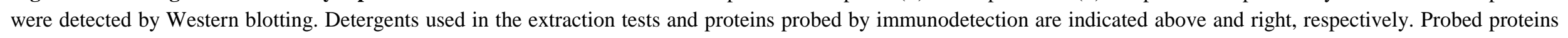
cover five different protein classes abundant at the synapse: SV, AZ and AZ-associated, PM, postsynaptic and mitochondrial proteins. 


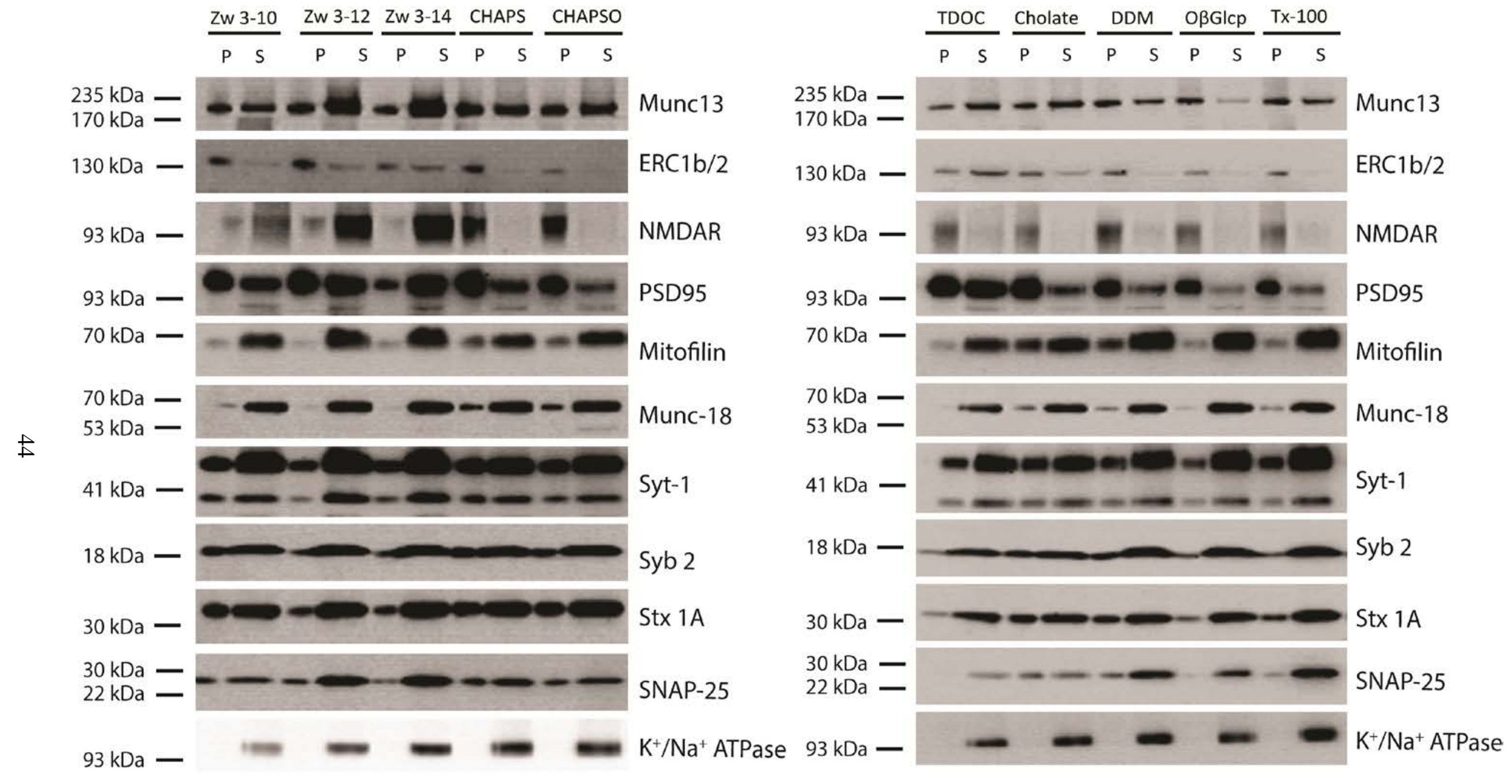

Figure 3.2. Detergent screen for solubilization of LP1 fraction. Same amount of protein from pellet (P) and supernatant (S) fractions was separated by SDS-PAGE and were detected by Western blotting. Detergent used and proteins probed by immunodetection are indicated above and right, respectively. Probed proteins cover five different protein classes represented at the synapse: SV, AZ and AZ-associated, PM, postsynaptic and mitochondrial proteins. 
The list of detergents tested for protein extraction from synaptosomes and LP1 fraction (see Table 1.2) included two nonionic alkyl glycosidic detergents: octyl- $\beta$ glucopyranoside (OßGlcp) and dodecyl- $\beta$-D-maltoside (DDM), a glucoside and maltoside, respectively; the nonionic polyoxyethylene detergent Triton X-100 (Tx-100); five zwitterionic detergents: the two bile acid derivatives CHAPS and CHAPSO and three aliphatic homologues - zwittergent 3-10, 3-12 and 3-14; and two anionic bile acid derivatives: sodium cholate (cholate) and sodium taurodeoxycholate (TDOC). The solubilization potential of the detergents was evaluated by their ability to extract the representatives of five classes of proteins residing at the synapse: SV proteins (synaptobrevin 2 and synaptotagmin-1), plasma membrane (PM) proteins (SNAP-25, syntaxin $1 \mathrm{~A}$ and $\mathrm{K}^{+} / \mathrm{Na}^{+}$ATPase); AZ and AZ-associated proteins (Munc13, ERC1b/2 and Munc-18); postsynaptic density-associated proteins (PSD95 and NMDA receptor) and mitochondrial proteins (represented by mitofilin).

Mitofilin, a protein from the inner mitochondrial membrane, was solubilized to a great extent when both samples, synaptosomes and LP1 fraction, were treated with the listed detergents. However, some portion of the protein was detected by immunoblotting in the pellet when CHAPS, CHAPSO, DDM and cholate were used (see Figure 3.1 and Figure 3.2). Similarly, the soluble protein Munc-18 was exclusively detected in the supernatant regardless of the starting material. Only exception was observed when CHAPS and CHAPSO were used for the solubilization of LP1 fraction (Figure 3.2). Additionally, full extraction from synaptic membranes was observed for the $\mathrm{K}^{+} / \mathrm{Na}^{+}$ATPase, an enzyme that was one of the first membrane-bound proteins isolated from synaptosomes [161, 162]. In contrast to the ATPase, the two further plasma membrane proteins- SNAP-25 and sxt $1 \mathrm{~A}$, were not completely extracted by the used detergents in either samples as judged by the immunoblots (Figure 3.1 and Figure 3.2). Although the larger portion of both proteins was solubilized, Western blot signals were detected also in the pellets. These results were in line with the extraction pattern of the SV proteins syb 2 and syt-1, both single transmembrane domain-containing proteins like stx 1 . Although not quantitatively, they were also well solubilized by all detergents disregarding the used starting material. Interestingly, the AZ proteins Munc13 and ERC1b/2 (ERCs) showed more complex solubilization pattern. Munc13 was only partially solubilized by the listed detergents (Table 1.2), with OßGlcp and Triton X-100 being the least efficient detergents for its extraction. This finding was also in agreement with previous reports by others [163] (see Figure 3.2). Furthermore, OßGlcp, Tx-100 as well as DDM, CHAPS and CHAPSO failed 
in solubilizing ERCs from the synaptic membranes (see Figure 3.2). The only detergents that successfully extracted ERCs to some extent were cholate and TDOC (Figure 3.1 and Figure 3.2). In contrast to the observations on presynaptic and soluble proteins was the extraction profile of the postsynaptic density (PSD)-associated proteins PSD95 and NMDA receptor (see Figure 3.2). SV proteins, presynaptic plasma membrane and soluble proteins showed similar extractability pattern, whereas the postsynaptic proteins differed in their solubilization profile. The NMDA receptor, reported to be challenging for solubilization trials [164, 165], was completely extracted by the three homologues of the zwittergent family: zwittergent 3-10, 3-12 and 3-14. Zwittergents resemble in their properties nonionic detergents but are also capable of breaking protein-protein interactions [106, 166]. This fact might explain the full extraction of NMDAR only by these detergents. In contrast, the PSD95 protein, known to interact with NMDAR [167], was partially extracted also by other detergents than the zwittergents (Figure 3.2). This result indicated no correlation in the extraction of PSD95 and NMDAR despite their direct interaction.

The results from the detergent screen for solubilization of synaptosomes and LP1 fraction allowed drawing some conclusions. First, soluble and membrane proteins were efficiently extracted by all detergents although some minor differences were observed when CHAPS and CHAPSO were used. This pattern applied to SV proteins as well as proteins from the presynaptic plasma membrane and mitochondrial proteins. Second, proteins associated with the presynaptic cytomatrix or the postsynaptic density show differences in their extractability. While presynaptic proteins showed correlation in their extractability, postsynaptic proteins were differentially extracted. Interestingly, SV proteins as well as presynaptic membrane and soluble proteins were well extracted by glycosidic, zwitterionic (alkyl and bile acid) as well as anionic bile acid detergents. However, the detergents showed minor differences towards the AZ proteins ELKS and Munc13. The glycosidic DDM and OßGlcp as well as CHAPS, CHAPSO and Triton X100 showed poor extraction of ELKS (Figure 3.2). They also poorly solubilized Munc13, which, in contrast, was well extractable when TDOC and cholate were used. In addition, all detergents, except the zwittergent family members, were unable of extracting NMDAR and only slighty solubilized PSD95. The PSD-associated proteins showed different extraction pattern. Zwittergent detergents completely extracted NMDAR and only partially solubilized PSD95. When other detergents were applied, PSD95 showed partial extraction, but NMDAR was quantitatively found in the pellet. These results confirmed the differential behavior of the immunodetected protein groups towards different detergents. 
Since the major goal of our study was characterization of presynaptic membrane proteins complexes, we focused in more detail on presynaptic cytomatrix-associated and membrane proteins. Therefore, additional extractions with four of the tested detergents were performed. Based on the initial results (Figure 3.1 and Figure 3.2), we decided to further investigate the solubilization potential of TDOC, cholate, Triton X-100 and zwittergent 3-14. First, TDOC and cholate showed similar extraction profile, the solubilization efficiency towards the ELKS proteins was crucial for that choice of TDOC (see Figure 3.1and Figure 3.2). Second, DDM was chosen over OßGlcp due to better extraction of Munc13 (Figure 3.2). Triton X-100 was used as standard detergent in membrane biochemistry and finally yet importantly, zwittergent 3-14, which efficiently extracted NMDAR and PSD95 as well as presynaptic membrane, mitochondrial and SV proteins, was picked as novel candidate for further analyses.

Solubilization procedures were repeated with the LP1 fraction as described above. Equal amounts of protein from $\mathrm{P}$ and $\mathrm{S}$ were resolved and fractions were immunoprobed for more proteins. The extended protein list contained plasma membrane, AZ and CAZ proteins, as well as PSD-associated and scaffolding proteins. The results obtained after the DDM treatment of LP1 fraction are shown below (Figure 3.3).
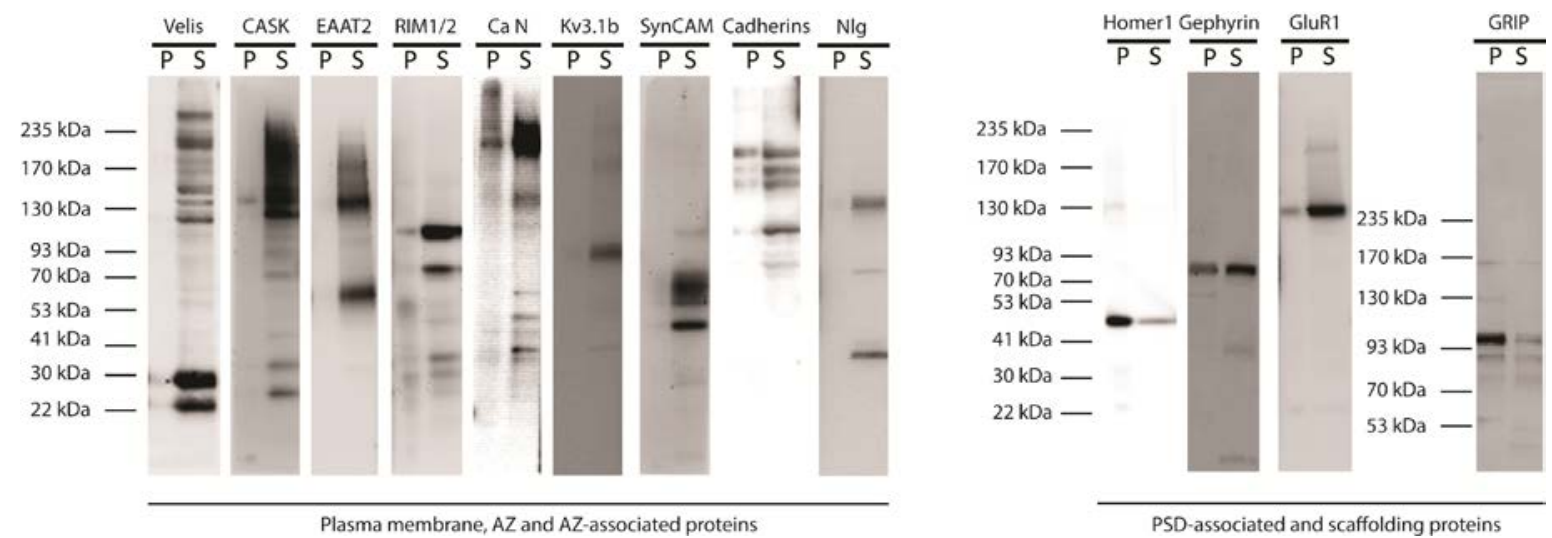

Figure 3.3. Extraction pattern of LP1-resident proteins with DDM. LP1 sample was isolated after hypoosmotic lysis of freshly isolated synaptosomes. A pre-centrifugation step was performed at $100000 \mathrm{~g}$ for 20 min in a S140AT4 rotor. Equal amounts of protein from pellet (P) and supernatant (S) was loaded on a $4-12 \%$ gradient SDS-PAGE gel. Immunodetection of the indicated proteins (above the blots) was conducted. 
DDM extracted almost completely the probed proteins from the presynaptic plasma membrane but also CAZ-associated proteins and ion channels (Figure 3.3). The list of plasma membrane proteins that were detected by immunoblots was extended and included the excitatory amino acid transporter isoform 2 (EAAT2), potassium channel Kcnc1 (Kv3.1b), VGCC of N-type (Ca N), neuroligins as well as the cell adhesion molecules of the IgG superfamily - SynCAM 1, 2 and 3 ( 100 kDa, $60 \mathrm{kDa}$ and $45 \mathrm{kDa}$, respectively) and $\alpha$-protocadherin ( 100 kDa). In contrast, a differential extraction was observed for the detected PSD-associated proteins, confirming the results from the initial experiments (Figure 3.1 and Figure 3.2). Gephyrin was partially extractable, glutamate receptorinteraction protein (GRIP) and Homer1 were exclusively found in the pellet, whereas the GluR1 subunit of the ionotropic AMPA receptor was almost quantitatively extracted from the LP1 fraction (Figure 3.3).

A similar solubilization analysis was performed using the nonionic Triton X-100 and the anionic bile acid detergent TDOC (Figure 3.4 and Figure 3.5, respectively).
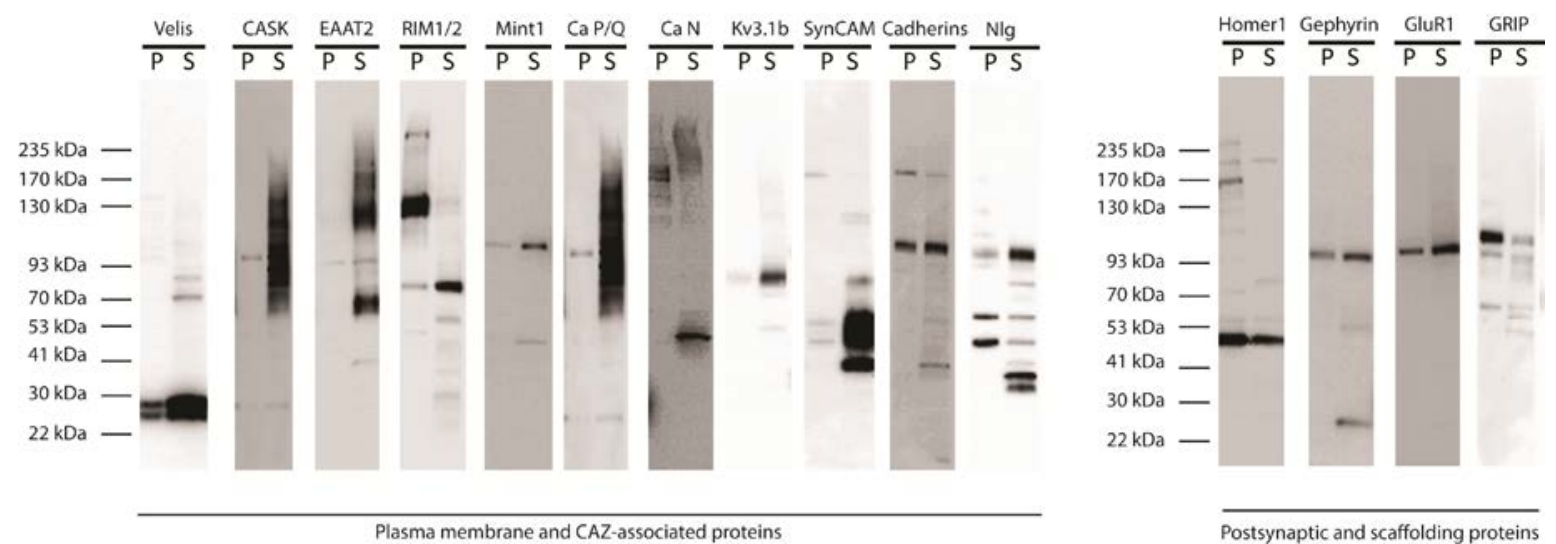

Figure 3.4 Extraction pattern of LP1-resident proteins Triton X-100. LP1 sample was isolated after hypotonic osmotic lysis of freshly isolated synaptosomes. A pre-centrifugation step was performed at 100 $000 \mathrm{~g}$ for $20 \mathrm{~min}$ in a S140AT4 rotor. Equal amount of protein from pellet (P) and supernatant (S) was loaded on a 4-12\% gradient SDS-PAGE gel. Indicated proteins (above the blots) were detected by Western blots.

Triton X-100’s solubilization profile was intriguing since no study so far examined in detail which synaptic proteins can be extracted by this detergent. In addition to the presynaptic and CAZ-associated proteins probed in the DDM solubilization experiment (Figure 3.3), pellet and supernatant were immunoprobed also for Munc 18-interaction protein 1 (Mint1) and the VGCC of P/Q-type (Figure 3.4). A major difference in 
solubilization pattern between DDM and Tx100 represented the extraction of RIM1/2: Tx100 extracted only the short splice variant ( $70 \mathrm{kDa})$ of the protein (see Figure 3.4 ) whereas DDM solubilized it completely. Similar to the previous experiment with DDM, all plasma membrane and CAZ-associated proteins were well extractable. In agreement with the former data, the extraction profile of the postsynaptic proteins emphasized their differentiated solubilization pattern. They were either partially (Homer1, gephyrin, the GluR1 subunit of AMPA receptor) or not extracted (GRIP) (Figure 3.4).

Interestingly, TDOC solubilized completely not only the presynaptic membrane and cytomatrix-associated proteins, but also all postsynaptic scaffolding proteins: Homer1, gephyrin, GRIP and the AMPA receptor (Figure 3.5). The extraction of membrane proteins and AZ-residing constituents was in line with the previous observations. However, the extractability of the PSD-associated proteins from the LP1 fraction after TDOC treatment was a novel and intriguing finding.
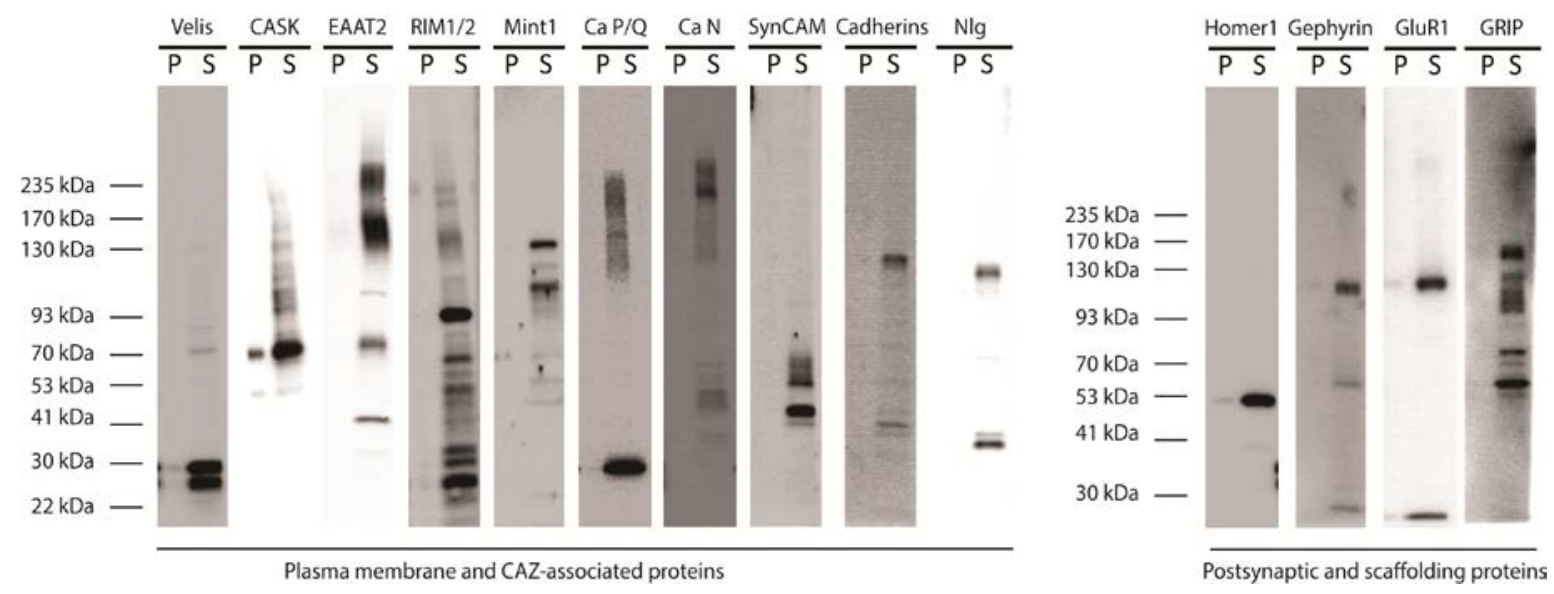

Figure 3.5. Extraction pattern of LP1-resident proteins with TDOC. LP1 sample was isolated from freshly prepared synaptosomes. A pre-centrifugation step at $100000 \mathrm{~g}$ for $20 \mathrm{~min}$ (S140AT4 rotor) yielded two samples - pellet (P) and supernatant (S). Equal amount of protein from both samples was loaded on a gradient SDS-PAGE gel and indicated proteins (above the blots) were immunodetected. 
All proteins immunoprobed after LP1 solubilization with zwittergent 3-14 were completely extracted except the PSD scaffolding protein Homer1 (Figure 3.6).
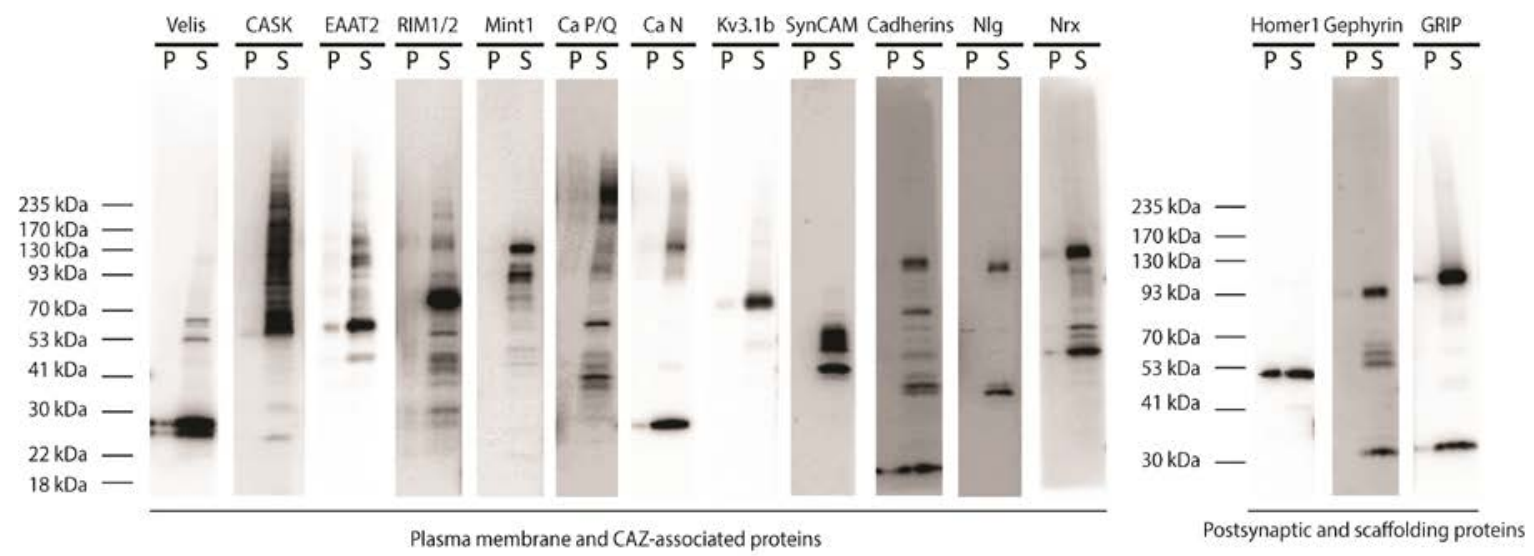

Figure 3.6. Solubilization of LP1 fraction with Zwittergent 3-14. LP1 sample was isolated from freshly isolated synaptosomes. A pre-centrifugation step at $100000 \mathrm{~g}$ for $20 \mathrm{~min}$ in a S140AT4 rotor yielded two fractions - pellet (P) and supernatant (S). Equal amount of protein from both samples was loaded on a 4-12\% gradient SDS-PAGE gel. Indicated proteins (above the blots) were detected by Western blots.

One of the great challenges in solubilization studies on synaptosomes has been the extraction of the two scaffolding proteins Bassoon ( 420 kDa) and Piccolo ( 550 kDa). Studies conducted with the detergent Triton X-100 reported major loss of the Piccolo protein in the pellet after a post-solubilizational centrifugation step [70]. Therefore, we tested whether the four detergents mentioned above were able of extracting Piccolo and Bassoon. In addition to zwittergent 3-14, Triton X-100, DDM and TDOC, two recently reported 1\% detergent solutions CL 91 and CL 114 were also tested [135] (Figure 3.7). The results confirmed the inability of Triton X-100 to extract both scaffolding proteins. In addition to the full-length proteins, the antibodies detected protein bands $\sim 60 \mathrm{kDa}$ in the supernatant. Those could be due to protein degradation or represented short splice variants of the proteins that were solubilized due to their low molecular weight [76, 77]. When any of zwittergent 3-14, CL91 or CL114 was used, no clear immunodetection was possible. CL91 and CL114 detergent solutions impaired the detection of full length Bassoon and Piccolo via Western blotting (Figure 3.7). However, interesting results were obtained when the detergents TDOC and DDM were used for solubilization of LP1 fraction (Figure 3.7). 

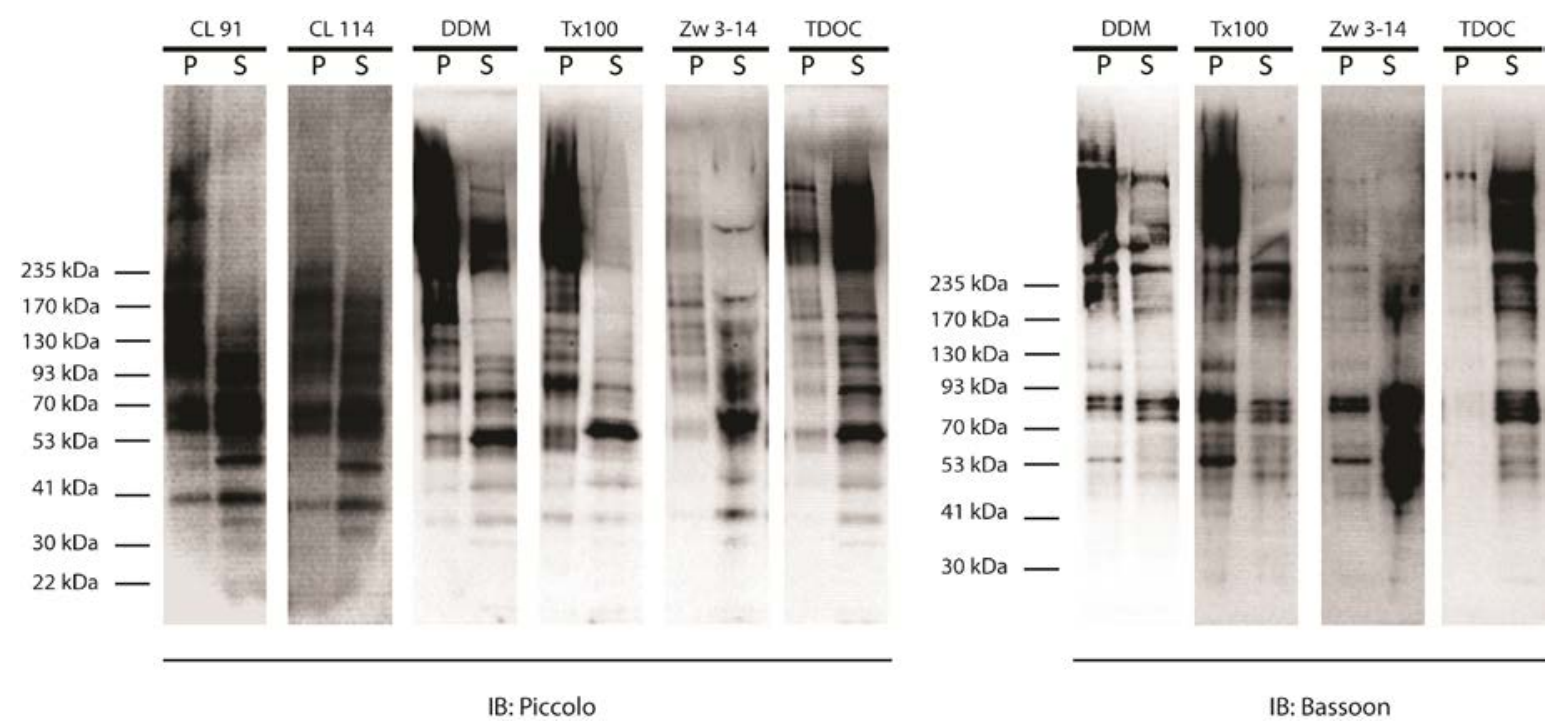

Figure 3.7. Extraction of Piccolo and Bassoon. LP1 fraction isolated from freshly prepared synaptosomes was subjected to solubilization with the detergents (stated above each blot). Equal amounts of protein from the pellet (P) and supernatant (S) fractions, obtained by centrifugation at $100000 \mathrm{~g}$ for $20 \mathrm{~min}$ in S140AT4 rotor, was resolved by SDS-PAGE. Western blots with polyclonal antibodies against Piccolo and Bassoon (indicated below the WB membranes) were developed.

Up to date, no studies reported the extraction neither of Piccolo nor of Bassoon from synaptosomes using bile acid or glycosidic detergents. TDOC quantitatively extracted Bassoon and almost fully solubilized Piccolo. In contrast, DDM solubilized Piccolo only partially whereas Bassoon remained in the pellet fraction. These results suggested that no correlation in the extractability of both proteins exists.

Based on the results from the screen few conclusions were drawn. First, the probed plasma membrane, SV and CAZ-associated proteins were efficiently extracted by most of the tested detergents. These observations also applied to mitochondrial and soluble proteins. Second, proteins associated either with CAZ or PSD showed major differences in the extractability. While presynaptic proteins showed good correlative extraction, no such trend was observed for the PSD-associated proteins. Importantly, these results were strongly dependent on the solubilization conditions, i.e. conditions under which the membrane loses its lamellar integrity due to detergent treatment [95]. Thus, one critical parameter that affects the extraction of membrane proteins and their complexes is the detergent:protein ratio used during solubilization. Another factor is the pelleting efficiency of the rotor used in the centrifugation step after solubilization. This step determines whether only detergent-insoluble membrane remaining resides in the pellet or also large 
protein assemblies are removed from the suspension. Therefore, the importance of the two factors was extensively addressed in the following sections.

\subsubsection{Time- and detergent concentration-dependent solubilization}

Optimal detergent concentrations for solubilization must be determined experimentally for each membrane model. Hjelmeland and co-coworkers provided some guidelines for establishing solubilization protocols $[106,168]$, and underlined the need for an empirical determination of protein:detergent ratios. Furthermore, analyses emphasized that the effective detergent:lipid:protein mole ratio is relevant for solubilization $[169,170]$.

Up to date, studies addressing extraction times and detergent concentrations reported results from the solubilization of supported lipid bilayers [171, 172]. These results are not necessarily applicable to a more complex system. Therefore, it was important to test the effect of these two variables - time and detergent concentration - on synaptic membranes. For this purpose, LP1 fraction isolated from freshly prepared synaptosomes was solubilized in different protein:detergent ratios with TDOC (Figure 3.8). The same protocol was followed for both, DDM and cholate, but not shown here. A centrifugation step post-solubilization was performed as mentioned earlier (at $100000 \mathrm{~g}$ for $20 \mathrm{~min}$, S140AT4 rotor), the proteins from pellet and supernatant were resolved by SDS-PAGE and immunoblotted for presynaptic and postsynaptic proteins. The solubilization pattern of the immunoblotted proteins resembled the previous results obtained with TDOC (Figure 3.2 and Figure 3.5). Presynaptic CAZ-associated, SV as well as soluble proteins were well extracted after 5 min of incubation with detergent. This pattern did not change for up to $4 \mathrm{~h}$ of incubation time for neither of the probed proteins (Figure 3.8). Unchanged time- and concentration-dependent solubilization behavior showed also the postsynaptic proteins PSD95 and NMDAR. In summary, the presynaptic cytomatrix proteins were well extractable whereas no correlation in the extraction pattern was observed for the PSD proteins. Moreover, the extraction of the proteins was detectable already after short time and remained unchanged with an increase in the detergent concentration. 


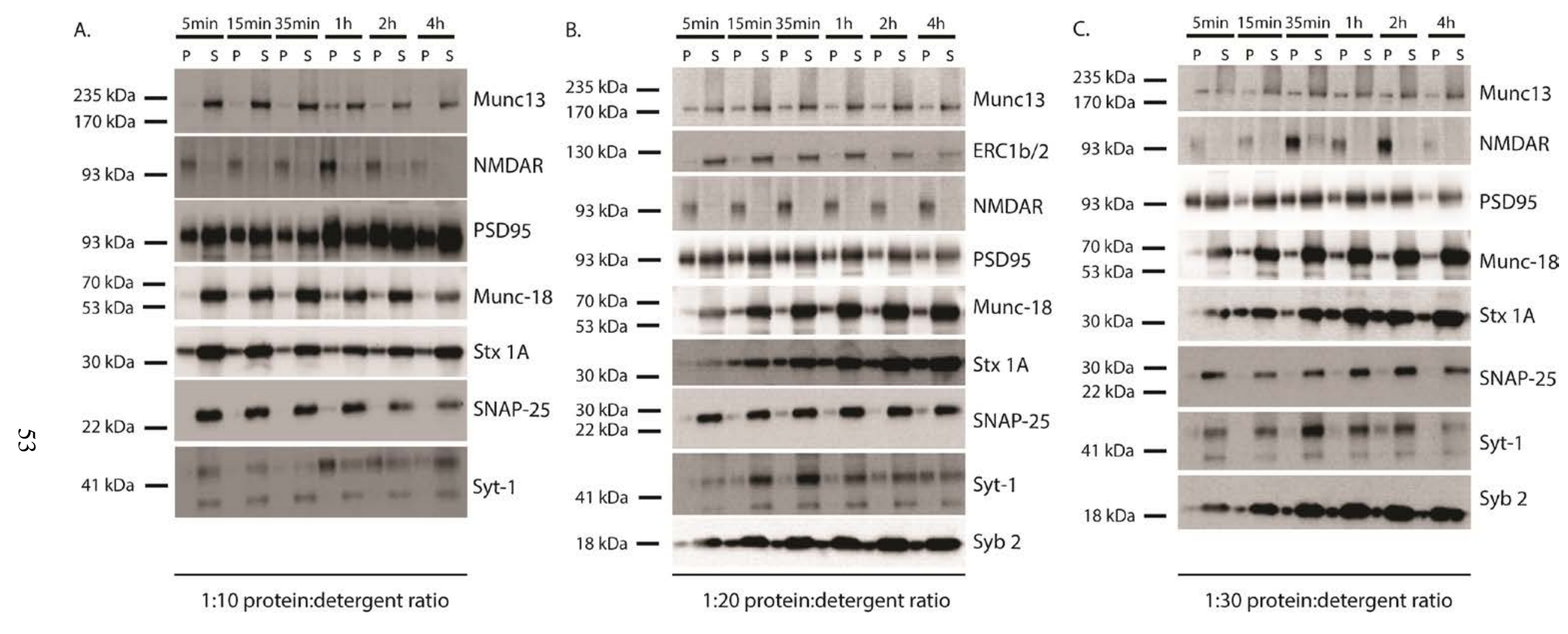

Figure 3.8. Time- and concentration-dependent solubilization of LP1 fraction. LP1 fraction isolated by osmotic lysis of freshly prepared synaptosomes was solubilized with TDOC in (A) 1:10, (B) 1:20 or (C) 1:30 ratio of protein to detergent. After the indicated time points, solubilization was terminated by centrifugation at $100000 \mathrm{~g}$ for 20 min (S140AT4). Equal amounts of protein from the pellet (P) and supernatant (S) fractions were resolved by SDS-PAGE and probed with antibodies for the indicated proteins. 


\subsubsection{New centrifugation protocol for solubilization experiments}

The selection of centrifugation parameters for separation of solubilized membrane material from detergent-insoluble residues is determined empirically [95]. However, the systematic characterization of different centrifugation conditions' effect on the protein content of extracted material remains to be investigated. A recent report indicated a possibly too strong pelleting efficiency of our clearance step in S140AT4 rotor (Sorvall) [135]. This was confirmed by preliminary trials to isolate protein complexes in an immunoaffinity approach combined with mass spectrometry (AP-MS). They revealed lack of some previously reported protein-protein interactions. In addition, trials to immobilize and immunostain extracted proteins (data not shown) failed in detecting some core AZ constituents (e.g. Bassoon and liprin- $\alpha 3$ ).

It is well known that not the $g$ force and centrifugation time determine the pelleting efficiency of a rotor, but its clearing factor $k_{a d j}$ at the actual rotation speed [173]. Thus, an actual pelleting efficiency of $\mathrm{k}_{\mathrm{adj}}=53$ was calculated for the S140AT4 rotor (Table 3.1). The clearing factor was used to estimate also the maximal sedimentation coefficient of the particles remaining in solution $-\mathrm{S}_{\text {coeff,max }} \approx 160 \mathrm{~S}$. This value was compared to recently published results [135]. It suggested removal of the proteins of interest and their interacting partners from the suspension in the preliminary affinity purifications. Therefore, a new centrifugation procedure was adopted. It consisted of a single centrifugation step at 100 $000 \mathrm{~g}$ for $20 \mathrm{~min}$ in a TLA100.3 rotor (Beckman). Calculations showed that the pelleting efficiency of the TLA100.3 rotor was thus set to $\mathrm{k}_{\mathrm{adj}}=75$ and $\mathrm{S}_{\text {coeff,max }} \approx 227 \mathrm{~S}$ (Table 3.1). 
Table 3.1. Centrifugation conditions used in previously reported and following experiments. The clearing factor $\mathrm{k}_{\mathrm{adj}}$ at the actual used rotation speed ( $\mathrm{rpm}_{\mathrm{actual}}$ ) was calculated for two rotors - S140AT4 and TLA100.3. The actual clearing factor was used to calculate the maximal sedimentation coefficient $\mathrm{S}_{\text {coeff,max }}$, at which solubilized material remained in the supernatant.

\begin{tabular}{|c|c|c|}
\hline \multirow[b]{2}{*}{$\begin{array}{c}\text { Centrifugation/Rotor } \\
\text { parameters }\end{array}$} & \multicolumn{2}{|c|}{ Rotor type } \\
\hline & $\begin{array}{l}\text { S140AT4 } \\
\text { (Sorvall) }\end{array}$ & $\begin{array}{l}\text { TLA100.3 } \\
\text { (Beckman) }\end{array}$ \\
\hline $\begin{array}{l}\text { Centrifugation time of } \\
\text { clearance step (min) }\end{array}$ & 20 & 20 \\
\hline $\begin{array}{l}\text { Maximum rotation speed } \\
\text { of rotor }(\mathrm{rpm})\end{array}$ & 140000 & 100000 \\
\hline $\mathbf{k}$ factor at $\mathbf{r p m}_{\max }$ & 5 & 14 \\
\hline $\begin{array}{c}\text { Rotation speed in } \\
\text { experiment (rpm } \\
\text { actual) }\end{array}$ & 43000 & 43000 \\
\hline$g$ force at rpm actual & 100000 & 100000 \\
\hline $\mathrm{k}_{\mathrm{adj}}=\mathrm{k}^{*}\left(\mathrm{rpm}_{\mathrm{max}} / \mathrm{rpm}_{\text {actual }}\right)^{\wedge 2}$ & 53 & 75 \\
\hline $\mathrm{S}_{\text {coeff,max }}$ (Sverdberg, S) & 160 & 227 \\
\hline
\end{tabular}

With the newly optimized centrifugation procedure, the majority of the extracted proteins remained in solution, enabling the characterization of their protein-protein interactions. In order to validate the less intense pelleting efficiency by the adopted protocol change and to confirm the presence of the extracted proteins in solution, Western blots were performed. The LP1 fraction was solubilized with TDOC, Triton X-100 and DDM. Solubilization with the harsh detergent zwittergent 3-14 was omitted due to its potential denaturation character. In addition, the extraction properties of a cheaper commercial alternative to TDOC - cholate, were tested comprehensively. Pellet (P) and supernatant (S) fractions were obtained according to the changed protocol (TLA100.3 rotor centrifugation) and their protein contents resolved by SDS-PAGE.

The list of immonoblotted proteins was extended in order to cover the whole range of proteins associated with the AZ: SV and PM SNAREs, trafficking, scaffolding and regulatory proteins as well as transporters and ion channels. Major PSD-associated proteins and receptors were also immunoprobed. The first solubilizations were performed with TDOC (Figure 3.9 and Figure 3.10). 

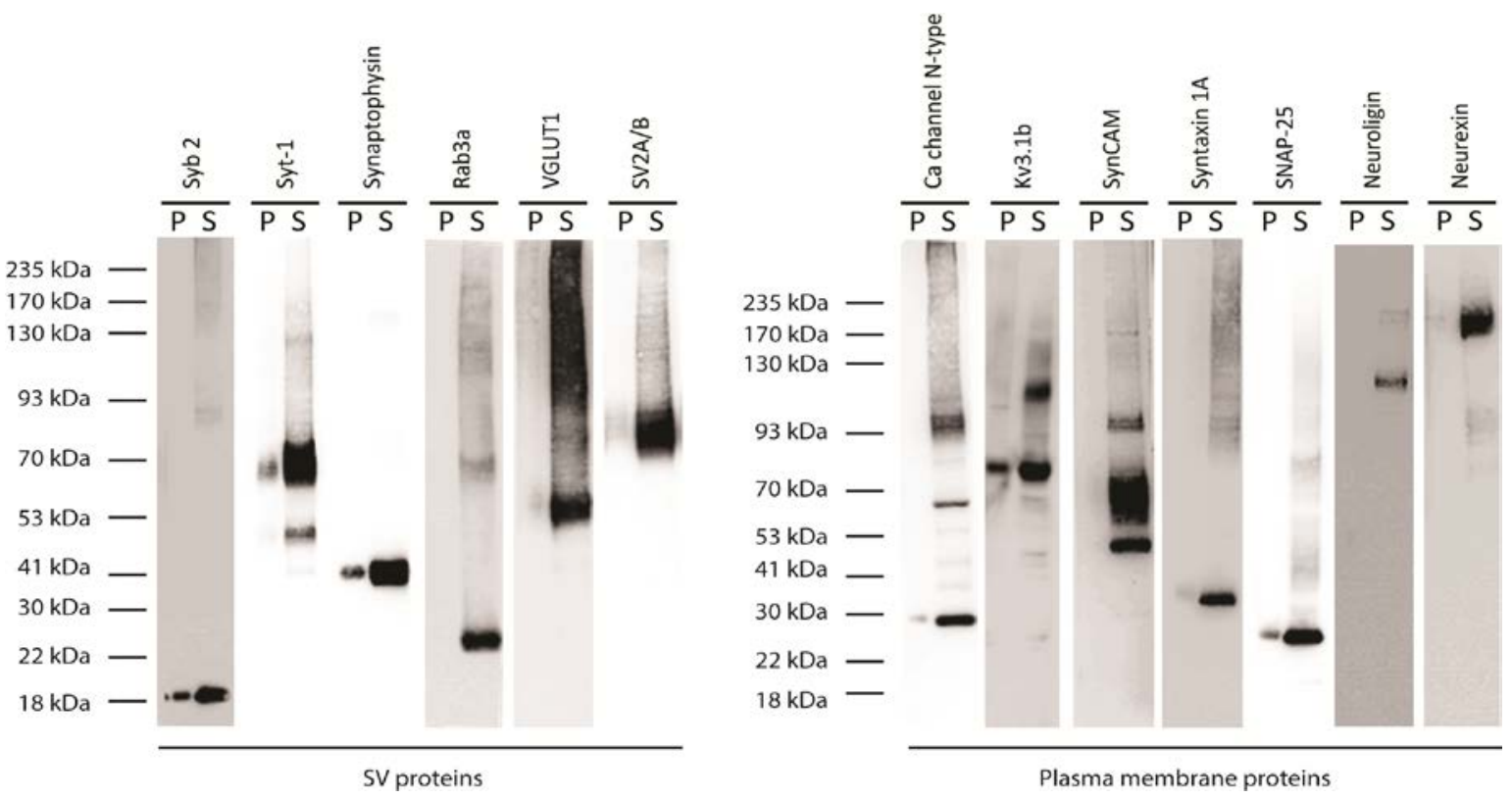

Figure 3.9. Extraction of SV and plasma membrane proteins by TDOC-solubilization of LP1 fraction. Solubilization of LP1 fraction isolated from freshly prepared synaptosomes was performed at 1:10 protein:detergent ratio. Suspension was centrifuged at $100000 \mathrm{~g}$ for $20 \mathrm{~min}$ in a TLA100.3 rotor. Constituents from the pellet $(\mathrm{P})$ and supernatant $(\mathrm{S})$ fractions were resolved and immunoblotted for the indicated proteins.

The SNARE proteins syb 2, SNAP-25 and stx 1 were well extractable in TDOC. Single transmembrane domain (TMD)-containing protein syt-1 and four TMD-containing synaptophysin were solubilized by the detergent as well as the 12 TMD-containing protein SV2 and the VGLUT1 transporter. In addition, good extractability was observed also for ion channels (VGCC of N-type and potassium channel Kv3.1b) and cell adhesion molecules (Figure 3.9). Remarkably, the scaffolding protein Bassoon was quantitatively extracted as well as large portion of Piccolo (see Figure 3.10). Importantly, lowering the pelleting efficiency of the centrifugation step resulted in nearly complete extraction of the core AZ proteins: liprin $\alpha-3$ isoform, Munc13-1, ERC and, RIM protein isoforms (Figure 3.10). Moreover, soluble CAZ-associated proteins like Munc18, Mint1, MAGUK superfamily protein CASK and its interacting partner CASKIN1 as well as the adaptor protein MALS (Lin-7 or Velis) were extracted and remained in the supernatant In line with the results from the initial experiments (section 3.1.1), the proteins associated with the AZ cytomatrix and plasma membrane were easier to extract than the PSD proteins. In contrast to the preliminary results obtained with the S140AT4 rotor (see Figure 3.2), the ionotropic glutamate NMDA receptor was well extracted with TDOC when the new centrifugation conditions were applied (Figure 3.10). 


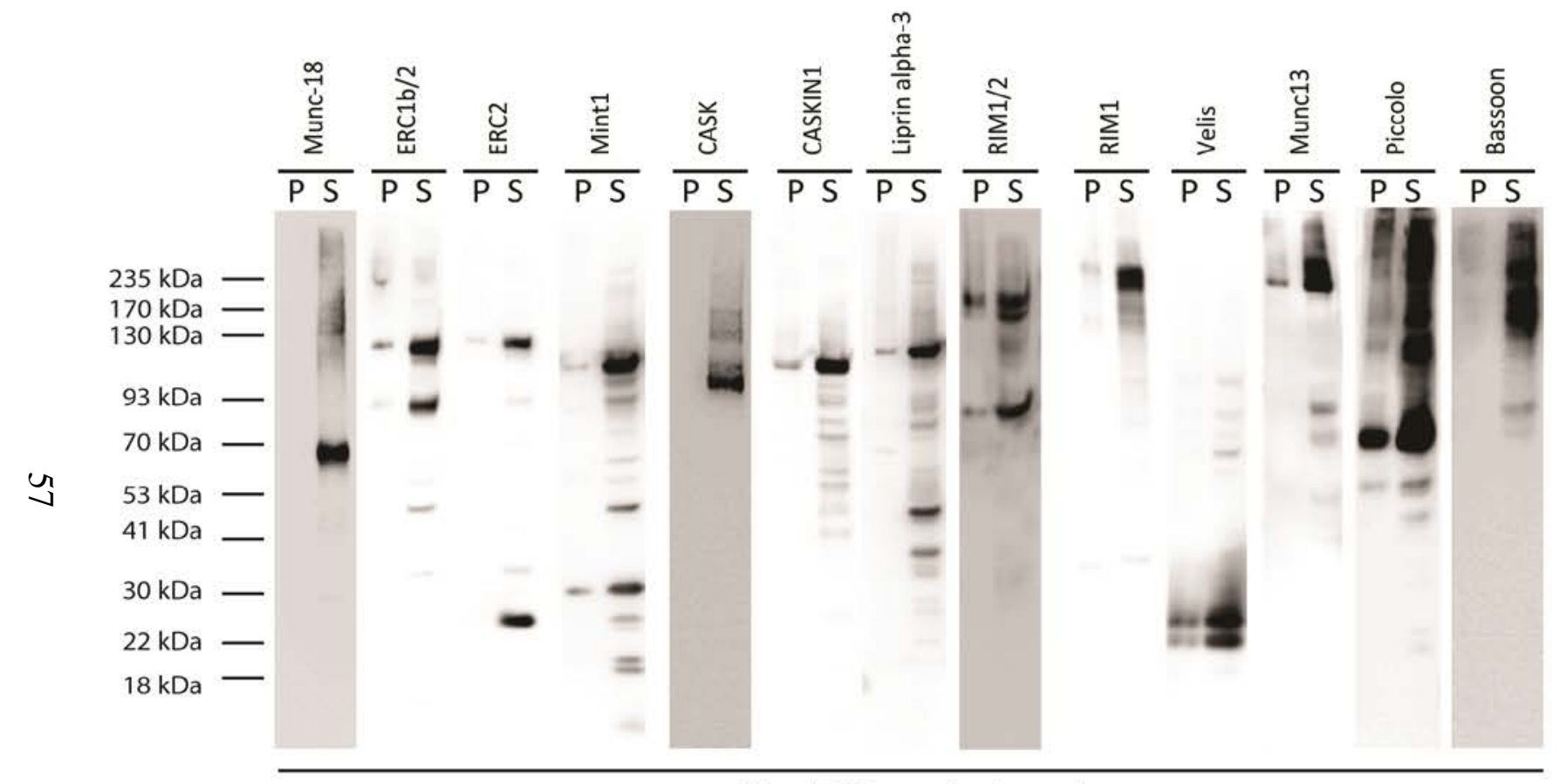

$A Z$ and $C A Z$-associated proteins

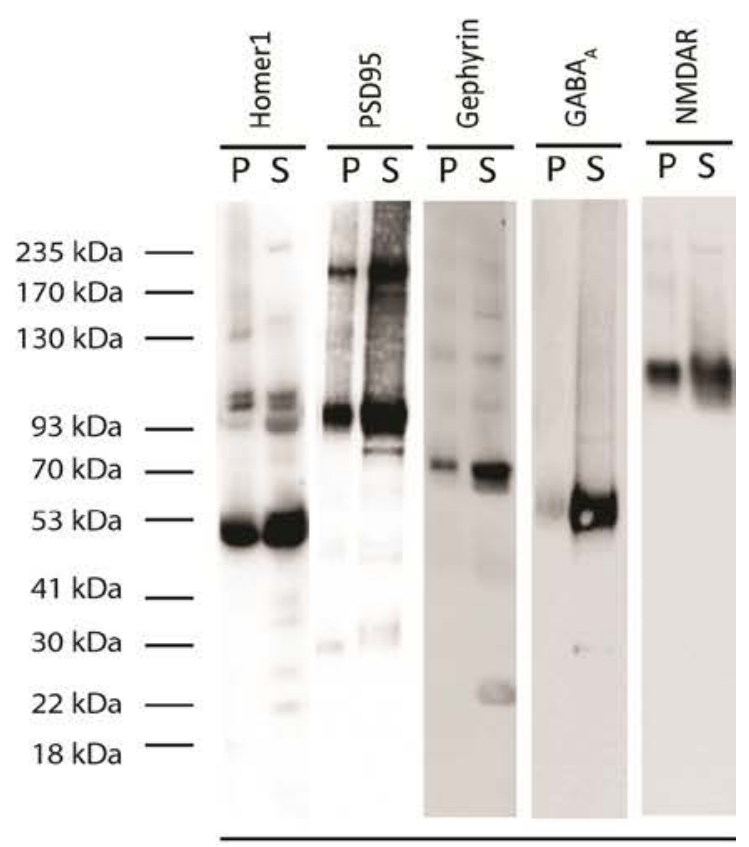

Postsynaptic and scaffolding proteins

Figure 3.10. Extraction of active zone, CAZ-associated and postsynaptic proteins by TDOC from LP1 fraction. Representative active zone, CAZ-associated as well as

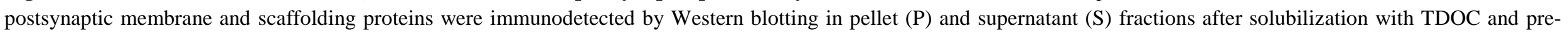
centrifugation step of $100000 \mathrm{~g}$ for $20 \mathrm{~min}$ (TLA100.3 rotor). 
When a structural analog of TDOC - cholate was used (Figure 3.11), the presynaptic cytomatrix-associated proteins remained well extractable. Only few differences in the solubilization pattern of the proteins were observed as compared to TDOC (Figure 3.10). The extraction profile of the SV and PM proteins showed minor changes compared to TDOC. Synaptophysin as well as syt-1 and VGLUT1 transporter were well, however less extractable in cholate (Figure 3.11). Same trend was observed for the VGCC of N-type and the PM SNAREs SNAP-25 and stx 1A (see Figure 3.10 and Figure 3.11). Nevertheless, other immunoprobed PM proteins like VGCC of P/Q-type, potassium channels Kv2.2 and Kv3.1 as well as the adhesion molecules (SynCAM isoforms, neuroligins and neurexins) were well extractable with cholate. Importantly, all immunodetected core AZ constituents, CAZ-associated and scaffolding proteins (e.g. Piccolo and Bassoon) remained in the supernatant after the centrifugation step with TLA100.3 rotor (see Figure 3.11). Furthermore, larger portions of Munc13 and ELKS proteins were detected by Western blotting in the detergent-soluble fraction (see Figure 3.2 and Figure 3.11). However, the postsynaptic glutamate receptor NMDAR remained in the pellet also when the new centrifugation protocol was applied. In contrast, the ionotropic receptor $\mathrm{GABA}_{\mathrm{A}}$ was partially extracted by cholate as well as by TDOC. The profile of the other PSD-associated proteins remained unchanged. These results confirmed an independent solubilization profile for the PSD-associated and showed better extractability for the proteins associated with the presynaptic cytomatrix.

Solubilization of LP1 fraction with DDM (Figure 3.12), followed by the newly adjusted centrifugation step, resulted in a similar extraction profile of the presynaptic proteins as obtained with TDOC and cholate (Figure 3.10 and Figure 3.11). CAZ proteins, PM and SV SNAREs were well solubilized, as well as multispanners such as VGLUT1, SV2A/B and synaptophysin. Liprin- $\alpha 3$ protein was less extractable with DDM than with TDOC and cholate. DDM solubilization of LP1 fraction resulted in retrieval of ERC1b/2 in the supernatant when the novel centrifugation step was applied (Figure 3.12). The protein was exclusively found in the pellet when the suspension was centrifuged in a S140AT4 rotor. In addition, the extraction of RIM-binding protein 1 (RIM-BP1) and RIM1/2 differed. Only the small splice variants of RIM ( 70 kDa) were extracted, leaving the fulllength protein in the pellet. At the same time, RIM-BP1 was well retained in the detergentsoluble fraction. Homer1, gephyrin and NMDAR showed stronger immunodetection signal in the supernatant compared to the results obtained with the S140AT4 centrifugation protocol. 

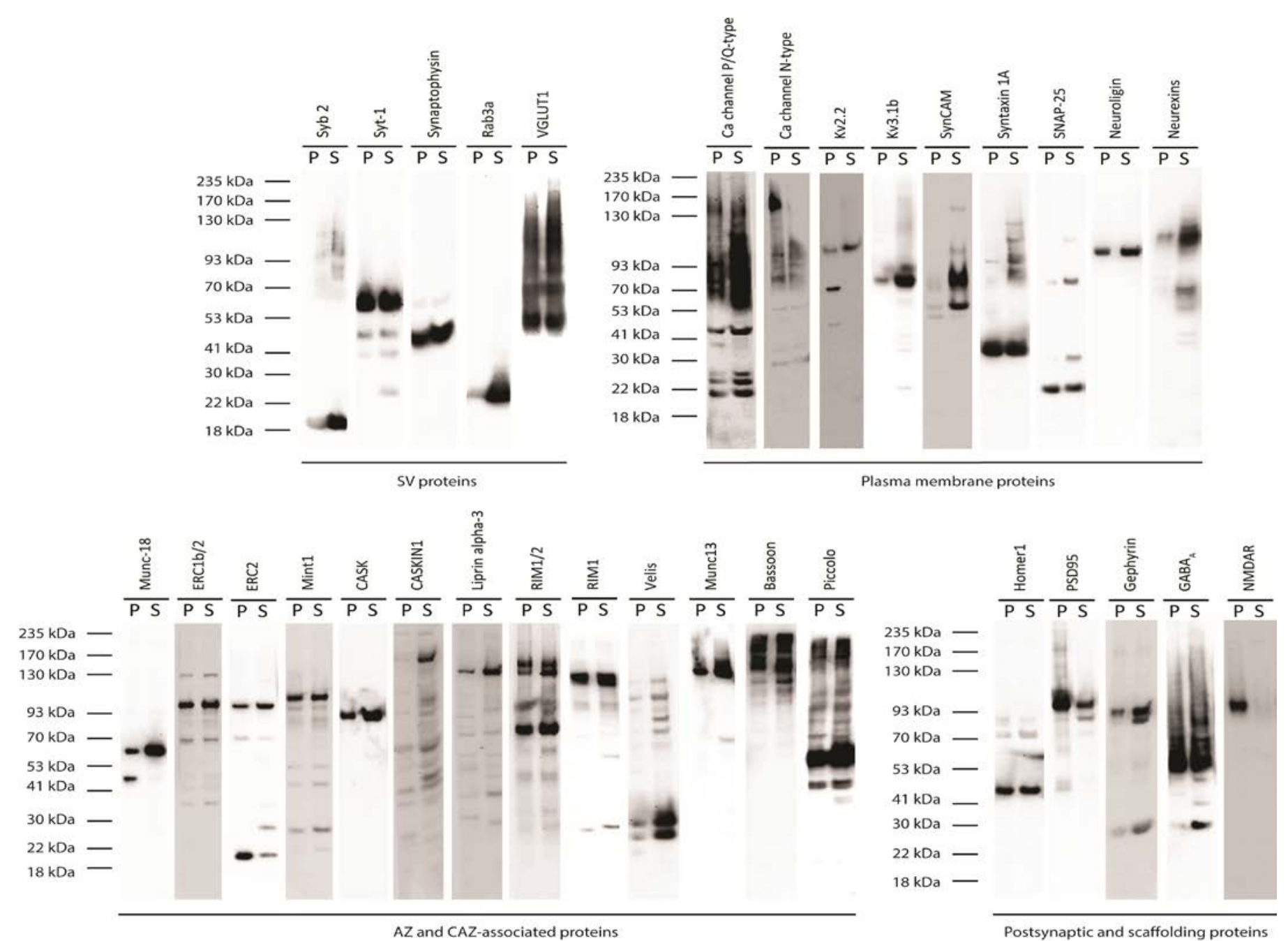

Figure 3.11. Protein extraction profile after LP1 solubilization with cholate. LP1 fraction isolated from freshly prepared synaptosomes was solubilized in a 1:10 protein:detergent ratio with cholate and suspension was subjected to centrifugation with TLA100.3 rotor. The centrifugation step lasted $20 \mathrm{~min}$ at $100000 \mathrm{~g}$. Same amount of protein from pellet (P) and supernatant (S) was resolved by SDS-PAGE and the indicated proteins were immunodetected by Western blots. 

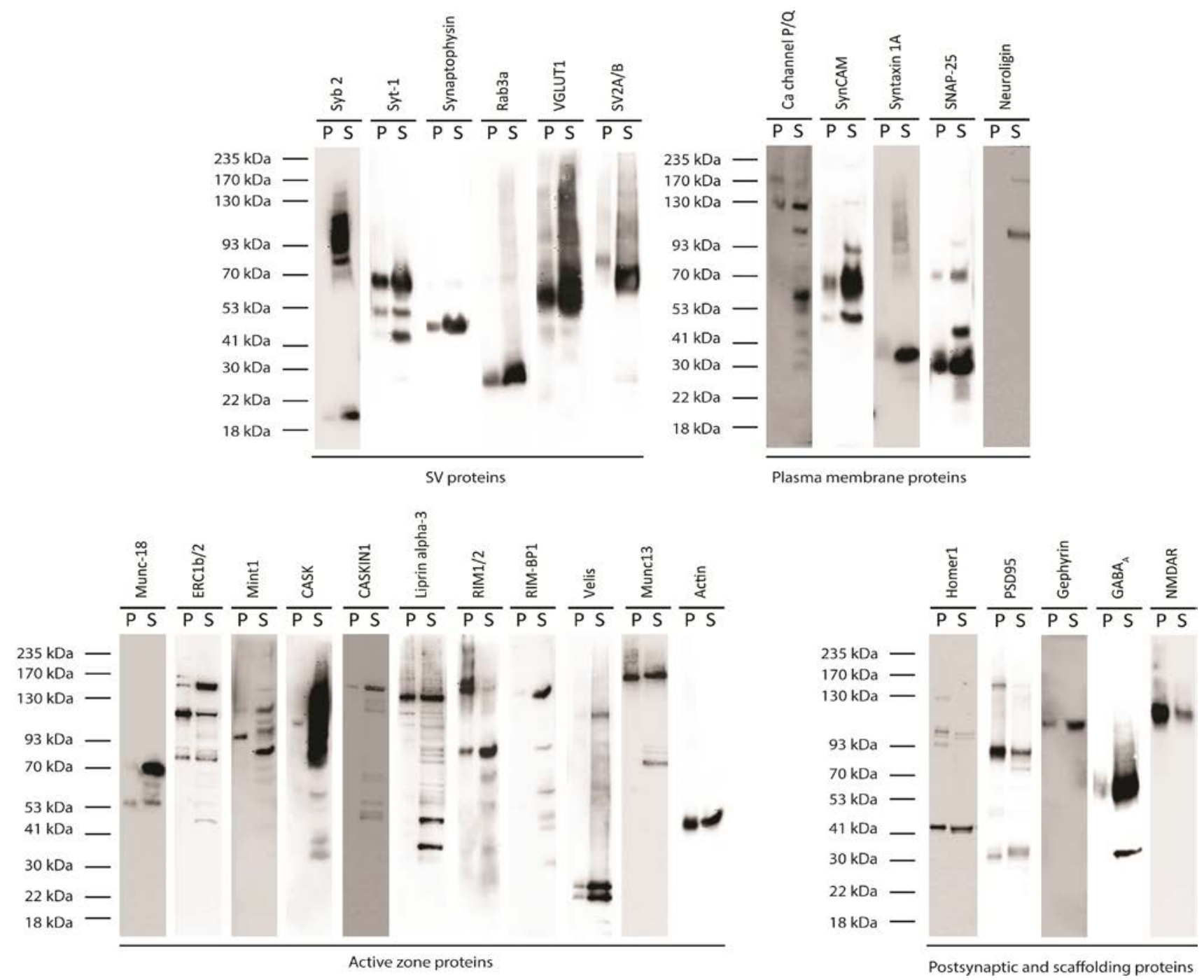

Figure 3.12. Protein extraction profile after LP1 solubilization with DDM. LP1 fraction isolated from freshly prepared synaptosomes was solubilized in a 1:10 protein:detergent ratio with DDM. The suspension was subjected to centrifugation with TLA100.3 rotor for 20 min at $100000 \mathrm{~g}$. Same amount of protein from pellet (P) and supernatant (S) was resolved by SDS-PAGE and protein indicated were immunodetected by Western blots. 
Additionally, a solubilization of LP1 fraction was performed with Triton X-100 (Figure 3.13 and Figure 3.14). Detection of the proteins by Western blotting was more difficult compared with the cholate, TDOC and DDM. The antibodies often detected smeared protein bands or failed in detecting the proteins. However, similar to TDOC, cholate and DDM, Triton X-100 showed good extraction properties towards SV and PM proteins. Triton X-100 successfully extracted the potassium channels Kv2.2 and Kv3.1b, but also SNAREs like stx 1A, SNAP.25 and syb 2. Synaptophysin was quantitatively extracted, as well as Rab3a, although they showed weak Western blot signals. In contrast to the potassium channels, VGCC of N-type was not extracted well and P/Q-type VGCC could not be detected by Western blot.
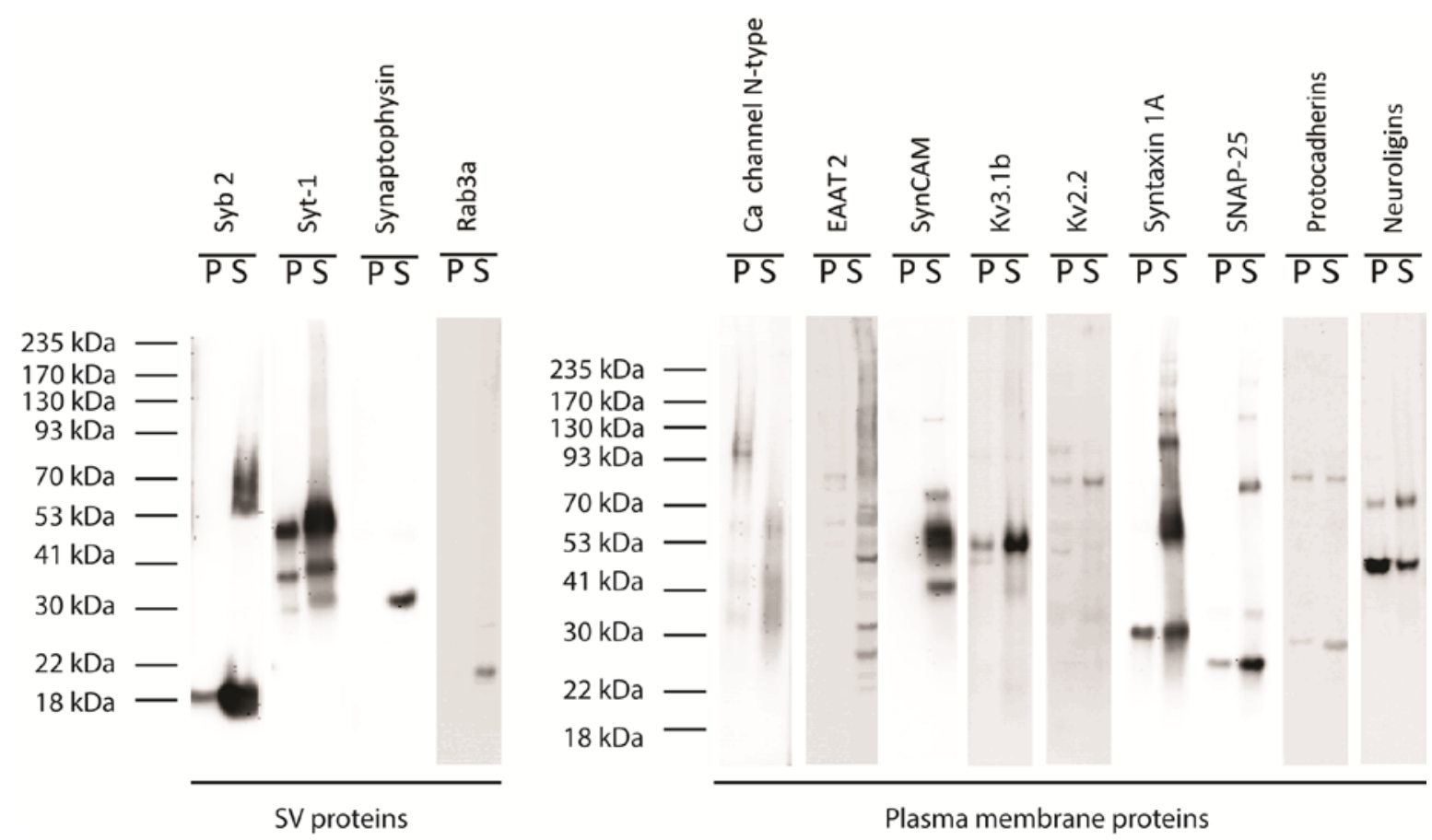

Figure 3.13. Extraction of SV and plasma membrane proteins from LP1 fraction with Triton X-100. LP1 fraction was solubilized in 1:10 protein:detergent ratio with Triton X-100. Same amount of protein from pellet (P) and supernatant (S) was resolved by SDS-PAGE and the indicated proteins were immunodetected (Western blots).

Despite milder centrifugation conditions in the novel protocol, major AZ and presynaptic soluble proteins as well as cell adhesion molecules remained insoluble in Triton X-100 and were exclusively detected in the pellet (see Figure 3.14) 

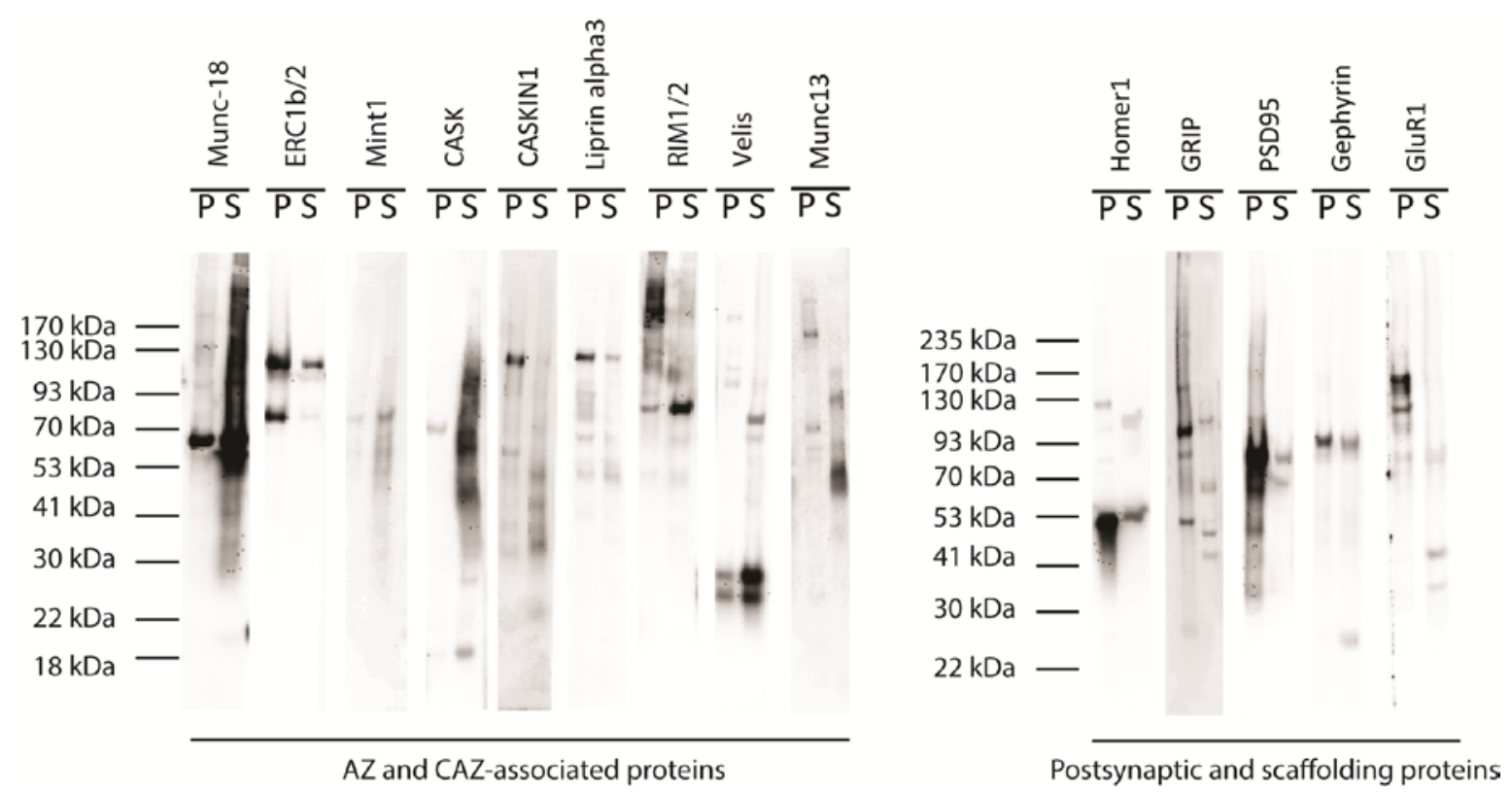

Figure 3.14. Extraction of active zone, postsynaptic and plasma membrane (PM) proteins from LP1 fraction with Triton X-100. LP1 fraction was solubilized in 1:10 protein:detergent ratio with Triton X-100. Same amount of protein from pellet (P) and supernatant (S) was resolved by SDS-PAGE and the indicated proteins were immunodetected (Western blots).

The AZ proteins Munc13, liprin $\alpha$-3, RIMs and ELKS were poorly extracted by Tx100. Only small splice variants of RIMs were detectable in the supernatant. Although CASK was well extracted, CASKIN1 was detected in the pellet. In addition, the soluble Munc-18 protein remained partially associated with the protein pellet post-solubilization and post-centrifugation. An advantage of Triton X-100 was the unextractability of postsynaptic proteins, which were mainly detected in the pellet even under the mild centrifugation conditions. NMDAR and neurexins failed in the immunodetection. However, neuroligins and neurexins were well solubilized by the other detergents, suggesting that neurexins might be extracted with Tx-100.

The detergents TDOC, cholate, DDM and Triton X-100 were screened for their ability to extract presynaptic CAZ- or PSD-associated proteins using a novel optimized centrifugation protocol. Among the tested detergents, Triton X-100 showed poor potential to extract core AZ constituents as also emphasized in earlier reports by others [70, 163]. However, an advantage of Triton X-100 is its disability to solubilize proteins associated with the postsynaptic density proteins. In addition, the mild centrifugation step after membrane solubilization did not improve the protein extraction. In contrast, TDOC and cholate extracted well all immunoprobed presynaptic CAZ-associated membrane, soluble and scaffolding proteins when applied in combination with the novel centrifugation step. 
TDOC almost quantitatively extracted all probed presynaptic proteins, whereas cholate was less efficient but extracted well all presynaptic proteins of interest. This did not apply to the PSD proteins when both detergents were used. In comparison with the bile acid detergents, DDM extracted well SV and PM proteins but showed limited solubilization potential towards major AZ proteins like Munc13, liprin, ERC1b/2 and RIMs. It solubilized poorly the NMDAR in contrast to TDOC. Thus, the novel solubilization and centrifugation procedure enabled extraction of the postsynaptic receptor NMDA, whose interactions are poorly studied due to its difficult extractability by detergents $[164,165]$. Importantly, cholate and TDOC, as well as DDM to some extent, showed great potential for extaction of presynaptic membrane and scaffolding proteins using the novel protocol.

\subsection{Fractionation of LP1 extracts by sucrose density gradient centrifugation}

\subsubsection{LP1 derived from non-treated synaptosomes}

Up to now, experimental variables like protein:detergent ratio, solubilization time and starting material were evaluated. In addition, the extraction behavior of pre- and postsynaptic proteins in distinct detergents was analyzed. The performed experiments helped selecting few detergents (cholate, TDOC and DDM) with potential for isolation of presynaptic cytomatrix-associated proteins and their interacting partners. Density gradient centrifugation was chosen as technique to separate the protein components of detergent extracts from LP1 fraction. The use of gradient centrifugation in the presence of detergent was reported earlier for the characterization of the $20 \mathrm{~S}$ particle, composed of syb 2, stx 1A, syt-1 and SNAP-25 [174, 175] and the 7S particle, consisting of syb2, stx 1A, SNAP25 assembled with NSF and $\alpha$ SNAP [176]. Moreover, the existence of distinct multimeric complexes of SV membrane proteins was proved using combination of detergents and density gradients [159].

For this reason, LP1 fraction was isolated from freshly prepared synaptosomes $[138,146]$ and solubilized at protein:detergent ratio $1: 10$ for 15 min at $4{ }^{\circ} \mathrm{C}$ with TDOC. TDOC was chosen arbitrary over Triton X-100, cholate or DDM. Pre-centrifugation of the solubilized membrane fraction was performed at $33000 \mathrm{~g}$ for $15 \mathrm{~min}$ and the supernatant was loaded on a 5-30\% sucrose gradient. Collected fractions were immunoprobed for AZ (Munc13 and ERC), PSD-associated (PSD95), soluble (Munc-18), PM (SNAP-25 and stx 
1A), and SV (syb 2, syt-1) proteins (Figure 3.15). The immunoblotted proteins were poorly separated and enriched in top fractions 17-23 of the gradient (Figure 3.15).

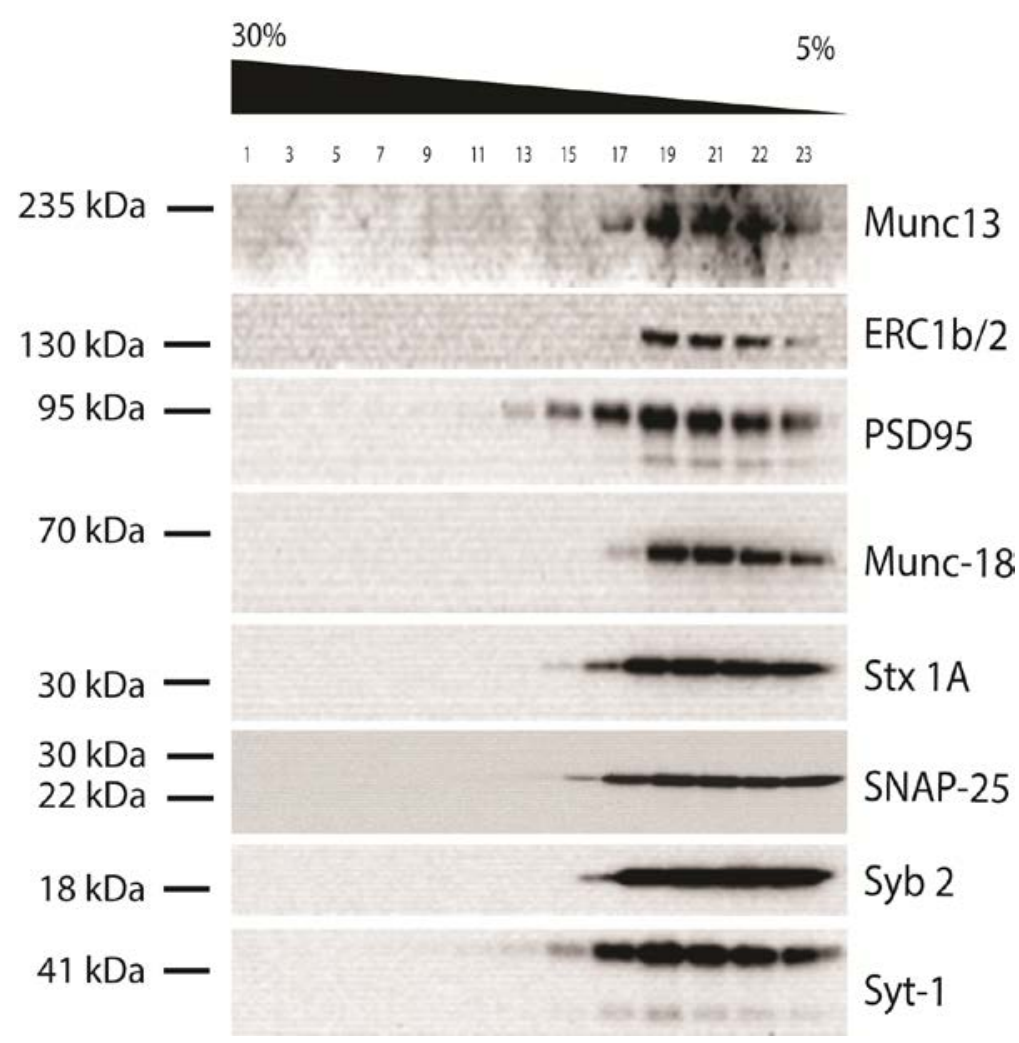

Figure 3.15. TDOC solubilization of LP1 fraction and linear gradient centrifugation. LP1 fraction was isolated from freshly prepared synaptosomes and solubilized with TDOC in a 1:10 protein:detergent ratio. After mild centrifugation step at $33000 \mathrm{~g}$ for $15 \mathrm{~min}$ (S140AT4 rotor), proteins from the supernatant were separated on a 5-30\% sucrose gradient in a $14 \mathrm{~h}$ centrifugation at $70000 \mathrm{~g}$ (SW41 rotor). Proteins (indicated on the left of the blots) were probed by Western blot.

In order to explore the separation potential of the technique and to test whether the separation profile could be improved by the use of another gradient medium or starting material, the experiment was repeated with two changed parameters. First, freshly prepared synaptosomes were used for the solubilization instead of LP1 fraction. Second, four different gradients were tested: 5-20\% sucrose, 5-15\% Ficoll, 5-30\% and 10-20\% glycerol (Figure 3.16). 


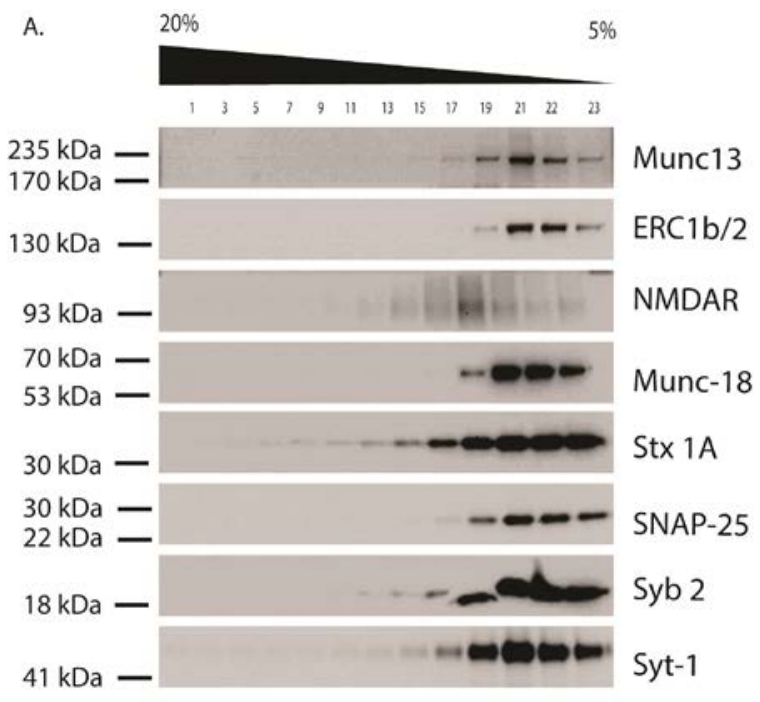

B. $\quad 15 \%$
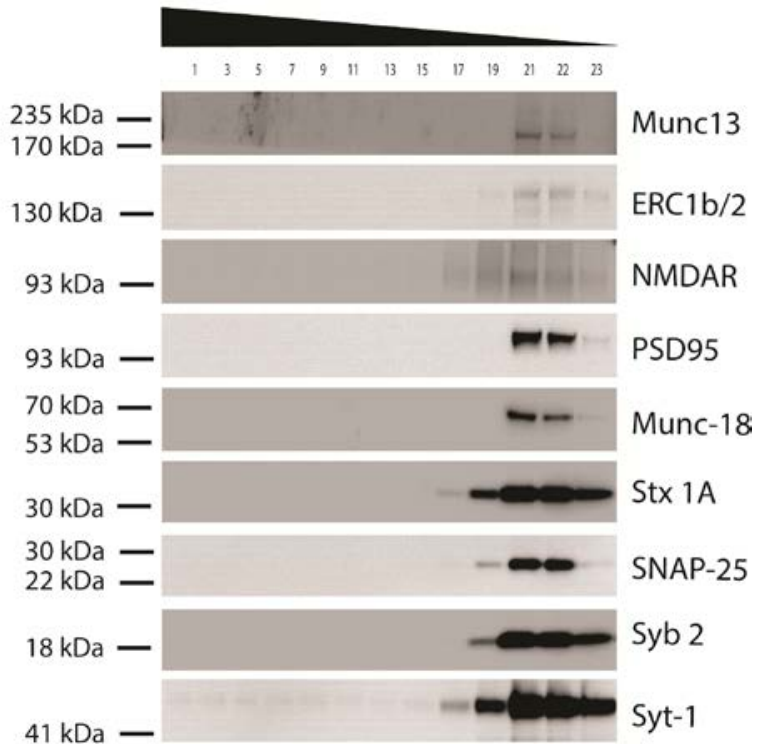

41 kDa -

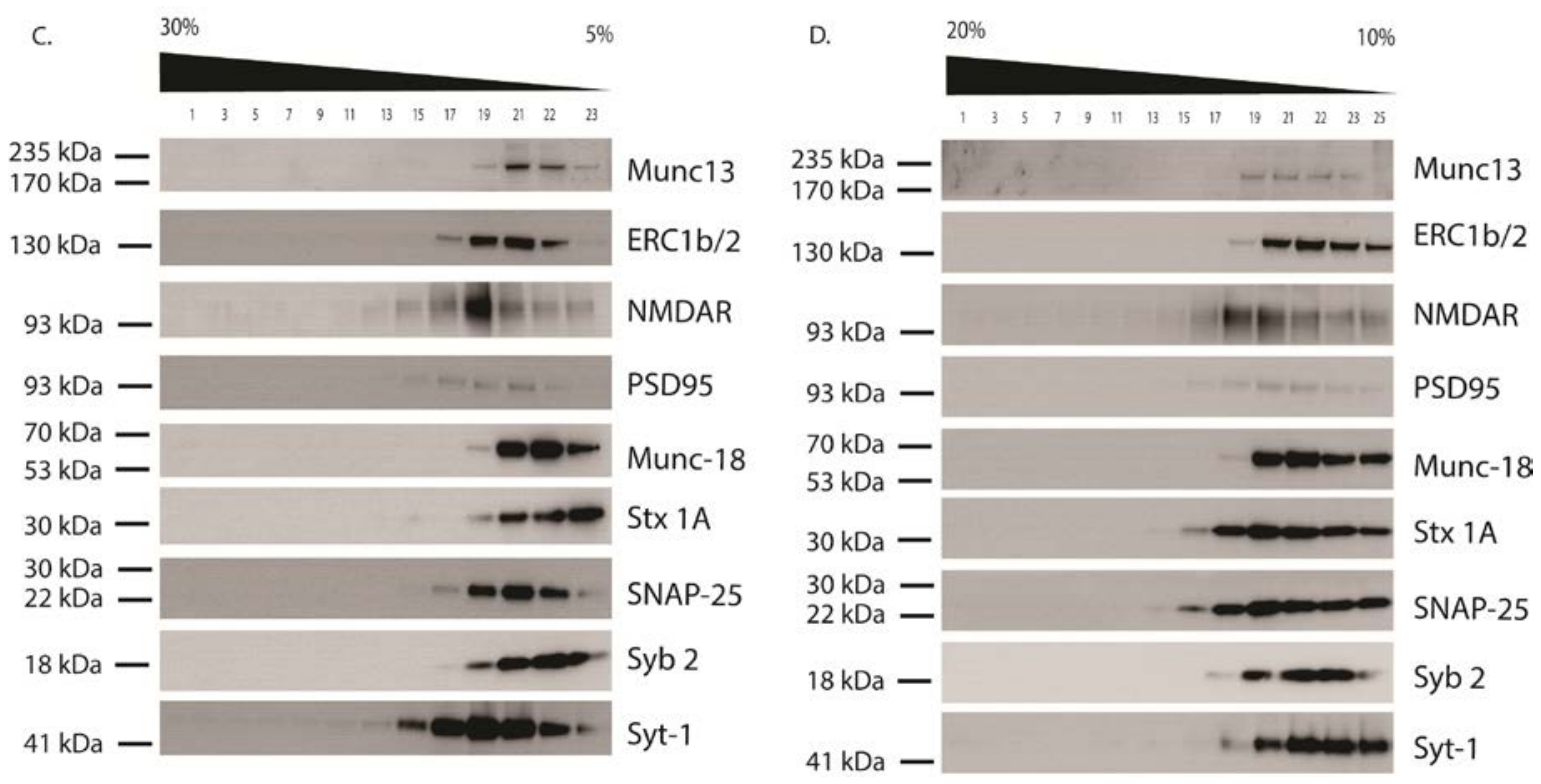

Figure 3.16. Gradient media screen for linear density centrifugation after solubilization of freshly prepared synaptosomes with TDOC. Separation was conducted by a centrifugation on a continuous density gradient of (A) 5-20\% sucrose, (B) 5-15\% Ficoll, (C) 5-30\% glycerol or (D) 10-20\% glycerol for $14 \mathrm{~h}$ at 70 $000 \mathrm{~g}$ in a SW41 rotor. Proteins indicated on the left of the blots were detected by Western blotting. 
Since none of the newly tested conditions showed improved separation of the extracted proteins, we decided to keep unchanged the initially tested sucrose gradient medium and the concentration range of 5-30\%. As further optimization step for better resolution, we increased the applied $g$ force to the the max value for the SW41 rotor - $271000 \mathrm{~g}$. In addition, the centrifugation duration was extended to $18 \mathrm{~h}$ instead of $14 \mathrm{~h}$. Centrifugation times longer than $18 \mathrm{~h}$ led to protein degradation and were omitted. The list of immunoprobed proteins was extended as well. The detected proteins were associated with the presynaptic AZ, SVs, postsynaptic density or were embedded in the plasma membrane. Longer centrifugation step improved the resolution of separation. Small and soluble proteins like syb 2 and MALS, respectively, were enriched in the upper gradient fractions. This might be due to their participation of smaller protein complexes. Stx 1A, SNAP-25, syt-1 and Munc-18 migrated together in fractions 17-19, whereas Munc13 and ERC1b/2 were peak-separated in different fractions. Generally, the presynaptic membrane and CAZ proteins showed broader distribution among the fractions and were detected in the lower density fractions. In contrast, PSD-associated proteins like NMDA receptor and gephyrin migrated to higher density portions of the gradient. This might indicate their association in detergent-insoluble assemblies, since they were either partially or incompletely extracted by TDOC (see Figure 3.10).

The results with 5-30\% sucrose gradient and $18 \mathrm{~h}$ centrifugation step at $271000 \mathrm{~g}$ showed good separation of the extracted proteins. However, the question remained unanswered whether the co-migrating proteins were associated in protein complexes. In addition, the presence of postsynaptic proteins in the sample increased the complexity in the fractions complicating their analysis. For this reason, an additional step of limited proteolysis of synaptosomes prior to osmotic lysis was introduced [146]. This procedure is described in the following section and aimed on reducing the number of protein components in the individual fractions. 


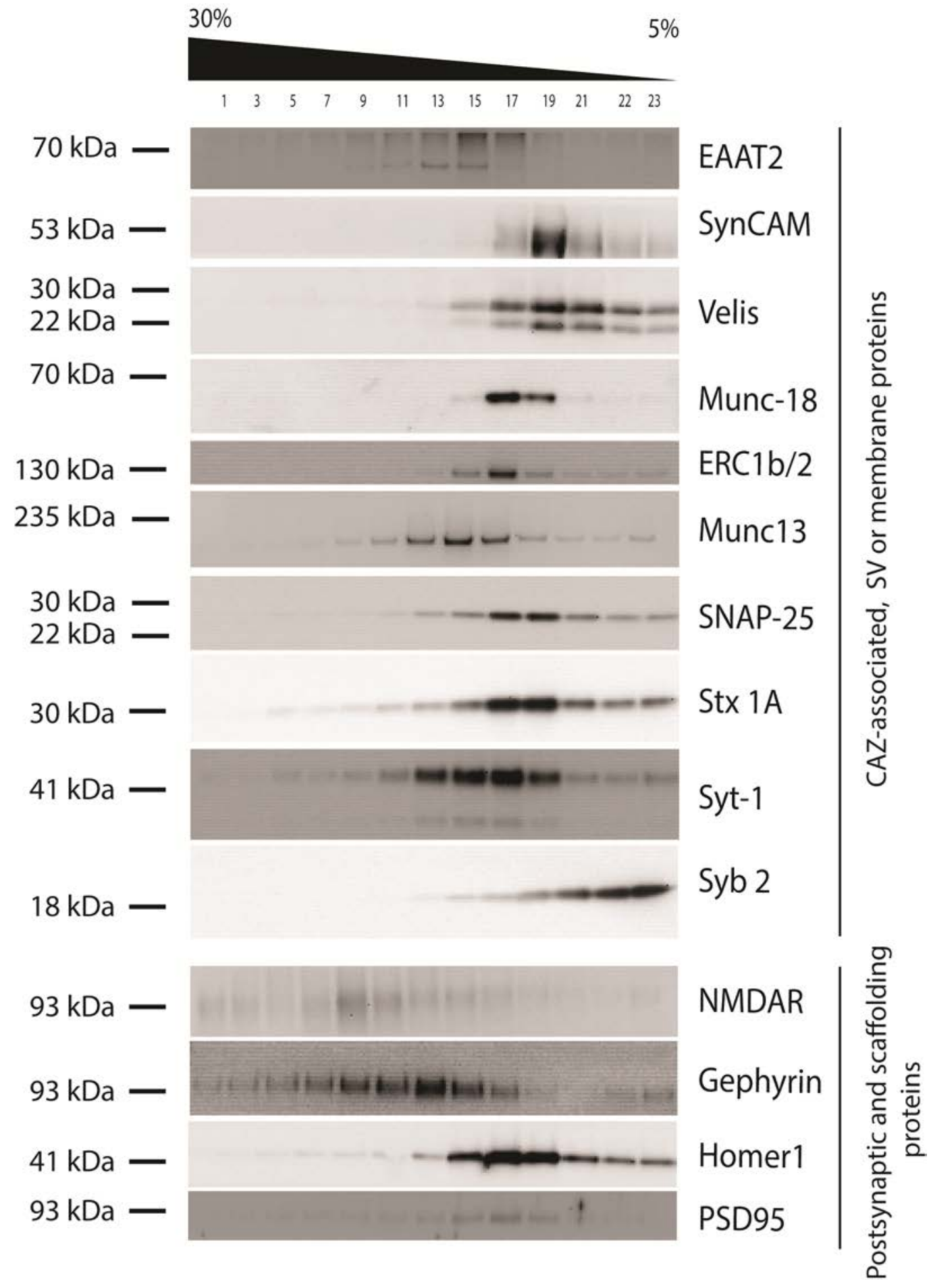

Figure 3.17. TDOC solubilization of LP1 fraction and extract separation by $18 \mathrm{~h}$ centrifugation step at 271000 g. LP1 fraction was isolated from fresh "non-shaved" synaptosomes. Solubilization and clearance were conducted as described above. Extracted proteins were separated on a 5-30\% sucrose gradient for $18 \mathrm{~h}$ at $271000 \mathrm{~g}$ (SW41 rotor). Proteins (indicated on the left of the blots) were immunoprobed. 


\subsubsection{LP1 derived from synaptosomes subjected to limited proteolysis prior to lysis}

The solubilization of synaptic membrane with TDOC and the centrifugation step at $271000 \mathrm{~g}$ for $18 \mathrm{~h}$ (SW41 rotor) showed good separation of proteins and co-migration of some proteins reported earlier to form complexes together, e.g. SNAP-25, syb 2 and stx 1A [174] or stx $1 \mathrm{~A}$ and syt-1 [160]. It was aimed to reduce the content complexity in the fractions and thus to reduce the protein background for immunoisolation experiments from individual gradient fractions (not shown). This was achieved by subjecting of synaptosomes to limited proteolysis with trypsin as described recently [146]. The proteolytic step removed some of the PSD-associated proteins except of PSD95, which was in agreement with previous reports [146]. Interestingly, the removal of postsynaptic and cell adhesion molecules did not alter the distribution and co-migration profile of the probed proteins regardless of the used detergent (Figure 3.18). SNAP-25 and stx 1A comigrated only partially with syb 2 as observed in the previous experiment (Figure 3.17). Similar to the previous observation, syb 2 showed a concentrated presence in the lowdensity fractions, probably as a single protein or a component of smaller protein complexes. Same distribution profile was observed for MALS (Velis 1/2/3). Munc-18 was enriched in the same fractions as stx1A suggesting possible association in a complex. Moreover, syt-1 showed peak in fractions 17-19, same as stx 1A disregarding the detergent used. Actin was spread over the whole range of gradient, probably as a cytomatrixassociated and supporting component in different complex associations.

The solubilization of LP1 fraction derived from proteolytically untreated or treated synaptosomes in combination with density centrifugation allowed drawing some conclusions. First, the limited trypsinization of synaptosomes successfully removed PSDassociated proteins, which were not in the focus of our study. Second, good reproducibility of the extract separation was observed regardless of the used detergent. Third, the separation profile of the probed proteins did not differ disregarding detergent and presence of postsynaptic proteins during membrane solubilization. This might indicate either similar mechanism of protein extraction and membrane solubilization or possibly preservation of protein-protein interactions regardless of the used detergent. 
A.

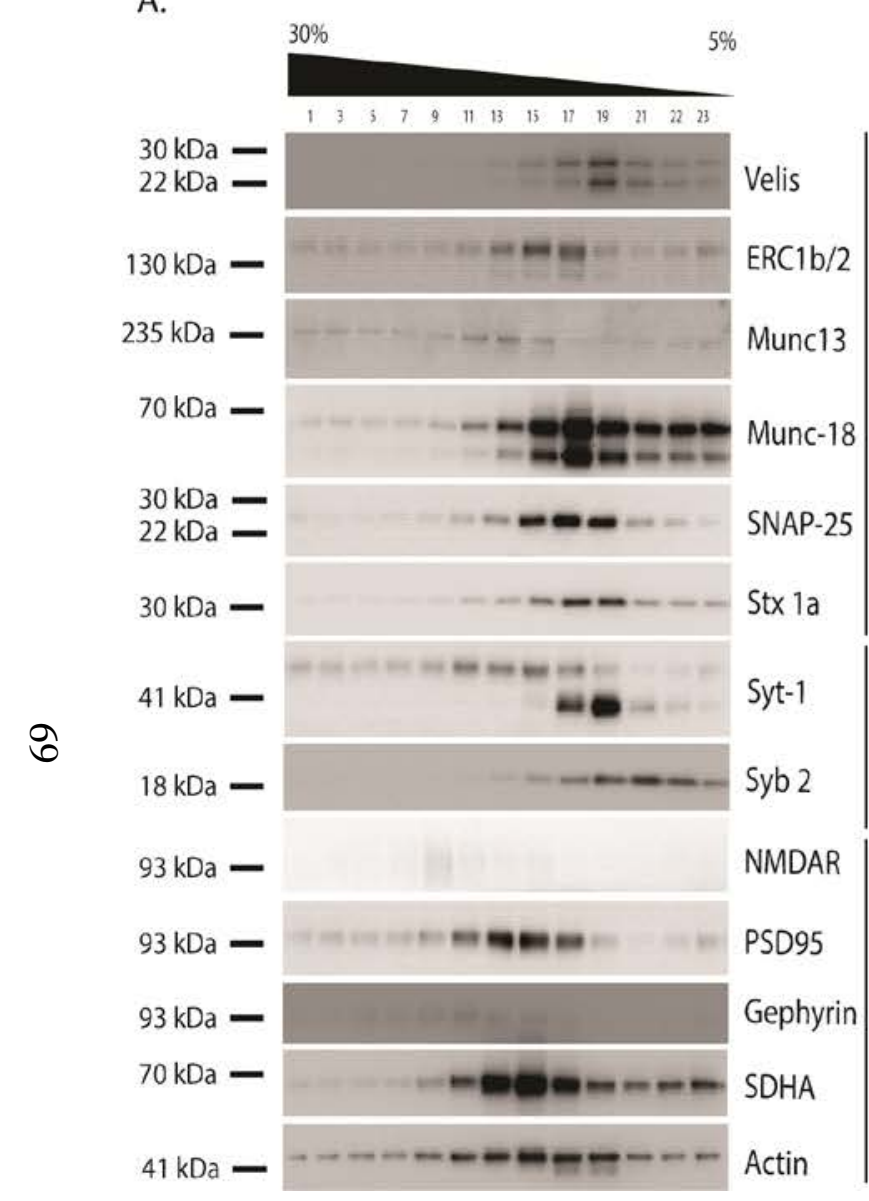

B.

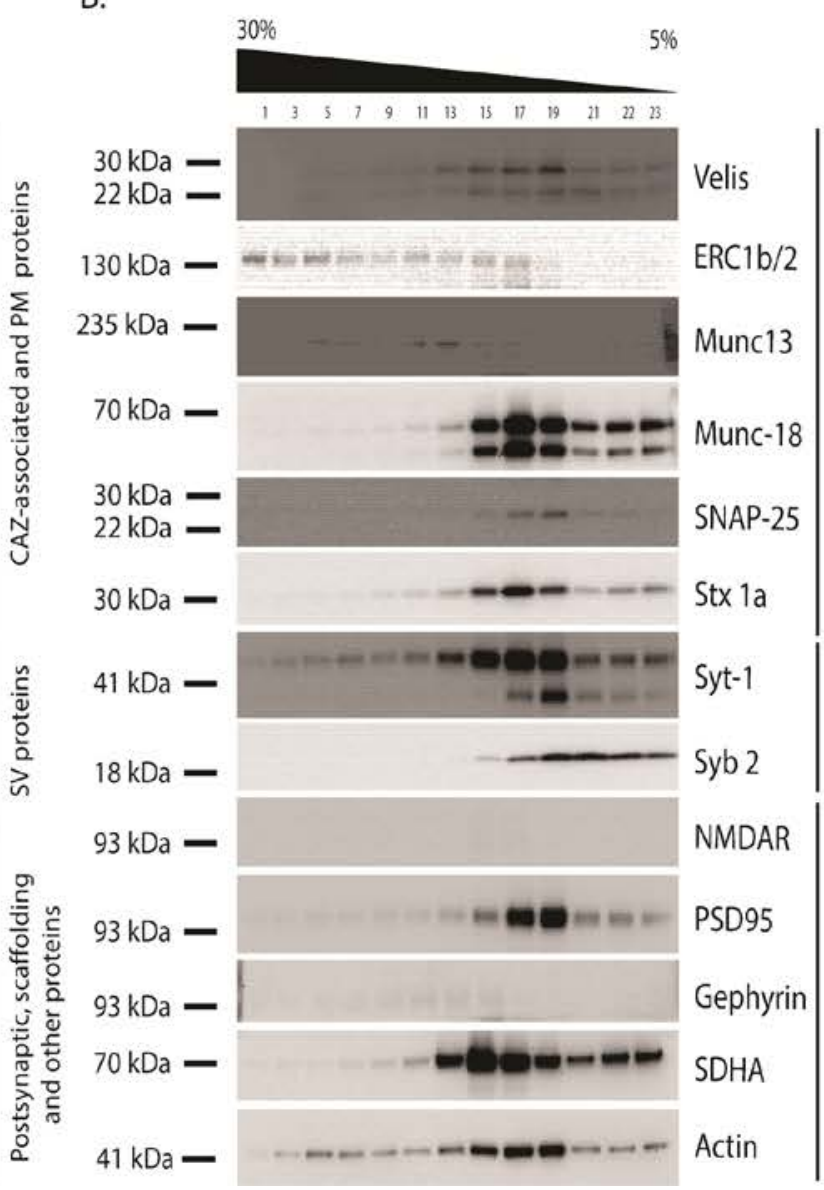

C.

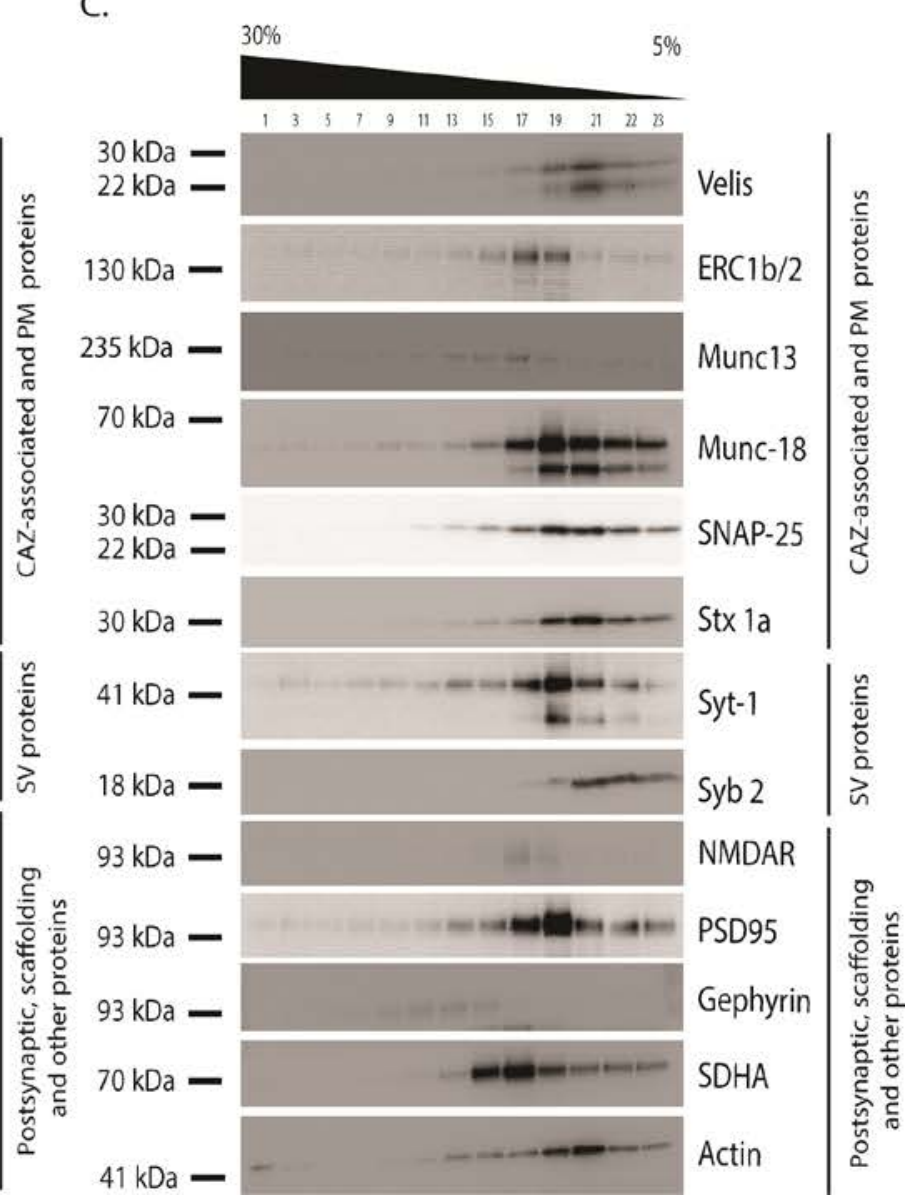

Figure 3.18. LP1 fraction isolated from proteolytically treated synaptosomes was solubilized with (A) TDOC, (B) Tx-100 and (C) Zwittergent 3-14. LP1 fraction (two $\mathrm{mg}$ ) isolated from partially trypsinized synaptosomes was solubilized with three different detergents and pre-centrifuged at $33000 \mathrm{~g}$ for $15 \mathrm{~min}$ (S140AT4 rotor). Supernatants were loaded on $5-30 \%$ linear sucrose gradients containing $1 \%$ of the solubilizing detergent and the extracted proteins were separated in a $18 \mathrm{~h}$ centrifugation step at $271000 \mathrm{~g}$ (SW41 rotor). Gradient fractions were immunoprobed for the indicated proteins. 


\subsection{Chromatographic fractionation of synaptic protein complexes}

The sucrose gradient separation of LP1 extracts showed low resolution. To improve protein separation of the solubilized membrane-enriched fraction, extracted material was subjected to size exclusion (gel filtration, GF) chromatography. This biochemical technique allows separation of particles and protein complexes over a broad molecularweight range. Although it is frequently used for isolation of synaptic vesicles from rat and mouse brains [139, 177], its application for separation of extracted synaptic protein complexes has been barely explored [159]. As the molecular weight of the solubilized synaptic complexes was unknown, superose 6, a cross-linked agarose-based matrix, provided the optimal separation from $5 \mathrm{kDa}$ to $5 \mathrm{MDa}$. The LP1 fraction (ten to twenty mg) was solubilized in a 1:10 protein:detergent ratio, pre-centrifuged at $100000 \mathrm{~g}$ for 20 min in a TLA100.3 rotor and the supernatant was applied on a pre-equilibrated Superose 6 10/300 GL column (1\% detergent in PBS). A representative chromatogram is shown in Figure 3.19. The large peak at the beginning of the chromatogram indicated proteincontaining particles eluted in or close to the void volume of the column $(1 \mathrm{CV}=24 \mathrm{~mL})$. The eluate was collected and the resolution of separation was evaluated by immunodetection of the proteins in the SEC fractions (Figure 3.20). The proteins probed by Western blotting belonged to five different groups: synaptic vesicle, active zone and CAZ-associated, postsynaptic membrane and scaffolding, plasma membrane and cytoskeleton proteins. In addition, the distribution profile of Bassoon and Piccolo was analyzed (Figure 3.21). 


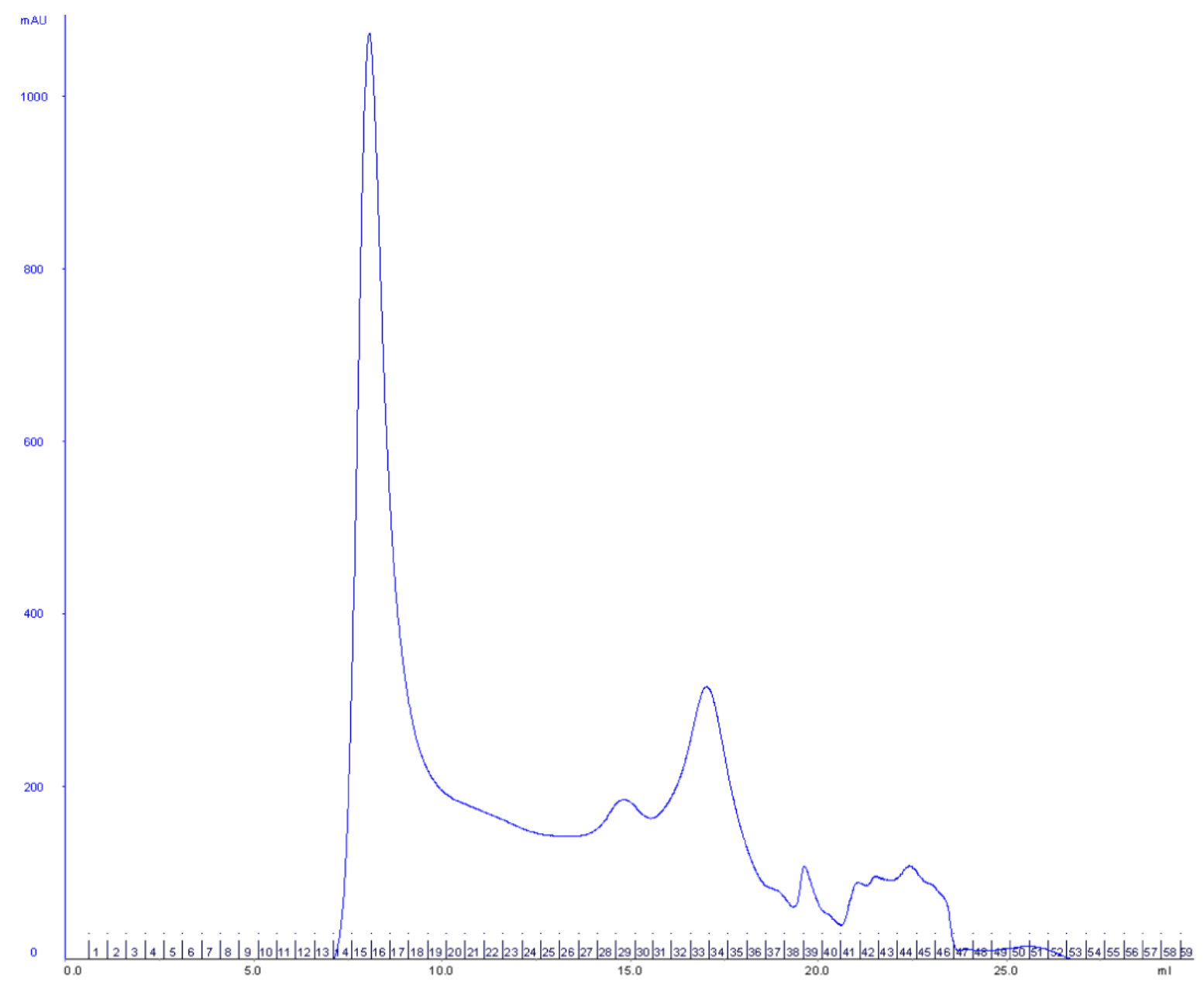

Figure 3.19. Chromatographic separation of cholate-solubilized LP1 fraction. LP1 fraction was solubilized with cholate and pre-centrifuged at $100000 \mathrm{~g}$ for $20 \mathrm{~min}$ in a TLA100.3 rotor. Supernatant was loaded on a pre-equilibrated (1\% cholate/PBS) Superpose 6 10/300 GL gel filtration column and extracted proteins were separated within $1 \mathrm{CV}$. Protein elution was monitored at $280 \mathrm{~nm}$ and the concentration is represented in arbitrary units (mAU, y axis). First 60 fractions were collected (x axis) and analyzed by Western blotting.

The separation of extracted proteins by size exclusion chromatography (SEC) showed better resolution than by density gradient centrifugation (Figure 3.20). SEC allowed following the co-elution profile of proteins reported earlier to interact. For example synaptophysin, syt-1 and syb 2 co-eluted from the column, suggesting confirmation of results from earlier studies with detergents by Bennett et al. on the solubilization of vesicle membrane protein complexes using CHAPS [159]. Additionally, the plasma membrane Q-SNAREs SNAP-25 and stx 1A, which form SNARE complex with syb $2[174,176]$, showed an elution peak in the same fractions (15-23) (see Figure 3.20). 

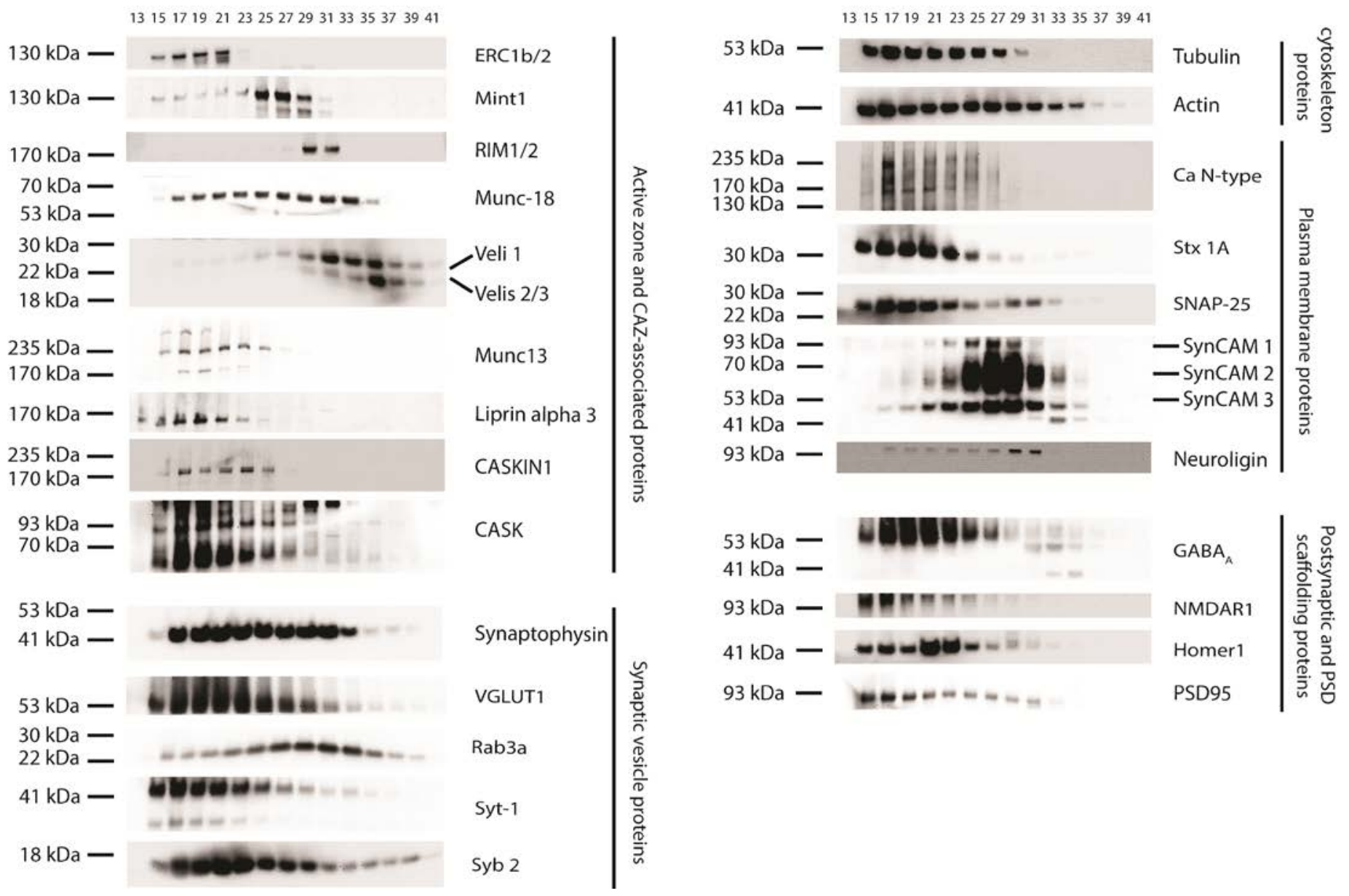

Figure 3.20. Protein separation profile after cholate solubilization of LP1 fraction. Suspension after solubilization of LP1 fraction with cholate was pre-centrifuged for 20 min at $100000 \mathrm{~g}$ in a TLA100.3 rotor. The supernatant was loaded on a Superose 6 10/300 GL size exclusion column. Fractions were collected (indicated above the blots) and probed by Western blotting for proteins from five different classes - SV, AZ and CAZ-associated, PSD and PSD-associated scaffolding, PM proteins and cytoskeleton proteins. 
The SV protein synaptophysin showed moderate distribution among the chromatographic fractions. Among others, it co-eluted with the R-SNARE syb 2. Both proteins were reported to interact, therefore it could be speculated that at least partially they were assembled in an extracted protein complex $[178,179]$. Furthermore, we found that synaptophysin's elution overlapped with that of syt-1, SV2A/B and stx 1A (Figure 3.20). Previous work by Bennett et al. reported the co-purification of these proteins in antisyt-1 immunoprecipitations performed on solubilized crude SV fraction, supporting the idea of a preserved cholate-extracted protein complex [160]. Interestingly, the larger portion of syt-1 eluted close to the void volume. On the one hand, this indicated protein's participation in large protein-containing particles, which were not resolved by SEC. On the other hand, it might be suggestive of an interaction with a ternary SNARE complex, the components of which also peak eluted in the same fractions 13-21 (see Figure 3.20) [174, 180]. In comparison, the small GTPase Rab3a was later peak eluted (fractions 25-29) than the SNARE proteins (syb 2, SNAP-25 and stx 1A) and synaptophysin. This result resembled also earlier observations [159]. Nonetheless, Rab3a's elution overlapped partially with that of syt-1. This was an interesting result since both proteins were recently shown to interact directly [181]. Furthermore, the immunodetection signals of Rab3a and RIM protein overlapped to some extent, which suggested a possible binding of RIM to GTP-bound Rab3 via RIM's N-terminal $\alpha$-helices [21, 36]. Interestingly, in SEC fractions 19-23, which were also positive for Rab3a, RIM's full-length isoforms co-eluted with Munc13-1 (Figure 3.20). This was an intriguing observation because the proteins can form a tripartite complex via RIM's ZF domain binding to the C2A domain of Munc13-1 [35]. The major AZ proteins ELKS and liprin as well as N-type VGCC were eluted in a narrow range of fractions (15-21) close to the void volume of the column indicating a possible association in large protein complexes. The $\mathrm{N}$-terminal coiled-coil domain of $\alpha$-liprins was shown to interact directly with ELKS family proteins [57]. The overlap between ELKS and RIM proteins in fractions 19-21 suggested a possible co-assembly at the central PDZ domain of RIM (Figure 3.20). Additionally, both proteins were reported to recruit Munc13-1 and Bassoon [37]. A possible confirmation for this complex formation delivered the elution of full length Bassoon and its smaller splice variants in the same fractions (Figure 3.21). It is possible that only a portion of the RIM protein is associated in a complex via direct binding to Munc13-1 and indirect binding to Basssoon via ELKS. In addition, RIM's PDZ domain was reported to interact with the N-type VGCC [11], which showed peak elution in the same fractions as judged by the immunoblot signals. 
Furthermore, the separation and co-elution profile of the mentioned proteins affirmed possible binding of the RIM C2B domain to liprin $\alpha-3$ and syt-1 [28] and protein's potential interference with vesicle docking and fusion by interaction with SNAP-25 and syt-1 [39], as all these proteins were identified in same SEC fractions. Additionally, Munc13-1 was reported to be involved in priming through an interaction with stx 1A [45]. An direct interaction between both proteins was confirmed in co-immunoprecipitation experiments after synaptosomes solubilization with cholate [49]. Our results showed an enrichment of stx 1A in the fractions 15-23 together with Munc13-1, supporting this hypothesis. The vesicular glutamate transporter 1 (VGLUT1) [133] was broadly distributed over the elution fractions. It is a multispanning 12 TMD-containing protein with only few known interaction partners (e.g. endophilins 1 and 3; Galpha (o2) [182-185]), however none of them was probed here. While the mammalian homolog of C. elegans unc-18 protein (Munc-18) was detected in the most of the SEC fractions, its interaction partner Mint1 was enriched only in fractions 25-29 [186]. The co-elution of Munc18 overlapped to some extent with that of stx1A and Mint1. These three proteins were reported to interact within a multimeric complex and Munc-18 was identified as stx 1A binding protein [187, 188]. The CAZ-associated proteins CASK and CASKIN1 were eluted in fractions 15-25 together with the core AZ constituent liprin $\alpha$-3. At the same time, Velis (MALS) isoforms were eluted later, similar to Rab3a, and SynCAM1/2/3 eluted in the fractions 25-31 (Figure 3.20). The protein distribution might indicate specific protein associations. This hypothesis was supported by the findings of Butz et al. who described an isolation of tripartite complex composed of Velis, CASK and Mint1 [81]. However, only a small portion of Velis, mainly the Veli 1 isoform, co-eluted with CASK and Mint1, suggesting only partial participation of the protein in the protein complex. In addition, under consideration of the elution profile of Munc18, it is likely that it is also associated to the heterotrimeric VeliCASK-Mint1 complex through the Munc18-interacting domain of Mint1. In the context of the tripartite complex, CASKIN1 was shown to compete with Mint1 for binding to CASK including the formation of an alternative Veli-CASK-CASKIN1 trimeric complex [80]. However, the elution pattern of Velis let its the participation in alternative protein complexes appear questionable in our study. It seemed that the protein was dissociated from the complexes, possibly due to the use of cholate instead of Triton X-100 as in the reported studies [80, 81]. Another protein complex consisting of liprins, CASK and Velis was identified from immunoprecipitations on Triton X-100 solubilized material [58]. Nonetheless, the CASK interaction with liprin might be preserved to some extent also in 
cholate since both proteins were detected in the same fractions 27-31 (Figure 3.20). Also, co-elution of CASK and SynCAM in fractions 21-29 could be affiliated to their association with each other [94]. In the same fractions, neuroligins and PSD95 protein from postsynaptic structures were eluted together with NMDA receptor. This observation was in line with PSD95 binding to NMDA receptor subunits [167]. The elution pattern of CASK, PSD95 and the synaptic cleft proteins neurexins and neuroligins was also consistent with previous reports on complex between these proteins [189]. The GF fractions were probed also for cytoskeleton proteins, such as tubulin and actin (Figure 3.20). Both are present in the pre- and the postsynapse, which explained their broad distribution profile. The GABA $\mathrm{A}_{\mathrm{A}}$ receptor and the PSD-associated scaffolding protein Homer1 were eluted in the first fractions of the chromatogram close to the void volume (Figure 3.20). Their interaction with each other and other postsynaptic protein were reported earlier (for review and references [190]).

The two large AZ scaffolding proteins Piccolo and Bassoon and their splice variants were eluted according to their size and protein interactions as shown in Figure 3.21. Both proteins co-eluted with most of the probed proteins. Some reported interactions with the core AZ proteins ELKS, RIM and Munc13 as well as with the presynaptic cytoskeleton were possibly preserved during the isolation and separation based on their codistribution pattern [64, 78, 79, 92]. Although both proteins are associated in supramolecular scaffolding complexes in synapses (for review [16, 191]), the interactome of Piccolo and Bassoon is barely studied due to the large size and poor extraction [70, 71]. Our novel protocol enables an extensive characterization of their interactions with presynaptic cytomatrix-associated proteins.

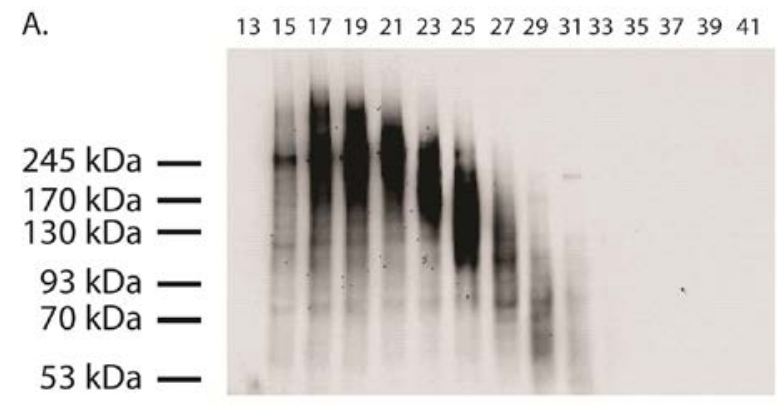

IB: Piccolo/Aczonin

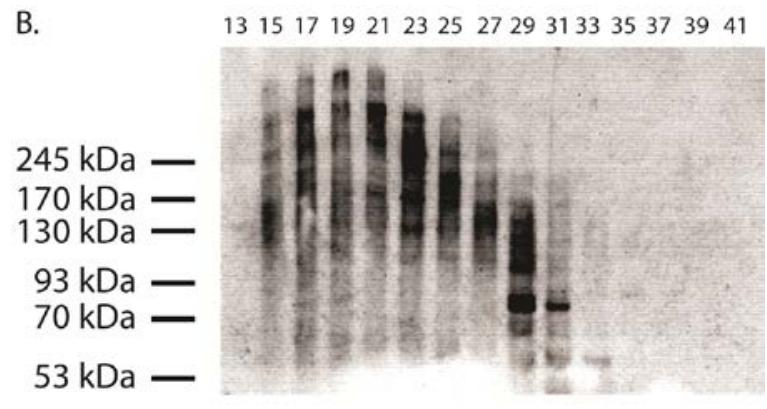

IB: Bassoon

Figure 3.21. Chromatographic separation of (A) Piccolo and (B) Bassoon after LP1 solubilization with cholate. After solubilization with cholate, pre-centrifuged LP1 fraction was loaded on superpose 6 10/300 GL column and collected fractions were analyzed for the distribution of Piccolo and Bassoon. 
Importantly, protein complexes in different constellations and component stoichiometries were possibly formed and partially separated by SEC, representing distinct temporal and spatial steps in the presynaptic exocytosis process. Unfortunately, the identification of individual protein associations was not possible at this point due to limited resolution of the applied technique.

In addition to cholate, protein separation by size exclusion chromatography was performed with TDOC and DDM. The protein elution profiles were similar to the ones obtained when cholate (see Appendices 1-4). A major difference between the three detergents (cholate, TDOC and DDM) was the size of the elution peak close to the void volume of the chromatogram (see also Figure 3.22 and Figure 3.23). Apart from the peak size, a few additional differences were observed. First, when using TDOC (see Appendix 1), CASK and liprin $\alpha-3$ did not elute in the same fractions unlike with cholate- and DDM (Figure 3.20 and Appendix 2), suggesting disruption of possible protein-protein interactions [59]. Second, in comparison to cholate, proteins like Munc-18, synaptophysin and Rab3a, but also PSD-associated Homer1 and were better solubilized when TDOC and DDM were used. The elution profile of synaptophysin, Munc-18 and $\mathrm{GABA}_{\mathrm{A}}$ differed when DDMextraction was performed. Third, despite the bigger size of DDM micelles ( $50 \mathrm{kDa})$ compared to cholate ( $1.3 \mathrm{kDa}$ ) or TDOC ( $2.1 \mathrm{kDa}$ ) (see Table 1.2), DDM-solubilized protein complexes appeared smaller. DDM has a smaller CMC value $(0.15 \mathrm{mM})$ than cholate (15 mM) and TDOC (4 mM) and for the mobile phase in the SEC experiments, 1\% $(\mathrm{w} / \mathrm{v})$ detergent in PBS was used. Thus, the difference between used and CMC concentration of the detergent was bigger for DDM than for cholate and TDOC. It is known that the formation of smaller micelles is favored when the used detergent concentration is much higher than the CMC of the detergent (for review [99, 172, 192]). And finally yet importantly, the chromatographic resolution was better when cholate was used. Cholate had the smallest detergent micelles among the three detergents and better separation is achieved when the difference between protein-containing and non-protein-containing micelles is bigger [96, 100]. 


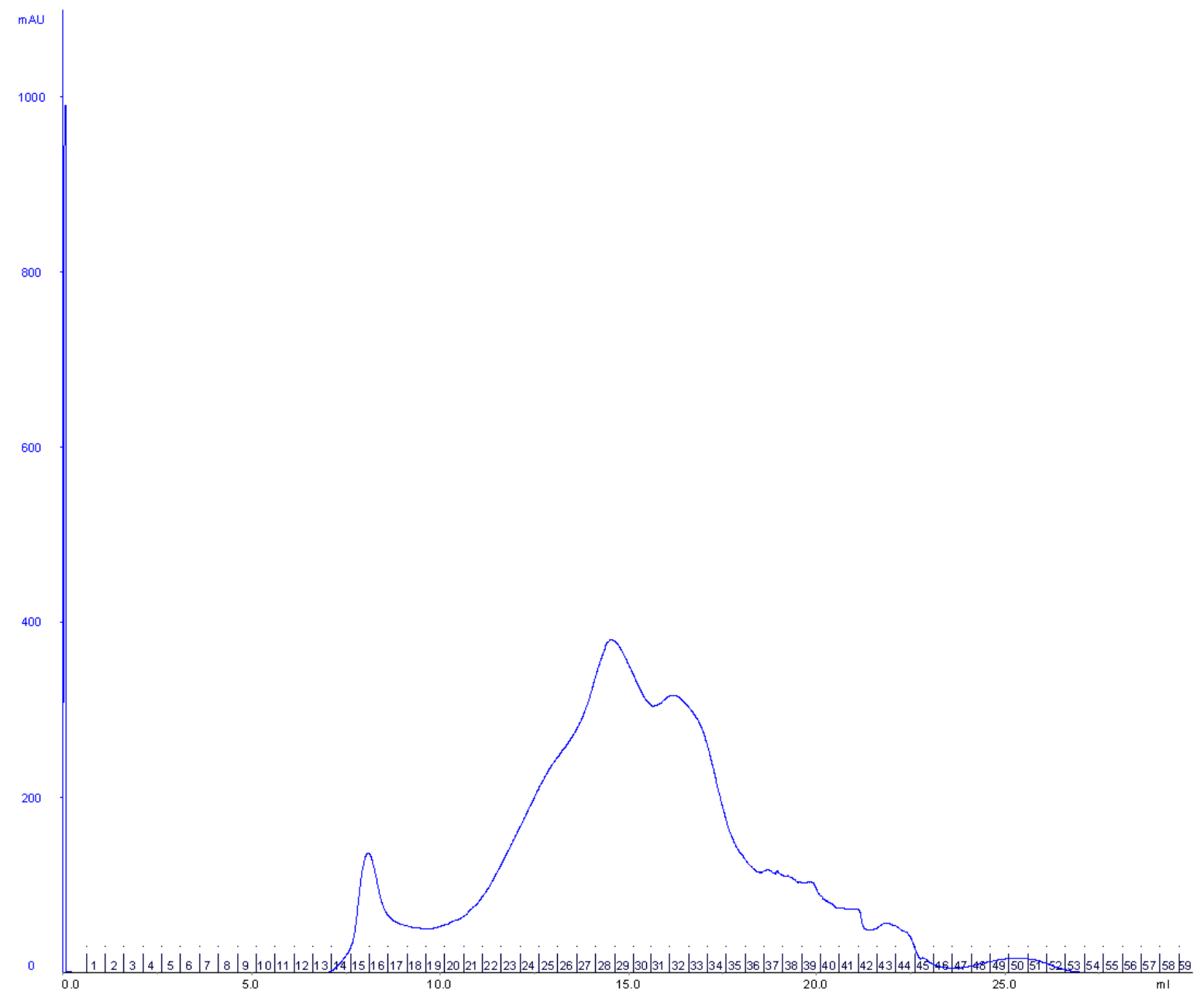

Figure 3.22. Chromatographic separation of TDOC-solubilized LP1 fraction. LP1 fraction was isolated from freshly prepared synaptosomes and proteins were extracted with taurodeoxycholate in 1:10 protein:detergent ratio. Pre-centrifuged extract (100 $000 \mathrm{~g}$ for $20 \mathrm{~min}$ in TLA100.3 rotor) was loaded on Superose 6 10/300 GL column and proteins were eluted with 1\% TDOC/PBS. 


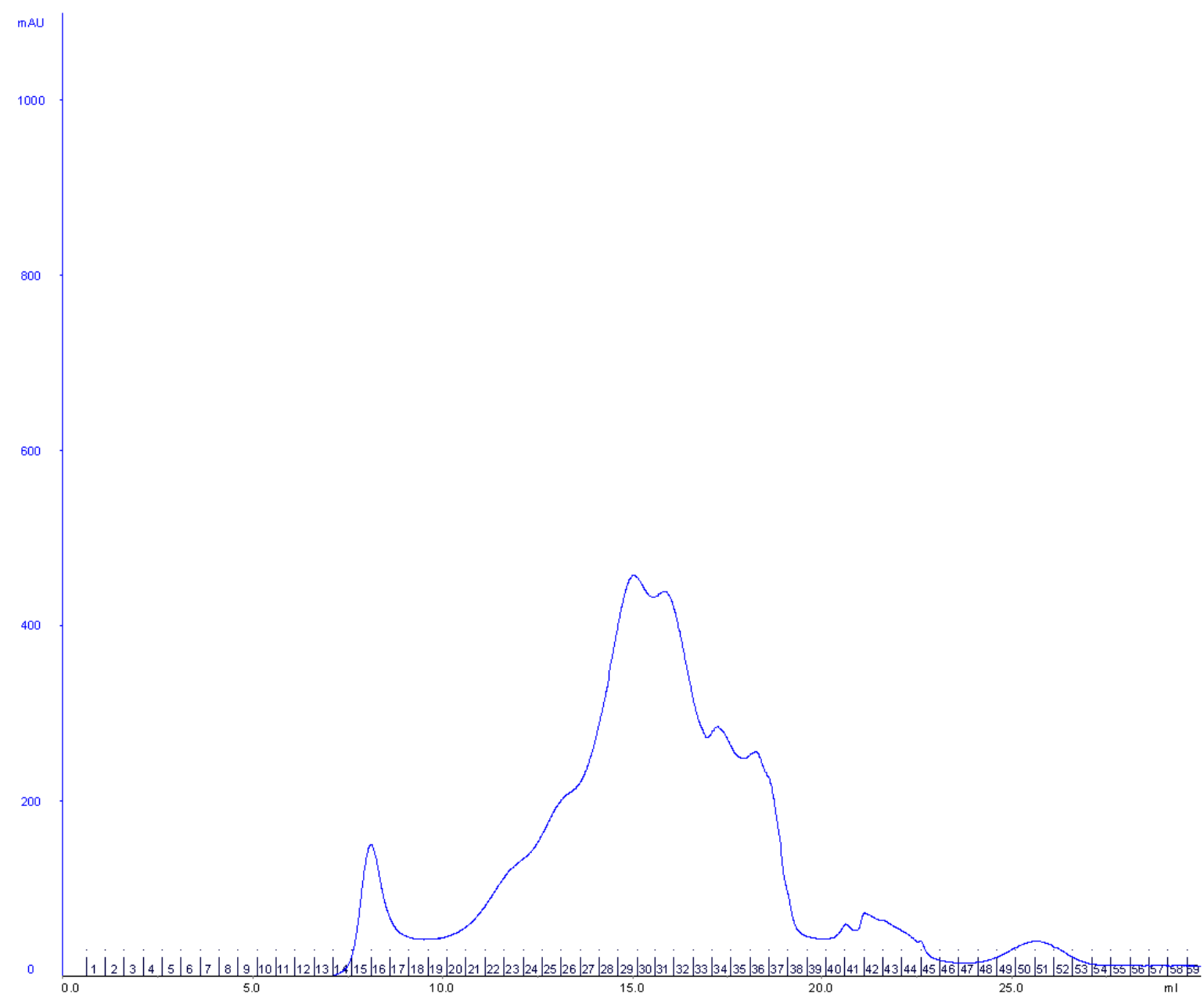

Figure 3.23 Chromatographic separation of DDM-solubilized LP1 fraction. LP1 fraction was isolated from freshly prepared synaptosomes and solubilized with DDM in 1:10 protein:detergent ratio. Pre-centrifuged extract (100 $000 \mathrm{~g}$ for $20 \mathrm{~min}$ in TLA100.3 rotor) was loaded on Superose 6 10/300 GL column and proteins were eluted with $1 \%$ DDM/PBS.

In summary, the established solubilization protocol in combination with SEC represents a good tool for separation of extracted membrane protein complexes composed of presynaptic CAZ-associated proteins. The extract separation by SEC was better than by density gradient centrifugation. The technique, combined with immunodetection of proteins of interest, allows monitoring of possible protein-protein associations. However, it should be kept in mind, that co-elution of proteins in same fractions does not necessary indicated their assembly in protein complexes. It could reflect co-separation of distinct complexes of similar size. Trials to isolate complexes from individual fractions failed due to low protein amount accompanied by additional loss due to binding of the proteins to the walls of the Eppendorf tubes, which is well known problem in IP experiments. 


\subsection{Immunoprecipitation of presynaptic membrane proteins under optimized extraction and centrifugation conditions}

The performed detergent screen helped us to assess the extraction properties of synaptic proteins by different detergents. Cholate, TDOC and DDM were able to solubilize the synaptic membranes and extract a broad range of integral proteins (see section 3.1). SEC-based separation of the extracted proteins and a subsequent characterization of their elution pattern by immunoblotting suggested preservation at least of a portion of the reported protein interactions. One of our goals was development of solubilization protocol with focus on presynaptic CAZassociated proteins. Second, we wanted to characterize presynaptic membrane protein complexes isolated by immunoprecipitation following the optimized extraction procedure. For this reason, a screen of selected antibodies for immune-enrichment experiments in the presence of cholate, TDOC or DDM was performed. The results of the screen are summarized in Table 3.2. The LP1 fraction was solubilized with any of the three detergents, centrifuged at $100000 \mathrm{~g}$ for $20 \mathrm{~min}$ (TLA100.3 rotor) and subjected to immunoprecipitation (IP) with the respective antibody. Magnetic Protein A or Protein G-coated Dynabeads were used as immunoisolation matrix. They were chosen instead of Sepharose beads due to less unspecific binding of proteins and easier handling. For the washing steps, the magnetic beads were "soft precipitated" by application of external magnetic field and not by centrifugation. This should prevent beads aggregation as well as loss of the when the supernatant is removed during the washing steps.

Most of the tested antibodies were able to bind and isolate their targets in the presence of detergent (see Table 3.2). Positive results in all three detergent conditions were obtained e.g. with anti-stx 1A monoclonal antibody, whereas anti-SynCAM1/2/3 polyclonal antibody failed in the immunoisolation trials (Figure 3.24). 
Table 3.2. List of immunoprecipitated proteins after LP1 solubilization with cholate, DDM or TDOC. Successful IPs were marked with “+”, whereas failed immunoprecipitations with “-“. N.A. indicates non-tested combination of antibody in the presence of certain detergent.

\begin{tabular}{|c|c|c|c|c|}
\hline \multirow{2}{*}{ Antibody } & \multirow{2}{*}{$\begin{array}{c}\text { Source and } \\
\text { catalog \# }\end{array}$} & \multicolumn{3}{|c|}{ Detergent } \\
\hline & & Cholate & Dodecyl- $\beta$-D-maltoside & Taurodeoxycholate \\
\hline Bassoon & 141021 (SySy) & + & + & + \\
\hline Piccolo & 142111 (SySy) & - & N.A. & N.A. \\
\hline Piccolo & 142104 (SySy) & N.A. & - & + \\
\hline Piccolo & 142113 (SySy) & N.A. & N.A. & - \\
\hline CASKIN1 & 185003 (SySy) & + & + & + \\
\hline CASK & 150002 (SySy) & - & N.A. & N.A. \\
\hline & $75-000$ & & & \\
\hline CASK & $\begin{array}{c}\text { (Cl K56A/50, } \\
\text { Neuromab) }\end{array}$ & N.A. & + & + \\
\hline Munc-18 & 116011 (SySy) & + & + & + \\
\hline Liprin-alpha3 & 169002 (SySy) & - & N.A. & - \\
\hline ERC1b/2 & 143003 (SySy) & + & N.A. & + \\
\hline RIM1/2 & 140203 (SySy) & + & + & + \\
\hline RIM2 & 140303 (SySy) & + & N.A. & N.A. \\
\hline Mint1 & 144103 (SySy) & + & - & - \\
\hline Syt-1 & 105011 (SySy) & + & + & - \\
\hline Stx 1A & 110111 (SySy) & + & + & + \\
\hline SynCAM & $\begin{array}{c}\text { Ab3910 } \\
\text { (Abcam Ltd.) }\end{array}$ & - & N.A. & N.A. \\
\hline Velis1/2/3 & 184003 (SySy) & + & + & + \\
\hline Munc13-1 & 126103 (SySy) & + & + & + \\
\hline Munc13-1 & 126102 (SySy) & + & N.A. & N.A. \\
\hline
\end{tabular}


A.
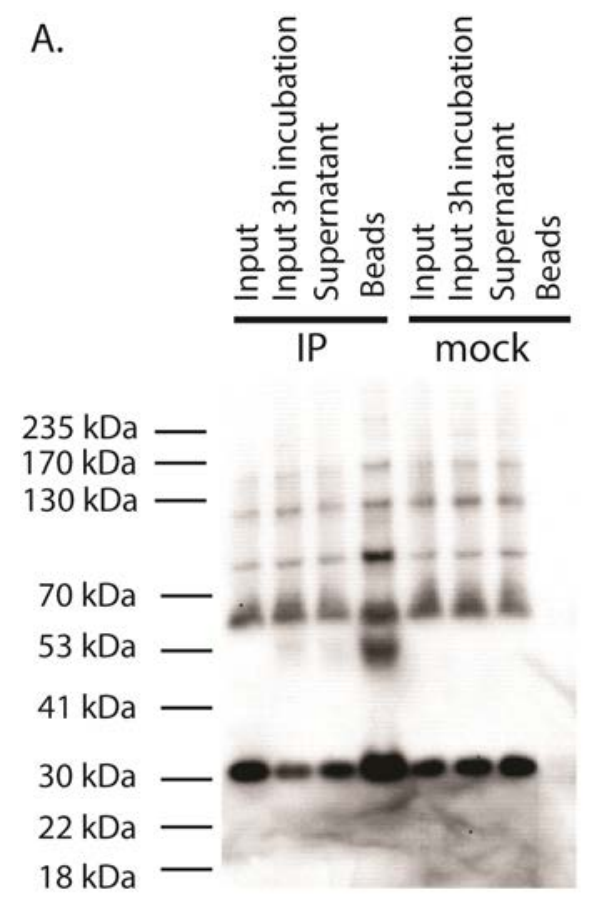

B.
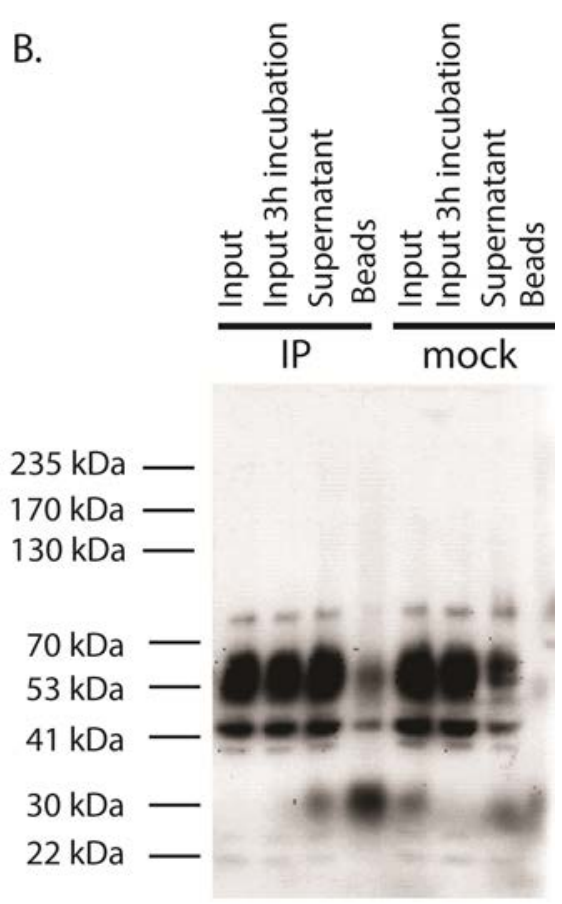

Figure 3.24. Affinity enrichment of (A) stx 1A and (B) SynCAM1/2/3 from cholate-solubilized LP1 fraction. Antibody-saturated magnetic Protein A Dynabeads were incubated with pre-centrifuged LP1 extract for $4 \mathrm{~h}$ at $4{ }^{\circ} \mathrm{C}$. After three hours of incubation, an aliquot was taken to check for target degradation. Samples were resolved by SDS-PAGE. A heavy chain-specific HRP-conjugated secondary antibody was used for detection of stx 1A (36 kDa). A light chain-specific HRP-conjugated secondary antibody was used for detection of the SynCAM isoforms ( 40 kDa, $53 \mathrm{kDa}$ and $75 \mathrm{kDa}$ ).

Based on the initial IP screen, stx 1A was selected as target for further immunoisolation experiments. As a core component of the minimal exocytotic machinery and transmembrane domain-containing protein, stx $1 \mathrm{~A}$ represented a suitable candidate for our study.

\subsubsection{Immunoprecipitation of stx 1A after cholate solubilization of LP1 fraction}

The immunoisolation experiments with stx 1A were performed with cholate as detergent. It showed overall milder solubilization properties compared to TDOC, but it was still capable of extracting the two scaffolding proteins Piccolo and Bassoon (see Figure 3.11).

In order to find proper conditions for the immunoprecipitation, three different monoclonal antibodies against stx 1 were tested. In addition, two different washing steps after immunoprecipitation were tested. The aim was to find experimental conditions, under which the 
target antigen and its protein-protein interactions were most efficiently preserved and immunoprecipitated, while keeping the background binding of contaminating proteins low (evaluated by mass spectrometry analysis). At first, we tested HPC-1 anti-stx 1 antibody (Ab) (Figure 3.25).
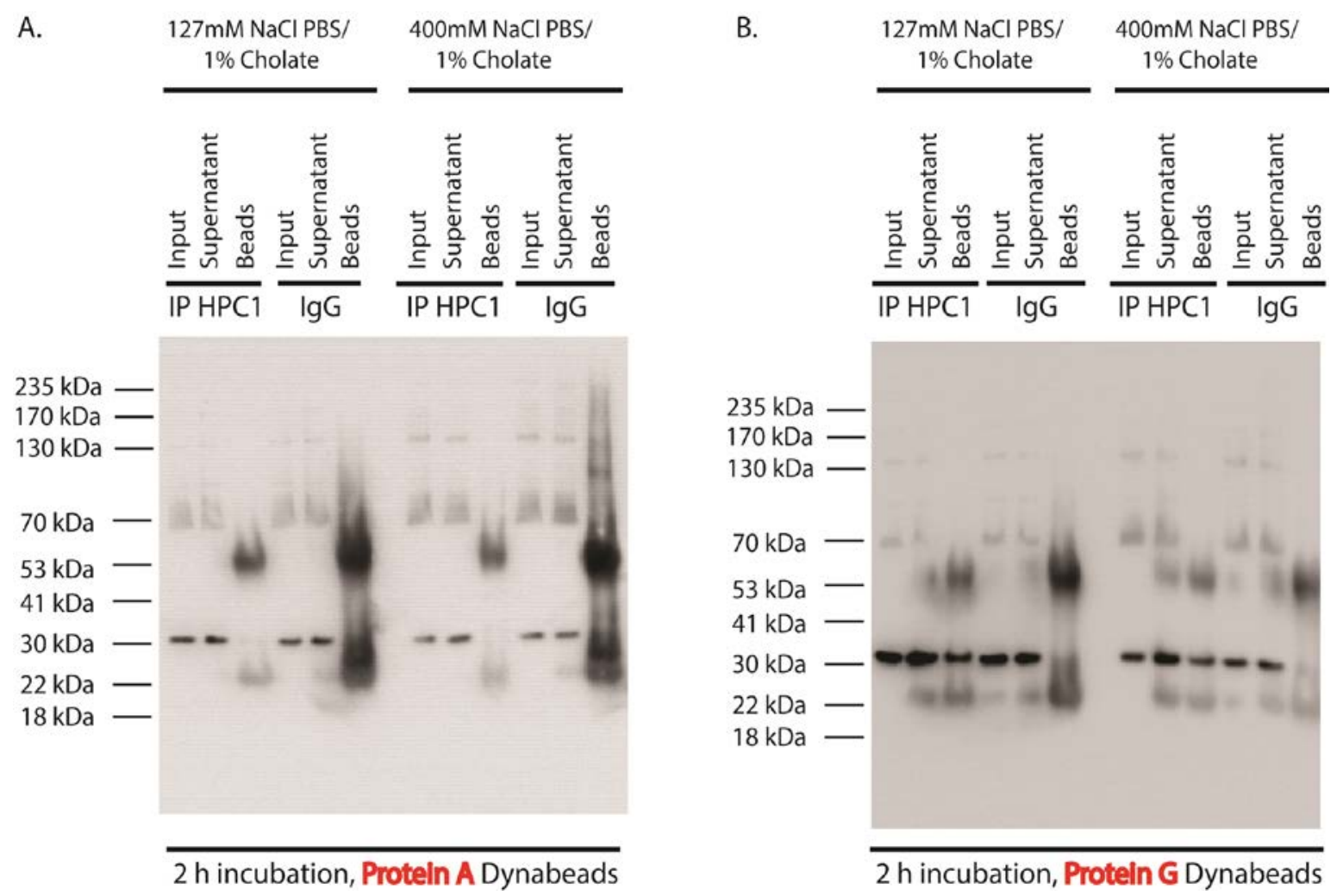

Figure 3.25. Stx 1 immunoprecipitation from cholate-solubilized LP1 fraction usingHPC-1 antibody. Precentrifuged suspension after LP1 solubilization was rotated for $2 \mathrm{~h}$ with Protein A- or Protein G-coated Dynabeads, which were pre-incubated with an excess of HPC-1 or mouse IgG (control) antibody. After $2 \mathrm{~h}$, beads were washed either with low salt ( $1 \%$ cholate/127 mM NaCl-containing PBS) or high salt $(1 \%$ cholate/400 mM NaCl-containing PBS) buffer. Input, supernatant after IP and beads were boiled in SDS sample buffer and their protein content was separated by SDS-PAGE. For immunodetection, mAb Cl 78.3 (1:1000) was used.

Additionally, low salt (127 mM) and high salt (400 mM) washing buffers were compared, as high salt concentration stabilizes hydrophobic protein interactions and reduces unspecific ionic and polar binding. HPC-1 antibody could bind only to Protein G-coated Dynabeads. However, the isolation efficiency was poor, especially under the high salt condition (see Figure 3.25). When Protein A Dynabeads were used, the control (mouse) IgGs bound stronger to the beads than the HPC-1 Ab, as judged by the IB signals of the light (LC, $25 \mathrm{kDa}$ ) and heavy chain (HC, $55 \mathrm{kDa}$ ) of the antibodies. 
Better results were obtained when anti-stx 1A mAb ( $\mathrm{Cl} 78.3)$ was used (see Appendix 5). In contrast to the HPC-1 Ab, Cl 78.3 Ab bound better to Protein A-coated Dynabeads. The high salt condition seemed to stabilize the interaction of the anti-stx $1 \mathrm{Ab}$ and the mock IgGs with the magnetic beads. Due to the "stickiness" of transmembrane proteins, a weak signal for stx 1A (36 $\mathrm{kDa}$ ) was immunodetected also in the negative control. Importantly, the IP matrix composed of Protein A-coated Dynabeads and $\mathrm{Cl} 78.3$ Ab was able to immunoprecipitate stx 1A with similar efficiency under low and high salt conditions.

Strong affinity enrichment of stx 1 was obtained also with the anti-Stx $1 \mathrm{Cl} 78.2 \mathrm{Ab}$. It is an IgG1 isotype antibody (compared to IgG2a in the case of $\mathrm{Cl} 78.3$ ) and it could bind well to both kinds of beads: Protein A- and Protein G-coated Dynabeads. Under both washing conditions, the use of Protein G-coated Dynabeads with $\mathrm{Cl} 78.2$ anti-stx 1 Ab showed stronger immunodetection of the antigen (Figure 3.26).
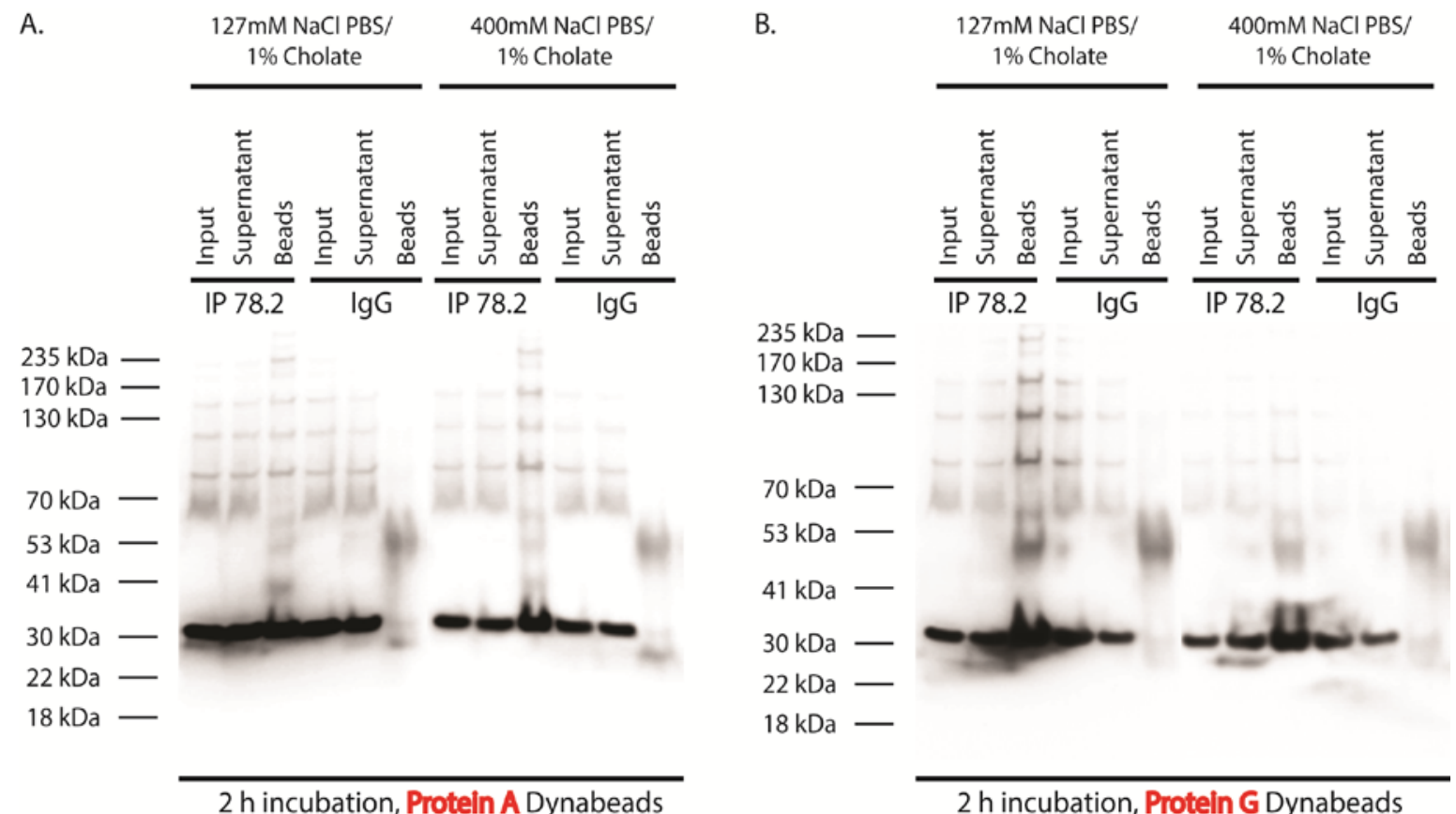

Figure 3.26. Stx 1 immunoprecipitation from cholate-solubilized LP1 fraction with Cl 78.2 antibody. Precentrifuged extract of LP1 fraction was rotated for $2 \mathrm{~h}$ with Protein A- or Protein G-coated Dynabeads, which were pre-incubated with an excess of $\mathrm{Cl} 78.2 \mathrm{Ab}$ or mouse IgG (control) antibody. Beads were washed with either low salt or high salt washing buffer. Input, supernatant after IP and beads were boiled in SDS sample buffer and their protein content was separated by SDS-PAGE. For immunodetection mAb Cl 78.3 (1:1000) was used. 
The results from the immunoprecipitation experiments showed that both, $\mathrm{Cl} 78.3$ and $\mathrm{Cl}$ 78.2, anti-stx 1 antibodies were suitable the immunoprecipitation of the protein. However, mass spectrometry analysis of the IP and mock samples showed high abundance of mitochondrial and ribosomal proteins. Thus, both antibodies were covalently coupled to non-porous Eupergit beads. Their application in immunoisolation experiments and low affinity for unspecific binding were reported earlier $[144,146]$. However, the immunoprecipitation after direct coupling of $\mathrm{Cl} 78.3$ Ab to Eupergit beads failed. This was probably due to destroying of the paratope, i.e. the epitope-binding region of the antibody. Therefore, bridging polyclonal rabbit anti-mouse IgGs were used in order to enable $\mathrm{Cl} 78.3$ Ab's use for the isolation of stx 1 (see Appendix 6). In contrast, the $\mathrm{Cl} 78.2 \mathrm{Ab}$ was successfully coupled directly to the beads. In order to estimate the amount of beads suitable for optimal immunoprecipitation of stx 1, $10 \mu \mathrm{l}, 20 \mu \mathrm{l}$ and $40 \mu \mathrm{l}$ of 25\% beads slurry were tested (Appendix 6 and Figure 3.27). The strong enrichment of stx 1 under low as well as under high salt conditions was verified by Western blots and mass spectrometry (results not shown). Both $\mathrm{Cl} 78.3$ and $\mathrm{Cl} 78.2$ monoclonal antibodies, but not the HPC-1 antibody, were suitable for the immunoprecipitation of our target. For any further experiments, we used $40 \mu \mathrm{l}$ of Eupergit-Cl 78.2 immunobeads and an incubation time of $2 \mathrm{~h}$.

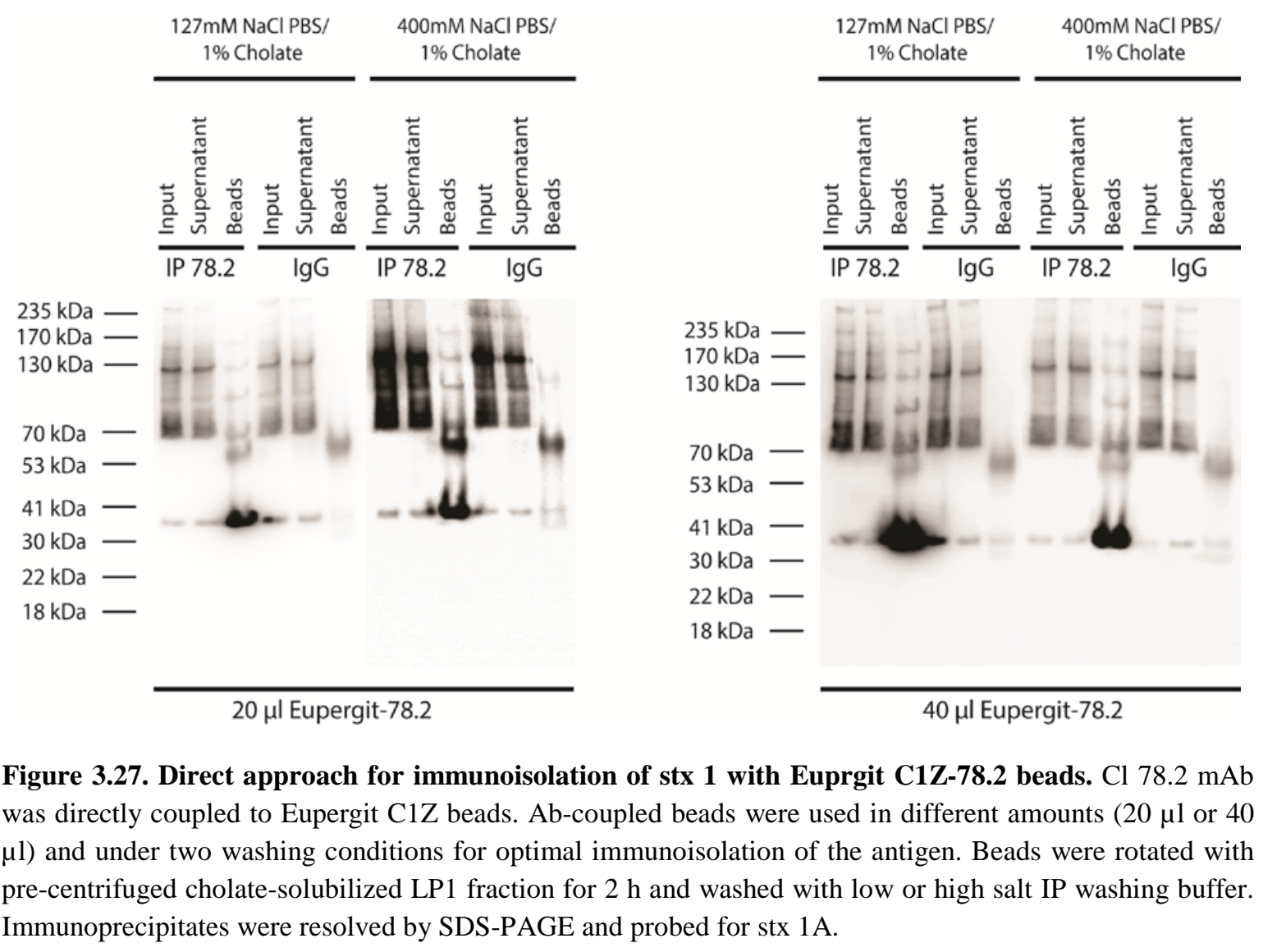


By systematical analysis of the variable parameters in the IP experiments, we were able to establish a protocol for an efficient affinity precipitation of stx 1 and detection of the co-immunopurified proteins using label-free quantitative mass spectrometry. The results from the affinity purifications and the analyzed proteomics data are discussed in the next section.

\subsection{Mass spectrometry}

\subsubsection{Sample preparation for mass spectrometry}

Immunoprecipitates containing stx 1 and stx1-interacting proteins were analyzed in a label-free quantification approach combined with tandem mass spectrometry (nanoLCMS/MS) [132]. First step in a sample preparation for mass spectrometry analysis is the elution of bound proteins from beads with denaturing SDS containing sample buffer. This step is followed by protein separation on a SDS-PAGE gel, in-gel digestion, extraction of digestive peptides from the gel pieces and their mass spectrometry analysis. However, this procedure covers mainly soluble and highly abundant proteins and allows only partial identification of hydrophobic proteins, e.g. channels and transporters. This is due to the limited enzymatic proteolysis of membrane proteins in gel stripes, their poor extraction after sample digestion as well as limited detection in mass spectrometers. Moreover, boiling of beads for protein elution at $95{ }^{\circ} \mathrm{C}$ causes aggregation and precipitation of the membrane proteins.

In order to overcome these limitations, two strategies were tested. First alternative involved elution of bound proteins in $2 \%$ SDS solution at $60{ }^{\circ} \mathrm{C}$ or $95^{\circ} \mathrm{C}$. Application of this approach was reported to completely elute proteins from beads matrices [193]. Second method consisted of direct digestion of immunoprecipitates on the beads. This strategy is based on modified version of published protocol [146, 147] that covered most of the synaptic integral and peripheral proteins in mass spectrometry studies.

The elution with 2\% SDS solution was conducted at two different temperatures. The reason was that boiling of samples containing membrane proteins at $95^{\circ} \mathrm{C}$ caused their aggregation. Thus, an alternative condition was tested in which samples were heated at 60 ${ }^{\circ} \mathrm{C}$ for $15 \mathrm{~min}$. In addition, direct tryptic digestion of immunoprecipitates on the beads was tested with different amounts of trypsin: either with $5 \mu \mathrm{g}$ or $10 \mu \mathrm{g}$ trypsin. Proteolytic 
enzymes used for protein digestion can be partially denatured or inactivated by detergent remaining on the beads after the IP washing steps. In addition, it is well known that digestion directly on the beads has limited efficiency. When the elution procedure was applied, proteins were first acetone precipitated overnight and their tryptic proteolysis was conducted the next day in parallel with the on-beads-digestion. Beads were boiled in SDS sample buffer after trypsinization and elution. Proteins from boiled beads and digested samples were loaded on SDS-PAGE and the gels were silver stained in order to assess the efficiency of elution, on-beads-digestion and protein proteolysis (Figure 3.28).

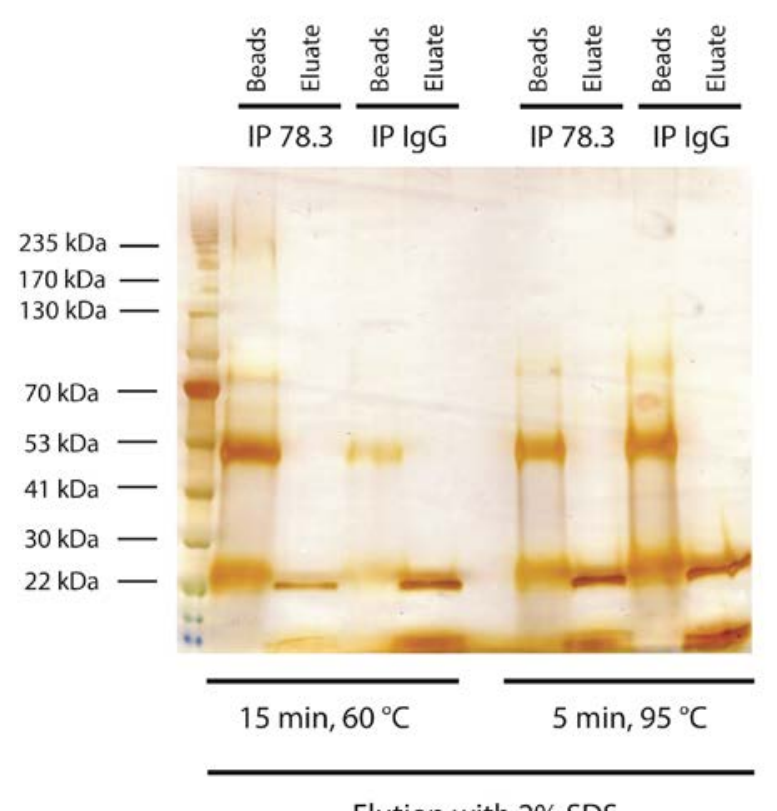

Elution with $2 \%$ SDS

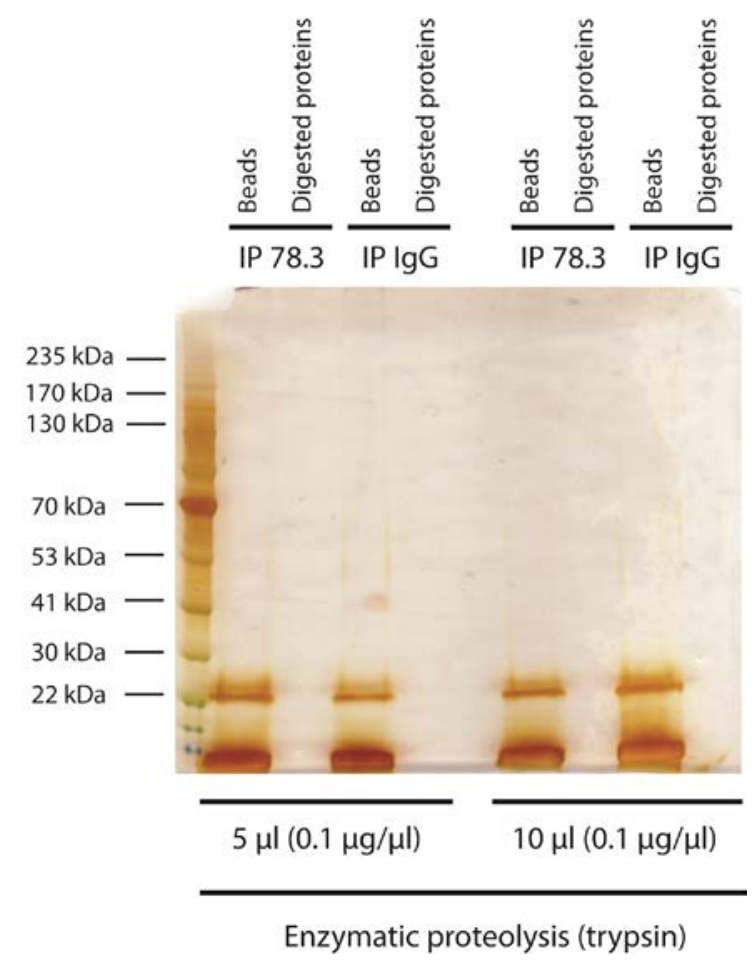

Enzymatic proteolysis (trypsin)

Figure 3.28. Silver stained SDS-PAGE gels of beads' supernatants, trypsinized samples and eluates. Beads were boiled in SDS sample buffer after on-beads-protein trypsinization or 2\% SDS elution. Digested eluates and on-bead trypsinized proteins were also boiled in SDS sample buffer. The contents of the samples were resolved on SDS-PAGE gels. Gels were silver stained in order to assess the efficiency of the alternative protocols and tofind best proteolysis approach.

After the SDS elution, some protein bands were still detected on the silver stained gels $(\sim 75 \mathrm{kDa})$. This observation was more pronounced when elution was performed by sample boiling at $95{ }^{\circ} \mathrm{C}$ and was independent of the sample (IP as well negative control). The advantage of this approach was emphasized by the detection of antibody's LC and HC on the beads, at $\sim 25 \mathrm{kDa}$ and $\sim 55 \mathrm{kDa}$ respectively. This result indicated that the antibodies remained largely attached to the beads and were, if at all, only partially coeluted with the immunoenriched proteins. A protein band visible at $\sim 26 \mathrm{kDa}$ in the eluate fractions corresponded to trypsin, which was not completely removed from the 
proteolytically digested sample by acidic precipitation (see Figure 3.28). In contrast to these results, the tryptic processing directly on the beads successfully digested the coimmunopurified proteins as judged by the silver staining of the gel. Although the sensitivity of the staining procedure lies in the nanomolar range [194], it is possible that low abundant proteins and very hydrophobic proteins remained undigested. The obtained results in the on-beads-digestion protocol were similar regardless of the enzyme amount used. Thus, we proceeded for further experiments with $5 \mu \mathrm{g}$ trypsin per $40 \mu \mathrm{l}$ Eupergit-Cl 78.2-coupled beads (25\% slurry).

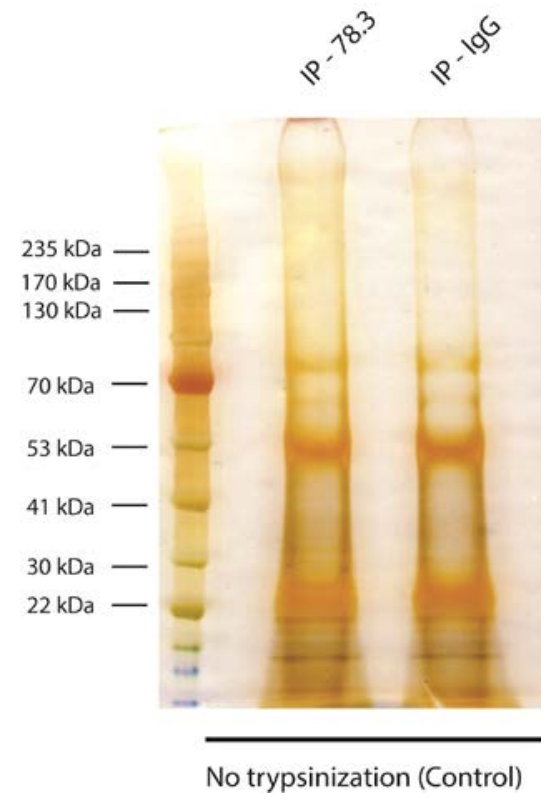

Figure 3.29. Silver staining of SDS-PAGE-resolved proteins from an IP and negative control sample. Immunoisolated proteins from an IP and mock samples were separated electrophoretically and visualized by silver staining. Since no trypsinization of the samples was performed, they were used as a control.

The protein constituents of unprocessed samples (IP and mock) were resolved by SDS-PAGE and the gel was silver stained. Thus, it served as control to evaluate the efficiency of elution and trypsinization (Figure 3.29).

Analysis of the results and comparison of both protocols allowed drawing few conclusions. First, elution of immunoprecipitated proteins with $2 \%$ SDS at $60{ }^{\circ} \mathrm{C}$ or $95{ }^{\circ} \mathrm{C}$ showed no significant differences. In both cases, the main portion of antibodies remained attached to the beads whereas most of the proteins were eluted (Figure 3.28). This result 
offers an advantage since antibodies are unwanted in the AP-MS method due to their high abundance. They mask peptide signals from low abundant proteins, thus impairing their detection and identification. However, protein elution was not complete and this represented main limitation. In addition, the SDS detergent remained attached to the digestive peptides even after acetone washing post-precipitation. Consequently, only few peptides could be detected in the mass spectrometer. In contrast to these findings, tryptic digestion of immunoisolates directly on the beads showed good results. All proteins were fully trypsinized in a single step within $16 \mathrm{~h}$. In addition, after the enzymatic proteolysis, trypsin was completely removed by acidic precipitation as a part of the standard sample processing procedure. This allowed collection of peptides derived only from precipitated proteins and not from the enzyme. Based on these results, in all following experiments, the proteolytic digestion of immunoprecipitates was performed directly on the beads with $5 \mu \mathrm{g}$ trypsin. Furthermore, in an additional experiment (not shown), the on-beads-digestion protocol showed same protein coverage as achieved by using a standard protocol (protein separation on SDS-PAGE gel followed by an in-gel trypsinization).

\subsubsection{Study of the proteins co-immunoprecipitated with stx 1 by label-free quantitative proteomics}

The proteins, which co-immunopurified with stx 1, were studied by label-free quantitative proteomics under two conditions: washing of the Ab-coupled Eupergit beads with low (127 mM NaCl) and high (400 mM NaCl) salt containing buffer. Affinity purification in combination with mass spectrometry (AP-MS) detection of proteins allows identification of protein complex constituents [195]. Two main difficulties accompany this method. First, the lack of an antibody often hinders the isolation of endogenous complexes. Second, it is difficult to distinguish true positive from false positive interaction partners because target non-related proteins co-purify due to unspecific binding to beads and antibody.

The results obtained from the IP experiments showed strong and efficient immunoprecipitation when two monoclonal anti-stx 1 antibodies ( $\mathrm{Cl} 78.2$ and $\mathrm{Cl} 78.3$ ) were used (see 3.4.1). Thereby, the first restriction for a successful AP-MS experiment was overcome. 
Quantitative label-free mass spectrometry allowed solving the second problem. Quantitative ratios of proteins in the IP and mock sample helped distinguishing true interaction partners from background binders. These ratios were obtained by comparing the integrated signals of peptides from mass spectrometric measurements (label-free quantification) using MaxQuant software and Perseus [137, 196]. The bioinformatics package analyzed the raw data in label-free quantification (LFQ) mode considering unique and razor (non-unique peptides assigned to a protein) peptides. Immunoprecipitations in combination with LFQ data analysis must be performed at least in triplicate because the data validation is based on t-test statistics. In our study, data obtained from 5 biological replicates in two technical repeats in either condition (high and low salt) was used. Significant interaction partners were determined using a volcano-plot method based on ratio of proteins in the IP vs. the mock sample and t-test algorithm as recently described [137, 197]. This approach combines the p-values from a two-sample (equal group variance) t-test and the logarithmic ratio of protein intensities in stx 1 vs. control IP samples. Therefore, the logarithmic ratios of the intensities were plotted against the negative logarithmic p-values of t-test performed on the five biological replicates. Significance lines in the volcano plot were set according to a given false discovery rate (FDR) determined by a permutation based method [198]. The value of FDR was set at 0.01 . There are no recommendations for FDR value. FDR=0.01 and $\mathrm{SO}=1$ (=significance line bend) were selected as a high threshold based on previous reports [137]. The SO value is a minimal fold change parameter, which determines the margin between significantly and non-significantly enriched proteins. At $\mathrm{SO}=0$, no fold change on the ratio logarithmic scale is observed and FDR equals the p-value from the two sample t-test. Proteins with low p-value (highly significant) were found in the top of the volcano plot. Due to the logarithmic fold-change of quantity ratios (x axis), enrichment of proteins in either sample resulted in equidistant distribution of proteins form the center (zero value). In this way, major regions of interest were observed in the top of the plot and far distant from the center on the left or right side. These points represented proteins identified with large fold-changes and high statistical significance.

In total, 1872 proteins (excluding identified with reverse sequence or by site and MS contaminants, e.g. keratins) were identified in the immunoisolates in either condition. This list included protein isoforms and 17 detected UPS2 standard proteins, which were added to the immunoisolates and proteolytically co-digested. The results are presented in more details in the following sections. 


\subsubsection{Proteins co-purified with stx 1 under high salt conditions}

In the IP samples under high salt condition, 173 of 1872 proteins passed the threshold criteria (FDR=0.01 and $\mathrm{SO}=1$ ). All significant proteins above the threshold values are listed in the appendix according to their significance in decreasing order (Appendix 7). 158 of these proteins were found above the significance curve in the anti-stx 1 IP (right in the plot, see Figure 3.30). The remaining 15 proteins were significantly and high fold-change enriched in the negative control (left in the plot, see Figure 3.30 and Appendix 8). As indicated in the volcano plot, stx 1A showed lowest p-value from all 158 significant hits in the IP sample and high fold enrichment. This result confirmed successful affinity enrichment of the target protein. Moreover, the 158 proteins were categorized according to their subcellular localization and biological function using previous reports as reference [133, 146]. A chart representing protein annotation and number of proteins in each group is shown below (Figure 3.31).

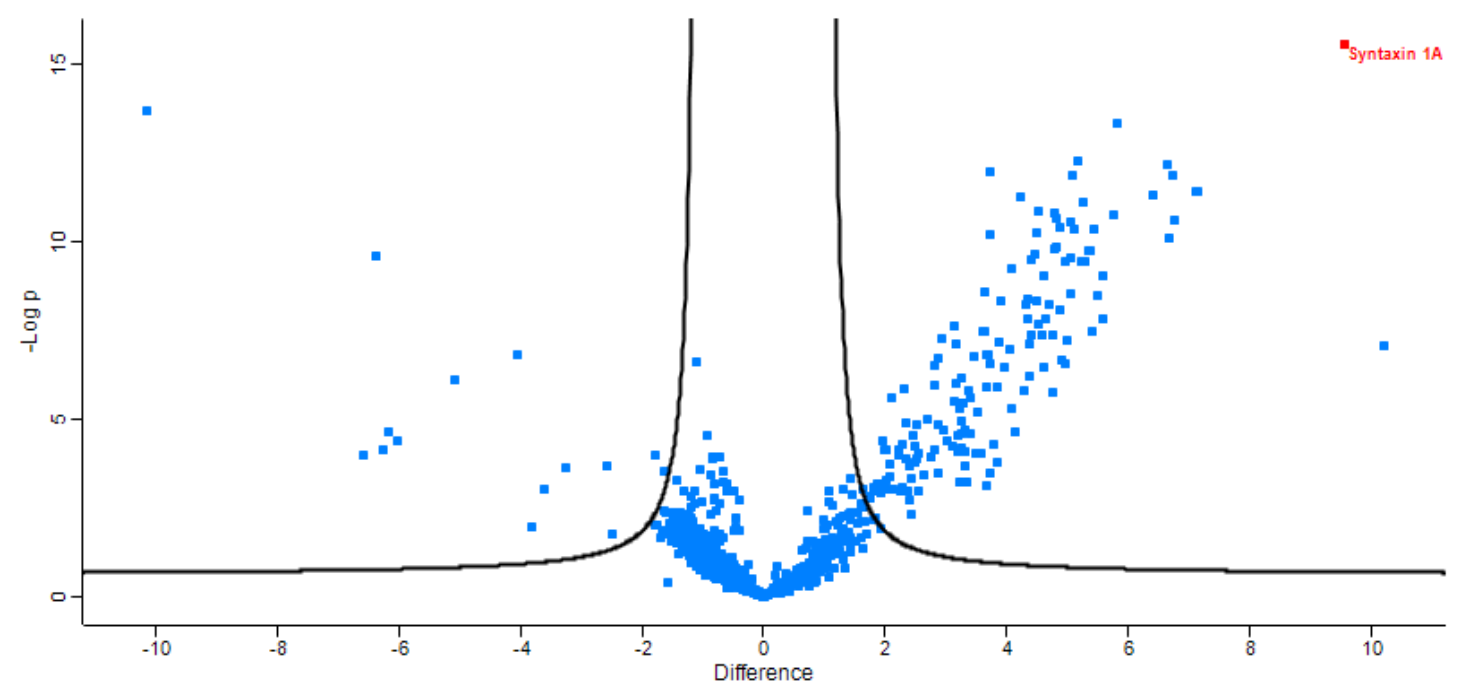

Figure 3.30. Volcano plot representing results from stx 1 immunoprecipitation with Eupergit C1Z-Cl 78.2 beads under high salt conditions. Logarithmic ratio of protein intensities difference was plotted against negative p-values from two sample t-test. Identified proteins from all biological and technical replicates were analyzed with LFQ algorithm in MaxQuant and Perseus software. Significantly, enriched proteins in IP (right in the plot) and negative control (left in the plot) are represented as blue squares above the threshold curve. Stx1A showed highest fold enrichment change and lowest p-value among all samples (Stx1 in upper right corner of the plot). 


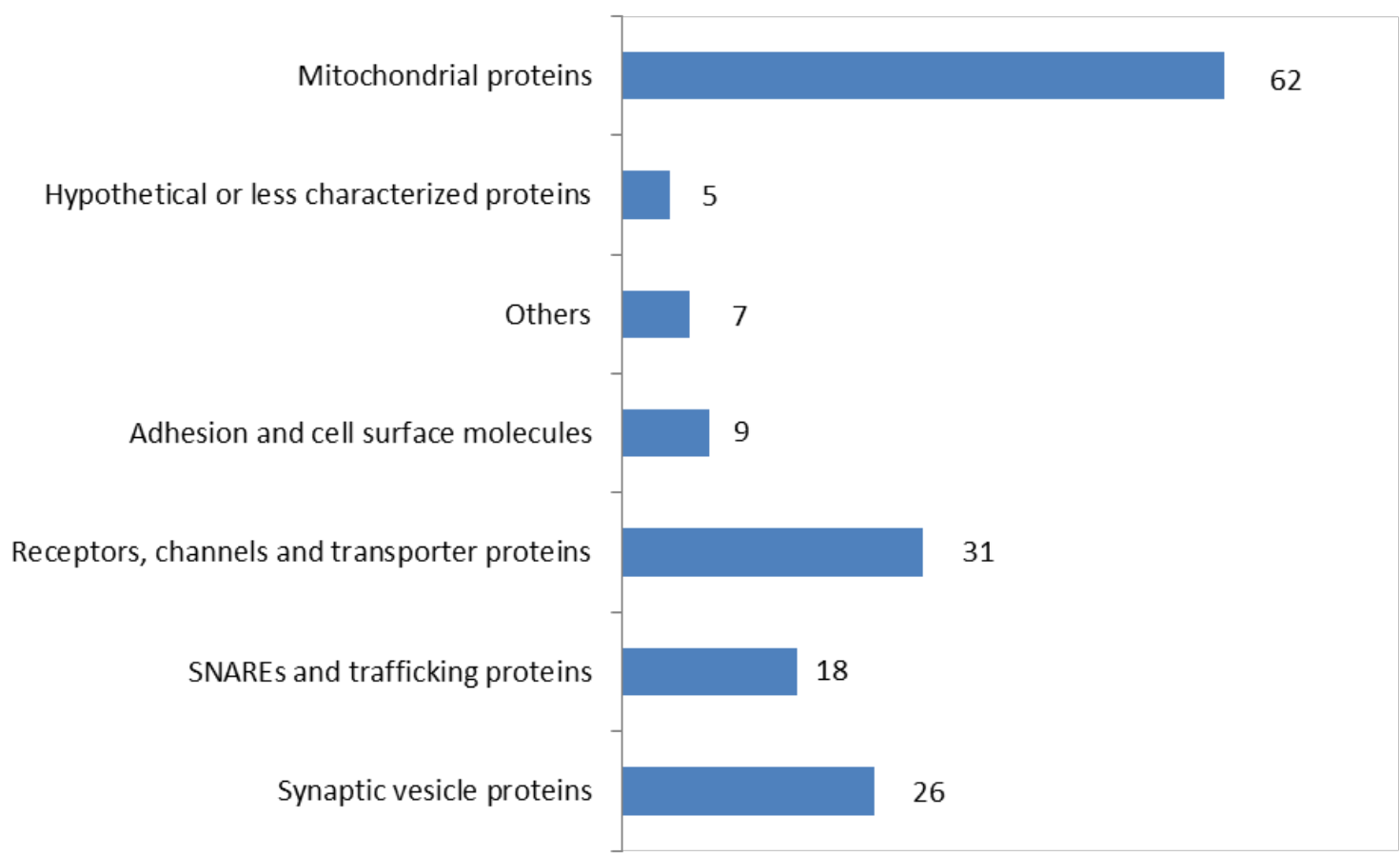

Figure 3.31. Protein groups and number of identified proteins in each group stx1 immuno-precipitate at high salt concentration. Proteins were annotated manually according to their subcellular localization and biological functions and categorized in seven groups: mitochondrial proteins; hypothetical/poorly characterized proteins; adhesion and cell surface proteins; receptors, transporters and channels; SNAREs and trafficking proteins; synaptic vesicle proteins and others;. Number of proteins in each category is indicated (left to the charts).

\subsection{Synaptic vesicle proteins}

26 from 158 proteins were annotated as SV constituents based on previous reports $[133,146]$ or sequence similarity. Proteins were sorted in decreasing order of their significance and enrichment in the stx 1 IPs (see Table 3.3). As summarized in Table 3.3, many major synaptic vesicle proteins were identified. This included synaptophysin, VGLUT isoforms 1 and 2, VGAT, SV2A and SV2B, Scamp1/3/5, synaptotagmins (1, 2 and 12). Interestingly, different isoforms of the proteins were detected with different significance in the IP samples. This might indicate their participation in distinct complexes with the participation of stx 1 . The distribution of some of the listed SV proteins in the scatter plot is shown in Figure 3.32. Interestingly, some less studied SV proteins were identified in the IPs: synaptogyrin 3 (syngr3), transmembrane protein 163 (SV31), orphan transporter NTT4 [199] and MAL2-like protein. Recent findings showed that syngr3 colocalizes with Vamp1/2, Stx1A/B and Vglut1/2 [200], and SV31 protein was identified in 
2007 as synaptic vesicle protein [201]. SV31 shows binding affinity for divalent $\mathrm{Zn}^{2+}$ cations and was detected in Stx1A and SNAP25 positive puncta in immunocytochemistry studies in PC12 cells [202]. Interestingly, MAL2-like protein was also identified. It shows $99.4 \%$ identity with MAL2A protein by sequence alignment.

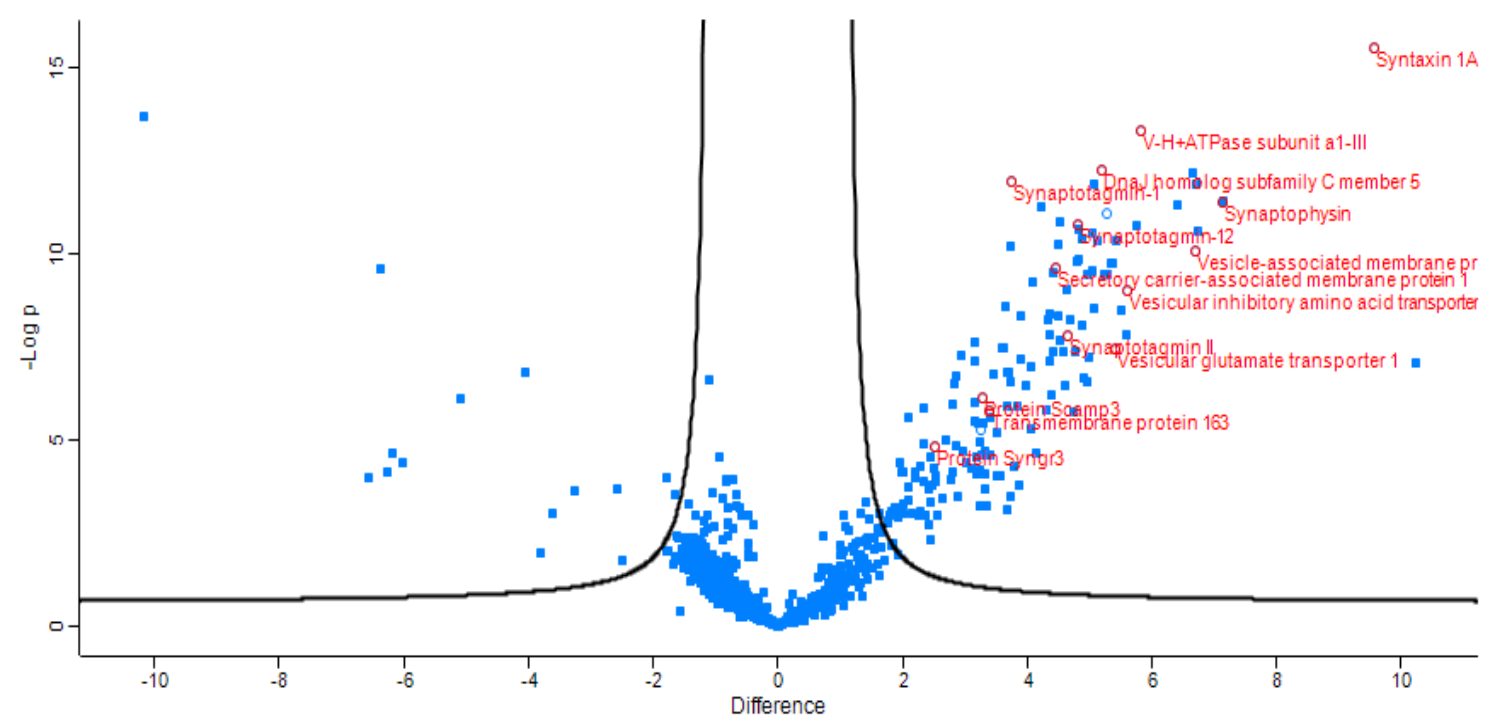

Figure 3.32. Distribution of significantly enriched SV proteins in anti-stx 1 IPs. Some of the listed 26 SV proteins identified with high significance and large fold-change enrichment in stx1 IPs are indicated in the scatter plot.

\subsection{SNAREs and trafficking proteins}

Under the threshold conditions set for the data analysis, no core AZ proteins were not identified. Munc13, earlier reported to interact with stx 1 [49], did not pass the threshold criteria. It was detected in only three from five stx 1 IP samples and was not significantly enriched. This finding was in partial agreement with previous studies, which failed detecting Munc13 [146, 203]. This might be due to limited number of peptides or their hydrophobic character, what would limit their detection by mass spectrometry. Another explanation would be the use of $\mathrm{Cl} 78.2 \mathrm{Ab}$, which has partial affinity to stx $1 \mathrm{~B}$, not only to stx $1 \mathrm{~A}$. However, this fact is ambiguous because Munc13 binds to stx $1 \mathrm{~B}$ as well as to stx 2 as shown in yeast two-hybrid screen [49]. In addition, Stxbp1 (Munc18) was also missed in the significant hits. 
Among the positive protein hits in the Stx1 IP, 18 proteins were annotated as SNARE (soluble N-ethyl-maleimide-sensitive factor attachment protein receptor) and regulatory proteins (see Table 3.4).

Table 3.3. SV proteins identified as significantly enriched in the stx1 IP samples. Proteins are listed according to their significance in a decreasing order.

\begin{tabular}{|l|l|l|}
\hline \multicolumn{1}{|c|}{$\begin{array}{c}\text { Protein } \\
\text { ID }\end{array}$} & Gene name & \\
\hline P07825 & Syp & Synaptophysin \\
\hline Q5M7T6 & Atp6v0d1 & ATPase, H+ transporting, lysosomal 38kDa, V0 subunit d1 \\
\hline Q216B2 & Atp6v0a1 & V-H+ATPase subunit a1-III \\
\hline P63045 & Vamp2 & Vesicle-associated membrane protein 2 \\
\hline Q63564 & Sv2b & Synaptic vesicle glycoprotein 2B \\
\hline P60905 & Dnajc5 & DnaJ homolog subfamily C member 5 (CSP) \\
\hline Q6QIX3 & SIc30a3 & Zinc transporter 3 \\
\hline O35458 & SIc32a1 & Vesicular inhibitory amino acid transporter \\
\hline M0RCJ9 & LOC100911027 & Protein LOC100911027 (MAL2-like) \\
\hline P97610 & Syt12 & Synaptotagmin-12 \\
\hline Q62634 & Slc17a7 & Vesicular glutamate transporter 1 \\
\hline Q6IRF8 & Atp6ap1 & ATPase, H+ transporting, lysosomal accessory protein 1 \\
\hline P63081 & Atp6v0c & V-type proton ATPase 16 kDa proteolipid subunit \\
\hline P56603 & Scamp1 & Secretory carrier-associated membrane protein 1 \\
\hline F1M9V2 & Vamp1 & Vesicle-associated membrane protein 1 (Fragment) \\
\hline G3V6M3 & Syt2 & Synaptotagmin II \\
\hline P21707 & Syt1 & Synaptotagmin-1 \\
\hline Q02563 & Sv2a & Synaptic vesicle glycoprotein 2A \\
\hline P31662 & Slc6a17 & Sodium-dependent neutral amino acid transporter SLC6A17 (NTT4) \\
\hline A9CMA6 & Tmem163 & Transmembrane protein 163 (SV31) \\
\hline E9PTW1 & Scamp3 & Protein Scamp3 \\
\hline G3V851 & Slc17a6 & $\begin{array}{l}\text { Solute carrier family 17 (Sodium-dependent inorganic phosphate } \\
\text { cotransporter), member 6 (VGLUT2) }\end{array}$ \\
\hline F1M882 & Scamp5 & Secretory carrier-associated membrane protein 5 (Fragment) \\
\hline D4A133 & Atp6v1a & Protein Atp6v1a \\
\hline D4ABK1 & Syngr3 & Protein Syngr3 \\
\hline P62815 & Atp6v1b2 & V-type proton ATPase subunit B, brain isoform \\
\hline
\end{tabular}

SNARE proteins form complexes, which represent the minimal exocytotic machinery. These complexes are formed in different constellations and are regulated by Sec1/Munc18-like (SM) proteins. Such regulatory proteins are the syntaxin binding proteins (Stxbp). Interestingly, Stxbp5 (tomosyn) was found as a positive hit in our IP experiments (see Table 3.4). It forms a $10 \mathrm{~S}$ complex with stx 1A, SNAP-25 and syt and is able of dissociating bound Munc-18 from stx 1A [204]. A novel tomosyn-like (stxbp5-like, 
stxbp5l) protein of unknown function with 60.8\% sequence similarity (by sequence alignment) to stxbp5 was also found among the co-immunoisolated proteins. In addition, stxbp6 (amysin) passed the set threshold parameters in our data analysis. Amysin a soluble brain-enriched protein without a transmembrane anchor but contains tomosyn- and VAMPlike coiled-coil domain. It was reported to bind specifically to stx 1A [205]. SV membrane SNAREs SNAP29 and SNAP47, plasma membrane anchored t-SNARE SNAP-25 [133], Sec22b, which forms a non-fusiogenic trans-SNARE complex with stx 1 [206], were also found among the true stx 1-interacting proteins. In addition, SNARE proteins syntaxin 6, 7 and 13 and VAMP7 were also co-purified with the stx 1 in the IP samples. Syntaxin 6 resides on Golgi membranes showing sequence similarity to SNAP-25 [207], but it was also found with lysosomal SNARE stx 7 enriched in SV fractions [133] (see Figure 3.33). Interestingly, two less characterized proteins were identified and placed in this group: PRAF3 and PRA1 domain family 2 (PRAF2) protein. PRAF3 is proposed to bind to prenylated Rab1a and Rab3a GTPases by similarity and shown to bind to EAAT3 glutamate transporter and regulate its activity [208, 209]. PRFA2 is recently described and involved in endo/exocytic vesicle trafficking [210-212].

Table 3.4. SNAREs and trafficking proteins identified with high significance and fold-change enrichment in stx 1 IPs. Proteins are listed according to their significance in a decreasing order.

\begin{tabular}{|c|c|c|}
\hline \multicolumn{3}{|c|}{ SNAREs and trafficking proteins } \\
\hline Protein ID & Gene name & Protein name \\
\hline Q9QXG3 & Stx1a & Syntaxin $1 \mathrm{~A}$ \\
\hline Q9WU70-2 & Stxbp5 & Isoform 2 of Syntaxin-binding protein 5 (M-tomosyn) \\
\hline P60881 & Snap25 & Synaptosomal-associated protein 25 \\
\hline P61265 & Stx1b & Syntaxin-1B \\
\hline D3ZU84 & Stxbp5I & Protein Stxbp5I \\
\hline Q9JHW5 & Vamp7 & Vesicle-associated membrane protein 7 \\
\hline 070257 & Stx7 & Syntaxin-7 \\
\hline G3V7P1 & Stx13 & Syntaxin-13 \\
\hline D3ZCI5 & Stxbp6 & Protein Stxbp6 \\
\hline Q6P6S0 & Snap47 & Synaptosomal-associated protein 47 \\
\hline Q63635 & Stx6 & Syntaxin-6 \\
\hline Q5EGY4 & ykt6 & Synaptobrevin homolog YKT6 \\
\hline P60881-2 & SNAP-25a & Isoform 2 of Synaptosomal-associated protein 25 \\
\hline Q4KM74 & $\sec 22 b$ & Vesicle-trafficking protein SEC22b \\
\hline Q9ES40 & Arl6ip5 & PRA1 family protein 3 (PRAF3) \\
\hline D3ZAAO & Praf2 & PRA1 domain family 2(PRAF2) \\
\hline Q9JI56 & snap29 & Synaptosomal-associated protein 29 \\
\hline F1LNC4 & Vti1b & Protein LOC100359512 (Vti1b) \\
\hline
\end{tabular}




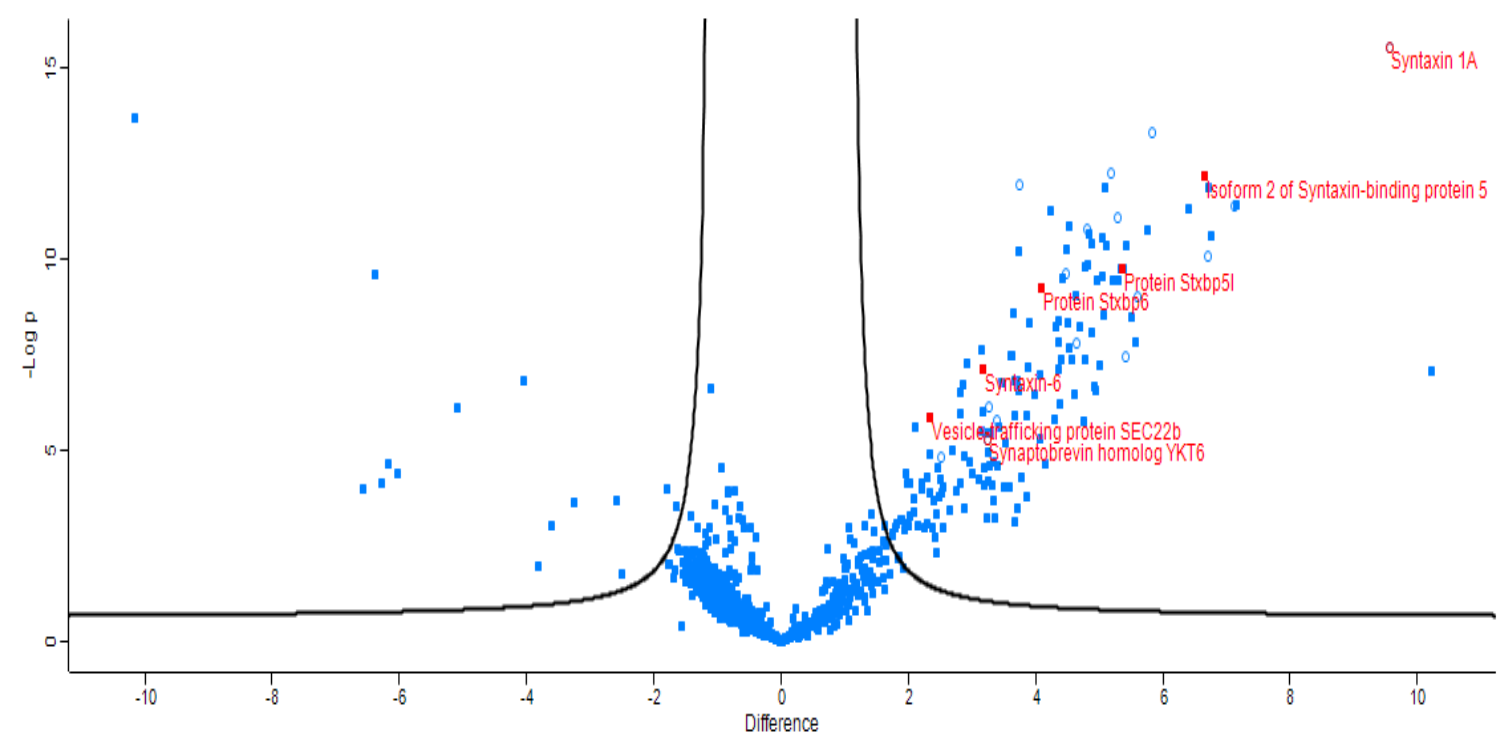

Figure 3.33. Distribution of significantly enriched SNARE and trafficking proteins in stx 1 IP samples. 18 SNARE and regulatory proteins were identified with high significance and large fold-change enrichment in stx 1 immunopurifications. Some of these 18 proteins are indicated in the scatter plot.

\subsection{Receptor, transporter and channel proteins}

Synaptic transmission is governed by a broad spectrum of transmembrane proteins with various functions. Nevertheless, up to now their study has been restrained by insufficient solubilization and low number of digestive peptides for mass spectrometric identification. However, we successfully identified 31 transporter, channel and receptor molecules including protein subunits/isoforms. Three $\alpha$ (1, 2 and 3$)$ and one $\beta$ (2) subunits of $\mathrm{Na}+/ \mathrm{K}^{+}$ATPase were detected (Table 3.5). The ATPase plays important role in cation equilibrium across the membrane, it is involved in recovery of resting potential in neurons and exchanges three $\mathrm{Na}^{+}$outwards for two $\mathrm{K}^{+}$ions inwards [213, 214]. In addition, it directly regulates the activity of glutamate transporters Eaat1/2, also identified among our positive hits, and thus terminates glutamate-mediated neurotransmission [215]. Significant enrichment in electrochemical and ion driven transporters was observed, e.g. $\mathrm{Na}^{+} / \mathrm{Ca}^{2+}$ exchanger, Na-K-Cl co-transporter, plasma membrane calcium-transporting ATPase 2, electrogenic sodium bicarbonate co-transporter 1 (isoform 3) and sodium-driven chloride bicarbonate exchanger (isoform 4) (Table 3.5). Interestingly, $\mathrm{Na}^{+} / \mathrm{Ca}^{2+}$ exchanger regulates presynaptic $\mathrm{Ca}^{2+}$ homeostasis [216], whereas electrogenic sodium bicarbonate co- 
transporter 1 was reported glia membrane-associated [217]. Furthermore, the function of sodium-driven chloride bicarbonate exchanger suggested its implication in $\mathrm{pH}$ regulation in the brain, where it was found in high expression levels [218].

Table 3.5. Receptor, transporter and channel proteins identified with high significance and fold-change enrichment in the stx 1 immunoprecipitates. Proteins are listed according to their significance in a decreasing order.

\begin{tabular}{|c|c|c|}
\hline \multicolumn{3}{|r|}{ Receptor, transporter and channel proteins } \\
\hline Protein ID & Gene name & Protein name \\
\hline P04775 & $\operatorname{Scn} 2 a$ & Sodium channel protein type 2 subunit alpha \\
\hline Q07647 & Slc2a3 & Solute carrier family 2 , facilitated glucose transporter member 3 \\
\hline F1LNE4 & Gria2 & Glutamate receptor 2 \\
\hline F1M585 & Atp8a1 & Phospholipid-transporting ATPase \\
\hline P19492 & Gria3 & Glutamate receptor 3 \\
\hline P07340 & Atp1b1 & Sodium/potassium-transporting ATPase subunit beta-1 \\
\hline Q63633-2 & Slc12a5 & Isoform 2 of Solute carrier family 12 member 5 \\
\hline P06685 & Atp1a1 & Sodium/potassium-transporting ATPase subunit alpha-1 \\
\hline G3V846 & Eaat1 & Excitatory amino acid transporter 1 \\
\hline Q9JI66-3 & Slc4a4 & Isoform 3 of Electrogenic sodium bicarbonate cotransporter 1 \\
\hline P06687 & Atp1a3 & Sodium/potassium-transporting ATPase subunit alpha-3 \\
\hline P23978 & Slc6a1 & Sodium- and chloride-dependent GABA transporter 1 \\
\hline P63138 & Gabrb2 & Gamma-aminobutyric acid receptor subunit beta- 2 \\
\hline F1M9A2 & Slc8a2 & Sodium/calcium exchanger 2 \\
\hline P19490 & Gria1 & Glutamate receptor 1 \\
\hline D4A6L0 & Gpr158 & Probable G-protein coupled receptor 158 \\
\hline G3V8F1 & Slc6a7 & L-proline transmembrane transporter \\
\hline P31596-2 & Eaat2 & Isoform Glt-1A of Excitatory amino acid transporter 2 \\
\hline $088917-2$ & Lphn1 & Isoform 2 of Latrophilin-1 \\
\hline Q01728-2 & Slc8a1 & Isoform 2 of Sodium/calcium exchanger 1 \\
\hline P31421 & Grm2 & Metabotropic glutamate receptor 2 \\
\hline Q5M9H4 & Atp1b2 & ATPase, $\mathrm{Na}+/ \mathrm{K}+$ transporting, beta 2 polypeptide \\
\hline Q9QX10 & Slc12a2 & $\mathrm{Na}-\mathrm{K}-\mathrm{Cl}$ cotransporter \\
\hline Q62976 & Kcnma1 & Calcium-activated potassium channel subunit alpha-1 \\
\hline P11506-8 & Atp2b2 & Isoform ZB of Plasma membrane calcium-transporting ATPase 2 \\
\hline P06686 & Atp1a2 & Sodium/potassium-transporting ATPase subunit alpha-2 \\
\hline Q80ZA5-4 & Slc4a10 & Isoform 4 of Sodium-driven chloride bicarbonate exchanger \\
\hline Q6AY41 & Tmem30a & Cell cycle control protein 50A (CDC50A) \\
\hline Q91XV6-2 & Fxyd6 & Isoform 2 of FXYD domain-containing ion transport regulator 6 \\
\hline Q6PW52 & Gabrg2 & GABA-A gamma2 long isoform \\
\hline P29994-8 & Itpr1 & Isoform 8 of Inositol 1,4,5-trisphosphate receptor type 1 \\
\hline P04775 & $\operatorname{Scn} 2 a$ & Sodium channel protein type 2 subunit alpha \\
\hline
\end{tabular}


Interestingly, also inositol 1,4,5-trisphosphate receptor type 1 passed the significance threshold in the stx 1 IPs. The receptor was recently reported to interact directly with SNARE domain of stx 1B [219] (Table 3.5). Kcnma1 or Ca-dependent potassium channel (BK channel), a regulator of glutamatergic neurotransmission [220] and iono- and metabotropic GABA receptors were also highly enriched in stx 1 IP samples. However, it remains unclear whether GABA receptors were postsynaptic contamination or had presynaptic localization.The distribution of some channels, transporters and receptors in the volcano plot is shown below (Figure 3.34). With few exceptions, the proteins from this group were derived from the plasma membrane. Itpr1 receptor is intracellular as well as partially the phospholipid-transporting ATPase, which was identified among the positive hits together with its accessory component CDC50A protein. The ATPase undergoes CDC50A-dependent translocation from ER to Golgi and PM [221, 222]. And last but not least, Fxyd6 has a brain development-dependent expression [223] and has been shown to be a $\mathrm{Na}^{+} / \mathrm{K}^{+}$ATPase regulator [224-227].

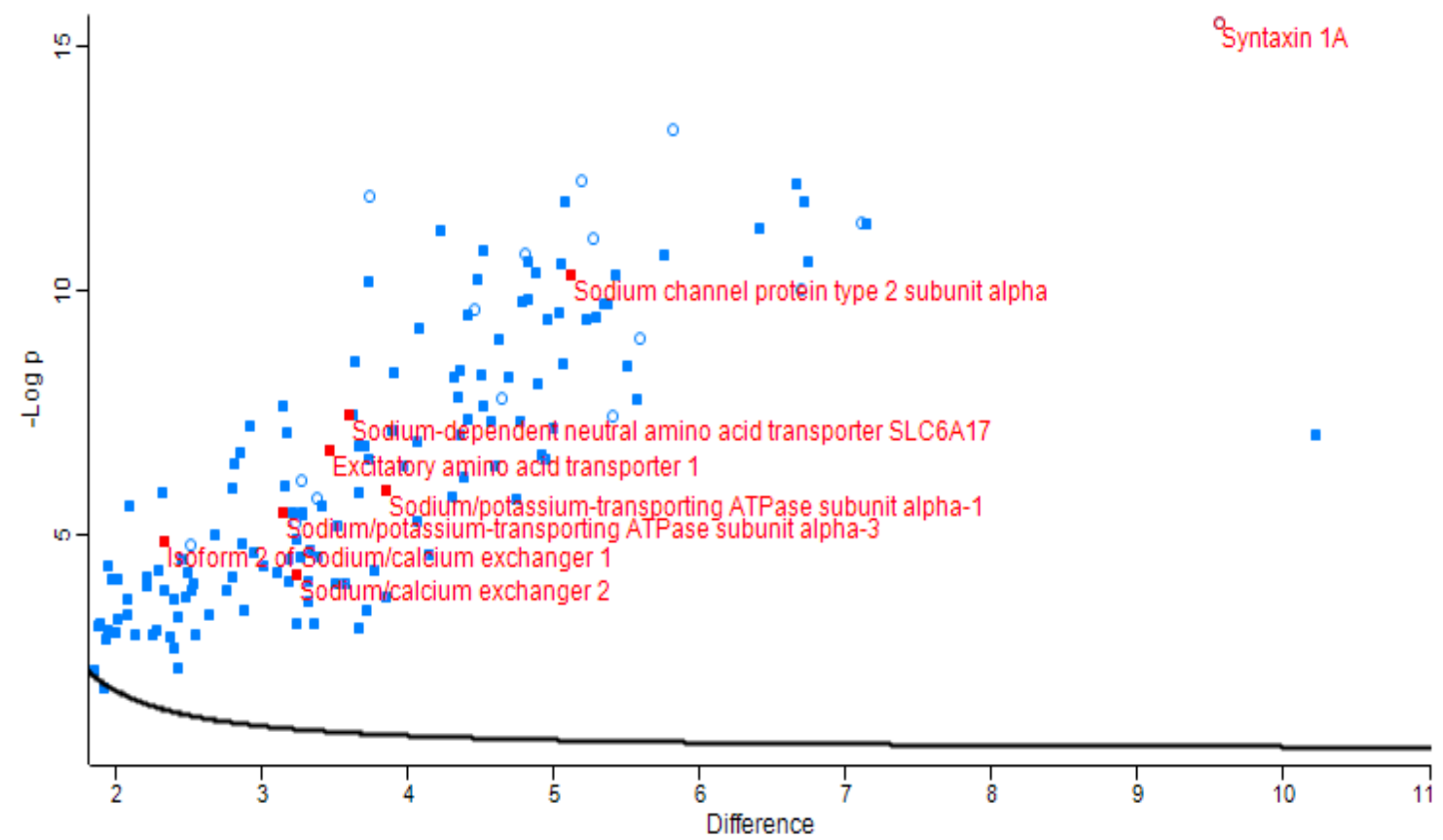

Figure 3.34. Significant and fold-change enriched transporter, channel and receptor proteins in stx 1 IP samples. Some significantly IP-co-purified transmembrane transporter, channel or receptor molecules are indicated in a zoomed right corner of volcano plot (random selection due to representation restrictions). 


\subsection{Adhesion and cell surface molecules}

Among the 158 enriched proteins in the stx 1 IP samples, nine proteins were adhesion and cell surface molecules. The glycoproteins M6a and M6b, involved in neurite outgrowth control [228] and neuronal differentiation [229], were found with low p-values but different fold-change distribution (Figure 3.35 and Table 3.6).

Table 3.6. Adhesion and cell surface proteins identified with high significance and fold-change enrichment in stx 1 IPs. Proteins are listed according to their significance in a decreasing order.

\begin{tabular}{|l|l|l|}
\hline \multicolumn{3}{|c|}{ Adhesion and cell surface molecules } \\
\hline Protein ID & Gene name & \multicolumn{1}{c|}{ Protein name } \\
\hline Q812E9 & Gpm6a & Neuronal membrane glycoprotein M6-a \\
\hline F1LNY3 & Ncam1 & Neural cell adhesion molecule 1 (Fragment) \\
\hline P97846 & Cntnap1 & Contactin-associated protein 1 \\
\hline F1M8G9 & Ncam2 & Protein Ncam2 (Fragment) \\
\hline P97829-2 & Cd47 & Isoform 2 of Leukocyte surface antigen CD47 \\
\hline Q6P9V1 & Cd81 & CD81 antigen \\
\hline Q63198 & Cntn1 & Contactin-1 \\
\hline E9PSV8 & Gpm6b & Neuronal membrane glycoprotein M6-b \\
\hline Q6MFX9 & Mog & Myelin oligodendrocyte glycoprotein \\
\hline
\end{tabular}

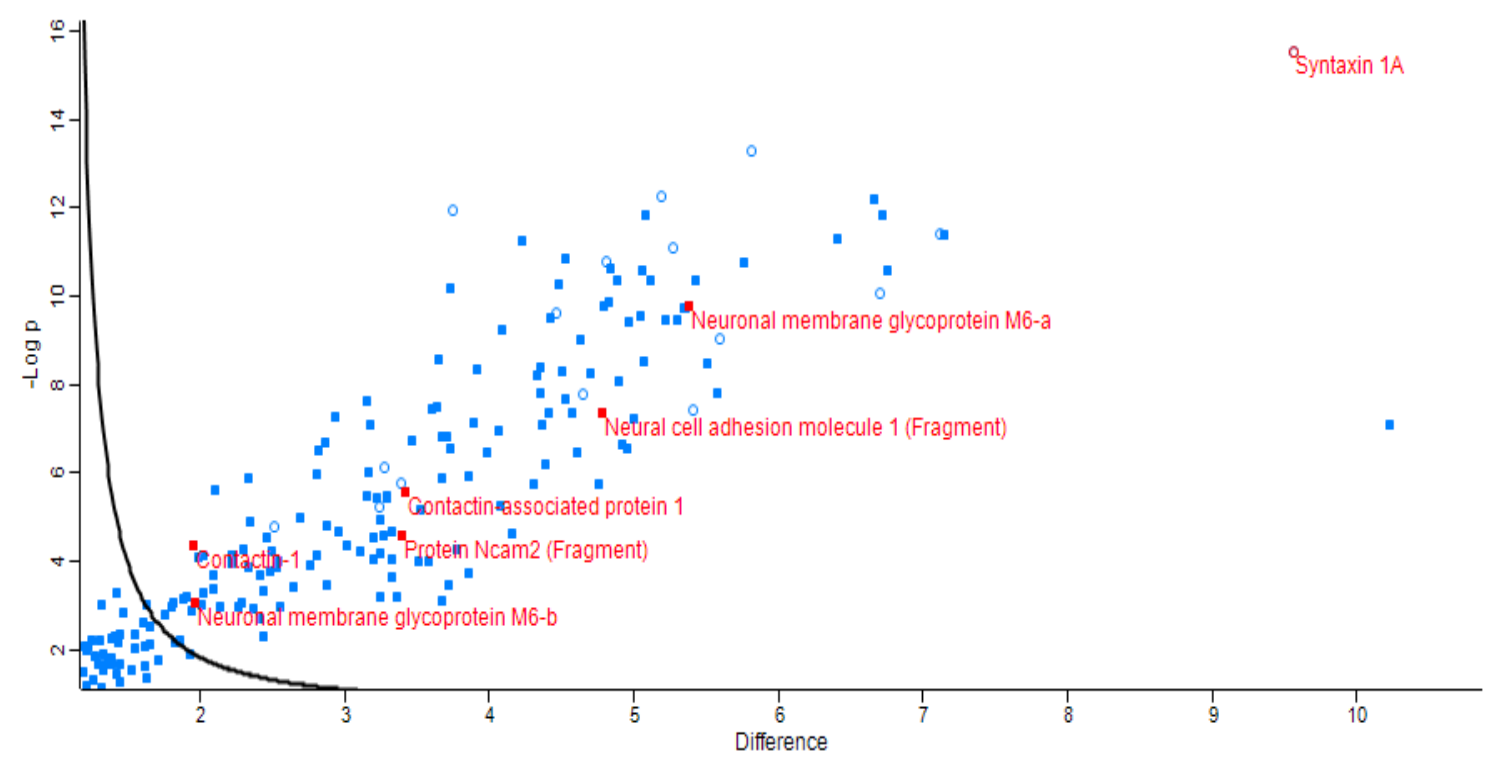

Figure 3.35. Significantly and fold-change enriched cell surface and adhesion proteins in stx 1 IPs. Significantly IP-co-purified synaptic adhesion and surface molecules are indicated in a zoomed right corner of volcano plot (random selection due to representation restrictions). 
CD47, CD81, neuronal cell adhesion molecules (Ncam) isoforms 1 and 2 and myelin glycoprotein were as well among the positive hits (Table 3.6). Cd47 and Cd81 were identified as integrin-interacting partners [230, 231]. Although main portions of the molecules are localized between cells, they usually possess intracellular domains, which could link extracellular signals to intracellular signaling molecules.

\subsection{Hypothetical and less characterized proteins}

Few hypothetical and less characterized proteins were detected among the enriched hits in the IP samples (Table 3.7). These proteins had higher p-values and less ratio foldchange than other identified proteins. They were distributed in proximity to the significance (threshold) curve set by the FDR value (FDR=0.01). Fas apoptotic inhibitory molecule 2 (Faim2) was reported to have neuroprotective role after ischemia [232]. Ttyh1 has a predicted chloride channel function with predominant neuronal expression [233].

Table 3.7. Hypothetical or poorly characterized proteins identified with high significance and foldchange enrichment in the stx 1 IPs. Proteins are listed according to their significance in a decreasing order.

\begin{tabular}{|l|l|l|}
\hline \multicolumn{3}{|c|}{ Hypothetical proteins or proteins with poorly characterized functions } \\
\hline \multicolumn{1}{|c|}{ Protein ID } & \multicolumn{1}{|c|}{ Gene name } & \multicolumn{1}{c|}{ Protein name } \\
\hline D4A7L6 & Rpia & Protein Rpia \\
\hline Q64304 & ILAT & RATLE LLAT protein \\
\hline D4A3N4 & Adcy1 & Adenylate cyclase 1 (Predicted) \\
\hline B4F773 & Ttyh1 & Ttyh1 protein \\
\hline M0R531 & Faim2 & FAIM2 protein \\
\hline
\end{tabular}

\subsection{Others}

Only 7 of the 158 proteins detected over the threshold parameters were assigned as metabolic enzymes or homeostasis regulatory molecules (Table 3.8). Some of them are enzymes with functions in lipid metabolism (acyl carrier protein), glycerol uptake regulation (glycerol kinase). 
Table 3.8. Metabolic proteins identified with high significance and fold-change enrichment in anti-Stx1 immunoprecipitation sample. Proteins are listed according to their significance in a decreasing order.

\begin{tabular}{|c|c|c|}
\hline \multicolumn{3}{|r|}{ Others } \\
\hline $\begin{array}{l}\text { Protein } \\
\text { ID }\end{array}$ & $\begin{array}{c}\text { Gene } \\
\text { name }\end{array}$ & Protein name \\
\hline D3ZF13 & LOC683884 & Acyl carrier protein \\
\hline Q5BJZ3 & Nnt & Nicotinamide nucleotide transhydrogenase \\
\hline P27605 & Hprt1 & Hypoxanthine-guanine phosphoribosyltransferase \\
\hline Q6AY30 & Sccpdh & Saccharopine dehydrogenase-like oxidoreductase \\
\hline D3ZCI0 & Gk & Glycerol kinase \\
\hline P05708 & Hk1 & Hexokinase-1 \\
\hline G3V864 & Lppr4 & Lipid phosphate phosphatase-related protein type 4 \\
\hline
\end{tabular}

In addition to the described proteins, 62 mitochondrial proteins were identified among the 158 positive hits (Appendix 9). Preliminary iBAQ quantification showed that their quantities are minor compared to the abundance of all other proteins identified. These proteins were annotated as NADH dehydrogenase complex components, ATP synthase subunits or Cox proteins. They are with highly hydrophobic character and their binding to the bead matrix and/or Abs are possibly favored under high salt concentrations. However, it should be emphasized that the distribution of these proteins was not random, but rather specific.

\subsubsection{Proteins co-purified with stx 1 under low salt conditions}

The analysis of proteomics data obtained under low salt washing conditions was conducted by applying the same threshold parameters as in the previous experiments (section 3.5.2.1): $\mathrm{FDR}=0.01$ and $\mathrm{SO}=1$.As a result, 275 and 457 proteins passed the threshold line in IP and mock sample, respectively (Appendix 10 and Appendix 11, respectively and Figure 3.36). Comparison of the identified proteins above the threshold line in the IP samples under both conditions showed nearly complete overlap (Figure 3.37). Only three proteins identified under high salt condition were not present among the positive hits in the low salt condition. These proteins were: uncharacterized protein with protein ID D3ZC50 (predicted respiratory chain component in mitochondria); cell cycle control protein 50A and apoptosis inhibitor protein Faim2. The data emphasized clearly 
that large number of unspecific proteins were enriched in the mock sample (457 proteins) under the low salt washing conditions. Not surprisingly, the number of co-purified proteins which were enriched above the threshold margin was increased.

High salt concentrations favored preservation of hydrophobic interactions and helped reducing the unspecific polar and ionic protein binding to beads and Ab. 155 of the proteins which passed the threshold criteria were found in both conditions. Thus, they will not be listed repeatedly in the following section. Only the additional 120 positive hits in the stx 1 IP samples were categorized as in the previous section (see 3.5.2.1) and discussed in more detail below.

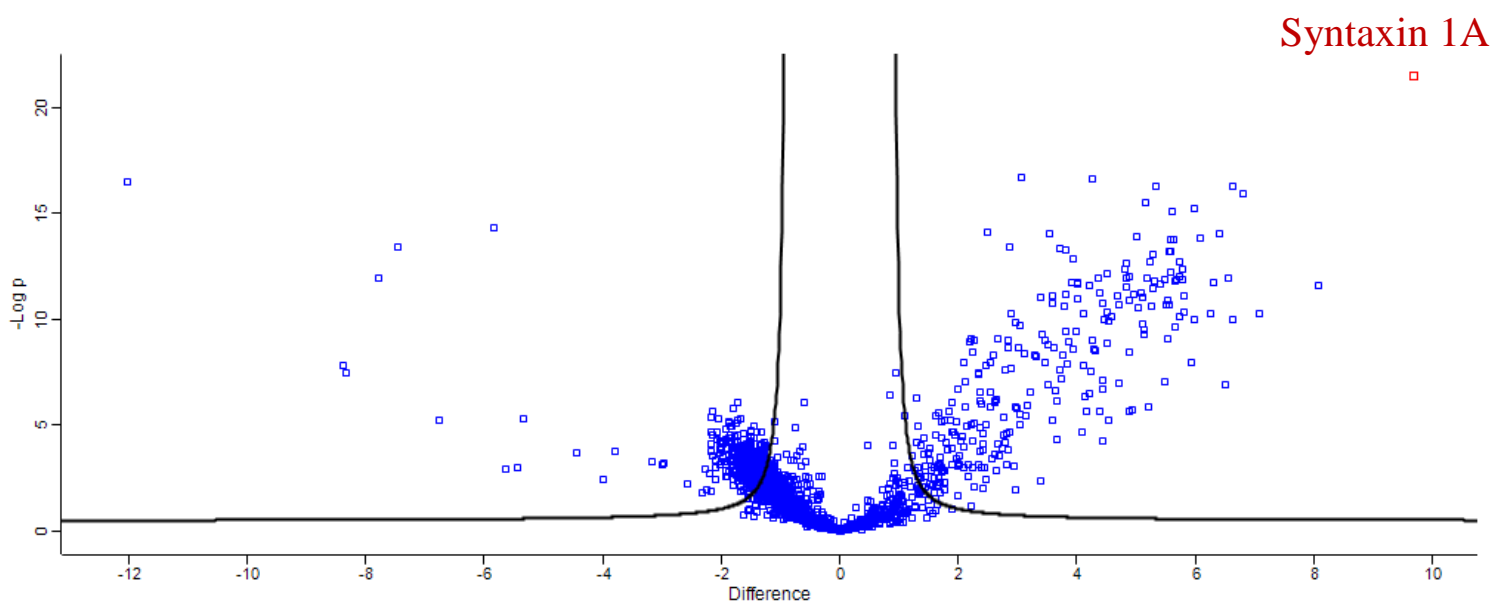

Figure 3.36. Volcano plot representation of results from stx 1 IP with Eupergit C1Z-Cl 78.2 beads under low salt conditions. Logarithmic ratio of protein intensities difference was plotted against negative pvalues from two sample t-test. Identified proteins from all biological and technical replicates were analyzed with LFQ algorithm in MaxQuant and Perseus software. Significantly, enriched proteins in IP (right in the plot) and negative control (left in the plot) are represented as blue squares above the threshold curve. Stx1A showed highest fold enrichment change and lowest p-value among all samples (Stx1 in upper right corner of the plot). 


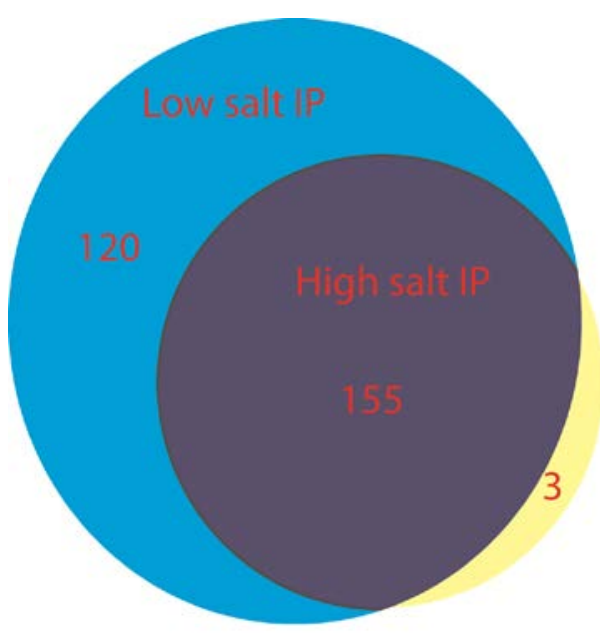

Figure 3.37. Overlap of proteins identified as positive hits under low and high salt IP conditions. Venn diagram was used to represent the overlap of proteins identified above the threshold line in both conditions [234]. Except of three proteins (Faim2; cell cycle control protein 50 (Tmem30A, CDC50A) and uncharacterized protein with protein ID: D3ZC50, predicted respiratory chain constituent), all 155 proteins identified in the high salt condition as positive hits were found as well in the stx 1 IP samples under low salt conditions. In addition, 120 more proteins were found above the threshold curve in the low salt IP condition.

\subsection{Synaptic vesicle proteins}

In total, $31 \mathrm{SV}$ proteins were classified as significantly enriched under low salt conditions in the stx 1 IP samples. In addition to the 26 proteins detected before, five more proteins were found. Four positive hits represented $\mathrm{H}^{+}$transporting ATPase subunits. Synaptogyrin1 was detected among the SV proteins in addition to synaptogyrin-3. Furthermore, synaptogyrin-1 was found among the positive hits. Synaptogyrins are implicated in neutransmission regulation and synaptic vesicle biogenesis in Drosophila [235-238].

Table 3.9. SV proteins additionally identified as significantly enriched under low salt conditions in stx 1 IP samples.

\begin{tabular}{|c|c|c|}
\hline \multicolumn{3}{|r|}{ Synaptic vesicle proteins } \\
\hline $\begin{array}{l}\text { Protein } \\
\text { ID }\end{array}$ & $\begin{array}{l}\text { Gene } \\
\text { name }\end{array}$ & Protein name \\
\hline G3V7L8 & Atp6v1e1 & ATPase, $\mathrm{H}+$ transporting, $\mathrm{V} 1$ subunit $\mathrm{E}$ isoform 1 \\
\hline Q62876 & Syngr1 & Synaptogyrin-1 \\
\hline Q6P503 & Atp6v1d & ATPase, $\mathrm{H}+$ transporting, $\mathrm{V} 1$ subunit $\mathrm{D}$ \\
\hline Q5FVI6 & Atp6v1c1 & V-type proton ATPase subunit C 1 \\
\hline Q5XIL1 & Atp6v1h & ATPase, $\mathrm{H}+$ transporting, lysosomal V1 subunit $\mathrm{H}$ \\
\hline
\end{tabular}




\subsection{SNAREs and trafficking proteins}

When buffer with low salt concentration was used for IP washing, seven additional proteins were found enriched above the threshold line (Table 3.10). Among them were lysosomal syntaxin-8, two isoforms of NSF cofactor: alpha and gamma SNAPs (soluble NSF associated protein) and Vti1a. The VAMP-associated protein was reported to be essential for neurotransmitter release [239, 240] and was detected. In addition, Golgilocalized Sec1p-like protein VPS45 [241] and syntaphilin - syntaxin1 binding protein [242] were identified. Syntaphilin plays an important role in regulation of the neurotransmission process, because it competes with SNAP-25 for stx 1 binding and prevents SNARE complex assembly.

Table 3.10. SNAREs and trafficking proteins additionally identified under low salt conditions in stx 1 IP samples.

\begin{tabular}{|l|l|l|}
\hline \multicolumn{2}{|c|}{ SNAREs and trafficking proteins } \\
\hline $\begin{array}{l}\text { Protein } \\
\text { ID }\end{array}$ & $\begin{array}{l}\text { Gene } \\
\text { name }\end{array}$ & Protein name \\
\hline D4A0E2 & Napg & Protein Napg (gamma SNAP) \\
\hline O08700 & Vps45 & Vacuolar protein sorting-associated protein 45 \\
\hline Q9Z2Q7 & Stx8 & Syntaxin 8 \\
\hline Q9J151 & Vti1a & Vesicle transport through interaction with t-SNAREs homolog 1A \\
\hline B5DF41 & Snph & Syntaphilin \\
\hline Q9Z270 & Vapa & $\begin{array}{l}\text { Vesicle-associated membrane protein-associated protein A (VAMP-associated protein } \\
\text { A) }\end{array}$ \\
\hline P54921 & Napa & alpha SNAP \\
\hline
\end{tabular}

\subsection{Channels, receptors and transporter proteins}

In addition to the 31 receptor, channel and transporter proteins identified when high salt washing buffer was used, 27 proteins passed the threshold criteria when the low salt washing step was applied (Table 3.11). This extended list of total 58 proteins included VGCC of N- and R-type. Identification of the $\alpha$ subunits (here $1 \mathrm{~B}$ and $1 \mathrm{E}$, respectively) allowed precise annotation of the channel type. Stx 1 was reported to interact with VGCC $\mathrm{N}$-type channel by binding to the synprint site of the intracellular $\alpha$ subunit loop between 
membrane domains II and III [243]. Furthermore, further GABA receptor subunits and $\mathrm{GABA}_{\mathrm{B}}$ receptor auxiliary subunit Kctd16 [128] were found as hits. The full list of additionally identified receptors, channels and transporters is presented below (Table 3.11).

The list of integral proteins among the positive hits was longer under low salt conditions. Generally, hydrophobic interactions are stabilized when high salt buffers are used, but salt might also disturb weak protein-protein interactions at high concentrations. It is suggestive that the low salt containing buffer helped preserving such protein-protein interactions, which were lost before.

Table 3.11. Receptors, channels and transporter proteins additionally identified under low salt conditions in stx 1 IP samples.

\begin{tabular}{|c|c|c|}
\hline \multicolumn{3}{|r|}{ Channels, receptors and transporter proteins } \\
\hline Protein ID & $\begin{array}{l}\text { Gene } \\
\text { name }\end{array}$ & Protein name \\
\hline 089089 & Cacna1b & Voltage-dependent N-type calcium channel subunit alpha-1B \\
\hline F1M7K7 & Cacng8 & Voltage-dependent calcium channel gamma subunit \\
\hline D4ACN8 & Plgrkt & Plasminogen receptor $(\mathrm{KT})$ \\
\hline D3ZSU3 & Slc7a14 & L-amino acid transmembrane transporter \\
\hline D3ZW84 & Gabrb3 & Gamma-aminobutyric acid receptor subunit beta-3 \\
\hline P31422 & Grm3 & Metabotropic glutamate receptor 3 \\
\hline Q64568-3 & Atp2b3 & Plasma membrane calcium-transporting ATPase 3 \\
\hline M0R874 & Atp9a & Phospholipid-transporting ATPase \\
\hline Q76GL9 & Slc1a4 & Amino acid transporter \\
\hline Q9WUD2 & Trpv2 & Transient receptor potential cation channel subfamily $\vee$ member 2 \\
\hline P31647 & Slc6a11 & Sodium- and chloride-dependent GABA transporter 3 \\
\hline Q64542-3 & Atp2b4 & Plasma membrane calcium-transporting ATPase 4 \\
\hline P62813 & Gabra1 & Gamma-aminobutyric acid receptor subunit alpha-1 \\
\hline F1LMS1 & Cacna1e & Voltage-dependent R-type calcium channel subunit alpha-1E \\
\hline 054701 & Slc24a2 & Sodium/potassium/calcium exchanger 2 \\
\hline 088871 & Gabbr2 & Gamma-aminobutyric acid type B receptor subunit 2 \\
\hline F1M1G5 & Kctd16 & Protein Kctd16 \\
\hline P11505-4 & Atp2b1 & Plasma membrane calcium-transporting ATPase 1 \\
\hline F1LSG1 & Kcnt1 & Potassium channel subfamily T member 1 \\
\hline F1LPF3 & Slc44a1 & Choline transporter-like protein 1 \\
\hline P30191 & Gabra6 & Gamma-aminobutyric acid receptor subunit alpha- 6 \\
\hline P31423 & Grm4 & Metabotropic glutamate receptor 4 \\
\hline F1LSY2 & Nptxr & Neuronal pentraxin receptor \\
\hline G3V986 & Kcnd2 & Potassium voltage gated channel, Shal-related family, member 2 \\
\hline Q9JHZ9 & Slc38a3 & Sodium-coupled neutral amino acid transporter 3 \\
\hline P11507-2 & Atp2a2 & Sarcoplasmic/endoplasmic reticulum calcium ATPase 2 \\
\hline F1M6X3 & Kcnq2 & Potassium voltage-gated channel subfamily KQT member 2 \\
\hline
\end{tabular}




\subsection{Cell surface and adhesion molecules}

In total 14 cell adhesion and surface proteins passed the threshold criteria set for the data analysis, and 5 of them were only found at low salt concentrations (Table 3.12). Initially identified as hepatocyte adhesion, Hepacam, is predominantly expressed on glial cells [244]. Sirpa's detection failed under high salt conditions but was present when low salt washing buffer was used. Sirpa is immunoglobulin-like cell surface receptor for Cd47, which was also detected in both conditions. The interaction of latter two was reported to influence presynaptic patterning and organization [245].

Table 3.12. Cell surface and adhesion proteins additionally identified under low salt conditions in stx 1 IP samples.

\begin{tabular}{|l|l|l|}
\hline \multicolumn{2}{|c|}{ Cell adhesion and surface molecules } \\
\hline $\begin{array}{l}\text { Protein } \\
\text { ID }\end{array}$ & $\begin{array}{l}\text { Gene } \\
\text { name }\end{array}$ & Protein name \\
\hline P35565 & Canx & Calnexin \\
\hline P97710 & Sirpa & Tyrosine-protein phosphatase non-receptor type substrate 1 \\
\hline D3ZEI4 & Hepacam & Hepacam \\
\hline P08050 & Gja1 & Gap junction alpha-1 protein \\
\hline Q5XIN0 & Cldnd1 & Claudin domain containing 1 \\
\hline
\end{tabular}

\subsection{Cytoskeleton proteins}

Only three cytoskeleton proteins were identified: myosin 5a, Myo5a; septin 5 and septin 8. Interestingly, among the myosin isoforms, myosin 5 was reported to interact with stx $1 \mathrm{~A}$ in a $\mathrm{Ca}^{2+}$ dependent manner [246]. Furthermore, septin 5 is known bind to stx 1containing SNARE complex at the presynaptic AZ [247].

\subsection{Hypothetical and less characterized proteins}

When high salt washing was applied to the stx 1 IP samples, only five proteins were detected in this category among the significant hits in the volcano plot. This list was extended by ten additional proteins, identified only when low salt concentration was used for sample washing (Table 3.13). 
Table 3.13. Hypothetical or poorly characterized proteins identified with high significance and foldchange enrichment in stx 1 IP samples under low salt conditions.

\begin{tabular}{|l|l|l|}
\hline \multicolumn{3}{|c|}{ Hypothetical proteins and proteins with poorly characterized functions } \\
\hline $\begin{array}{l}\text { Protein } \\
\text { ID }\end{array}$ & $\begin{array}{l}\text { Gene } \\
\text { name }\end{array}$ & Protein name \\
\hline D4A8V2 & Ccdc177 & Protein Ccdc177 \\
\hline G3V881 & Lingo1 & Leucine rich repeat neuronal 6A \\
\hline D3ZSD8 & Tmem143 & Protein Tmem143 \\
\hline F1M8Y2 & Tspan7 & Tetraspanin \\
\hline D3ZWQ0 & Prrt3 & Protein Prrt3 \\
\hline D4A5X7 & Gdap1 & Ganglioside-induced differentiation-associated-protein 1 (Predicted) \\
\hline Q6MG82 & Prrt & Proline-rich transmembrane protein 1 \\
\hline D3ZFB6 & Prrt2 & Proline-rich transmembrane protein 2 \\
\hline M0R5F9 & M0R5F9 & Uncharacterized \\
\hline D4A249 & Mblac2 & Similar to metallo-beta-lactamase superfamily protein like (XL884) (Predicted) \\
\hline
\end{tabular}

\subsection{Others}

22 proteins involved in regulation of synaptic intracellular homeostasis and metabolic processes were detected (Table 3.14) in addition to the seven proteins from the same group identified before (see Table 3.8). Interestingly, pentraxins were detected in addition to the above mention pentraxin receptor (see Table 3.11). These proteins were suggested to function as novel neuronal uptake pathway involved in synaptic remodeling and function [248, 249]. 
Table 3.14. Metabolic proteins additionally identified under low salt conditions in stx 1 IP samples.

\begin{tabular}{|c|c|c|}
\hline \multicolumn{3}{|r|}{ Signaling proteins, enzymes and regulatory molecules } \\
\hline $\begin{array}{l}\text { Protein } \\
\text { ID }\end{array}$ & $\begin{array}{l}\text { Gene } \\
\text { name }\end{array}$ & Protein name \\
\hline Q6IMX4 & Ppap2b & Lipid phosphate phosphohydrolase 3 \\
\hline P47971 & Nptx1 & Neuronal pentraxin-1 \\
\hline Q9Z0V5 & Prdx4 & Peroxiredoxin-4 \\
\hline P62161 & Calm1 & Calmodulin \\
\hline Q765A7 & Pgap1 & GPI inositol-deacylase \\
\hline Q5YLM1 & Dagla & Sn1-specific diacylglycerol lipase alpha \\
\hline P07153 & Rpn1 & Dolichyl-diphosphooligosaccharide--protein glycosyltransferase subunit 1 \\
\hline D4ADS4 & Mgst3 & Microsomal glutathione S-transferase 3 \\
\hline Q2THW7 & Zdhhc5 & Palmitoyltransferase ZDHHC5 \\
\hline F1LRE1 & Gsr & Glutathione reductase \\
\hline Q52KJ9 & Tmx1 & Tmx1 \\
\hline D4A5W8 & Pgs1 & Similar to phosphatidylglycerophosphate synthase (Predicted) \\
\hline Q6AXS4 & Atp6ap2 & Renin receptor \\
\hline B5DEN4 & Ldha & L-lactate dehydrogenase \\
\hline Q04400 & Adcy5 & Adenylate cyclase type 5 \\
\hline P61023 & Chp1 & Calcineurin B homologous protein 1 \\
\hline F1LSY2 & Nptxr & Neuronal pentraxin receptor \\
\hline Q6IU14 & Acsl6 & Long-chain-fatty-acid--CoA ligase 6 \\
\hline B3SVE9 & Tecr & Neuroprotective protein 13 \\
\hline Q6AXX6 & Fam213a & Redox-regulatory protein FAM213A \\
\hline E9PSKO & Man2b2 & Alpha-mannosidase 2 \\
\hline P35704 & $\operatorname{Prd} \times 2$ & Peroxiredoxin-2 \\
\hline
\end{tabular}

In addition to the proteins described above, 38 of the 120 additionally identified proteins at low salt concentration were assigned manually as mitochondrial, ribosomal or nuclear pore-associated and are listed in Appendix 12.

In summary, the stx 1 immunoprecipitations under two conditions resulted in the co-purification of a broad spectrum of proteins. These proteins were manually sorted into seven groups according to their biological functions and cellular distribution: SV proteins, SNAREs and trafficking proteins; channels, receptors and transporter proteins; adhesion and cell surface molecules; metabolic proteins; cytoskeleton proteins and hypothetical/poorly characterized proteins. Although mitochondrial proteins were present among the positive hits, their distribution was not random and they included mainly the respiratory chain components. Apart from this fact, the identified channels, receptors, transporter molecules as well as SNAREs, trafficking and SV proteins represented the majority of the proteins. Some of the proteins were known interacting partners of stx 1 , however the explanation for the co-purification profile of others remains elusive. 
Importantly, the number of identified membrane proteins affirmed the potential of the extraction and isolation protocols and increased when a low salt washing condition was used. 


\section{Discussion and conclusions}

The cytomatrix at the active zone and its associated proteins are in main focus of research for neurobiologists and biochemists. The AZ structure represents a great experimental challenge since the core $\mathrm{AZ}$ constituents and their protein assemblies often fail in non-denaturing detergent-based isolation trials. The knowledge about the protein constituents of the synapse has grown due to development of sensitive mass spectrometry techniques and lowering the detection limits for novel protein discovery. Recent reports from our lab combined biochemical fractionations with quantitative mass spectrometry and revealed the protein constituents of SVs and the differences between excitatory and inhibitory release sites $[133,146]$. These findings together with the results of others $[203$, 250] advanced our knowledge on the organization and regulation of neurotransmission. However, revealing the protein composition of synaptic membranes and characterization of native protein membrane complexes remains elusive. Poor extractability or harsh solubilization conditions restrain the isolation of protein-protein interactions. Moreover, successful solubilization of a transmembrane protein does not equal preservation of its native interactions. Nonetheless, in recent years few reports pioneered the synaptic biochemistry field by identifying protein complexes within the synaptic membranes [121, 125-129, 134, 135, 164].

Main challenge in the development of the novel systematic protocol for protein extraction represented the centrifugation step after membrane solubilization. The solubilization process depends on the internal properties of the detergent as well as on the detergent:lipid:protein ratio [169, 170]. Practically, the degree of solubilization can be determined only by the use of further techniques like turbidity measurements and/or electron microscopy [95]. Usually, in daily biochemical work, the solubilization properties of a detergent are assessed by the presence or absence of a target protein in the supernatant after the centrifugation step. Importantly, the parameter influencing the outcome of this step is the pelleting efficiency of the centrifugation, which is determined by the centrifugation time, applied $g$ force and the $k$ factor of the rotor. It should be also considered that this step clears the suspension not only from detergent insoluble membrane remaining, but it could also remove large protein complexes from the supernatant by pelleting them. Therefore, we addressed this problem quantitatively by calculating the maximal sedimentation coefficient $S_{\text {coeff,max }}=227$ of protein-lipid-detergent particles 
remaining in the supernatant after centrifugation. Recently, Müller and co-workers reported that centrifugation steps, pelleting extracted protein complexes with $S_{\text {coeff,max }}>300$ might reduce the number of co-immunopurified proteins. This observation was valid for the affinity purifications of presynaptic $\mathrm{Ca}^{2+}$ channels and the max. S coefficient value was set considering the molecular weight and size of other intracellular membranous and nonmembranous particles [135]. In order to ensure complete removal of insolubilized (intact) membranes in our protocol, we used a harsher centrifugation step and probed the resulting supernatant for proteins associated with the presynaptic protein network or the postsynaptic density. Herewith, we report for first time the successful extraction of the large scaffolding proteins Bassoon and Piccolo using three different detergents - TDOC, cholate and DDM. Furthermore, we were able to extract, completely or partially, all core AZ constituents, scaffolding proteins as well as ion channels and receptors. However, this applied also to mitochondrial proteins, which are discussed below. Many presynaptic CAZ-associated proteins were well extracted in nearly all tested detergents with some minor exceptions (e.g. CHAPS, CHAPSO). Remarkable result was the successful extraction of hydrophobic proteins like ELKS, liprins, Munc13 and Mint1, which are difficult to solubilize and often missed in proteomic studies [146, 163, 203]. Our results also showed that presynaptic proteins are better extractable than the ones associated with the PSD. Interestingly, postsynaptic proteins showed more differentiated extraction profile than the CAZ proteins.

The extracted proteins were subjected to separation using two different techniques linear gradient centrifugation and size exclusion chromatography. These techniques were successfully used earlier for separation of solubilized crude SV fraction (i.e. LP2 fraction) $[159,174,176]$. In contrast to the published results, we observed poor separation of the extracted proteins by density gradient centrifugation. Due to the complexity of the extracts and the low amount of material that can be loaded on a gradient, further gradient experiments were omitted. However, better separation was achieved by SEC. Interestingly, when SEC was applied, similarity in the elution profiles of the protein was observed disregarding the detergent used. This suggests non-random, specific extraction of proteins possibly with preservation of their protein-protein interactions to some extent as discussed in sections 3.2 and 3.3. However, the co-elution profile of the immunodetected proteins does not necessary indicates intact protein-protein complex assemblies. There is a possibility that the proteins co-elute in the same fractions without complex formation. This question could be addressed by immunopurifications, followed by peptide elution and 
separation of eluted protein complexes via BN-PAGE. In addition, native mass spectrometry, a newly developed technique for separation of intact membrane protein complexes could be used [251]. Recently, the preservation of detergent-extracted protein complexes during native MS measurement was also confirmed theoretically by molecular dynamics simulations [252]. In addition, detergent solubilization and biochemical fractionation followed by AP-MS could be performed in combination with mild chemical cross-linking to stabilize protein interactions or to probe for stoichiometrical changes in the protein complexes [253, 254]. The use of chemical short length cross-linkers prior to membrane solubilization would rule out possible artefacts, which are introduced by the use of detergent. In other words, it is possible that the added detergent first extracts larger portion of the membrane lipids causing an artificial clustering of membrane proteins. More importantly, the existence of such an artefact would lead to co-immunoisolation of proteins, which are not interacting under native conditions.

In order to validate that our protocol not only enables extraction of integral proteins but also preserves their protein-protein interactions, we focused on the analysis of stx 1 coimmunopurified proteins. Here, for first time we use a reported affinity matrix (nonporous epoxy-beads Euprgit C1Z coupled with anti-stx1 Ab (Cl78.2)) [144] for the affinity purification of detergent-extracted proteins and their protein interactions. Importantly, the choice of affinity matrix is crucial because it affects the binding degree of targetnonspecific proteins $[114,134]$.

A positive extraction profile for the presynaptic CAZ-associated proteins was observed when cholate was used. At the same time, cholate did not extract many of the postsynaptic proteins, which were not in the focus of our study. Successful immuneenrichment of stx 1 in cholate, in combination with the newly adopted protocol for onbeads-proteolysis yielded better protein coverage than the follow of the classical in-gel digestion protocol. In total 1852 proteins were co-purified with stx 1 . The tandem use of LFQ AP-MS proteomics and volcano plots for data analysis and representation $[137,197]$ excluded significant number of nonspecifically bound proteins. Up to date, volcano plots were successfully used for identification of novel and known proteins associated with chromatin or anaphase-promoting complexes [136, 137]. Thus, for first time we report the application of the method for analysis of membrane protein co-immunoprecipitates. Out of 1852, 158 proteins passed the adopted threshold criteria $(\mathrm{SO}=1, \mathrm{FDR}=0.01)$ under the high-stringency co-IP condition (high salt washing step). First noteworthy observation was 
the reproducibility of the data among the five biological replicates. Highest enrichment and lowest p-value in the volcano plot showed stx 1 . This result confirmed successful immunoprecipitation of the target protein in all experiments. Over 95\% of the proteins above the threshold margin were integral proteins. This result was remarkable compared to the published data from the VGCC proteome study, in which only $40 \%$ of the identified 207 proteins were integral or membrane-associated [135]. This result affirmed efficient membrane solubilization, protein extraction upon preservation of protein-protein interactions as well as successful tryptic digestion by the novel protocol. Most of the identified proteins belonged to three protein groups: mitochondrial, synaptic vesicle and transporters/receptors/channel proteins. The presence of mitochondrial proteins was not surprising since they are common contamination in proteomic studies due to their high abundance and "stickiness" [114, 255]. Interestingly, the distribution of the mitochondrial proteins was not random, but rather specific. They exclusively belonged to the respiratory chain complex embedded in the inner mitochondrial membrane. Remarkably, no ribosomal, nuclear or heat shock proteins as well as only one myelin protein were detected among the positive hits when high salt washing steps were used. Only 7 proteins ( $\sim 4 \%$ of the positive hits) were metabolic enzymes.

The two following largest groups of proteins were SV proteins and presynaptic plasma membrane proteins (transporters, channels and receptors). The high abundance of SV proteins could be explained by that the presence of our target protein stx 1 on SVs, therefore its association with some vesicle proteins could be presumed [133]. Among the detected SNAREs, trafficking molecules and channels were many known protein interaction partners of stx 1. This suggested possible association of stx 1 in protein complexes with different compositions. These complexes might be involved in intracellular trafficking or in regulation of neurotransmission at different spatial and temporal points. Some of these protein-protein assemblies are discussed here. Stx 1 is a main component of the exocytotic machinery and forms a SNARE complex with two other proteins, SNAP-25 and syb 2, which were as well significantly enriched in our samples [174]. Interestingly, two isoforms of SNAP-25 were detected, suggesting participation of stx 1 in developmentally and functionally distinct SNARE complexes [256]. Also VGAT was identified among our hits. This finding was a further example of a preserved direct binding: VGAT and stx 1A were shown to interact [257] and syntaxin's binding to VGAT inhibits GABA uptake in hippocampal neurons. This interaction suggests a link between the neurotransmitter release and uptake machinery. Significantly enriched proteins with 
less characterized functions were also repeatedly found in our samples: e.g. SV31 protein, synaptogyrin 1 and 3, SV2A/B and Scamp protein isoforms. SV31 is a recently discovered SV protein, that was reported to co-localize with stx 1A and SNAP-25 in PC12 cells [201, 202] whereas syngr-3 co-localizes with syb 2, stx 1 and VGLUT1 [200]. Since VGLUT1 has no reported interaction with stx 1 , it could be speculated that the proteins are linked together in a multimeric complex formed at syngr-3. These complexes might indicate a role of syntaxin for linking the fusion machinery at the AZ with the neurotransmitter uptake in SVs. Moreover, specific stx 1 interacting proteins like syt-1 [160], stxbp5 (tomosyn) [204], stxbp6 (amysin) [205] and sec22b [206] were also detected above our threshold margin in both conditions. Interestingly, stxbp1 (Munc-18) was not identified in our IP samples. This could be due to binding of tomosyn to stx 1which causes dissociation of the bound Munc-18 protein [204, 258]. Well preserved interactions of stx 1 only at low salt concentration included syntaphilin [242], VGCCs of N- and R-type [243] and the cytoskeleton proteins myosin5a [246] and septin 5 [247]. Syntaphilin's association with stx 1A is phosphorylation dependent [259] and is possible that it was disrupted by high salt. Similarly, weak or polar interactions with ion channels might be lost during high salt washing procedures and were detectable only at low salt concentrations. As described, some of the identified proteins are direct binding partners of stx 1 , whereas others might suggest a role in trafficking or intracellular ion and $\mathrm{pH}$ homeostasis. This idea is supported by the long list of identified voltage-gated channels, transporters as well receptors (e.g. presynaptic metabotropic glutamate receptors [260]). This list was extended when low salt washing buffer was used.

A noteworthy remark is the excellent overlap of the results from the high-stringency condition with the ones obtained under the low salt IP conditions. Only three proteins identified under the high salt condition were not detected when low salt washings were used: antiapoptotic protein Faim2 (lifeguard 2) [261, 262], cell cycle control protein 50 (Tmem30A, CDC50A) and an uncharacterized protein with predicted electron chain association. Under low-stringency conditions, more proteins passed the threshold filtering criteria: in total 255. They included also more members of the receptor/transporter/channel protein group. These proteins were lost during the high salt washing step probably due to weak association with the immunopurified target, low number of protein complexes with participation of stx 1, inefficient digestion or missed detection. As presumed and indicated in the results section, also the number of mitochiondrial proteins under these conditions was significantly increased. It is worth mentioning that only 15 proteins were significantly 
enriched in the mock sample under the high-stringency conditions. . As comparison, more than 200 proteins were above the threshold line in the low salt IP experiments. These results emphasize the potential of our extraction, immunopurification and on-beadsdigestion protocols for specific enrichment and identification of great number of membrane proteins.

In summary, the successful application of the adopted protocols relies on few critical points. First, the selection of detergent, which efficiently extracts the membrane proteins of interest, is crucial. This experimental challenge can be addressed only empirically. Second, the choice of pre-centrifugation conditions after solubilization affects the amount of extracted proteins remaining in the supernatant. It should be kept in mind, that this step aims not only on removing insoluble membrane remaining but it could also clear the supernatant from high molecular protein complexes of interest. Thus, the centrifugation step should be chosen with pre-caution and must be validated experimentally. Third, the combination of label-free quantitative proteomics with sophisticated data analysis is crucial for identification of true positive hits in the immunoisolation experiments. However, this does not rule out the verification of the obtained results by other biochemical or biophysical techniques like asymmetric field-flow fractionation, mutation and binding studies.

The consideration of these points allows high enrichment and identification of membrane proteins upon preservation of their native protein-protein interactions. Furthermore, the established methodology can be used for the study of other presynaptic membrane proteins or core AZ constituents. Finally yet importantly, the systematic evaluation of the experimental parameters pointed out critical variables in the protocol. Their fine adjustment would allow the use of our protocol for the study of other membrane proteins and their interacting partners. 


\section{Bibliography}

1. Bennett, M.V., Seeing is relieving: electrical synapses between visualized neurons. Nat Neurosci, 2000. 3(1): p. 7-9.

2. Gibson, J.R., M. Beierlein, and B.W. Connors, Two networks of electrically coupled inhibitory neurons in neocortex. Nature, 1999. 402(6757): p. 75-9.

3. Galarreta, M. and S. Hestrin, A network of fast-spiking cells in the neocortex connected by electrical synapses. Nature, 1999. 402(6757): p. 72-5.

4. Jahn, R., Principles of exocytosis and membrane fusion. Ann N Y Acad Sci, 2004. 1014: p. 170-8.

5. Jahn, R. and D. Fasshauer, Molecular machines governing exocytosis of synaptic vesicles. Nature, 2012. 490(7419): p. 201-7.

6. Gray, E.G., Electron microscopy of presynaptic organelles of the spinal cord. J Anat, 1963. 97: p. 101-6.

7. Gray, E.G., Electron microscopy of synaptic contacts on dendrite spines of the cerebral cortex. Nature, 1959. 183(4675): p. 1592-3.

8. Couteaux, R. and M. Pecot-Dechavassine, [Synaptic vesicles and pouches at the level of "active zones" of the neuromuscular junction]. C R Acad Sci Hebd Seances Acad Sci D, 1970. 271(25): p. 2346-9.

9. Dresbach, T., et al., The presynaptic cytomatrix of brain synapses. Cell Mol Life Sci, 2001. 58(1): p. 94-116.

10. Phillips, G.R., et al., The presynaptic particle web: ultrastructure, composition, dissolution, and reconstitution. Neuron, 2001. 32(1): p. 63-77.

11. Kaeser, P.S., et al., RIM proteins tether Ca2+ channels to presynaptic active zones via a direct PDZ-domain interaction. Cell, 2011. 144(2): p. 282-95.

12. Pfenninger, K., et al., The fine structure of freeze-fractured presynaptic membranes. J Neurocytol, 1972. 1(2): p. 129-49.

13. Limbach, C., et al., Molecular in situ topology of Aczonin/Piccolo and associated proteins at the mammalian neurotransmitter release site. Proc Natl Acad Sci U S A, 2011. 108(31): p. E392-401.

14. Fernandez-Busnadiego, R., et al., Quantitative analysis of the native presynaptic cytomatrix by cryoelectron tomography. J Cell Biol, 2010. 188(1): p. 145-56.

15. Landis, D.M., et al., The organization of cytoplasm at the presynaptic active zone of a central nervous system synapse. Neuron, 1988. 1(3): p. 201-9.

16. Sudhof, T.C., The presynaptic active zone. Neuron, 2012. 75(1): p. 11-25.

17. Imig, C., et al., The morphological and molecular nature of synaptic vesicle priming at presynaptic active zones. Neuron, 2014. 84(2): p. 416-31.

18. Lang, T. and R. Jahn, Core proteins of the secretory machinery. Handb Exp Pharmacol, 2008(184): p. 107-27.

19. Milovanovic, D. and R. Jahn, Organization and dynamics of SNARE proteins in the presynaptic membrane. Front Physiol, 2015. 6: p. 89.

20. Garcia, E.P., et al., rbSec1A and B colocalize with syntaxin 1 and SNAP-25 throughout the axon, but are not in a stable complex with syntaxin. J Cell Biol, 1995. 129(1): p. 105-20.

21. Wang, Y., et al., Rim is a putative Rab3 effector in regulating synaptic-vesicle fusion. Nature, 1997. 388(6642): p. 593-8.

22. Wang, Y. and T.C. Sudhof, Genomic definition of RIM proteins: evolutionary amplification of a family of synaptic regulatory proteins. Genomics, 2003. 81(2): p. 126-37.

23. Kaeser, P.S., et al., RIM1alpha and RIM1beta are synthesized from distinct promoters of the RIM1 gene to mediate differential but overlapping synaptic functions. J Neurosci, 2008. 28(50): p. 13435-47. 
24. Wang, Y., S. Sugita, and T.C. Sudhof, The RIM/NIM family of neuronal C2 domain proteins. Interactions with Rab3 and a new class of Src homology 3 domain proteins. J Biol Chem, 2000. 275(26): p. 20033-44.

25. Gracheva, E.O., et al., Direct interactions between C. elegans RAB-3 and Rim provide a mechanism to target vesicles to the presynaptic density. Neurosci Lett, 2008. 444(2): p. 137-42.

26. Han, Y., et al., RIM determines $\mathrm{Ca}(2)+$ channel density and vesicle docking at the presynaptic active zone. Neuron, 2011. 69(2): p. 304-16.

27. Stigloher, C., et al., The presynaptic dense projection of the Caenorhabditis elegans cholinergic neuromuscular junction localizes synaptic vesicles at the active zone through SYD-2/liprin and UNC-10/RIM-dependent interactions. J Neurosci, 2011. 31(12): p. 438896.

28. Schoch, S., et al., RIM1alpha forms a protein scaffold for regulating neurotransmitter release at the active zone. Nature, 2002. 415(6869): p. 321-6.

29. Deng, L., et al., RIM proteins activate vesicle priming by reversing autoinhibitory homodimerization of Munc13. Neuron, 2011. 69(2): p. 317-31.

30. Koushika, S.P., et al., A post-docking role for active zone protein Rim. Nat Neurosci, 2001. 4(10): p. 997-1005.

31. Calakos, N., et al., Multiple roles for the active zone protein RIM1alpha in late stages of neurotransmitter release. Neuron, 2004. 42(6): p. 889-96.

32. Castillo, P.E., et al., RIM1alpha is required for presynaptic long-term potentiation. Nature, 2002. 415(6869): p. 327-30.

33. Betz, A., et al., Functional interaction of the active zone proteins Munc13-1 and RIM1 in synaptic vesicle priming. Neuron, 2001. 30(1): p. 183-96.

34. Lu, J., et al., Structural basis for a Munc13-1 homodimer to Munc13-1/RIM heterodimer switch. PLoS Biol, 2006. 4(7): p. e192.

35. Dulubova, I., et al., A Munc13/RIM/Rab3 tripartite complex: from priming to plasticity? EMBO J, 2005. 24(16): p. 2839-50.

36. Fukuda, M., Distinct Rab binding specificity of Rim1, Rim2, rabphilin, and Noc2. Identification of a critical determinant of Rab3A/Rab27A recognition by Rim2. J Biol Chem, 2003. 278(17): p. 15373-80.

37. Ohtsuka, T., et al., Cast: a novel protein of the cytomatrix at the active zone of synapses that forms a ternary complex with RIM1 and munc13-1. J Cell Biol, 2002. 158(3): p. 57790 .

38. Saksela, K. and P. Permi, SH3 domain ligand binding: What's the consensus and where's the specificity? FEBS Lett, 2012. 586(17): p. 2609-14.

39. Coppola, T., et al., Direct interaction of the Rab3 effector RIM with Ca2+ channels, SNAP25, and synaptotagmin. J Biol Chem, 2001. 276(35): p. 32756-62.

40. Brenner, S., The genetics of Caenorhabditis elegans. Genetics, 1974. 77(1): p. 71-94.

41. Augustin, I., et al., Munc13-1 is essential for fusion competence of glutamatergic synaptic vesicles. Nature, 1999. 400(6743): p. 457-61.

42. Brose, N., et al., Mammalian homologues of Caenorhabditis elegans unc-13 gene define novel family of C2-domain proteins. J Biol Chem, 1995. 270(42): p. 25273-80.

43. Koch, H., K. Hofmann, and N. Brose, Definition of Munc13-homology-domains and characterization of a novel ubiquitously expressed Munc13 isoform. Biochem J, 2000. 349(Pt 1): p. 247-53.

44. Basu, J., et al., A minimal domain responsible for Munc13 activity. Nat Struct Mol Biol, 2005. 12(11): p. 1017-8.

45. Stevens, D.R., et al., Identification of the minimal protein domain required for priming activity of Munc13-1. Curr Biol, 2005. 15(24): p. 2243-8.

46. Ma, C., et al., Munc13 mediates the transition from the closed syntaxin-Munc18 complex to the SNARE complex. Nat Struct Mol Biol, 2011. 18(5): p. 542-9. 
47. Junge, H.J., et al., Calmodulin and Munc13 form a Ca2+ sensor/effector complex that controls short-term synaptic plasticity. Cell, 2004. 118(3): p. 389-401.

48. Sakaguchi, G., et al., A novel brain-specific isoform of beta spectrin: isolation and its interaction with Munc13. Biochem Biophys Res Commun, 1998. 248(3): p. 846-51.

49. Betz, A., et al., Direct interaction of the rat unc-13 homologue Munc13-1 with the $N$ terminus of syntaxin. J Biol Chem, 1997. 272(4): p. 2520-6.

50. Orita, S., et al., Physical and functional interactions of Doc2 and Munc13 in Ca2+dependent exocytotic machinery. J Biol Chem, 1997. 272(26): p. 16081-4.

51. Serra-Pages, C., et al., The LAR transmembrane protein tyrosine phosphatase and a coiledcoil LAR-interacting protein co-localize at focal adhesions. EMBO J, 1995. 14(12): p. 282738.

52. Serra-Pages, C., et al., Liprins, a family of LAR transmembrane protein-tyrosine phosphatase-interacting proteins. J Biol Chem, 1998. 273(25): p. 15611-20.

53. Zhen, M. and Y. Jin, The liprin protein SYD-2 regulates the differentiation of presynaptic termini in C. elegans. Nature, 1999. 401(6751): p. 371-5.

54. Kaufmann, N., et al., Drosophila liprin-alpha and the receptor phosphatase Dlar control synapse morphogenesis. Neuron, 2002. 34(1): p. 27-38.

55. Taru, H. and Y. Jin, The Liprin homology domain is essential for the homomeric interaction of SYD-2/Liprin-alpha protein in presynaptic assembly. J Neurosci, 2011. 31(45): p. 162618.

56. Dai, Y., et al., SYD-2 Liprin-alpha organizes presynaptic active zone formation through ELKS. Nat Neurosci, 2006. 9(12): p. 1479-87.

57. Ko, J., et al., Interaction of the ERC family of RIM-binding proteins with the liprin-alpha family of multidomain proteins. J Biol Chem, 2003. 278(43): p. 42377-85.

58. Olsen, O., et al., Neurotransmitter release regulated by a MALS-liprin-alpha presynaptic complex. J Cell Biol, 2005. 170(7): p. 1127-34.

59. Wei, Z., et al., Liprin-mediated large signaling complex organization revealed by the liprinalpha/CASK and liprin-alpha/liprin-beta complex structures. Mol Cell, 2011. 43(4): p. 58698.

60. Wang, Y., et al., A family of RIM-binding proteins regulated by alternative splicing: Implications for the genesis of synaptic active zones. Proc Natl Acad Sci U S A, 2002. 99(22): p. 14464-9.

61. Deguchi-Tawarada, M., et al., CAST2: identification and characterization of a protein structurally related to the presynaptic cytomatrix protein CAST. Genes Cells, 2004. 9(1): p. 15-23.

62. Ohtsuka, T., CAST: functional scaffold for the integrity of the presynaptic active zone. Neurosci Res, 2013. 76(1-2): p. 10-5.

63. Ko, J., et al., Organization of the presynaptic active zone by ERC2/CAST1-dependent clustering of the tandem PDZ protein syntenin-1. J Neurosci, 2006. 26(3): p. 963-70.

64. Wang, X., et al., A protein interaction node at the neurotransmitter release site: domains of Aczonin/Piccolo, Bassoon, CAST, and rim converge on the $N$-terminal domain of Munc13-1. J Neurosci, 2009. 29(40): p. 12584-96.

65. Wagh, D.A., et al., Bruchpilot, a protein with homology to ELKS/CAST, is required for structural integrity and function of synaptic active zones in Drosophila. Neuron, 2006. 49(6): p. 833-44.

66. Kittel, R.J., et al., Bruchpilot promotes active zone assembly, Ca2+ channel clustering, and vesicle release. Science, 2006. 312(5776): p. 1051-4.

67. Paul, M.M., et al., Bruchpilot and Synaptotagmin collaborate to drive rapid glutamate release and active zone differentiation. Front Cell Neurosci, 2015. 9: p. 29.

68. Hibino, H., et al., RIM binding proteins (RBPs) couple Rab3-interacting molecules (RIMs) to voltage-gated $\mathrm{Ca}(2+)$ channels. Neuron, 2002. 34(3): p. 411-23. 
69. Liu, K.S., et al., RIM-binding protein, a central part of the active zone, is essential for neurotransmitter release. Science, 2011. 334(6062): p. 1565-9.

70. Wang, X., et al., Aczonin, a 550-kD putative scaffolding protein of presynaptic active zones, shares homology regions with Rim and Bassoon and binds profilin. J Cell Biol, 1999. 147(1): p. 151-62.

71. Fenster, S.D., et al., Piccolo, a presynaptic zinc finger protein structurally related to bassoon. Neuron, 2000. 25(1): p. 203-14.

72. tom Dieck, S., et al., Bassoon, a novel zinc-finger CAG/glutamine-repeat protein selectively localized at the active zone of presynaptic nerve terminals. J Cell Biol, 1998. 142(2): p. 499509.

73. Altrock, W.D., et al., Functional inactivation of a fraction of excitatory synapses in mice deficient for the active zone protein bassoon. Neuron, 2003. 37(5): p. 787-800.

74. Mukherjee, K., et al., Piccolo and bassoon maintain synaptic vesicle clustering without directly participating in vesicle exocytosis. Proc Natl Acad Sci U S A, 2010. 107(14): p. 6504-9.

75. Gerber, S.H., et al., An unusual C(2)-domain in the active-zone protein piccolo: implications for $\mathrm{Ca}(2+)$ regulation of neurotransmitter release. EMBO J, 2001. 20(7): p. 1605-19.

76. Fenster, S.D. and C.C. Garner, Gene structure and genetic localization of the PCLO gene encoding the presynaptic active zone protein Piccolo. Int J Dev Neurosci, 2002. 20(3-5): p. 161-71.

77. Garcia, J., et al., A conformational switch in the Piccolo C2A domain regulated by alternative splicing. Nat Struct Mol Biol, 2004. 11(1): p. 45-53.

78. Shibasaki, T., et al., Interaction of ATP sensor, CAMP sensor, Ca2+ sensor, and voltagedependent Ca2+ channel in insulin granule exocytosis. J Biol Chem, 2004. 279(9): p. 795661.

79. Takao-Rikitsu, E., et al., Physical and functional interaction of the active zone proteins, CAST, RIM1, and Bassoon, in neurotransmitter release. J Cell Biol, 2004. 164(2): p. 301-11.

80. Tabuchi, K., et al., CASK participates in alternative tripartite complexes in which Mint 1 competes for binding with caskin 1, a novel CASK-binding protein. J Neurosci, 2002. 22(11): p. 4264-73.

81. Butz, S., M. Okamoto, and T.C. Sudhof, A tripartite protein complex with the potential to couple synaptic vesicle exocytosis to cell adhesion in brain. Cell, 1998. 94(6): p. 773-82.

82. Hata, Y., S. Butz, and T.C. Sudhof, CASK: a novel dlg/PSD95 homolog with an N-terminal calmodulin-dependent protein kinase domain identified by interaction with neurexins. J Neurosci, 1996. 16(8): p. 2488-94.

83. Fejtova, A. and E.D. Gundelfinger, Molecular organization and assembly of the presynaptic active zone of neurotransmitter release. Results Probl Cell Differ, 2006. 43: p. 49-68.

84. Harlow, M.L., et al., The architecture of active zone material at the frog's neuromuscular junction. Nature, 2001. 409(6819): p. 479-84.

85. Schoch, S. and E.D. Gundelfinger, Molecular organization of the presynaptic active zone. Cell Tissue Res, 2006. 326(2): p. 379-91.

86. Monier, S., et al., Characterization of novel Rab6-interacting proteins involved in endosome-to-TGN transport. Traffic, 2002. 3(4): p. 289-97.

87. Shin, H., et al., Association of the kinesin motor KIF1A with the multimodular protein liprinalpha. J Biol Chem, 2003. 278(13): p. 11393-401.

88. Pulido, R., et al., The LAR/PTP delta/PTP sigma subfamily of transmembrane proteintyrosine-phosphatases: multiple human LAR, PTP delta, and PTP sigma isoforms are expressed in a tissue-specific manner and associate with the LAR-interacting protein LIP.1. Proc Natl Acad Sci U S A, 1995. 92(25): p. 11686-90.

89. Wyszynski, M., et al., Interaction between GRIP and liprin-alpha/SYD2 is required for AMPA receptor targeting. Neuron, 2002. 34(1): p. 39-52. 
90. Ko, J., et al., Interaction between liprin-alpha and GIT1 is required for AMPA receptor targeting. J Neurosci, 2003. 23(5): p. 1667-77.

91. Maruyama, I.N. and S. Brenner, A phorbol ester/diacylglycerol-binding protein encoded by the unc-13 gene of Caenorhabditis elegans. Proc Natl Acad Sci U S A, 1991. 88(13): p. 5729-33.

92. Fenster, S.D., et al., Interactions between Piccolo and the actin/dynamin-binding protein Abp1 link vesicle endocytosis to presynaptic active zones. J Biol Chem, 2003. 278(22): p. 20268-77.

93. Stafford, R.L., et al., The molecular basis of the Caskin1 and Mint1 interaction with CASK. J Mol Biol, 2011. 412(1): p. 3-13.

94. Biederer, T., et al., SynCAM, a synaptic adhesion molecule that drives synapse assembly. Science, 2002. 297(5586): p. 1525-31.

95. Helenius, A. and K. Simons, Solubilization of membranes by detergents. Biochim Biophys Acta, 1975. 415(1): p. 29-79.

96. Helenius, A., et al., Properties of detergents. Methods Enzymol, 1979. 56: p. 734-49.

97. McBain, E.L.a.H., E. , Solubilization and Related Phenomena. Academic Press, New York, 1955.

98. Tanford, C., The Hydrophobic Effect: Formation of Micelles and Biological Membranes. New York: John Wiley\&Sons, Inc. , 1st ed. 1973.

99. Garavito, R.M. and S. Ferguson-Miller, Detergents as tools in membrane biochemistry. J Biol Chem, 2001. 276(35): p. 32403-6.

100. Neugebauer, J., A guide to the Properties and Uses of Detergents in Biology and Biochemistry. 1994, 5th Edition: p. 1-62.

101. Rosen, M., Surfactants and Interfacial Phenomena. Hoboken: John Wiley\&Sons, Inc., 3rd Ed. 2004.

102. Corrin, M.L. and W.D. Harkins, The effect of salts on the critical concentration for the formation of micelles in colloidal electrolytes. J Am Chem Soc, 1947. 69(3): p. 683-8.

103. Ray, A. and G. Nemethy, Effects of ionic protein denaturants on micelle formation by nonionic detergents. J Am Chem Soc, 1971. 93(25): p. 6787-93.

104. Ericsson, C.A., et al., Effects of temperature, salt, and deuterium oxide on the selfaggregation of alkylglycosides in dilute solution. 1. n-nonyl-beta-D-glucoside. Langmuir, 2004. 20(4): p. 1401-8.

105. Qin, X., et al., Concentration-dependent aggregation of CHAPS investigated by NMR spectroscopy. J Phys Chem B, 2010. 114(11): p. 3863-8.

106. Mohan, S.M.B.a.C., Detergents: A guide to the properties and uses of detergents in biology and biochemistry. 2007: p. 1-42.

107. Schick, M.J., Nonionic Surfactants. New York: Marcel Dekker, 1967: p. p. 607.

108. Pryde, J.G. and J.H. Phillips, Fractionation of membrane proteins by temperature-induced phase separation in Triton X-114. Application to subcellular fractions of the adrenal medulla. Biochem J, 1986. 233(2): p. 525-33.

109. Bordier, C., Phase separation of integral membrane proteins in Triton X-114 solution. J Biol Chem, 1981. 256(4): p. 1604-7.

110. Fields, S. and R. Sternglanz, The two-hybrid system: an assay for protein-protein interactions. Trends Genet, 1994. 10(8): p. 286-92.

111. Parrish, J.R., K.D. Gulyas, and R.L. Finley, Jr., Yeast two-hybrid contributions to interactome mapping. Curr Opin Biotechnol, 2006. 17(4): p. 387-93.

112. Uetz, P., et al., A comprehensive analysis of protein-protein interactions in Saccharomyces cerevisiae. Nature, 2000. 403(6770): p. 623-7.

113. von Mering, C., et al., Comparative assessment of large-scale data sets of protein-protein interactions. Nature, 2002. 417(6887): p. 399-403.

114. Gingras, A.C., et al., Analysis of protein complexes using mass spectrometry. Nat Rev Mol Cell Biol, 2007. 8(8): p. 645-54. 
115. Kratchmarova, I., et al., Mechanism of divergent growth factor effects in mesenchymal stem cell differentiation. Science, 2005. 308(5727): p. 1472-7.

116. Blagoev, B., et al., A proteomics strategy to elucidate functional protein-protein interactions applied to EGF signaling. Nat Biotechnol, 2003. 21(3): p. 315-8.

117. Himeda, C.L., et al., Quantitative proteomic identification of six4 as the trex-binding factor in the muscle creatine kinase enhancer. Mol Cell Biol, 2004. 24(5): p. 2132-43.

118. Ranish, J.A., et al., The study of macromolecular complexes by quantitative proteomics. Nat Genet, 2003. 33(3): p. 349-55.

119. Tate, S., et al., Label-free quantitative proteomics trends for protein-protein interactions. J Proteomics, 2013. 81: p. 91-101.

120. Bantscheff, M., et al., Quantitative mass spectrometry in proteomics: critical review update from 2007 to the present. Anal Bioanal Chem, 2012. 404(4): p. 939-65.

121. Berkefeld, H., et al., BKCa-Cav channel complexes mediate rapid and localized Ca2+activated K+ signaling. Science, 2006. 314(5799): p. 615-20.

122. Bildl, W., et al., Protein kinase CK2 is coassembled with small conductance $\mathrm{Ca}(2+)$ activated K+ channels and regulates channel gating. Neuron, 2004. 43(6): p. 847-58.

123. Liu, J., et al., CatSperbeta, a novel transmembrane protein in the CatSper channel complex. J Biol Chem, 2007. 282(26): p. 18945-52.

124. Nadal, M.S., et al., The CD26-related dipeptidyl aminopeptidase-like protein DPPX is a critical component of neuronal A-type K+ channels. Neuron, 2003. 37(3): p. 449-61.

125. Schulte, U., et al., The epilepsy-linked Lgi1 protein assembles into presynaptic Kv1 channels and inhibits inactivation by Kvbeta1. Neuron, 2006. 49(5): p. 697-706.

126. Schwenk, J., et al., Regional diversity and developmental dynamics of the AMPA-receptor proteome in the mammalian brain. Neuron, 2014. 84(1): p. 41-54.

127. Schwenk, J., et al., Functional proteomics identify cornichon proteins as auxiliary subunits of AMPA receptors. Science, 2009. 323(5919): p. 1313-9.

128. Schwenk, J., et al., Native $G A B A(B)$ receptors are heteromultimers with a family of auxiliary subunits. Nature, 2010. 465(7295): p. 231-5.

129. Schwenk, J., et al., High-resolution proteomics unravel architecture and molecular diversity of native AMPA receptor complexes. Neuron, 2012. 74(4): p. 621-33.

130. Megger, D.A., et al., Label-free quantification in clinical proteomics. Biochim Biophys Acta, 2013. 1834(8): p. 1581-90.

131. Wang, M., et al., Label-free mass spectrometry-based protein quantification technologies in proteomic analysis. Brief Funct Genomic Proteomic, 2008. 7(5): p. 329-39.

132. Zhu, W., J.W. Smith, and C.M. Huang, Mass spectrometry-based label-free quantitative proteomics. J Biomed Biotechnol, 2010. 2010: p. 840518.

133. Takamori, S., et al., Molecular anatomy of a trafficking organelle. Cell, 2006. 127(4): p. 831-46.

134. Bildl, W., et al., Extending the dynamic range of label-free mass spectrometric quantification of affinity purifications. Mol Cell Proteomics, 2012. 11(2): p. M111 007955.

135. Muller, C.S., et al., Quantitative proteomics of the Cav2 channel nano-environments in the mammalian brain. Proc Natl Acad Sci U S A, 2010. 107(34): p. 14950-7.

136. Smits, A.H., et al., Stoichiometry of chromatin-associated protein complexes revealed by label-free quantitative mass spectrometry-based proteomics. Nucleic Acids Res, 2013. 41(1): p. e28.

137. Hubner, N.C., et al., Quantitative proteomics combined with BAC TransgeneOmics reveals in vivo protein interactions. J Cell Biol, 2010. 189(4): p. 739-54.

138. Whittaker, V.P., I.A. Michaelson, and R.J. Kirkland, The separation of synaptic vesicles from nerve-ending particles ('synaptosomes'). Biochem J, 1964. 90(2): p. 293-303.

139. Huttner, W.B., et al., Synapsin I (protein I), a nerve terminal-specific phosphoprotein. III. Its association with synaptic vesicles studied in a highly purified synaptic vesicle preparation. J Cell Biol, 1983. 96(5): p. 1374-88. 
140. Smith, P.K., et al., Measurement of protein using bicinchoninic acid. Anal Biochem, 1985. 150(1): p. 76-85.

141. Creighton, T.E., Protein Structure, A Practical Approach. IRL Press, 1997: p. 1-12.

142. Laemmli, U.K., Cleavage of structural proteins during the assembly of the head of bacteriophage T4. Nature, 1970. 227(5259): p. 680-5.

143. Towbin, H., T. Staehelin, and J. Gordon, Immunoblotting in the clinical laboratory. J Clin Chem Clin Biochem, 1989. 27(8): p. 495-501.

144. Burger, P.M., et al., Synaptic vesicles immunoisolated from rat cerebral cortex contain high levels of glutamate. Neuron, 1989. 3(6): p. 715-20.

145. Fischer von Mollard, G., T.C. Sudhof, and R. Jahn, A small GTP-binding protein dissociates from synaptic vesicles during exocytosis. Nature, 1991. 349(6304): p. 79-81.

146. Boyken, J., et al., Molecular profiling of synaptic vesicle docking sites reveals novel proteins but few differences between glutamatergic and GABAergic synapses. Neuron, 2013. 78(2): p. 285-97.

147. Li, K.W., et al., Quantitative proteomics and protein network analysis of hippocampal synapses of CaMKIlalpha mutant mice. J Proteome Res, 2007. 6(8): p. 3127-33.

148. Shevchenko, A., et al., Mass spectrometric sequencing of proteins silver-stained polyacrylamide gels. Anal Chem, 1996. 68(5): p. 850-8.

149. Rappsilber, J., M. Mann, and Y. Ishihama, Protocol for micro-purification, enrichment, prefractionation and storage of peptides for proteomics using StageTips. Nat Protoc, 2007. 2(8): p. 1896-906.

150. Schwanhausser, B., et al., Global quantification of mammalian gene expression control. Nature, 2011. 473(7347): p. 337-42.

151. Wilhelm, B.G., et al., Composition of isolated synaptic boutons reveals the amounts of vesicle trafficking proteins. Science, 2014. 344(6187): p. 1023-8.

152. Fiszer, S. and E.D. Robertis, Action of triton X-100 on ultrastructure and membrane-boundenzymes of isolated nerve endings from rat brain. Brain Res, 1967. 5(1): p. 31-44.

153. Cotman, C.W., et al., An ultrastructural and chemical analysis of the effect of triton $X-100$ on synaptic plasma membranes. Biochim Biophys Acta, 1971. 249(2): p. 406-18.

154. Cotman, C.W. and D. Taylor, Isolation and structural studies on synaptic complexes from rat brain. J Cell Biol, 1972. 55(3): p. 696-711.

155. Davis, G.A. and F.E. Bloom, Isolation of synaptic junctional complexes from rat brain. Brain Res, 1973. 62(1): p. 135-53.

156. Cotman, C.W., et al., Isolation of postsynaptic densities from rat brain. J Cell Biol, 1974. 63(2 Pt 1): p. 441-55.

157. Blomberg, F., R.S. Cohen, and P. Siekevitz, The structure of postsynaptic densities isolated from dog cerebral cortex. II. Characterization and arrangement of some of the major proteins within the structure. J Cell Biol, 1977. 74(1): p. 204-25.

158. Cohen, R.S., et al., The structure of postsynaptic densities isolated from dog cerebral cortex. I. Overall morphology and protein composition. J Cell Biol, 1977. 74(1): p. 181-203.

159. Bennett, M.K., et al., Synaptic vesicle membrane proteins interact to form a multimeric complex. J Cell Biol, 1992. 116(3): p. 761-75.

160. Bennett, M.K., N. Calakos, and R.H. Scheller, Syntaxin: a synaptic protein implicated in docking of synaptic vesicles at presynaptic active zones. Science, 1992. 257(5067): p. 2559.

161. Albers, R.W., L. Rodriguezde, and E. Derobertis, Sodium-Potassium-Activated Atpase and Potassium-Activated P-Nitrophenylphosphatase: A Comparison of Their Subcellular Localizations in Rat Brain. Proc Natl Acad Sci U S A, 1965. 53: p. 557-64.

162. Hosie, R.J., The localization of adenosine triphosphatases in morphologically characterized subcellular fractions of guinea-pig brain. Biochem J, 1965. 96(2): p. 404-12. 
163. Geumann, C., et al., A sandwich enzyme-linked immunosorbent assay for the quantification of insoluble membrane and scaffold proteins. Anal Biochem, 2010. 402(2): p. 161-9.

164. Husi, H., et al., Proteomic analysis of NMDA receptor-adhesion protein signaling complexes. Nat Neurosci, 2000. 3(7): p. 661-9.

165. Wenthold, R.J., et al., Detergent solubilization and immunoprecipitation of native NMDA receptors. Methods Mol Biol, 1999. 128: p. 113-9.

166. Gonenne, A. and R. Ernst, Solubilization of membrane proteins by sulfobetaines, novel zwitterionic surfactants. Anal Biochem, 1978. 87(1): p. 28-38.

167. Kornau, H.C., et al., Domain interaction between NMDA receptor subunits and the postsynaptic density protein PSD-95. Science, 1995. 269(5231): p. 1737-40.

168. Hjelmeland, L.M.a.C., A., Membranes, detergents, and receptor solubilization. 1984. 1: p. 35-46.

169. Schuck, S., Honsho, M. and Simons, K., Detergent-resistant membranes and the use of cholesterol depletion. Cell Biology: A Laboratory Handbook, 2006. 2.

170. Lingwood, D. and K. Simons, Detergent resistance as a tool in membrane research. Nat Protoc, 2007. 2(9): p. 2159-65.

171. Garner, A.E., D.A. Smith, and N.M. Hooper, Visualization of detergent solubilization of membranes: implications for the isolation of rafts. Biophys J, 2008. 94(4): p. 1326-40.

172. Lichtenberg, D., H. Ahyayauch, and F.M. Goni, The mechanism of detergent solubilization of lipid bilayers. Biophys J, 2013. 105(2): p. 289-99.

173. Rickwood, D., Centrifugation: A practical approach. 1984(2nd Edition).

174. Sollner, T., et al., A protein assembly-disassembly pathway in vitro that may correspond to sequential steps of synaptic vesicle docking, activation, and fusion. Cell, 1993. 75(3): p. 409-18.

175. Sollner, T., et al., SNAP receptors implicated in vesicle targeting and fusion. Nature, 1993. 362(6418): p. 318-24.

176. Pevsner, J., et al., Specificity and regulation of a synaptic vesicle docking complex. Neuron, 1994. 13(2): p. 353-61.

177. Ahmed, S., et al., Small-scale isolation of synaptic vesicles from mammalian brain. Nat Protoc, 2013. 8(5): p. 998-1009.

178. Calakos, N. and R.H. Scheller, Vesicle-associated membrane protein and synaptophysin are associated on the synaptic vesicle. J Biol Chem, 1994. 269(40): p. 24534-7.

179. Edelmann, L., et al., Synaptobrevin binding to synaptophysin: a potential mechanism for controlling the exocytotic fusion machine. EMBO J, 1995. 14(2): p. 224-31.

180. Scheller, R.H., Membrane trafficking in the presynaptic nerve terminal. Neuron, 1995. 14(5): p. 893-7.

181. Xie, C., et al., Rab3A is a new interacting partner of synaptotagmin I and may modulate synaptic membrane fusion through a competitive mechanism. Biochem Biophys Res Commun, 2014. 444(4): p. 491-5.

182. Santos, M.S., et al., Protein interactions of the vesicular glutamate transporter VGLUT1. PLoS One, 2014. 9(10): p. e109824.

183. De Gois, S., et al., Identification of endophilins 1 and 3 as selective binding partners for VGLUT1 and their co-localization in neocortical glutamatergic synapses: implications for vesicular glutamate transporter trafficking and excitatory vesicle formation. Cell Mol Neurobiol, 2006. 26(4-6): p. 679-93.

184. Weston, M.C., et al., Interplay between VGLUT isoforms and endophilin A1 regulates neurotransmitter release and short-term plasticity. Neuron, 2011. 69(6): p. 1147-59.

185. Winter, S., et al., Galphao2 regulates vesicular glutamate transporter activity by changing its chloride dependence. J Neurosci, 2005. 25(18): p. 4672-80.

186. Rogelj, B., et al., The X11/Mint family of adaptor proteins. Brain Res Rev, 2006. 52(2): p. 305-15. 
187. Okamoto, M. and T.C. Sudhof, Mints, Munc18-interacting proteins in synaptic vesicle exocytosis. J Biol Chem, 1997. 272(50): p. 31459-64.

188. Hata, Y., C.A. Slaughter, and T.C. Sudhof, Synaptic vesicle fusion complex contains unc-18 homologue bound to syntaxin. Nature, 1993. 366(6453): p. 347-51.

189. Sudhof, T.C., Neuroligins and neurexins link synaptic function to cognitive disease. Nature, 2008. 455(7215): p. 903-11.

190. Verpelli, C., et al., Scaffold proteins at the postsynaptic density. Adv Exp Med Biol, 2012. 970: p. 29-61.

191. Chua, J.J., et al., The architecture of an excitatory synapse. J Cell Sci, 2010. 123(Pt 6): p. 819-23.

192. Lichtenberg, D., et al., Detergent solubilization of lipid bilayers: a balance of driving forces. Trends Biochem Sci, 2013. 38(2): p. 85-93.

193. Sousa, M.M., et al., Antibody cross-linking and target elution protocols used for immunoprecipitation significantly modulate signal-to noise ratio in downstream 2D-PAGE analysis. Proteome Sci, 2011. 9: p. 45.

194. Chevallet, M., S. Luche, and T. Rabilloud, Silver staining of proteins in polyacrylamide gels. Nat Protoc, 2006. 1(4): p. 1852-8.

195. Kocher, T. and G. Superti-Furga, Mass spectrometry-based functional proteomics: from molecular machines to protein networks. Nat Methods, 2007. 4(10): p. 807-15.

196. Cox, J. and M. Mann, MaxQuant enables high peptide identification rates, individualized p.p.b.-range mass accuracies and proteome-wide protein quantification. Nat Biotechnol, 2008. 26(12): p. 1367-72.

197. Hubner, N.C. and M. Mann, Extracting gene function from protein-protein interactions using Quantitative BAC InteraCtomics (QUBIC). Methods, 2011. 53(4): p. 453-9.

198. Tusher, V.G., R. Tibshirani, and G. Chu, Significance analysis of microarrays applied to the ionizing radiation response. Proc Natl Acad Sci U S A, 2001. 98(9): p. 5116-21.

199. Parra, L.A., et al., The orphan transporter Rxt1/NTT4 (SLC6A17) functions as a synaptic vesicle amino acid transporter selective for proline, glycine, leucine, and alanine. Mol Pharmacol, 2008. 74(6): p. 1521-32.

200. Bragina, L., et al., Heterogeneity of glutamatergic and GABAergic release machinery in cerebral cortex: analysis of synaptogyrin, vesicle-associated membrane protein, and syntaxin. Neuroscience, 2010. 165(3): p. 934-43.

201. Burre, J., H. Zimmermann, and W. Volknandt, Identification and characterization of SV31, a novel synaptic vesicle membrane protein and potential transporter. J Neurochem, 2007. 103(1): p. 276-87.

202. Barth, J., H. Zimmermann, and W. Volknandt, SV31 is a Zn2+-binding synaptic vesicle protein. J Neurochem, 2011. 118(4): p. 558-70.

203. Morciano, M., et al., Immunoisolation of two synaptic vesicle pools from synaptosomes: a proteomics analysis. J Neurochem, 2005. 95(6): p. 1732-45.

204. Fujita, Y., et al., Tomosyn: a syntaxin-1-binding protein that forms a novel complex in the neurotransmitter release process. Neuron, 1998. 20(5): p. 905-15.

205. Scales, S.J., et al., Amisyn, a novel syntaxin-binding protein that may regulate SNARE complex assembly. J Biol Chem, 2002. 277(31): p. 28271-9.

206. Petkovic, M., et al., The SNARE Sec22b has a non-fusogenic function in plasma membrane expansion. Nat Cell Biol, 2014. 16(5): p. 434-44.

207. Bock, J.B., R.C. Lin, and R.H. Scheller, A new syntaxin family member implicated in targeting of intracellular transport vesicles. J Biol Chem, 1996. 271(30): p. 17961-5.

208. Butchbach, M.E., L. Lai, and C.L. Lin, Molecular cloning, gene structure, expression profile and functional characterization of the mouse glutamate transporter (EAAT3) interacting protein GTRAP3-18. Gene, 2002. 292(1-2): p. 81-90.

209. Ikemoto, M.J., et al., Identification of addicsin/GTRAP3-18 as a chronic morphineaugmented gene in amygdala. Neuroreport, 2002. 13(16): p. 2079-84. 
210. Fo, C.S., et al., Genomic organization, expression profile, and characterization of the new protein PRA1 domain family, member 2 (PRAF2). Gene, 2006. 371(1): p. 154-65.

211. Koomoa, D.L., et al., Expression profile of PRAF2 in the human brain and enrichment in synaptic vesicles. Neurosci Lett, 2008. 436(2): p. 171-6.

212. Geerts, D., et al., Expression of prenylated Rab acceptor 1 domain family, member 2 (PRAF2) in neuroblastoma: correlation with clinical features, cellular localization, and cerulenin-mediated apoptosis regulation. Clin Cancer Res, 2007. 13(21): p. 6312-9.

213. Holmgren, M., et al., Three distinct and sequential steps in the release of sodium ions by the Na+/K+-ATPase. Nature, 2000. 403(6772): p. 898-901.

214. Hernandez, R.J., Na+/K(+)-ATPase regulation by neurotransmitters. Neurochem Int, 1992. 20(1): p. 1-10.

215. Rose, E.M., et al., Glutamate transporter coupling to Na,K-ATPase. J Neurosci, 2009. 29(25): p. 8143-55.

216. Lee, S.H., et al., $\mathrm{Na}+\mathrm{Ca} 2+$ exchange and $\mathrm{Ca} 2+$ homeostasis in axon terminals of mammalian central neurons. Ann N Y Acad Sci, 2007. 1099: p. 396-412.

217. Giffard, R.G., et al., The electrogenic sodium bicarbonate cotransporter: developmental expression in rat brain and possible role in acid vulnerability. J Neurosci, 2000. 20(3): p. 1001-8.

218. Wang, C.Z., et al., The Na+-driven $\mathrm{Cl}-/ \mathrm{HCO}-$ exchanger. Cloning, tissue distribution, and functional characterization. J Biol Chem, 2000. 275(45): p. 35486-90.

219. Tanaka, S., et al., Inositol 1, 4, 5-trisphosphate receptor interacts with the SNARE domain of syntaxin 1B. J Physiol Sci, 2011. 61(3): p. 221-9.

220. $\mathrm{Hu}, \mathrm{H}$., et al., Presynaptic Ca2+-activated $\mathrm{K}+$ channels in glutamatergic hippocampal terminals and their role in spike repolarization and regulation of transmitter release. $J$ Neurosci, 2001. 21(24): p. 9585-97.

221. van der Velden, L.M., et al., Heteromeric interactions required for abundance and subcellular localization of human CDC50 proteins and class 1 P4-ATPases. J Biol Chem, 2010. 285(51): p. 40088-96.

222. Bryde, S., et al., CDC50 proteins are critical components of the human class-1 P4-ATPase transport machinery. J Biol Chem, 2010. 285(52): p. 40562-72.

223. Kadowaki, K., et al., Phosphohippolin expression in the rat central nervous system. Brain Res Mol Brain Res, 2004. 125(1-2): p. 105-12.

224. Yamaguchi, F., et al., Molecular cloning and characterization of a novel phospholemmanlike protein from rat hippocampus. Brain Res Mol Brain Res, 2001. 86(1-2): p. 189-92.

225. Sweadner, K.J. and E. Rael, The FXYD gene family of small ion transport regulators or channels: cDNA sequence, protein signature sequence, and expression. Genomics, 2000. 68(1): p. 41-56.

226. Delprat, B., J.L. Puel, and K. Geering, Dynamic expression of FXYD6 in the inner ear suggests a role of the protein in endolymph homeostasis and neuronal activity. Dev Dyn, 2007. 236(9): p. 2534-40.

227. Delprat, B., et al., FXYD6 is a novel regulator of Na,K-ATPase expressed in the inner ear. J Biol Chem, 2007. 282(10): p. 7450-6.

228. Alfonso, J., et al., The stress-regulated protein $M 6 a$ is a key modulator for neurite outgrowth and filopodium/spine formation. Proc Natl Acad Sci U S A, 2005. 102(47): p. 17196-201.

229. Mukobata, S., et al., M6a acts as a nerve growth factor-gated $\mathrm{Ca}(2+)$ channel in neuronal differentiation. Biochem Biophys Res Commun, 2002. 297(4): p. 722-8.

230. Stipp, C.S. and M.E. Hemler, Transmembrane-4-superfamily proteins CD151 and CD81 associate with alpha 3 beta 1 integrin, and selectively contribute to alpha 3 beta 1 dependent neurite outgrowth. J Cell Sci, 2000. 113 ( Pt 11): p. 1871-82.

231. Jiang, P., C.F. Lagenaur, and V. Narayanan, Integrin-associated protein is a ligand for the P84 neural adhesion molecule. J Biol Chem, 1999. 274(2): p. 559-62. 
232. Reich, A., et al., Fas/CD95 regulatory protein Faim2 is neuroprotective after transient brain ischemia. J Neurosci, 2011. 31(1): p. 225-33.

233. Matthews, C.A., et al., Expression and evolution of the mammalian brain gene Ttyh1. J Neurochem, 2007. 100(3): p. 693-707.

234. Oliveros, J.C., Venny. An interactive tool for comparing lists with Venn's diagrams. http://bioinfogp.cnb.csic.es/tools/venny/index.html 2007-2015.

235. Belizaire, R., et al., Characterization of synaptogyrin 3 as a new synaptic vesicle protein. J Comp Neurol, 2004. 470(3): p. 266-81.

236. Stenius, K., et al., Structure of synaptogyrin (p29) defines novel synaptic vesicle protein. J Cell Biol, 1995. 131(6 Pt 2): p. 1801-9.

237. Sugita, S., R. Janz, and T.C. Sudhof, Synaptogyrins regulate Ca2+-dependent exocytosis in PC12 cells. J Biol Chem, 1999. 274(27): p. 18893-901.

238. Stevens, R.J., et al., Abnormal synaptic vesicle biogenesis in Drosophila synaptogyrin mutants. J Neurosci, 2012. 32(50): p. 18054-67, 18067a.

239. Skehel, P.A., et al., A VAMP-binding protein from Aplysia required for neurotransmitter release. Science, 1995. 269(5230): p. 1580-3.

240. Weir, M.L., A. Klip, and W.S. Trimble, Identification of a human homologue of the vesicleassociated membrane protein (VAMP)-associated protein of 33 kDa (VAP-33): a broadly expressed protein that binds to VAMP. Biochem J, 1998. 333 ( Pt 2): p. 247-51.

241. Tellam, J.T., et al., Identification of a mammalian Golgi Sec1p-like protein, mVps45. J Biol Chem, 1997. 272(10): p. 6187-93.

242. Lao, G., et al., Syntaphilin: a syntaxin-1 clamp that controls SNARE assembly. Neuron, 2000. 25(1): p. 191-201.

243. Sheng, Z.H., et al., Identification of a syntaxin-binding site on $\mathrm{N}$-type calcium channels. Neuron, 1994. 13(6): p. 1303-13.

244. Favre-Kontula, L., et al., GlialCAM, an immunoglobulin-like cell adhesion molecule is expressed in glial cells of the central nervous system. Glia, 2008. 56(6): p. 633-45.

245. Umemori, H. and J.R. Sanes, Signal regulatory proteins (SIRPS) are secreted presynaptic organizing molecules. J Biol Chem, 2008. 283(49): p. 34053-61.

246. Watanabe, M., et al., Myosin-Va regulates exocytosis through the submicromolar Ca2+dependent binding of syntaxin-1A. Mol Biol Cell, 2005. 16(10): p. 4519-30.

247. Yang, Y.M., et al., Septins regulate developmental switching from microdomain to nanodomain coupling of $\mathrm{Ca}(2+)$ influx to neurotransmitter release at a central synapse. Neuron, 2010. 67(1): p. 100-15.

248. Dodds, D.C., et al., Neuronal pentraxin receptor, a novel putative integral membrane pentraxin that interacts with neuronal pentraxin 1 and 2 and taipoxin-associated calciumbinding protein 49. J Biol Chem, 1997. 272(34): p. 21488-94.

249. Kirkpatrick, L.L., et al., Biochemical interactions of the neuronal pentraxins. Neuronal pentraxin (NP) receptor binds to taipoxin and taipoxin-associated calcium-binding protein 49 via NP1 and NP2. J Biol Chem, 2000. 275(23): p. 17786-92.

250. Volknandt, W. and M. Karas, Proteomic analysis of the presynaptic active zone. Exp Brain Res, 2012. 217(3-4): p. 449-61.

251. Laganowsky, A., et al., Mass spectrometry of intact membrane protein complexes. Nat Protoc, 2013. 8(4): p. 639-51.

252. Rouse, S.L., et al., Dodecyl maltoside protects membrane proteins in vacuo. Biophys J, 2013. 105(3): p. 648-56.

253. Chen, F., et al., On the Efficiency of NHS Ester Cross-Linkers for Stabilizing Integral Membrane Protein Complexes. J Am Soc Mass Spectrom, 2014.

254. Schmidt, C. and C.V. Robinson, A comparative cross-linking strategy to probe conformational changes in protein complexes. Nat Protoc, 2014. 9(9): p. 2224-36. 
255. Vermeulen, M., N.C. Hubner, and M. Mann, High confidence determination of specific protein-protein interactions using quantitative mass spectrometry. Curr Opin Biotechnol, 2008. 19(4): p. 331-7.

256. Puffer, E.B., et al., Differential roles of developmentally distinct SNAP-25 isoforms in the neurotransmitter release process. Biochemistry, 2001. 40(31): p. 9374-8.

257. Beckman, M.L., E.M. Bernstein, and M.W. Quick, Protein kinase C regulates the interaction between a GABA transporter and syntaxin 1A. J Neurosci, 1998. 18(16): p. 6103-12.

258. Burkhardt, P., et al., Munc18a controls SNARE assembly through its interaction with the syntaxin N-peptide. EMBO J, 2008. 27(7): p. 923-33.

259. Boczan, J., A.G. Leenders, and Z.H. Sheng, Phosphorylation of syntaphilin by CAMPdependent protein kinase modulates its interaction with syntaxin-1 and annuls its inhibitory effect on vesicle exocytosis. J Biol Chem, 2004. 279(18): p. 18911-9.

260. Asuni, A.A., K. Lidwell, and V. O'Connor, Biochemical evidence for the differential association of metabotropic glutamate receptors within synaptic complexes. Neurosci Lett, 2008. 444(1): p. 27-30.

261. Somia, N.V., et al., LFG: an anti-apoptotic gene that provides protection from Fasmediated cell death. Proc Natl Acad Sci U S A, 1999. 96(22): p. 12667-72.

262. Fernandez, M., et al., Lifeguard/neuronal membrane protein 35 regulates Fas ligandmediated apoptosis in neurons via microdomain recruitment. J Neurochem, 2007. 103(1): p. 190-203. 


\section{Acknowledgements}

I want to thank Prof. Reinhard Jahn for giving me the opportunity to work under his supervision. Dear Reinhard, I am deeply grateful for the once-in-life-chance you gave me. I have never thought that the little boy from a small Bulgarian village, grown up with cows, goats, rabbits and chasing chickens would ever have the honor to work and learn from a great scientist and life mentor like you. Thank you for the constant support and scientific freedom. I loved the bike tours and looking forward to the next one.

I want to thank also Dr. Janina Boyken, who introduced me to the lab. Without her and her lab rotation project, I wouldn't have had the opportunity go get an insider into neurosciences. Janina, thank you for teaching me how to prepare synaptosomes, to question observations and to repeat cloning tireless till it works. And please forgive me that at our first synaptosomes’ preparation day, I overslept with two hours. We still did it!

I am thankful to Prof. Dr. Henning Urlaub and Prof. Dr. Silvio Rizzoli for being members of my $\mathrm{PhD}$ thesis committee. Thank you for your time, fruitful ideas and honest and critical comments.

I want to thank Dr. Steffen Burkhardt and Kerstin Grüniger from the International Max Planck Research School (IMPRS) in Molecular Biology for their generous support during the Masters and $\mathrm{PhD}$ time, for their professional engagement and advices.

I would like to thank Dr. Gottfried Mieskes and Dr. Hans Dieter Schmitt for being great lab managers and scientists open for discussions and helping to solve problems.

I want to thank Sascha and Thomas from the Animal facility at Tower 6 for taking care of the rats and being extremely helpful during all this time. Thank you, Uwe, Annika and Monika from the mass spectrometry lab. Without your tremendous effort, I would still wait for my results.

I am very thankful to my friends, current and former members of the Neurobiology department and the institute for the nice working atmosphere. Big thanks to my lab friends Julia, Hale, Dominika, Angel, Beyenech and Sunit for the critical comments and discussions, but also for the support not only in the last weeks but also during the whole $\mathrm{PhD}$ time. Dear friends, we started this journey together and finish it together as a good 
team! Also not to forget our beloved Ursel, whose cakes (chocolate and zucchini, no nuts for Angel!) brought a lot of happiness and smiles to our coffee breaks!

I want to thank all my teachers and friends at the Faculty of Chemisty and Pharmacy, University of Sofia, Bulgaria and at the Weizmann Institute of Science, Israel! Thank you very much Dr. Donka Tasheva, Roi (Dr. Roi Avraham), Yossi (Prof. Yosef Yarden), dear Martie and Eliza, Silvia, Fresia, Gur, Moshit, Merav, Jean, Mattia, Maria, Shai, Eias...

I am deeply grateful to all my friends (I need to save space - can’t mention you all by name, I don't want the list to be longer than the thesis), especially to Yati and Alex, Stefan, Dennis, Tsveta, Vessi, Nikola, Veronika, Anna, Leigh, Louise, Seol-hee, Claudio and Luigi. My dearest ones - you know what you mean to me! You encourage, support and love me in good and bad times. You are the ones who mostly stood me, my black humor, jokes and annoying mood (with a glass of butter scotch either like Dennis, or with good (Korean) food and a lot of wine).

Dear YFU family members - what would I have done without you? I hug you warm dear Christel and Achim (music and soul mates, thank you for all the heart warming and delicious time together), Claudia, Bernd, Agnes.

I am cordially thankful for having part of my family in Braunschweig - thank you for all the special moments in my life, dear Hildegard, Jürgen, Elsa, Daniel and Nora!

Finally yet importantly, I want to thank you - my mom Vanya, my dad Nikolay and my sister Preslava for the love, support and sacrifices you made during the years in order to make it possible for me to study and follow my heart and passion.

Мамо, татко, како, посвещавам тази работа на вас, които ме подкрепяте винаги с много любов и с цената на много усилия и жертви! Благодаря ви и ви обичам много! 


\section{Appendix}

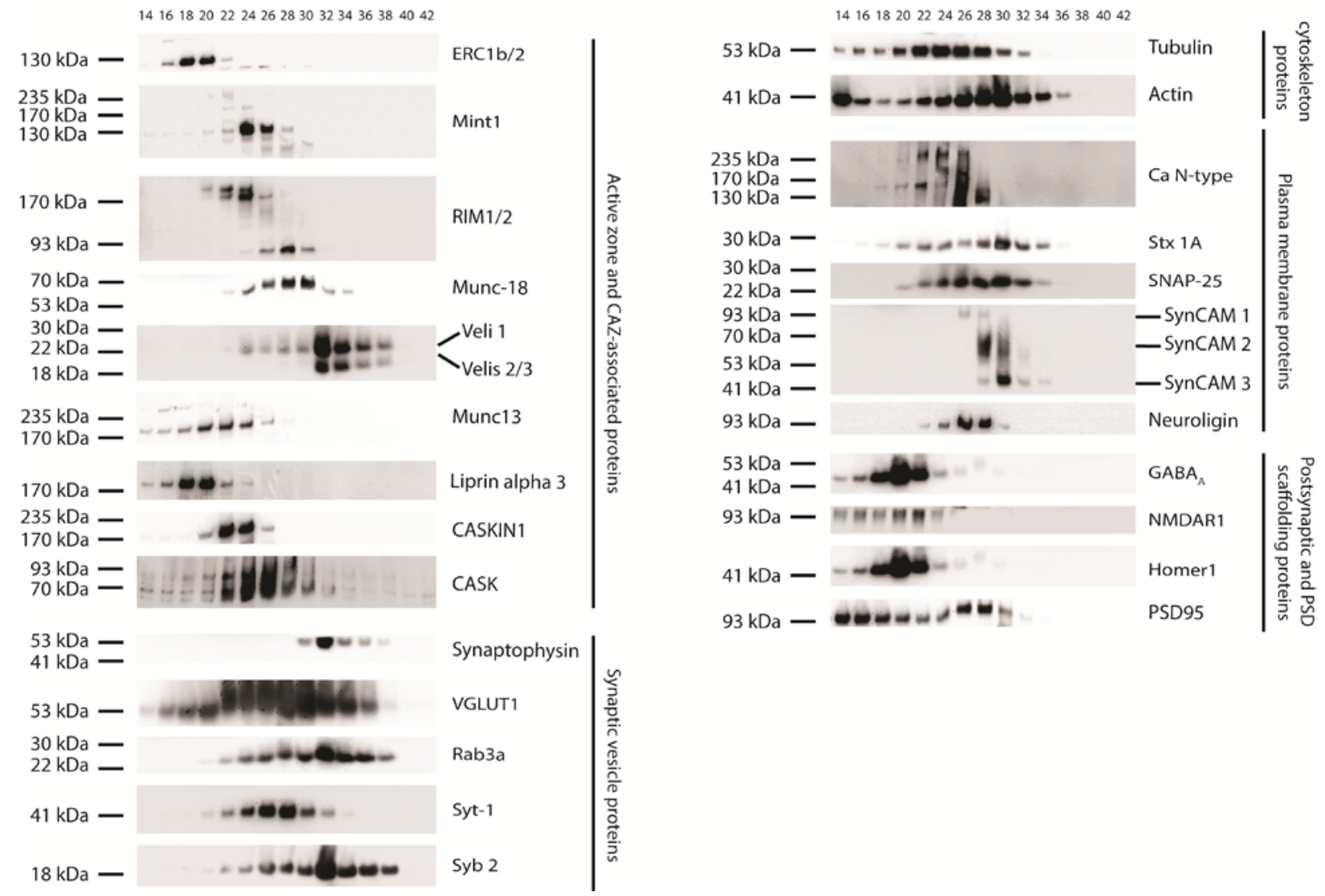

Appendix 1. Protein separation profile after TDOC solubilization of LP1 fraction. Pre-centrifuged extract after LP1 solubilization was loaded on Superose 6 10/300 GL gel filtration column. Fractions were collected (indicated above) and immunoprobed for proteins from five different classes - SV, AZ and CAZ-associated, PSD and PSDscaffolding, PM and cytoskeleton proteins. 


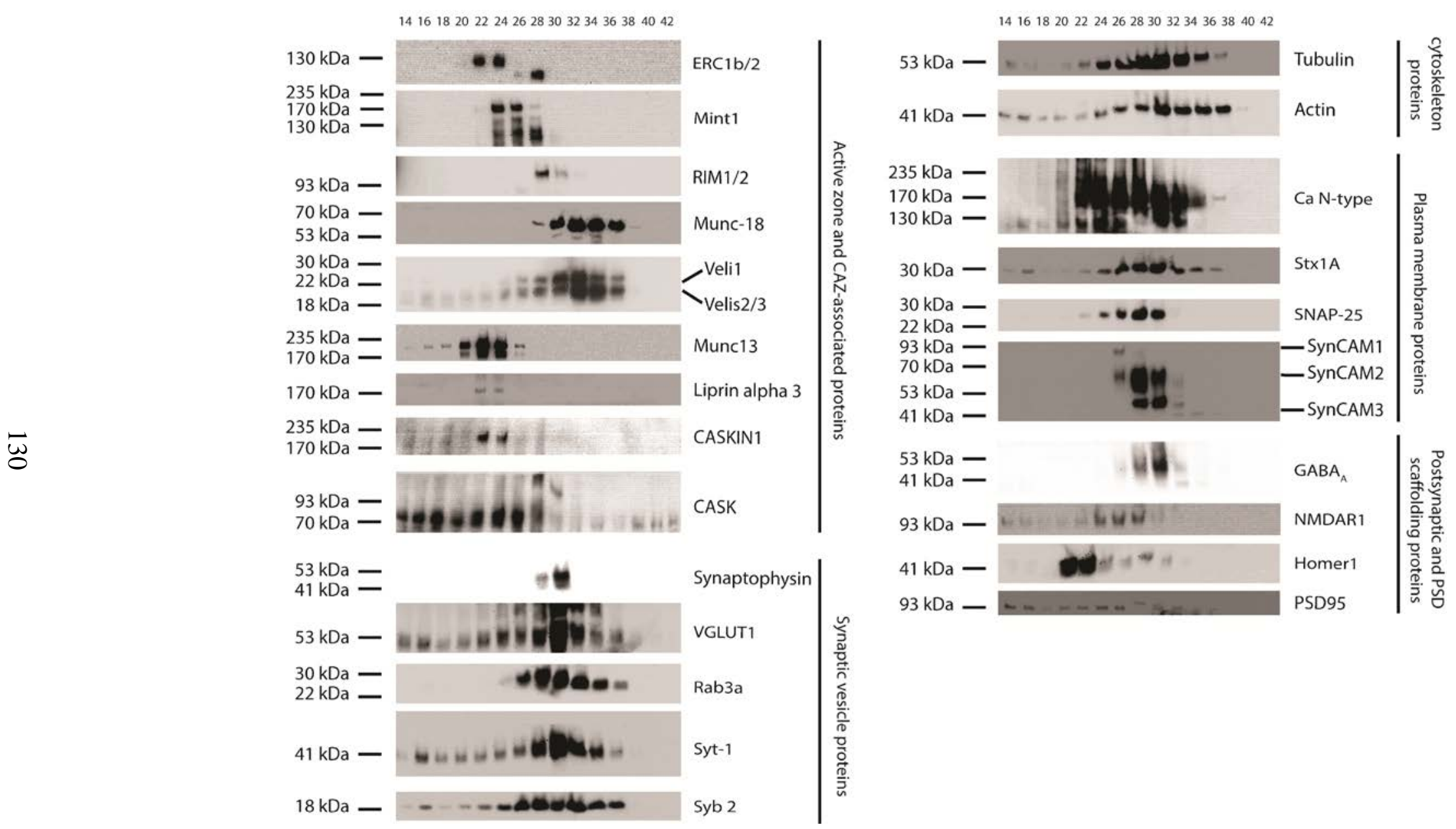

Appendix 2. Protein separation profile after DDM solubilization of LP1 fraction. Pre-centrifuged extract after LP1 solubilization was loaded on Superose 6 10/300 GL gel filtration column. Fractions were collected (indicated above) and immunoprobed for proteins from five different classes - SV, AZ and CAZ-associated, PSD and PSDscaffolding, PM and cytoskeleton proteins. 
A.

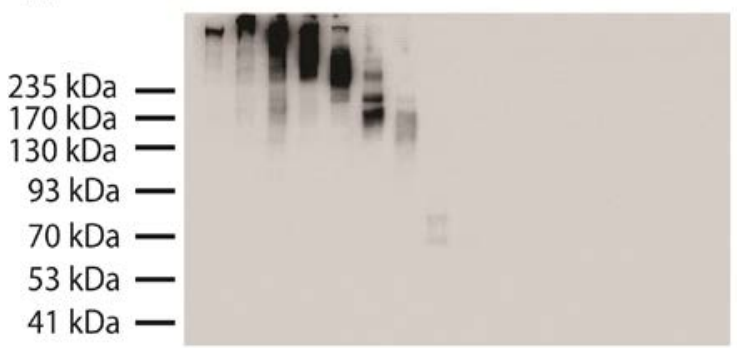

IB: Bassoon
B. $\quad 14161820222426283032343638404244$

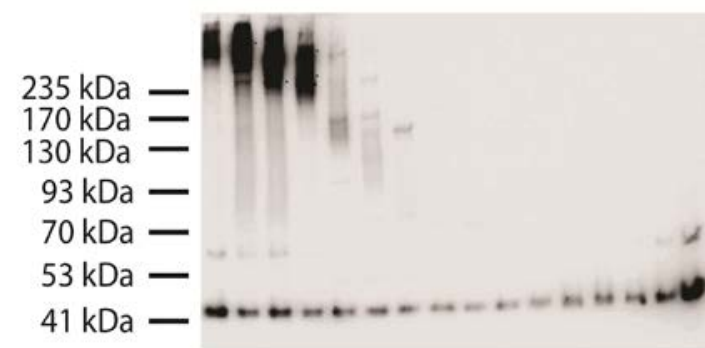

IB: Piccolo

Appendix 3. (A) Bassoon and (B) Piccolo elution profile after TDOC solubilization of LP1 fraction. After pre-centrifugation of TDOC-solubilized LP1 fraction at $100000 \mathrm{~g}$ for $20 \mathrm{~min}$ (TLA100.3), supernatant was separated on a gel filtration column (Superose 6 10/300 GL). Sample fractions were probed for both scaffolding proteins by immunoblotting (IB).

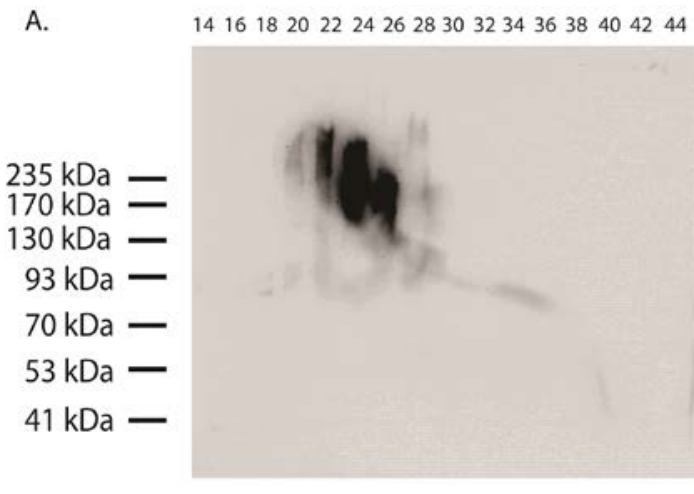

IB: Bassoon

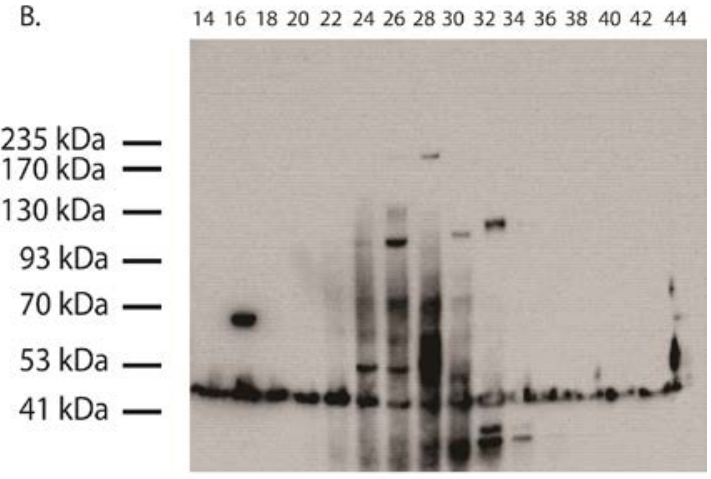

IB: Piccolo

Appendix 4. (A) Bassoon and (B) Piccolo elution after DDM solubilization of LP1 fraction. After precentrifugation of DDM-solubilized LP1 fraction at $100000 \mathrm{~g}$ for $20 \mathrm{~min}$ (TLA100.3), supernatant was separated on a gel filtration column (Superose 6 10/300 GL). Sample fractions were probed for both scaffolding proteins by immunoblotting (IB). As shown before, Piccolo was less extractable in DDM than in cholate and TDOC. Therefore, only protein degradation products and/or splice variants were detected by immunoblotting (IB). 
A.

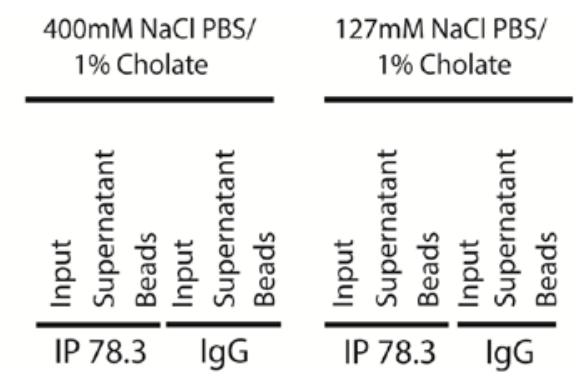

$235 \mathrm{kDa}$

$170 \mathrm{kDa}-$

$130 \mathrm{kDa}$

$70 \mathrm{kDa}-$

$53 \mathrm{kDa}-$

$41 \mathrm{kDa}-$

$30 \mathrm{kDa}-$

$22 \mathrm{kDa}$

$18 \mathrm{kDa}$

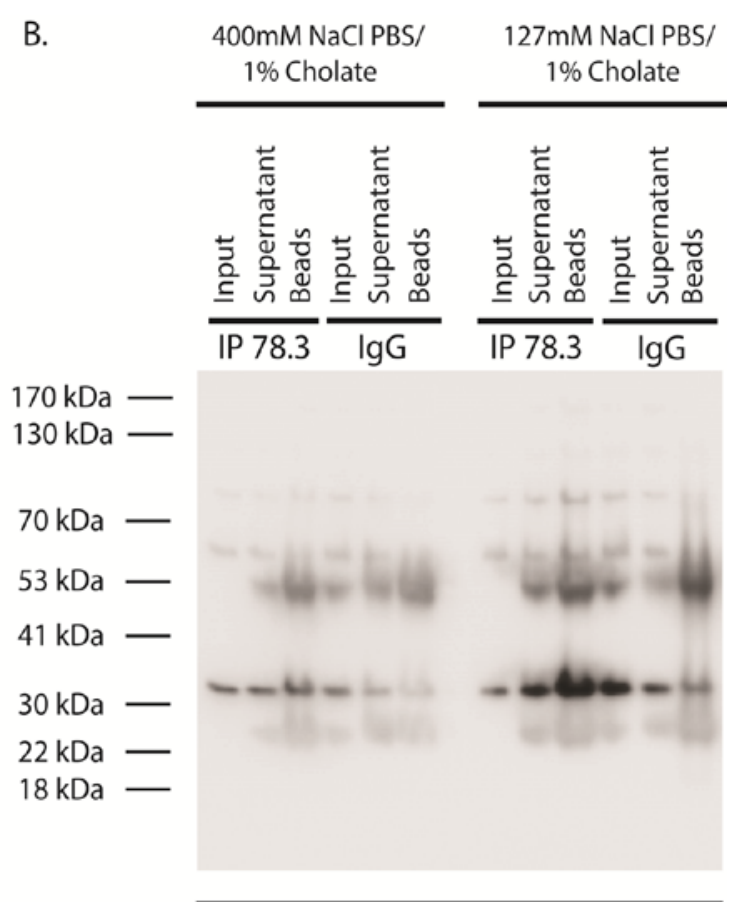

$\overline{2 \mathrm{~h} \text { incubation, Proteln G Dynabeads }}$

Appendix 5. Stx 1A immunoprecipitation from cholate-solubilized LP1 fraction with Cl 78.3 antibody. The pre-centrifuged suspension after LP1 solubilization was rotated for $2 \mathrm{~h}$ with Protein A- or Protein Gcoated Dynabeads, which were pre-incubated with an excess of $\mathrm{Cl} 78.3 \mathrm{Ab}$ or mouse IgG (control) antibody. After $2 \mathrm{~h}$, beads were washed with either low salt or high salt washing buffer. Input, supernatant after IP and beads were boiled in SDS sample buffer and their protein content was separated by SDS-PAGE. For immunodetection, mAb Cl 78.3 (1:1000) was used. 


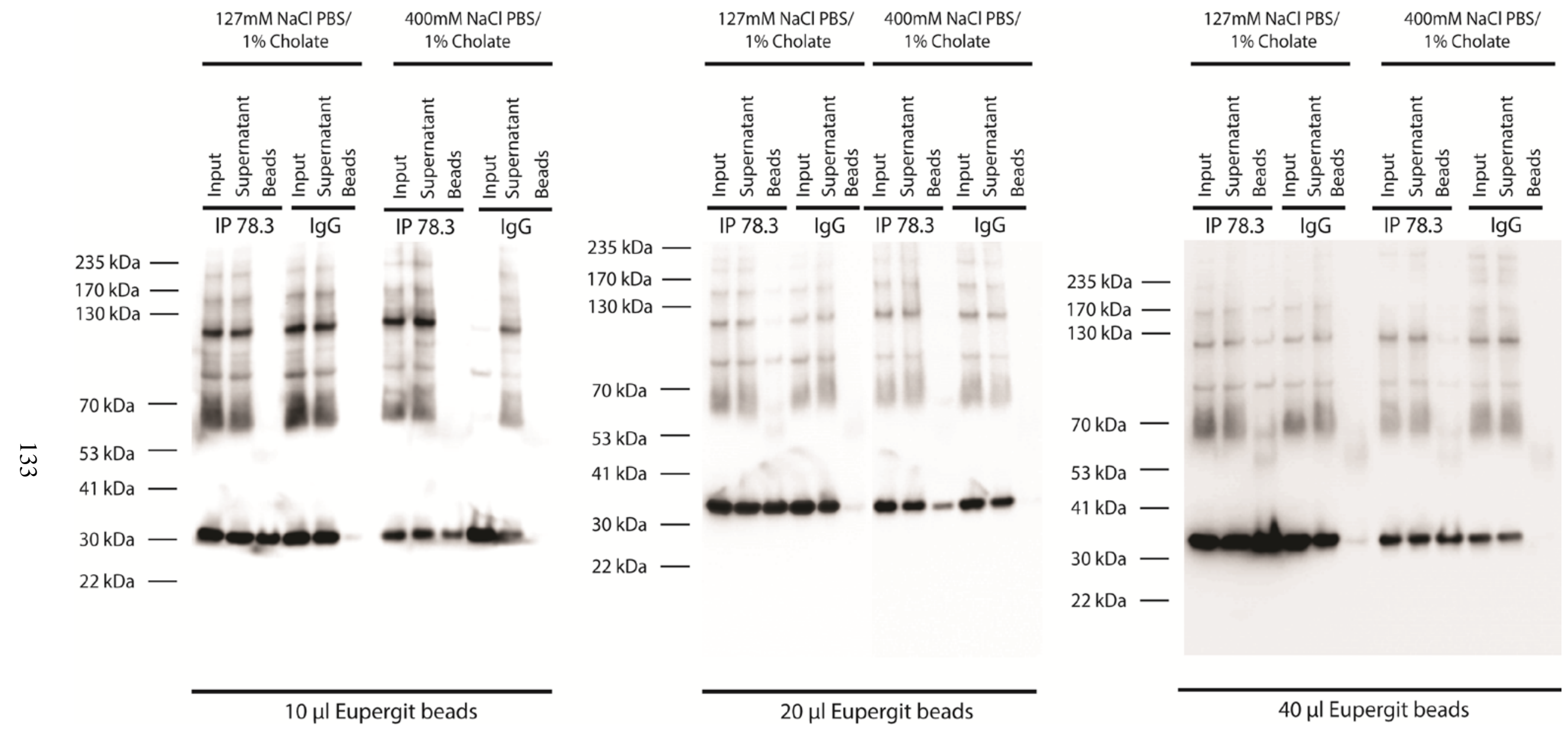

Appendix 6. Immunoisolation of stx 1A with Euprgit C1Z-78.3 beads via rabbit anti-mouse bridging IgG molecules. $\mathrm{Cl} 78.3 \mathrm{mAb}$ failed in direct coupling approach to Eupergit C1Z beads. A conjugate of Eupergit beads and anti-mouse IgGs was used to bind Cl $78.3 \mathrm{Ab}$. Different amounts $(10 \mu \mathrm{l}, 20 \mu \mathrm{l}$ or $40 \mu \mathrm{l})$ of the resulting immunomatrix were used under two washing conditions for optimal immunoisolation of the target. Beads were rotated with pre-centrifuged cholate-solubilized LP1 fraction for $2 \mathrm{~h}$ and washed with low or high salt IP washing buffer. 
Appendix 7. List of 158 significantly enriched proteins in stx 1 IP sample under high salt conditions.

\begin{tabular}{|c|c|}
\hline Protein ID & Protein name \\
\hline Q9QXG3 & Syntaxin $1 \mathrm{~A}$ \\
\hline P19804 & Nucleoside diphosphate kinase B \\
\hline P07825 & Synaptophysin \\
\hline Q9WU70-2 & Isoform 2 of Syntaxin-binding protein 5 \\
\hline P60881 & Synaptosomal-associated protein 25 \\
\hline P61265 & Syntaxin-1B \\
\hline Q5M7T6 & ATPase, $\mathrm{H}+$ transporting, lysosomal $38 \mathrm{kDa}, \mathrm{V} 0$ subunit d1 \\
\hline P11951 & Cytochrome c oxidase subunit $6 \mathrm{C}-2$ \\
\hline Q216B2 & V-H+ATPase subunit a1-III \\
\hline P63045 & Vesicle-associated membrane protein 2 \\
\hline Q63564 & Synaptic vesicle glycoprotein 2B \\
\hline P60905 & DnaJ homolog subfamily $\mathrm{C}$ member 5 \\
\hline Q6QIX3 & Zinc transporter 3 \\
\hline D4A0T0 & Protein Ndufb10 \\
\hline Q641Y2 & NADH dehydrogenase [ubiquinone] iron-sulfur protein 2, mitochondrial \\
\hline Q812E9 & Neuronal membrane glycoprotein M6-a \\
\hline D3ZU84 & Protein Stxbp5I \\
\hline Q5XIN6 & LETM1 and EF-hand domain-containing protein 1, mitochondrial \\
\hline 035458 & Vesicular inhibitory amino acid transporter \\
\hline P04775 & Sodium channel protein type 2 subunit alpha \\
\hline MORCJ9 & Protein LOC100911027 \\
\hline D3ZF13 & Acyl carrier protein \\
\hline D4A3V2 & NADH dehydrogenase [ubiquinone] 1 alpha subcomplex subunit 6 \\
\hline P12075 & Cytochrome c oxidase subunit 5B, mitochondrial \\
\hline P97610 & Synaptotagmin-12 \\
\hline Q5XIF3 & NADH dehydrogenase [ubiquinone] iron-sulfur protein 4, mitochondrial \\
\hline D3ZZ21 & NADH dehydrogenase (Ubiquinone) 1 beta subcomplex, 6 (Predicted) \\
\hline B0BNE6 & NADH dehydrogenase (Ubiquinone) Fe-S protein 8 (Predicted), isoform CRA \\
\hline D4A565 & NADH dehydrogenase (Ubiquinone) 1 beta subcomplex, 5 (Predicted), isoform CRA \\
\hline Q07647 & Solute carrier family 2 , facilitated glucose transporter member 3 \\
\hline Q9JHW5 & Vesicle-associated membrane protein 7 \\
\hline 070257 & Syntaxin-7 \\
\hline Q8SEZ5 & Cytochrome c oxidase subunit 2 \\
\hline B5DEL8 & NADH dehydrogenase (Ubiquinone) Fe-S protein 5 \\
\hline Q62634 & Vesicular glutamate transporter 1 \\
\hline Q6IRF8 & ATPase, $\mathrm{H}+$ transporting, lysosomal accessory protein 1 \\
\hline P19234 & NADH dehydrogenase [ubiquinone] flavoprotein 2, mitochondrial \\
\hline P63081 & V-type proton ATPase $16 \mathrm{kDa}$ proteolipid subunit \\
\hline P56603 & Secretory carrier-associated membrane protein 1 \\
\hline F1LNE4 & Glutamate receptor 2 \\
\hline G3V7P1 & Syntaxin-12 \\
\hline D3ZLT1 & NADH dehydrogenase (Ubiquinone) 1 beta subcomplex, 7 (Predicted) \\
\hline
\end{tabular}




\begin{tabular}{|c|c|}
\hline F1M9V2 & Vesicle-associated membrane protein 1 (Fragment) \\
\hline F1M585 & Protein Atp8a1 (Fragment) \\
\hline G3V6M3 & Synaptotagmin II \\
\hline F1LNY3 & Neural cell adhesion molecule 1 (Fragment) \\
\hline Q5XIH3 & NADH dehydrogenase (Ubiquinone) flavoprotein 1 \\
\hline P21707 & Synaptotagmin-1 \\
\hline Q5BK63 & NADH dehydrogenase [ubiquinone] 1 alpha subcomplex subunit 9, mitochondrial \\
\hline B2RYSO & Cox7a2 protein \\
\hline D3ZE15 & Protein Ndufa13 \\
\hline Q68FY0 & Cytochrome b-c1 complex subunit 1, mitochondrial \\
\hline D3ZCI5 & Protein Stxbp6 \\
\hline P11240 & Cytochrome c oxidase subunit $5 \mathrm{~A}$, mitochondrial \\
\hline A9UMV9 & Ndufa7 protein \\
\hline Q5PQZ9 & NADH dehydrogenase [ubiquinone] 1 subunit C2 \\
\hline Q66HF1 & NADH-ubiquinone oxidoreductase 75 kDa subunit, mitochondrial \\
\hline P10888 & Cytochrome c oxidase subunit 4 isoform 1 , mitochondrial \\
\hline Q63362 & NADH dehydrogenase [ubiquinone] 1 alpha subcomplex subunit 5 \\
\hline P19492 & Glutamate receptor 3 \\
\hline Q6P6S0 & Synaptosomal-associated protein 47 \\
\hline D4A4P3 & Protein LOC100361144 \\
\hline F1LQZ0 & Protein Tmem65 \\
\hline D3ZG43 & NADH dehydrogenase (Ubiquinone) Fe-S protein 3 (Predicted), isoform CRA \\
\hline Q8SEZ8 & NADH-ubiquinone oxidoreductase chain 1 (Fragment) \\
\hline Q02563 & Synaptic vesicle glycoprotein $2 \mathrm{~A}$ \\
\hline P07340 & Sodium/potassium-transporting ATPase subunit beta-1 \\
\hline B2RYW3 & NADH dehydrogenase (Ubiquinone) 1 beta subcomplex, 9 \\
\hline P31662 & Sodium-dependent neutral amino acid transporter SLC6A17 \\
\hline B2RYT5 & Cox7a2l protein \\
\hline Q63633-2 & Isoform 2 of Solute carrier family 12 member 5 \\
\hline Q5RJN0 & NADH dehydrogenase (Ubiquinone) Fe-S protein 7 \\
\hline P06685 & Sodium/potassium-transporting ATPase subunit alpha-1 \\
\hline F1LPG5 & Protein LOC688963 \\
\hline G3V846 & Excitatory amino acid transporter 1 \\
\hline D4A7L4 & NADH dehydrogenase (Ubiquinone) 1 beta subcomplex, 11 (Predicted) \\
\hline D3ZD09 & Cytochrome c oxidase subunit 6B1 \\
\hline F1LXA0 & NADH dehydrogenase (Ubiquinone) 1 alpha subcomplex, 12 (Predicted), isoform CRA \\
\hline Q63635 & Syntaxin-6 \\
\hline A9CMA6 & Transmembrane protein 163 \\
\hline P97846 & Contactin-associated protein 1 \\
\hline E9PTW1 & Protein Scamp3 \\
\hline B2RYS8 & NADH dehydrogenase (Ubiquinone) 1 beta subcomplex 8 \\
\hline Q5RKI8 & ATP-binding cassette sub-family B member 8 , mitochondrial \\
\hline P31399 & ATP synthase subunit $d$, mitochondrial \\
\hline Q920L2 & Succinate dehydrogenase [ubiquinone] flavoprotein subunit, mitochondrial \\
\hline
\end{tabular}




\begin{tabular}{|c|c|}
\hline 054755 & MIPP65 \\
\hline Q9JI66-3 & Isoform 3 of Electrogenic sodium bicarbonate cotransporter 1 \\
\hline Q6PCU8 & NADH dehydrogenase [ubiquinone] flavoprotein 3, mitochondrial \\
\hline Q5EGY4 & Synaptobrevin homolog YKT6 \\
\hline P06687 & Sodium/potassium-transporting ATPase subunit alpha-3 \\
\hline P23978 & Sodium- and chloride-dependent GABA transporter 1 \\
\hline B2RYX1 & LOC685322 protein \\
\hline F1M8G9 & Protein Ncam2 (Fragment) \\
\hline Q06QG6 & NADH-ubiquinone oxidoreductase chain 5 \\
\hline P21913 & Succinate dehydrogenase [ubiquinone] iron-sulfur subunit, mitochondrial \\
\hline P29419 & ATP synthase subunit e, mitochondrial \\
\hline P63138 & Gamma-aminobutyric acid receptor subunit beta-2 \\
\hline Q5BJZ3 & Nicotinamide nucleotide transhydrogenase \\
\hline P97829-2 & Isoform 2 of Leukocyte surface antigen CD47 \\
\hline P19643 & Amine oxidase [flavin-containing] B \\
\hline Q64304 & RATLE LLAT protein \\
\hline D3ZS58 & NADH dehydrogenase [ubiquinone] 1 alpha subcomplex subunit 2 \\
\hline P27605 & Hypoxanthine-guanine phosphoribosyltransferase \\
\hline F1M9A2 & Sodium/calcium exchanger 2 \\
\hline D3ZCZ9 & Protein LOC100912599 \\
\hline D3ZAF6 & ATP synthase subunit $f$, mitochondrial \\
\hline Q06QG7 & NADH-ubiquinone oxidoreductase chain 4 \\
\hline P60881-2 & Isoform 2 of Synaptosomal-associated protein 25 \\
\hline P19490 & Glutamate receptor 1 \\
\hline G3V851 & $\begin{array}{l}\text { Solute carrier family } 17 \text { (Sodium-dependent inorganic phosphate cotransporter), } \\
\text { member } 6\end{array}$ \\
\hline F1M882 & Secretory carrier-associated membrane protein 5 (Fragment) \\
\hline D4A133 & Protein Atp6v1a \\
\hline D4A7L6 & Protein Rpia \\
\hline D4A6L0 & Probable G-protein coupled receptor 158 \\
\hline P21571 & ATP synthase-coupling factor 6 , mitochondrial \\
\hline D3ZC50 & Uncharacterized protein \\
\hline D4ABK1 & Protein Syngr3 \\
\hline Q4KM74 & Vesicle-trafficking protein SEC22b \\
\hline G3V8F1 & Transporter \\
\hline P31596-2 & Isoform Glt-1A of Excitatory amino acid transporter 2 \\
\hline Q9ES40 & PRA1 family protein 3 \\
\hline $088917-2$ & Isoform 2 of Latrophilin-1 \\
\hline Q01728-2 & Isoform 2 of Sodium/calcium exchanger 1 \\
\hline Q6AY30 & Saccharopine dehydrogenase-like oxidoreductase \\
\hline D3ZFQ8 & Cytochrome c-1 (Predicted), isoform CRA \\
\hline Q4FZT0 & Stomatin-like protein 2 , mitochondrial \\
\hline P31421 & Metabotropic glutamate receptor 2 \\
\hline D4A3N4 & Adenylate cyclase 1 (Predicted) \\
\hline
\end{tabular}




\begin{tabular}{|c|c|}
\hline D3ZCIO & Glycerol kinase \\
\hline Q6PDU7 & ATP synthase subunit g, mitochondrial \\
\hline Q5M9H4 & ATPase, $\mathrm{Na}+/ \mathrm{K}+$ transporting, beta 2 polypeptide \\
\hline P62815 & V-type proton ATPase subunit B, brain isoform \\
\hline Q9QX10 & $\mathrm{Na}-\mathrm{K}-\mathrm{Cl}$ cotransporter \\
\hline Q62976 & Calcium-activated potassium channel subunit alpha-1 \\
\hline P11506-8 & Isoform ZB of Plasma membrane calcium-transporting ATPase 2 \\
\hline B4F773 & Ttyh1 protein \\
\hline P06686 & Sodium/potassium-transporting ATPase subunit alpha-2 \\
\hline Q6P9V1 & CD81 antigen \\
\hline B1WC61 & Acad9 protein \\
\hline Q63198 & Contactin-1 \\
\hline Q80ZA5-4 & Isoform 4 of Sodium-driven chloride bicarbonate exchanger \\
\hline Q6AY41 & Cell cycle control protein 50A \\
\hline Q91XV6-2 & Isoform 2 of FXYD domain-containing ion transport regulator 6 \\
\hline D3ZAA0 & PRA1 domain family 2 (Predicted) \\
\hline Q7TP78 & Aa2-258 \\
\hline Q6PW52 & GABA-A gamma2 long isoform \\
\hline M0R531 & Uncharacterized protein \\
\hline E9PSV8 & Neuronal membrane glycoprotein M6-b \\
\hline Q75Q39 & Mitochondrial import receptor subunit TOM70 \\
\hline Q9JI56 & Synaptosomal-associated protein \\
\hline B0BN30 & Mtch1 protein \\
\hline P29994-8 & Isoform 8 of Inositol 1,4,5-trisphosphate receptor type 1 \\
\hline P05708 & Hexokinase-1 \\
\hline G3V864 & Lipid phosphate phosphatase-related protein type 4 \\
\hline Q6MFX9 & Myelin oligodendrocyte glycoprotein \\
\hline Q561S0 & NADH dehydrogenase [ubiquinone] 1 alpha subcomplex subunit 10, mitochondrial \\
\hline F1LNC4 & Protein LOC100359512 \\
\hline
\end{tabular}


Appendix 8. List of 15 significantly enriched proteins in mock IP samples under high salt conditions

\begin{tabular}{|l|l|}
\hline Protein ID & Protein name \\
\hline P20761 & Ig gamma-2B chain C region \\
\hline D3ZBB2 & RCG64160 \\
\hline F1LVL4 & Uncharacterized protein \\
\hline M0R628 & Uncharacterized protein (Fragment) \\
\hline M9MMN0 & Protein Ighg3 (Fragment) \\
\hline M0RDZ5 & Uncharacterized protein (Fragment) \\
\hline F1LTN6 & Uncharacterized protein (Fragment) \\
\hline M0RBJ7 & Complement C3 \\
\hline F1LYF1 & Uncharacterized protein (Fragment) \\
\hline F1M5X4 & Uncharacterized protein (Fragment) \\
\hline P17078 & 60S ribosomal protein L35 \\
\hline M0R6R6 & Uncharacterized protein \\
\hline P54311 & Guanine nucleotide-binding protein $G(I) / G(S) / G(T)$ subunit beta-1 \\
\hline F1M195 & Uncharacterized protein (Fragment) \\
\hline D4A4I4 & Protein lqsec2 \\
\hline
\end{tabular}


Appendix 9. List of all 62 mitochondrial proteins identified above the threshold values in the stx 1 IP samples at high salt concentration.

\begin{tabular}{|c|c|}
\hline Protein ID & Protein name \\
\hline P19804 & Nucleoside diphosphate kinase B \\
\hline P11951 & Cytochrome c oxidase subunit $6 \mathrm{C}-2$ \\
\hline D4A0T0 & Protein Ndufb10 \\
\hline Q641Y2 & NADH dehydrogenase [ubiquinone] iron-sulfur protein 2, mitochondrial \\
\hline Q5XIN6 & LETM1 and EF-hand domain-containing protein 1, mitochondrial \\
\hline D4A3V2 & NADH dehydrogenase [ubiquinone] 1 alpha subcomplex subunit 6 \\
\hline P12075 & Cytochrome c oxidase subunit 5B, mitochondrial \\
\hline Q5XIF3 & NADH dehydrogenase [ubiquinone] iron-sulfur protein 4, mitochondrial \\
\hline D3ZZ21 & NADH dehydrogenase (Ubiquinone) 1 beta subcomplex, 6 (Predicted) \\
\hline BOBNE6 & NADH dehydrogenase (Ubiquinone) Fe-S protein 8 (Predicted), isoform CRA \\
\hline D4A565 & NADH dehydrogenase (Ubiquinone) 1 beta subcomplex, 5 (Predicted), isoform CRA \\
\hline Q8SEZ5 & Cytochrome c oxidase subunit 2 \\
\hline B5DEL8 & NADH dehydrogenase (Ubiquinone) Fe-S protein 5 \\
\hline P19234 & NADH dehydrogenase [ubiquinone] flavoprotein 2, mitochondrial \\
\hline D3ZLT1 & NADH dehydrogenase (Ubiquinone) 1 beta subcomplex, 7 (Predicted) \\
\hline Q5XIH3 & NADH dehydrogenase (Ubiquinone) flavoprotein 1 \\
\hline Q5BK63 & NADH dehydrogenase [ubiquinone] 1 alpha subcomplex subunit 9, mitochondrial \\
\hline B2RYSO & Cox7a2 protein \\
\hline D3ZE15 & Protein Ndufa13 \\
\hline Q68FY0 & Cytochrome b-c1 complex subunit 1 , mitochondrial \\
\hline P11240 & Cytochrome c oxidase subunit $5 \mathrm{~A}$, mitochondrial \\
\hline A9UMV9 & Ndufa7 protein \\
\hline Q5PQZ9 & NADH dehydrogenase [ubiquinone] 1 subunit C2 \\
\hline Q66HF1 & NADH-ubiquinone oxidoreductase $75 \mathrm{kDa}$ subunit, mitochondrial \\
\hline P10888 & Cytochrome c oxidase subunit 4 isoform 1, mitochondrial \\
\hline Q63362 & NADH dehydrogenase [ubiquinone] 1 alpha subcomplex subunit 5 \\
\hline D4A4P3 & Protein LOC100361144 \\
\hline F1LQZ0 & Protein Tmem65 \\
\hline D3ZG43 & NADH dehydrogenase (Ubiquinone) Fe-S protein 3 (Predicted), isoform CRA \\
\hline Q8SEZ8 & NADH-ubiquinone oxidoreductase chain 1 (Fragment) \\
\hline B2RYW3 & NADH dehydrogenase (Ubiquinone) 1 beta subcomplex, 9 \\
\hline B2RYT5 & Cox7a2l protein \\
\hline Q5RJNO & NADH dehydrogenase (Ubiquinone) Fe-S protein 7 \\
\hline F1LPG5 & Protein LOC688963 \\
\hline D4A7L4 & NADH dehydrogenase (Ubiquinone) 1 beta subcomplex, 11 (Predicted) \\
\hline D3ZD09 & Cytochrome c oxidase subunit 6B1 \\
\hline F1LXA0 & NADH dehydrogenase (Ubiquinone) 1 alpha subcomplex, 12 (Predicted), isoform CRA \\
\hline B2RYS8 & NADH dehydrogenase (Ubiquinone) 1 beta subcomplex 8 \\
\hline Q5RKI8 & ATP-binding cassette sub-family B member 8 , mitochondrial \\
\hline P31399 & ATP synthase subunit $d$, mitochondrial \\
\hline Q920L2 & Succinate dehydrogenase [ubiquinone] flavoprotein subunit, mitochondrial \\
\hline
\end{tabular}




\begin{tabular}{|c|c|}
\hline 054755 & MIPP65 \\
\hline Q6PCU8 & NADH dehydrogenase [ubiquinone] flavoprotein 3, mitochondrial \\
\hline B2RYX1 & LOC685322 protein \\
\hline Q06QG6 & NADH-ubiquinone oxidoreductase chain 5 \\
\hline P21913 & Succinate dehydrogenase [ubiquinone] iron-sulfur subunit, mitochondrial \\
\hline P29419 & ATP synthase subunit e, mitochondrial \\
\hline P19643 & Amine oxidase [flavin-containing] B (Monoamine oxidase type B) \\
\hline D3ZS58 & NADH dehydrogenase [ubiquinone] 1 alpha subcomplex subunit 2 \\
\hline D3ZCZ9 & Protein LOC100912599 \\
\hline D3ZAF6 & ATP synthase subunit $f$, mitochondrial \\
\hline Q06QG7 & NADH-ubiquinone oxidoreductase chain 4 \\
\hline P21571 & ATP synthase-coupling factor 6 , mitochondrial \\
\hline D3ZC50 & Uncharacterized protein \\
\hline D3ZFQ8 & Cytochrome c-1 (Predicted), isoform CRA \\
\hline Q4FZT0 & Stomatin-like protein 2 , mitochondrial \\
\hline Q6PDU7 & ATP synthase subunit g, mitochondrial \\
\hline B1WC61 & Acad9 protein \\
\hline Q7TP78 & Aa2-258 \\
\hline Q75Q39 & Mitochondrial import receptor subunit TOM70 \\
\hline BOBN30 & Mtch1 protein \\
\hline Q561S0 & NADH dehydrogenase [ubiquinone] 1 alpha subcomplex subunit 10 , mitochondrial \\
\hline
\end{tabular}


Appendix 10. List of 275 significantly enriched proteins in stx 1 IP sample under low salt conditions

\begin{tabular}{|c|c|}
\hline Protein ID & Protein name \\
\hline Q9QXG3 & Syntaxin $1 \mathrm{~A}$ \\
\hline Q9WU70-2 & Isoform 2 of Syntaxin-binding protein 5 \\
\hline P61265 & Syntaxin-1B \\
\hline P07825 & Synaptophysin \\
\hline F1LNY3 & Neural cell adhesion molecule 1 (Fragment) \\
\hline P60881 & Synaptosomal-associated protein 25 \\
\hline P19804 & Nucleoside diphosphate kinase B \\
\hline D3ZF13 & Acyl carrier protein \\
\hline P97610 & Synaptotagmin-12 \\
\hline Q5M7T6 & ATPase, $\mathrm{H}+$ transporting, lysosomal 38kDa, V0 subunit d1 \\
\hline D4A7L4 & NADH dehydrogenase (Ubiquinone) 1 beta subcomplex, 11 (Predicted) \\
\hline B2RYS8 & NADH dehydrogenase (Ubiquinone) 1 beta subcomplex 8 \\
\hline D3ZU84 & Protein Stxbp5I \\
\hline 035458 & Vesicular inhibitory amino acid transporter \\
\hline Q6IRF8 & ATPase, $\mathrm{H}+$ transporting, lysosomal accessory protein 1 \\
\hline Q5PQZ9 & NADH dehydrogenase [ubiquinone] 1 subunit $\mathrm{C} 2$ \\
\hline Q920L2 & Succinate dehydrogenase [ubiquinone] flavoprotein subunit, mitochondrial \\
\hline Q62634 & Vesicular glutamate transporter 1 \\
\hline F1M882 & Secretory carrier-associated membrane protein 5 (Fragment) \\
\hline Q5XIF3 & NADH dehydrogenase [ubiquinone] iron-sulfur protein 4, mitochondrial \\
\hline D3ZZ21 & NADH dehydrogenase (Ubiquinone) 1 beta subcomplex, 6 (Predicted) \\
\hline B5DEL8 & NADH dehydrogenase (Ubiquinone) Fe-S protein 5 \\
\hline F1M585 & Protein Atp8a1 (Fragment) \\
\hline D4A4P3 & Protein LOC100361144 \\
\hline D4A3V2 & NADH dehydrogenase [ubiquinone] 1 alpha subcomplex subunit 6 \\
\hline D3ZD09 & Cytochrome c oxidase subunit 6B1 \\
\hline Q63564 & Synaptic vesicle glycoprotein 2B \\
\hline Q216B2 & V-H+ATPase subunit a1-III \\
\hline Q06QG6 & NADH-ubiquinone oxidoreductase chain 5 \\
\hline P04775 & Sodium channel protein type 2 subunit alpha \\
\hline 054755 & MIPP65 \\
\hline P56603 & Secretory carrier-associated membrane protein 1 \\
\hline D4A0T0 & Protein Ndufb10 \\
\hline Q02563 & Synaptic vesicle glycoprotein $2 \mathrm{~A}$ \\
\hline Q07647 & Solute carrier family 2, facilitated glucose transporter member 3 \\
\hline Q8SEZ8 & NADH-ubiquinone oxidoreductase chain 1 (Fragment) \\
\hline F1M9V2 & Vesicle-associated membrane protein 1 (Fragment) \\
\hline Q5XIN6 & LETM1 and EF-hand domain-containing protein 1, mitochondrial \\
\hline B0BNE6 & NADH dehydrogenase (Ubiquinone) Fe-S protein 8 (Predicted), isoform CRA \\
\hline Q641Y2 & NADH dehydrogenase [ubiquinone] iron-sulfur protein 2, mitochondrial \\
\hline Q6QIX3 & Zinc transporter 3 \\
\hline B2RYX1 & LOC685322 protein \\
\hline
\end{tabular}




\begin{tabular}{|c|c|}
\hline MORCJ9 & Protein LOC100911027 \\
\hline F1LPG5 & Protein LOC688963 \\
\hline A9UMV9 & Ndufa7 protein \\
\hline D3ZCZ9 & Protein LOC100912599 \\
\hline Q6PCU8 & NADH dehydrogenase [ubiquinone] flavoprotein 3, mitochondrial \\
\hline F1LNE4 & Glutamate receptor 2 \\
\hline B2RYW3 & NADH dehydrogenase (Ubiquinone) 1 beta subcomplex, 9 \\
\hline 070257 & Syntaxin-7 \\
\hline F1M9A2 & Sodium/calcium exchanger 2 \\
\hline F1M8G9 & Protein Ncam2 (Fragment) \\
\hline D4A565 & NADH dehydrogenase (Ubiquinone) 1 beta subcomplex, 5 (Predicted), isoform CRA \\
\hline P19492 & Glutamate receptor 3 \\
\hline P23978 & Sodium- and chloride-dependent GABA transporter 1 \\
\hline P63045 & Vesicle-associated membrane protein 2 \\
\hline P97829-2 & Isoform 2 of Leukocyte surface antigen CD47 \\
\hline D4A133 & Protein Atp6v1a \\
\hline D3ZS58 & NADH dehydrogenase [ubiquinone] 1 alpha subcomplex subunit 2 \\
\hline D4A6L0 & Probable G-protein coupled receptor 158 \\
\hline Q63362 & NADH dehydrogenase [ubiquinone] 1 alpha subcomplex subunit 5 \\
\hline B2RYSO & Cox7a2 protein \\
\hline P60905 & DnaJ homolog subfamily C member 5 \\
\hline D3ZLT1 & NADH dehydrogenase (Ubiquinone) 1 beta subcomplex, 7 (Predicted) \\
\hline P21913 & Succinate dehydrogenase [ubiquinone] iron-sulfur subunit, mitochondrial \\
\hline P60881-2 & Isoform 2 of Synaptosomal-associated protein 25 \\
\hline Q5RJN0 & NADH dehydrogenase (Ubiquinone) Fe-S protein 7 \\
\hline B4F773 & Ttyh1 protein \\
\hline Q6P6S0 & Synaptosomal-associated protein 47 \\
\hline G3V7P1 & Syntaxin-12 \\
\hline 088917-2 & Isoform 2 of Latrophilin-1 \\
\hline P19643 & Amine oxidase [flavin-containing] B \\
\hline Q5EGY4 & Synaptobrevin homolog YKT6 \\
\hline Q5XIH3 & NADH dehydrogenase (Ubiquinone) flavoprotein 1 \\
\hline Q4FZT0 & Stomatin-like protein 2, mitochondrial \\
\hline Q561S0 & NADH dehydrogenase [ubiquinone] 1 alpha subcomplex subunit 10, mitochondrial \\
\hline P19490 & Glutamate receptor 1 \\
\hline D4A7L6 & Protein Rpia \\
\hline Q5RKI8 & ATP-binding cassette sub-family B member 8 , mitochondrial \\
\hline P62815 & V-type proton ATPase subunit B, brain isoform \\
\hline P97846 & Contactin-associated protein 1 \\
\hline Q5BK63 & NADH dehydrogenase [ubiquinone] 1 alpha subcomplex subunit 9, mitochondrial \\
\hline G3V8F1 & Transporter \\
\hline A9CMA6 & Transmembrane protein 163 \\
\hline B2RYS2 & Cytochrome b-c1 complex subunit 7 \\
\hline P19234 & NADH dehydrogenase [ubiquinone] flavoprotein 2 , mitochondrial \\
\hline
\end{tabular}




\begin{tabular}{|c|c|}
\hline P31662 & Sodium-dependent neutral amino acid transporter SLC6A17 \\
\hline Q64304 & RATLE LLAT protein \\
\hline Q66HF1 & NADH-ubiquinone oxidoreductase 75 kDa subunit, mitochondrial \\
\hline Q9JHW5 & Vesicle-associated membrane protein 7 \\
\hline F1LQZ0 & Protein Tmem65 \\
\hline G3V7L8 & ATPase, $\mathrm{H}+$ transporting, $\mathrm{V} 1$ subunit $\mathrm{E}$ isoform 1 , isoform CRA \\
\hline G3V9N1 & RCG21137 \\
\hline Q812E9 & Neuronal membrane glycoprotein M6-a \\
\hline Q7TP78 & Aa2-258 \\
\hline Q75Q39 & Mitochondrial import receptor subunit TOM70 \\
\hline G3V851 & $\begin{array}{l}\text { Solute carrier family } 17 \text { (Sodium-dependent inorganic phosphate cotransporter), } \\
\text { member } 6\end{array}$ \\
\hline P11951 & Cytochrome c oxidase subunit $6 \mathrm{C}-2$ \\
\hline B1WC61 & Acad9 protein \\
\hline B2RYT5 & Cox7a2l protein \\
\hline Q62976 & Calcium-activated potassium channel subunit alpha-1 \\
\hline P10888 & Cytochrome c oxidase subunit 4 isoform 1 , mitochondrial \\
\hline E9PTW1 & Protein Scamp3 \\
\hline Q8SEZ5 & Cytochrome c oxidase subunit 2 \\
\hline Q9QX10 & $\mathrm{Na}-\mathrm{K}-\mathrm{Cl}$ cotransporter \\
\hline D3ZG43 & NADH dehydrogenase (Ubiquinone) Fe-S protein 3 (Predicted), isoform CRA \\
\hline Q63633-2 & Isoform 2 of Solute carrier family 12 member 5 \\
\hline Q80ZA5-4 & Isoform 4 of Sodium-driven chloride bicarbonate exchanger \\
\hline Q68FY0 & Cytochrome b-c1 complex subunit 1, mitochondrial \\
\hline D3ZCI5 & Protein Stxbp6 \\
\hline Q9JI66-3 & Isoform 3 of Electrogenic sodium bicarbonate cotransporter 1 \\
\hline Q01728-2 & Isoform 2 of Sodium/calcium exchanger 1 \\
\hline Q4KM74 & Vesicle-trafficking protein SEC22b \\
\hline D3ZE15 & Protein Ndufa13 \\
\hline P11506-8 & Isoform ZB of Plasma membrane calcium-transporting ATPase 2 \\
\hline Q63635 & Syntaxin-6 \\
\hline D4ABK1 & Protein Syngr3 \\
\hline Q6P9V1 & CD81 antigen \\
\hline P31421 & Metabotropic glutamate receptor 2 \\
\hline P11240 & Cytochrome c oxidase subunit 5A, mitochondrial \\
\hline Q6AY30 & Saccharopine dehydrogenase-like oxidoreductase \\
\hline F1LXA0 & NADH dehydrogenase (Ubiquinone) 1 alpha subcomplex, 12 (Predicted), isoform CRA \\
\hline G3V6M3 & Synaptotagmin II \\
\hline 089089 & Pore-forming calcium channel alpha-1B subunit variant a \\
\hline Q62876 & Synaptogyrin-1 \\
\hline P07340 & Sodium/potassium-transporting ATPase subunit beta-1 \\
\hline P12075 & Cytochrome c oxidase subunit 5B, mitochondrial \\
\hline P06685 & Sodium/potassium-transporting ATPase subunit alpha-1 \\
\hline F1M7K7 & Voltage-dependent calcium channel gamma-8 subunit (Fragment) \\
\hline
\end{tabular}




\begin{tabular}{|c|c|}
\hline D4ACN8 & Plasminogen receptor (KT) \\
\hline P32551 & Cytochrome b-c1 complex subunit 2, mitochondrial \\
\hline Q91XV6-2 & Isoform 2 of FXYD domain-containing ion transport regulator 6 \\
\hline B1WBY5 & DnaJ (Hsp40) homolog, subfamily C, member 11 \\
\hline Q9JI56 & Synaptosomal-associated protein \\
\hline P21707 & Synaptotagmin-1 \\
\hline Q9QYF3 & Unconventional myosin-Va \\
\hline D3ZAA0 & PRA1 domain family 2 (Predicted) \\
\hline D3ZSU3 & Protein Slc7a14 \\
\hline Q6IMX4 & Lipid phosphate phosphohydrolase 3 \\
\hline D4A8V2 & Protein Ccdc177 \\
\hline P35565 & Calnexin \\
\hline Q06QG7 & $\mathrm{NADH}$-ubiquinone oxidoreductase chain 4 \\
\hline P35571 & Glycerol-3-phosphate dehydrogenase, mitochondrial \\
\hline D3ZW84 & Gamma-aminobutyric acid receptor subunit beta-3 (Fragment) \\
\hline Q63198 & Contactin-1 \\
\hline P63081 & V-type proton ATPase 16 kDa proteolipid subunit \\
\hline G3V864 & Lipid phosphate phosphatase-related protein type 4 \\
\hline P06687 & Sodium/potassium-transporting ATPase subunit alpha-3 \\
\hline Q9ES40 & PRA1 family protein 3 \\
\hline D4A0E2 & Protein Napg \\
\hline P47971 & Neuronal pentraxin-1 \\
\hline P63138 & Gamma-aminobutyric acid receptor subunit beta-2 \\
\hline MORDI5 & Protein Mcu \\
\hline P31422 & Metabotropic glutamate receptor 3 \\
\hline Q6AXV4 & Sorting and assembly machinery component 50 homolog \\
\hline G3V9Z6 & Septin 8 (Predicted) \\
\hline Q6PW52 & GABA-A gamma2 long isoform \\
\hline Q64568-3 & Isoform ZA of Plasma membrane calcium-transporting ATPase 3 \\
\hline P97710 & Tyrosine-protein phosphatase non-receptor type substrate 1 \\
\hline E9PSV8 & Neuronal membrane glycoprotein M6-b \\
\hline Q6P503 & ATPase, $\mathrm{H}+$ transporting, $\mathrm{V} 1$ subunit $\mathrm{D}$, isoform CRA \\
\hline M0R874 & Protein Atp9a (Fragment) \\
\hline G3V881 & Leucine rich repeat neuronal $6 \mathrm{~A}$, isoform CRA \\
\hline Q9Z0V5 & Peroxiredoxin-4 \\
\hline D3ZCIO & Glycerol kinase \\
\hline Q641Z9 & Protein Sdhc \\
\hline G3V7Y3 & ATP synthase subunit delta, mitochondrial \\
\hline D4A3N4 & Adenylate cyclase 1 (Predicted) \\
\hline Q76GL9 & Neutral amino acid transporter ASCT1 \\
\hline P62161 & Calmodulin \\
\hline P29994-8 & Isoform 8 of Inositol 1,4,5-trisphosphate receptor type 1 \\
\hline P31596-2 & Isoform Glt-1A of Excitatory amino acid transporter 2 \\
\hline Q9WUD2 & Transient receptor potential cation channel subfamily $\mathrm{V}$ member 2 \\
\hline
\end{tabular}




\begin{tabular}{|c|c|}
\hline Q5M9H4 & ATPase, $\mathrm{Na}+/ \mathrm{K}+$ transporting, beta 2 polypeptide \\
\hline D3ZSD8 & Protein Tmem143 \\
\hline M0R6L8 & Protein RGD1560220 \\
\hline A9UMW2 & Ndufa3 protein (Fragment) \\
\hline P31399 & ATP synthase subunit $d$, mitochondrial \\
\hline 008700 & Vacuolar protein sorting-associated protein 45 \\
\hline Q765A7 & GPI inositol-deacylase \\
\hline Q5BJZ3 & Nicotinamide nucleotide transhydrogenase \\
\hline Q5YLM1 & Sn1-specific diacylglycerol lipase alpha \\
\hline Q5FVI6 & V-type proton ATPase subunit C 1 \\
\hline P07153 & Dolichyl-diphosphooligosaccharide--protein glycosyltransferase subunit 1 \\
\hline D4ADS4 & Protein Mgst3 \\
\hline Q812B0 & Liver regeneration-related protein 1 \\
\hline P31647 & Sodium- and chloride-dependent GABA transporter 3 \\
\hline B0BN30 & Mtch1 protein \\
\hline F1LNC4 & Protein LOC100359512 \\
\hline P05708 & Hexokinase-1 \\
\hline P21571 & ATP synthase-coupling factor 6 , mitochondrial \\
\hline F1M8Y2 & Protein Tspan7 (Fragment) \\
\hline G3V846 & Excitatory amino acid transporter 1 \\
\hline D3ZWQ0 & Protein Prrt3 \\
\hline Q6IRL2 & Mitofusin 2 \\
\hline Q2THW7 & Palmitoyltransferase ZDHHC5 \\
\hline G3V8F5 & Mitochondrial import receptor subunit TOM40 homolog \\
\hline E9PU34 & Protein Rmnd1 \\
\hline Q64542-3 & Isoform ZA of Plasma membrane calcium-transporting ATPase 4 \\
\hline P36970-2 & $\begin{array}{l}\text { Isoform Cytoplasmic of Phospholipid hydroperoxide glutathione peroxidase, } \\
\text { mitochondrial }\end{array}$ \\
\hline F1LRE1 & Glutathione reductase \\
\hline Q6MFX9 & Myelin oligodendrocyte glycoprotein \\
\hline Q5UAJ5 & ATP synthase protein 8 \\
\hline P19511 & ATP synthase subunit $b$, mitochondrial \\
\hline D3ZEI4 & Protein Hepacam \\
\hline P62813 & Gamma-aminobutyric acid receptor subunit alpha-1 \\
\hline F1LMS1 & Voltage-dependent R-type calcium channel subunit alpha-1E \\
\hline D4A5X7 & Ganglioside-induced differentiation-associated-protein 1 (Predicted) \\
\hline 054701 & Sodium/potassium/calcium exchanger 2 \\
\hline Q6MG82 & Proline-rich transmembrane protein 1 \\
\hline Q75Q41 & Mitochondrial import receptor subunit TOM22 homolog \\
\hline P06686 & Sodium/potassium-transporting ATPase subunit alpha-2 \\
\hline P29419 & ATP synthase subunit e, mitochondrial \\
\hline Q52KJ9 & Protein Tmx1 \\
\hline 088871 & Gamma-aminobutyric acid type B receptor subunit 2 \\
\hline Q9Z142 & Transmembrane protein 33 \\
\hline
\end{tabular}




\begin{tabular}{|c|c|}
\hline Q9Z2Q7 & Syntaxin-8 \\
\hline D4A5W8 & Protein Pgs1 \\
\hline Q6AXS4 & Renin receptor \\
\hline P08050 & Gap junction alpha-1 protein \\
\hline D3ZUX5 & Coiled-coil-helix-coiled-coil-helix domain containing 3 (Predicted), isoform CRA \\
\hline Q9JI51 & Vesicle transport through interaction with t-SNAREs homolog $1 \mathrm{~A}$ \\
\hline F1M1G5 & Protein Kctd16 \\
\hline D3ZFB6 & Proline-rich transmembrane protein 2 \\
\hline B5DEN4 & L-lactate dehydrogenase \\
\hline B5DF41 & Syntaphilin \\
\hline P11505-4 & Isoform C of Plasma membrane calcium-transporting ATPase 1 \\
\hline Q04400 & Adenylate cyclase type 5 \\
\hline Q5M915 & Cytochrome b-c1 complex subunit 6, mitochondrial \\
\hline Q5XIN0 & Claudin domain containing 1 \\
\hline A1L1L6 & Mitochondrial Rho GTPase \\
\hline D3ZDH8 & Septin 5, isoform CRA \\
\hline F1LSG1 & Potassium channel subfamily T member 1 \\
\hline Q05BA4 & Myadm protein \\
\hline Q9R1Z0-2 & Isoform 2 of Voltage-dependent anion-selective channel protein 3 \\
\hline 089035 & Mitochondrial dicarboxylate carrier \\
\hline P61023 & Calcineurin B homologous protein 1 \\
\hline P97521 & Mitochondrial carnitine/acylcarnitine carrier protein \\
\hline MOR5F9 & Protein LOC100910864 \\
\hline Q97270 & Vesicle-associated membrane protein-associated protein $A$ \\
\hline Q9TEE8 & 9MURI Cytochrome c oxidase subunit 3 (Fragment) \\
\hline F1LYI5 & Protein RGD1564138 (Fragment) \\
\hline P27605 & Hypoxanthine-guanine phosphoribosyltransferase \\
\hline Q3KR86 & Mitochondrial inner membrane protein (Fragment) \\
\hline P34058 & Heat shock protein HSP 90-beta \\
\hline Q6PDU7 & ATP synthase subunit $g$, mitochondrial \\
\hline D3ZFQ8 & Cytochrome c-1 (Predicted), isoform CRA \\
\hline D3ZS75 & Protein Ndufc1 \\
\hline P63031 & Mitochondrial pyruvate carrier 1 \\
\hline D4A7N1 & Coiled-coil-helix-coiled-coil-helix domain-containing protein 6 , mitochondrial \\
\hline F1LPF3 & Choline transporter-like protein 1 (Fragment) \\
\hline P30191 & Gamma-aminobutyric acid receptor subunit alpha-6 \\
\hline P31423 & Metabotropic glutamate receptor 4 \\
\hline D3ZAF6 & ATP synthase subunit $f$, mitochondrial \\
\hline Q2TA68 & Dynamin-like $120 \mathrm{kDa}$ protein, mitochondrial \\
\hline F1LSY2 & Neuronal pentraxin receptor (Fragment) \\
\hline Q6IU14 & Acyl-CoA synthetase isoform 6 variant 2 \\
\hline Q8CFD0 & Sideroflexin-5 \\
\hline B3SVE9 & Neuroprotective protein 13 \\
\hline G3V986 & Potassium voltage gated channel, Shal-related family, member 2 \\
\hline
\end{tabular}




\begin{tabular}{|l|l|}
\hline Q80W89 & NADH dehydrogenase [ubiquinone] 1 alpha subcomplex subunit 11 \\
\hline Q6AXX6 & Redox-regulatory protein FAM213A \\
\hline P54921 & Alpha-soluble NSF attachment protein \\
\hline P32089 & Tricarboxylate transport protein, mitochondrial \\
\hline B0K020 & CDGSH iron-sulfur domain-containing protein 1 \\
\hline Q9JHZ9 & Sodium-coupled neutral amino acid transporter 3 \\
\hline P11507-2 & Isoform SERCA2A of Sarcoplasmic/endoplasmic reticulum calcium ATPase 2 \\
\hline E9PSK0 & Protein Man2b2 \\
\hline Q64548-2 & Isoform RTN1-S of Reticulon-1 \\
\hline Q5XIL1 & ATPase, H+ transporting, lysosomal V1 subunit H \\
\hline P35704 & Peroxiredoxin-2 \\
\hline F1M6X3 & Potassium voltage-gated channel subfamily KQT member 2 \\
\hline G3V6D3 & ATP synthase subunit beta \\
\hline B2RYK4 & Similar to RIKEN cDNA 1200007B05 \\
\hline D4A249 & Protein Mblac2 \\
\hline
\end{tabular}


Appendix 11. List of 457 significantly enriched proteins in the mock IP sample under low salt conditions.

\begin{tabular}{|c|c|}
\hline Protein ID & Protein name \\
\hline P20761 & Ig gamma-2B chain $\mathrm{C}$ region \\
\hline F1LVL4 & Uncharacterized protein \\
\hline D3ZBB2 & RCG64160 \\
\hline M0R628 & Uncharacterized protein (Fragment) \\
\hline M9MMNO & Protein Ighg3 (Fragment) \\
\hline M0RBJ7 & Complement C3 \\
\hline MORDZ5 & Uncharacterized protein (Fragment) \\
\hline F1M195 & Uncharacterized protein (Fragment) \\
\hline MOR6R6 & Uncharacterized protein \\
\hline F1LTN6 & Uncharacterized protein (Fragment) \\
\hline F1LYF1 & Uncharacterized protein (Fragment) \\
\hline D3ZYE2 & Uncharacterized protein \\
\hline F1M5X4 & Uncharacterized protein (Fragment) \\
\hline I7FKL4 & Myelin basic protein transcript variant 1 \\
\hline Q7M0E7 & $39 S$ ribosomal protein L14, mitochondrial \\
\hline D4A0X3 & Protein A830010M20Rik \\
\hline Q5BK32 & FAS-associated factor 2 \\
\hline D4AE56 & Prostaglandin E synthase 2 (Predicted), isoform CRA \\
\hline P13264 & Glutaminase kidney isoform, mitochondrial \\
\hline P62744 & AP-2 complex subunit sigma \\
\hline 008651 & D-3-phosphoglycerate dehydrogenase \\
\hline MORBX3 & Uncharacterized protein \\
\hline P49134 & Integrin beta-1 \\
\hline Q66HP7 & YME1-like 1 (S. cerevisiae) \\
\hline P22199 & Mineralocorticoid receptor \\
\hline Q5HZA9 & Transmembrane protein $126 \mathrm{~A}$ \\
\hline D3ZCB9 & Protein Fam92b \\
\hline P02091 & Hemoglobin subunit beta-1 \\
\hline D3ZF99 & Mitochondrial ribosomal protein L55 (Predicted), isoform CRA \\
\hline Q498U0 & Uncharacterized protein C4orf3 homolog \\
\hline$\overline{\text { Q3T1L5 }}$ & Dolichyl pyrophosphate Man9GIcNAc2 alpha-1,3-glucosyltransferase \\
\hline F1LRN5 & Netrin receptor DCC (Fragment) \\
\hline D4ADS9 & Protein Efr3a \\
\hline D4A9Z6 & Mitochondrial ribosomal protein S35 (Predicted) \\
\hline Q62761 & Casein kinase I isoform gamma-1 \\
\hline P28073 & Proteasome subunit beta type- 6 \\
\hline F1M7I8 & Protein RGD1565617 \\
\hline D3ZQX3 & Mitochondrial ribosomal protein S12 (Predicted) \\
\hline Q6XUZ6 & EG3-1RVC \\
\hline Q6Q3F5 & SID1 transmembrane family member 1 \\
\hline Q6PDV6 & 40 S ribosomal protein S14 \\
\hline F1LNM0 & Disks large homolog 1 \\
\hline
\end{tabular}




\begin{tabular}{|c|c|}
\hline Q5XIG5 & G kinase-anchoring protein 1 \\
\hline Q5FWU3 & Autophagy-related protein 9A \\
\hline BOBNBO & Golt1b protein \\
\hline D3Z949 & Protein RGD1561671 \\
\hline Q64560 & Tripeptidyl-peptidase 2 \\
\hline D4A229 & Serine/threonine-protein kinase $\mathrm{D}$ \\
\hline Q78P75 & Dynein light chain 2 , cytoplasmic \\
\hline P62074 & Mitochondrial import inner membrane translocase subunit Tim10 \\
\hline G3V8V3 & Phosphorylase \\
\hline Q6AYS7 & Aminoacylase-1A \\
\hline D3ZE26 & Protein Tmcc2 \\
\hline G3V7N9 & Complement C1q subcomponent subunit B \\
\hline F1M863 & Liprin-alpha-4 \\
\hline Q5FVJ0 & Protein RUFY3 \\
\hline Q9R1K2-4 & Isoform 4 of Teneurin-2 \\
\hline Q71UE8 & NEDD8 \\
\hline Q9R066-2 & Isoform 2 of Coxsackievirus and adenovirus receptor homolog \\
\hline C6JUM5 & Protocadherin gamma C5 \\
\hline D3ZAW2 & Protein Pisd (Fragment) \\
\hline D3ZGN7 & Protein Mical3 \\
\hline F1LNM4 & Protein LOC100909666 \\
\hline D3ZP98 & Histocompatibility 13 (Predicted), isoform CRA \\
\hline K4DIC3 & Cholinergic receptor, nicotinic, alpha polypeptide 4, isoform CRA \\
\hline D3ZY51 & Plakophilin 1 (Predicted) \\
\hline D3ZCH7 & Adducin 3 (Gamma), isoform CRA \\
\hline D3Z8L7 & Ras-related protein R-Ras \\
\hline G3V602 & Protein Xpr1 \\
\hline F1M3Y4 & Protein RGD1564184 \\
\hline D3ZPC4 & Neural cell adhesion molecule L1 \\
\hline D3ZG95 & Protein Efha2 \\
\hline B5DFG5 & Protein Sept6 \\
\hline F1LPB9 & Rabphilin-3A \\
\hline B2GUZ9 & Fam49b protein \\
\hline D4A899 & Protein Vps13a \\
\hline 035821 & Myb-binding protein $1 \mathrm{~A}$ \\
\hline P49088 & Asparagine synthetase [glutamine-hydrolyzing] \\
\hline D3ZF21 & Protein Gprin3 \\
\hline 035276 & Neuropilin-2 \\
\hline F1LSQ6 & Proteasome subunit alpha type \\
\hline 070196 & Prolyl endopeptidase \\
\hline Q9QUH6-5 & Isoform 5 of Ras GTPase-activating protein SynGAP \\
\hline Q5BK95 & Gdi1 protein \\
\hline F1M3T0 & ARF GTPase-activating protein GIT1 (Fragment) \\
\hline Q5XFV6 & Ribosomal protein L34 \\
\hline
\end{tabular}




\begin{tabular}{|c|c|}
\hline D3ZRN3 & Protein Actbl2 \\
\hline P68370 & Tubulin alpha-1A chain \\
\hline D3ZD48 & Protein Rab11fip2 \\
\hline B1WBY7 & ER lipid raft associated 1 \\
\hline D3ZJ86 & Sodium/hydrogen exchanger \\
\hline D3Z946 & Protein Tmem70 \\
\hline BOBMU4 & Presenilin associated, rhomboid-like \\
\hline F1M0Z1 & Protein Trio \\
\hline M0R5K2 & Protein Erbb2ip \\
\hline G3V856 & Neuronal guanine nucleotide exchange factor (Predicted) \\
\hline D3ZVN7 & Orexin \\
\hline $\mathrm{P} 27008$ & Poly [ADP-ribose] polymerase 1 \\
\hline F1LXY6 & Uncharacterized protein (Fragment) \\
\hline G3V945 & Aldehyde dehydrogenase family 5 , subfamily $A 1$ \\
\hline Q5BJZ2 & LOC367586 protein \\
\hline B1WC18 & Podocalyxin-like 2 \\
\hline F1LS01 & Protein Pcdh9 \\
\hline Q99P35 & Protein Syt7 \\
\hline Q6GT74 & Basigin \\
\hline P28023 & Dynactin subunit 1 \\
\hline P81795 & Eukaryotic translation initiation factor 2 subunit 3 \\
\hline Q5XI77 & Annexin \\
\hline F1LNF0 & Protein Myh14 \\
\hline P62494 & Ras-related protein Rab-11A \\
\hline D4ACG2 & IlvB (Bacterial acetolactate synthase)-like (Predicted), isoform CRA \\
\hline F1LMZ4 & Ribosome-releasing factor 2, mitochondrial \\
\hline Q5U302 & Catenin (Cadherin associated protein), alpha 1 \\
\hline E9PTD7 & Protein Kirrel3 \\
\hline P61314 & $60 \mathrm{~S}$ ribosomal protein $\mathrm{L} 15$ \\
\hline F1M790 & Prostaglandin F2 receptor negative regulator (Fragment) \\
\hline D3ZL45 & Protein RGD1560784 \\
\hline Q6P7B6 & Ephrin B1 \\
\hline Q62762 & Casein kinase I isoform gamma-2 \\
\hline 088767 & Protein DJ-1 \\
\hline D4A533 & Protein Tapt1 (Fragment) \\
\hline P04182 & Ornithine aminotransferase, mitochondrial \\
\hline F1M386 & Rap guanine nucleotide exchange factor 2 \\
\hline Q64617 & Protein kinase C eta type \\
\hline Q56A29 & Visinin-like 1 \\
\hline D3ZJY1 & Protein Mrpl28 \\
\hline 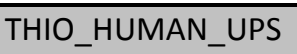 & UPS2 \\
\hline Q5BJQ0 & Chaperone activity of bc1 complex-like, mitochondrial \\
\hline D4A5X8 & Protein Ahcyl1 \\
\hline Q32Q06 & AP-1 complex subunit mu-1 \\
\hline
\end{tabular}




\begin{tabular}{|c|c|}
\hline Q63151-2 & Isoform Short of Long-chain-fatty-acid--CoA ligase 3 \\
\hline D3ZKD9 & Microtubule-associated protein \\
\hline Q5PPL3 & Sterol-4-alpha-carboxylate 3-dehydrogenase, decarboxylating \\
\hline Q6IRH7 & ClpB caseinolytic peptidase B homolog (E. coli) \\
\hline Q7TP91 & Ab1-205 \\
\hline Q68FU3 & Electron transfer flavoprotein subunit beta \\
\hline Q5U2T0 & Death associated protein 3 \\
\hline P07895 & Superoxide dismutase [Mn], mitochondrial \\
\hline F1M5X1 & Protein Rrbp1 \\
\hline Q5EB77 & Ras-related protein Rab-18 \\
\hline F1LZ55 & Protein LOC690114 (Fragment) \\
\hline D4AE00 & Protein Ap3b2 \\
\hline Q811P6 & Dimethyladenosine transferase 1 , mitochondrial \\
\hline BOBNA3 & Arginyl-tRNA synthetase 2 , mitochondrial \\
\hline Q8R491 & EH domain-containing protein 3 \\
\hline Q6PW35 & Neuronal cell adhesion molecule long isoform Nc7 \\
\hline G3V7U1 & Glutamate receptor, metabotropic 1, isoform CRA \\
\hline D4AAY3 & Protein Rasal2 \\
\hline D3ZXK3 & Protein Tacc2 \\
\hline F1LSL1 & Transcription factor Pur-beta \\
\hline D3ZK56 & Protein Rap2c \\
\hline D4ADA1 & Fibrinogen $\mathrm{C}$ domain containing 1 (Predicted) \\
\hline D3ZMJ7 & Protein Wnk2 \\
\hline D4ACU6 & Protein Gpr123 (Fragment) \\
\hline Q4G067 & Mitochondrial ribosomal protein L44 \\
\hline D3Z9Y3 & Protein Cerk \\
\hline D3ZH41 & Cytoskeleton-associated protein 4 (Predicted) \\
\hline P0C089 & Phosphatidylglycerophosphatase and protein-tyrosine phosphatase 1 \\
\hline Q6AYQ8 & Acylpyruvase FAHD1, mitochondrial \\
\hline Q4V887 & Zinc transporter ZIP6 \\
\hline F1M7T6 & Translocon-associated protein subunit gamma \\
\hline D3ZH98 & Uncharacterized protein \\
\hline Q4L2A2 & CD99 (Fragment) \\
\hline F1LTD1 & Uncharacterized protein (Fragment) \\
\hline F1LMT8 & Rab3 GTPase-activating protein non-catalytic subunit (Fragment) \\
\hline Q5BJP4 & Protein LOC100363776 \\
\hline D4A193 & Protein Reep1 \\
\hline Q9JMI9 & Short transient receptor potential channel 3 \\
\hline B5DEK8 & Vesicular, overexpressed in cancer, prosurvival protein 1 \\
\hline Q6IMA8 & ADP-ribosylation factor-like 10 \\
\hline Q62991 & Sec1 family domain-containing protein 1 \\
\hline 088420 & Sodium channel protein type 8 subunit alpha \\
\hline Q91V33 & $\mathrm{KH}$ domain-containing, RNA-binding, signal transduction-associated protein 1 \\
\hline Q9JIL3 & Interleukin enhancer-binding factor 3 \\
\hline
\end{tabular}




\begin{tabular}{|c|c|}
\hline Q8VHI8 & Vesicle transport protein SEC20 \\
\hline D4A7Q5 & DEAD (Asp-Glu-Ala-Asp) box polypeptide 28 (Predicted) \\
\hline Q5FVL8 & ATP-binding cassette, sub-family B (MDR/TAP), member 10 \\
\hline Q63638 & Striated muscle-specific serine/threonine-protein kinase \\
\hline P49804 & Regulator of G-protein signaling 8 \\
\hline D4A3H0 & Oxysterol-binding protein \\
\hline 008662 & 230kDa phosphatidylinositol 4-kinase \\
\hline MORAZ1 & Uncharacterized protein (Fragment) \\
\hline Q920Q0 & Paralemmin-1 \\
\hline Q6AYQ1 & Golgin subfamily A member 7 \\
\hline P61515 & Putative 60 S ribosomal protein $\mathrm{L} 37 \mathrm{a}$ \\
\hline E9PSS1 & Serine/threonine-protein kinase DCLK2 \\
\hline D3ZFK5 & Protein Spcs1 \\
\hline F1LNG7 & Protein Gna13 (Fragment) \\
\hline BОВМT9 & Protein Sqrdl \\
\hline P63182 & Cerebellin-1 \\
\hline B1WBX0 & Protein Fam57b \\
\hline M0R480 & Protein Sybu (Fragment) \\
\hline D3ZZIO & Protein Nipal3 \\
\hline P62142 & Serine/threonine-protein phosphatase PP1-beta catalytic subunit \\
\hline F1LW26 & RCG53373 \\
\hline F1M5M3 & Inactive serine/threonine-protein kinase TEX14 \\
\hline P97887 & Presenilin-1 \\
\hline D3ZZY4 & Protein LOC100360426 \\
\hline MORDF2 & Uncharacterized protein (Fragment) \\
\hline D3ZCF5 & E3 ubiquitin-protein ligase \\
\hline P12346 & Serotransferrin \\
\hline B5DF36 & Placenta-specific 8 \\
\hline D4A7T8 & Protein Fam81a \\
\hline Q6MG10 & Mitochondrial ribosomal protein S18B \\
\hline D3ZYX5 & Protein Myo6 \\
\hline Q7TP17 & Splicing factor U2AF 26 kDa subunit \\
\hline P49655 & ATP-sensitive inward rectifier potassium channel 10 \\
\hline Q62950 & Dihydropyrimidinase-related protein 1 \\
\hline LYSC_HUMAN_UPS & UPS2 \\
\hline B5DEX6 & Susd2 protein \\
\hline P00762 & Anionic trypsin-1 \\
\hline Q8CJG5 & Gene \\
\hline Q9JKM5 & Sphingosine 1-phosphate receptor 5 \\
\hline Q8VHW9 & Voltage-dependent calcium channel gamma-4 subunit \\
\hline D3ZQG0 & Protein RGD1309077 \\
\hline D4A771 & Protein LOC100362049 \\
\hline F1M8W5 & Disintegrin and metalloproteinase domain-containing protein 10 (Fragment) \\
\hline P07335 & Creatine kinase B-type \\
\hline
\end{tabular}




\begin{tabular}{|c|c|}
\hline B8YDD2 & HS1 binding protein variant $\mathrm{X}$ \\
\hline P13221 & Aspartate aminotransferase, cytoplasmic \\
\hline Q7TQ74 & Ac1573 \\
\hline F1LQ93 & Collagen alpha-1(IX) chain \\
\hline D4A4B1 & Mitochondrial ribosomal protein L15 (Predicted), isoform CRA \\
\hline D4AC23 & Protein Cct7 \\
\hline D3ZU27 & Protein Usp31 \\
\hline F1LV34 & Uncharacterized protein (Fragment) \\
\hline P10111 & Peptidyl-prolyl cis-trans isomerase $\mathrm{A}$ \\
\hline D3ZAN1 & Type I inositol 3,4-bisphosphate 4-phosphatase \\
\hline QOQER8 & Isocitrate dehydrogenase [NADP] (Fragment) \\
\hline F1M0B7 & Uncharacterized protein \\
\hline Q9ERC5 & Otoferlin \\
\hline D3ZNN7 & Anoctamin \\
\hline Q9JI66 & Electrogenic sodium bicarbonate cotransporter 1 \\
\hline $\mathrm{P} 21575-5$ & Isoform 5 of Dynamin-1 \\
\hline P24155 & Thimet oligopeptidase \\
\hline D3ZH53 & Protein RGD1561871 \\
\hline Q8R4Z9 & Mitofusin-1 \\
\hline A1L1L0 & Bobby sox homolog (Drosophila) \\
\hline Q5XI34 & Protein Ppp2r1a \\
\hline F1M013 & Protein LOC100910109 (Fragment) \\
\hline P68511 & 14-3-3 protein eta \\
\hline Q6AY58 & B-cell receptor-associated protein 31 \\
\hline D4A3K5 & Histone H1.1 \\
\hline G3V894 & Muscarinic acetylcholine receptor M4 \\
\hline G3V7Z6 & ATP-binding cassette sub-family D member 2 \\
\hline MORB74 & Protein Ipo5 \\
\hline P85108 & Tubulin beta-2A chain \\
\hline G3V9U7 & ATPase, $\mathrm{Ca}++$ transporting, ubiquitous, isoform CRA \\
\hline Q5M9G3 & Caprin-1 \\
\hline Q5XIU4 & B-cell receptor-associated protein 29 \\
\hline F1LST1 & Fibronectin \\
\hline D3ZF50 & Protein RGD1310335 \\
\hline M0R5Z5 & Uncharacterized protein \\
\hline F1LUS1 & Uncharacterized protein (Fragment) \\
\hline Q5PQV5 & Trophoblast glycoprotein \\
\hline 035244 & Peroxiredoxin-6 \\
\hline Q6P791 & Ragulator complex protein LAMTOR1 \\
\hline M0R4G1 & Uncharacterized protein \\
\hline D3ZCR2 & Protein Tm9sf3 \\
\hline D3ZZO2 & Uncharacterized protein \\
\hline Q71RJ2 & Voltage-dependent calcium channel gamma-2 subunit \\
\hline B5DF26 & Similar to oxysterol-binding protein-like protein 8 isoform a \\
\hline
\end{tabular}




\begin{tabular}{|c|c|}
\hline D4A978 & Protein Plcd3 \\
\hline D4A2F1 & Agrin \\
\hline M0R692 & Uncharacterized protein (Fragment) \\
\hline Q63754 & Beta-synuclein \\
\hline G3V8L9 & Polymerase I and transcript release factor \\
\hline D3ZAA9 & $\begin{array}{l}\text { Membrane protein, palmitoylated } 2 \text { (MAGUK p55 subfamily member } 2 \text { ), isoform } \\
\text { CRA }\end{array}$ \\
\hline D4A7X1 & Protein Mrps16 \\
\hline Q6AXX5 & Protein Rdh11 \\
\hline B5DEX3 & Copine 8 protein \\
\hline D3ZFQ3 & Protein Nubpl \\
\hline Q6AY17 & Alpha/beta hydrolase domain-containing protein 17B \\
\hline P11598 & Protein disulfide-isomerase $\mathrm{A} 3$ \\
\hline Q6AYT7 & Monoacylglycerol lipase ABHD12 \\
\hline G3V963 & RCG47487, isoform CRA \\
\hline P62914 & $60 S$ ribosomal protein $\mathrm{L} 11$ \\
\hline Q6P9V6 & Proteasome subunit alpha type \\
\hline Q510J0 & Immunoglobulin heavy chain (Gamma polypeptide) \\
\hline Q5XIM9 & T-complex protein 1 subunit beta \\
\hline F1LPT0 & Gap junction protein (Fragment) \\
\hline P20417 & Tyrosine-protein phosphatase non-receptor type 1 \\
\hline 035952-2 & Isoform 2 of Hydroxyacylglutathione hydrolase, mitochondrial \\
\hline D3ZRX7 & Protein Pcdh10 \\
\hline P16261 & Graves disease carrier protein (Fragment) \\
\hline Q9QYV1 & Tomoregulin-1 \\
\hline F1M5L5 & Uncharacterized protein (Fragment) \\
\hline G3V7Y7 & Sodium/hydrogen exchanger \\
\hline Q7TP48 & Adipocyte plasma membrane-associated protein \\
\hline F1MAA3 & Protein LOC100909464 \\
\hline M0R9Z7 & Uncharacterized protein \\
\hline P63004 & Platelet-activating factor acetylhydrolase IB subunit alpha \\
\hline D3ZEX7 & Protein Spire1 \\
\hline Q4G061 & Eukaryotic translation initiation factor 3 subunit B \\
\hline F1LTJ9 & Uncharacterized protein (Fragment) \\
\hline G3V9J8 & Glycerol-3-phosphate acyltransferase 1, mitochondrial \\
\hline D4A3H5 & Protein Clcn6 \\
\hline F1LUM5 & Protein Tubal3 \\
\hline P20171 & GTPase HRas \\
\hline F1MAQ3 & Protein Hgsnat \\
\hline Q6QI16 & LRRGT00192 \\
\hline D3ZBN4 & Protein RGD1310769 \\
\hline F1LQQ8 & Beta-glucuronidase \\
\hline P16617 & Phosphoglycerate kinase 1 \\
\hline Q8BHI5 & O-acyltransferase \\
\hline
\end{tabular}




\begin{tabular}{|c|c|}
\hline Q66H18 & Protein Sypl1 \\
\hline Q5XIK2 & Thioredoxin-related transmembrane protein 2 \\
\hline Q5HZE0 & Mitochondrial carnitine/acylcarnitine carrier protein CACL \\
\hline D4A435 & Protein Icam5 \\
\hline B4F7E6 & Syntaxin 3 \\
\hline P63322 & Ras-related protein Ral-A \\
\hline M0R5V7 & Murinoglobulin-2 (Fragment) \\
\hline Q70AM4 & Kinesin 13B \\
\hline Q5RK08 & Glioblastoma amplified sequence \\
\hline G3V879 & Ubiquinone biosynthesis protein $\mathrm{COQ7}$ homolog \\
\hline Q6AYT3 & tRNA-splicing ligase RtcB homolog \\
\hline D4A9C3 & Protein Psd3 \\
\hline MORDL8 & Protein RGD1561465 \\
\hline B3GNI6-3 & Isoform 3 of Septin-11 \\
\hline MORDY2 & Protein Fam185a \\
\hline D3ZIP8 & Protein Endod1 \\
\hline Q5PPG2 & Legumain \\
\hline M0RC66 & Adenylate kinase isoenzyme 1 (Fragment) \\
\hline Q5BJS4 & FUN14 domain-containing protein 1 \\
\hline F1M9X0 & Transient receptor potential cation channel subfamily M member 1 \\
\hline P04762 & Catalase \\
\hline F1LZY6 & Uncharacterized protein (Fragment) \\
\hline F1LWD0 & Uncharacterized protein (Fragment) \\
\hline D3ZWR4 & Copine VII (Predicted), isoform CRA \\
\hline D4A318 & Phospholipase D1 \\
\hline Q68FR6 & Elongation factor 1-gamma \\
\hline P34067 & Proteasome subunit beta type- 4 \\
\hline F1LT85 & Uncharacterized protein (Fragment) \\
\hline F1M1R0 & Uncharacterized protein \\
\hline Q71DI1 & Dermcidin \\
\hline M0R5Q9 & Glycerophosphodiester phosphodiesterase 1 \\
\hline P54313 & Guanine nucleotide-binding protein $\mathrm{G}(\mathrm{I}) / \mathrm{G}(\mathrm{S}) / \mathrm{G}(\mathrm{T})$ subunit beta-2 \\
\hline B5DEL9 & RCG62292, isoform CRA \\
\hline D3ZCJ3 & Protein Mfsd6 \\
\hline P58295-2 & Isoform b of Sodium- and chloride-dependent glycine transporter 2 \\
\hline P19945 & $60 \mathrm{~S}$ acidic ribosomal protein $\mathrm{PO}$ \\
\hline F1M4R1 & Uncharacterized protein (Fragment) \\
\hline D4A3E8 & Mitochondrial ribosomal protein S27 (Predicted), isoform CRA \\
\hline Q9R1T3 & Cathepsin Z \\
\hline P27139 & Carbonic anhydrase 2 \\
\hline Q5FVQ8 & NLR family member X1 \\
\hline Q4V8C2 & Centromere/kinetochore protein zw10 homolog \\
\hline P84889 & Vang-like protein 2 \\
\hline F1M3X3 & Uncharacterized protein (Fragment) \\
\hline
\end{tabular}




\begin{tabular}{|c|c|}
\hline D3ZCL4 & Protein Zscan18 \\
\hline P42123 & L-lactate dehydrogenase B chain \\
\hline Q63128 & CPG2 protein \\
\hline B5DEP7 & Protein LOC100911683 \\
\hline Q3B7V5 & Protein Rab2b \\
\hline B2RYN6 & Adaptor-related protein complex 1 , gamma 1 subunit, isoform CRA \\
\hline P43278 & Histone H1.0 \\
\hline F1M7V6 & Cell adhesion molecule 4 (Fragment) \\
\hline D3ZDC2 & Protein Slc43a2 \\
\hline D4AAS1 & G protein-coupled receptor 162 (Predicted) \\
\hline D3ZAN3 & Alpha glucosidase 2 alpha neutral subunit (Predicted) \\
\hline F1LX12 & Protein Frmd5 \\
\hline H9KVG0 & Serine/threonine-protein kinase BRSK2 (Fragment) \\
\hline Q8CFN2-2 & Isoform 2 of Cell division control protein 42 homolog \\
\hline Q9WV63 & Kinesin-like protein KIF2A \\
\hline P38983 & $40 S$ ribosomal protein SA \\
\hline Q6P6R2 & Dihydrolipoyl dehydrogenase, mitochondrial \\
\hline Q3ZB98-5 & Isoform 5 of Breast carcinoma-amplified sequence 1 homolog \\
\hline 008589 & Phospholemman \\
\hline P10818 & Cytochrome c oxidase subunit $6 \mathrm{~A} 1$, mitochondrial \\
\hline B2RZD1 & Protein Sec61b \\
\hline P84100 & $60 S$ ribosomal protein L19 \\
\hline Q6AYL4 & RIB43A-like with coiled-coils protein 1 \\
\hline D3ZTN1 & Protein Tesc \\
\hline D3Z9K9 & $\begin{array}{l}\text { Glycerophosphodiester phosphodiesterase domain containing } 2 \text { (Predicted), } \\
\text { isoform CRA }\end{array}$ \\
\hline Q6AY19 & Uncharacterized aarF domain-containing protein kinase 4 \\
\hline D4A3D4 & Abhydrolase domain containing 3 (Predicted) \\
\hline B2GUX6 & RGD1312005 protein \\
\hline Q5FVQ4 & Malectin \\
\hline F1MAG7 & Protein Ptpru \\
\hline Q6JP77-2 & Isoform Gamma of A-kinase anchor protein 7 isoforms delta and gamma \\
\hline Q07936 & Annexin A2 \\
\hline D4A604 & Phosphatidylinositol glycan, class T (Predicted), isoform CRA \\
\hline 055173 & 3-phosphoinositide-dependent protein kinase 1 \\
\hline F1LN88 & Aldehyde dehydrogenase, mitochondrial \\
\hline Q66HF3 & Electron transfer flavoprotein-ubiquinone oxidoreductase, mitochondrial \\
\hline D3KR63 & CAMPS \\
\hline $\mathrm{D} 4 \mathrm{~A} 8 \mathrm{X7}$ & LOC361111 (Predicted), isoform CRA \\
\hline P84076 & Neuron-specific calcium-binding protein hippocalcin \\
\hline B1WC28 & Histone $\mathrm{H} 2 \mathrm{~A}$ \\
\hline Q569C0 & Transmembrane protein 100 \\
\hline Q5IOH4 & Transmembrane and coiled-coil domains protein 1 \\
\hline D3ZLU0 & Protein $\mathrm{C} 2 \mathrm{~cd} 4 \mathrm{c}$ \\
\hline
\end{tabular}




\begin{tabular}{|c|c|}
\hline G3V667 & Integrin, alpha 6, isoform CRA \\
\hline Q32Q54 & Protein Uqcc \\
\hline Q9QZA2 & Programmed cell death 6-interacting protein \\
\hline Q512Z0 & Protein kinase $\mathrm{C}$ and casein kinase substrate in neurons 3 \\
\hline P70549 & Sodium/calcium exchanger 3 \\
\hline Q8VGC3-2 & Isoform 2 of Voltage-dependent L-type calcium channel subunit beta- 2 \\
\hline F1LU71 & AU RNA binding protein/enoyl-coenzyme A hydratase (Predicted), isoform CRA \\
\hline P01830 & Thy-1 membrane glycoprotein \\
\hline Q5U2V8 & ER membrane protein complex subunit 3 \\
\hline Q5XI78 & 2-oxoglutarate dehydrogenase, mitochondrial \\
\hline D3ZPN5 & PAP associated domain containing 1 (Predicted) \\
\hline Q68FV0 & Transmembrane protein $178 \mathrm{~A}$ \\
\hline D3ZA31 & Myotubularin related protein 2 (Predicted), isoform CRA \\
\hline Q66HI4 & Tissue factor \\
\hline D3ZX87 & Protein LOC100910017 \\
\hline D3ZYK3 & Potassium voltage-gated channel, Shal-related family, member 1 \\
\hline Q62717 & Calcium-dependent secretion activator 1 \\
\hline Q5XIP9 & Transmembrane protein 43 \\
\hline Q5RK00 & $39 S$ ribosomal protein $L 46$, mitochondrial \\
\hline F1M3E9 & Uncharacterized protein (Fragment) \\
\hline $\mathrm{Q} 8 \mathrm{CHJ1}$ & Phosphatidylinositol glycan anchor biosynthesis class U protein \\
\hline Q9ERS1 & Potassium channel subfamily $\mathrm{K}$ member 12 \\
\hline P09606 & Glutamine synthetase \\
\hline D4AB01 & Histidine triad nucleotide binding protein 2 (Predicted), isoform CRA \\
\hline Q498E0 & Thioredoxin domain-containing protein 12 \\
\hline F1M6U3 & Protein Pitpnm3 (Fragment) \\
\hline Q9WVJ4 & Synaptojanin-2-binding protein \\
\hline E9PT29 & Uncharacterized protein \\
\hline MORAQ6 & Hexokinase-1 \\
\hline P40307 & Proteasome subunit beta type- 2 \\
\hline P51792-2 & Isoform 2 of $\mathrm{H}(+) / \mathrm{Cl}(-)$ exchange transporter 3 \\
\hline F7F134 & Voltage-dependent calcium channel subunit alpha-2/delta-1 \\
\hline F1M9C9 & Protein Hars2 \\
\hline E9PSV5 & Protein Psat1 \\
\hline Q9Z1T4-2 & Isoform 2 of Connector enhancer of kinase suppressor of ras 2 \\
\hline Q66HA9 & Protein Sema4a \\
\hline B2RYTO & Mitochondrial ribosomal protein S21 (Predicted), isoform CRA \\
\hline Q6P9U5 & Ribosomal protein L9 \\
\hline P26772 & $10 \mathrm{kDa}$ heat shock protein, mitochondrial \\
\hline F1LUG5 & Protein 2310067B10Rik \\
\hline G3V612 & Adenylate cyclase 3 \\
\hline D3ZL30 & Protein Mast3 \\
\hline Q499N5 & Acyl-CoA synthetase family member 2 , mitochondrial \\
\hline MOR7A3 & Uncharacterized protein (Fragment) \\
\hline
\end{tabular}




\begin{tabular}{|c|c|}
\hline B1WC67 & Protein Slc25a24 \\
\hline P56819 & Beta-secretase 1 \\
\hline F1LSC8 & RIMS-binding protein 2 \\
\hline Q3B7U9 & Peptidyl-prolyl cis-trans isomerase FKBP8 \\
\hline P15865 & Histone H1.4 \\
\hline Q5PPM8 & Transmembrane protein 55B \\
\hline G3V874 & Erythrocyte protein band 4.1-like 3, isoform CRA \\
\hline Q6P3V8 & Eukaryotic translation initiation factor $4 \mathrm{~A} 1$ \\
\hline Q921A2 & Proton myo-inositol cotransporter \\
\hline Q5FWT1 & Protein FAM98A \\
\hline Q9QYJ4-3 & Isoform 3 of ATP-binding cassette sub-family B member 9 \\
\hline B1WBL7 & Tmem38a protein \\
\hline F1LVX6 & Protein Tmem132b \\
\hline Q6MG11 & Alpha-tubulin $\mathrm{N}$-acetyltransferase \\
\hline Q5PQL3 & Signal peptide peptidase-like 2B \\
\hline Q0D2L2 & Protein LOC683519 \\
\hline Q08415-2 & Isoform 2 of Kynurenine--oxoglutarate transaminase 1, mitochondrial \\
\hline G3V9S0 & Cytochrome b5 reductase 1 \\
\hline D4ADU2 & Protein Slc7a11 \\
\hline Q1JU68 & Eukaryotic translation initiation factor 3 subunit $A$ \\
\hline Q6PEC4 & S-phase kinase-associated protein 1 \\
\hline
\end{tabular}


Appendix 12. List of 38 mitochondrial proteins additionally identified above the threshold line in the stx 1 IPS.

\begin{tabular}{|c|c|}
\hline $\begin{array}{l}\text { Protein } \\
\text { ID }\end{array}$ & Protein name \\
\hline B2RYS2 & Cytochrome b-c1 complex subunit 7 \\
\hline G3V9N1 & Serine/threonine-protein phosphatase Pgam5 \\
\hline P32551 & Cytochrome b-c1 complex subunit 2, mitochondrial \\
\hline B1WBY5 & DnaJ (Hsp40) homolog, subfamily C, member 11 \\
\hline P35571 & Glycerol-3-phosphate dehydrogenase, mitochondrial \\
\hline MORDI5 & Protein Mcu \\
\hline Q6AXV4 & Sorting and assembly machinery component 50 homolog \\
\hline Q641Z9 & succinate dehydrogenase \\
\hline G3V7Y3 & ATP synthase subunit delta, mitochondrial \\
\hline MOR6L8 & Similar to homolog of yeast TIM14 isoform c (Predicted) \\
\hline A9UMW2 & Protein Ndufa3 \\
\hline Q812B0 & Liver regeneration-related protein 1 \\
\hline Q6IRL2 & Mitofusin 2 \\
\hline G3V8F5 & Mitochondrial import receptor subunit TOM40 homolog \\
\hline E9PU34 & Protein Rmnd1 \\
\hline P36970-2 & Phospholipid hydroperoxide glutathione peroxidase, mitochondrial \\
\hline Q5UAJ5 & ATP synthase protein 8 \\
\hline P19511 & ATP synthase $F(0)$ complex subunit $B 1$, mitochondrial \\
\hline Q75Q41 & Mitochondrial import receptor subunit TOM22 homolog \\
\hline Q9Z142 & Transmembrane protein 33 \\
\hline D3ZUX5 & Coiled-coil-helix-coiled-coil-helix domain containing 3 (Predicted) \\
\hline Q5M915 & Cytochrome b-c1 complex subunit 6, mitochondrial \\
\hline A1L1L6 & Mitochondrial Rho GTPase \\
\hline Q05BA4 & Myeloid-associated differentiation marker \\
\hline 089035 & Mitochondrial dicarboxylate carrier \\
\hline P97521 & Mitochondrial carnitine/acylcarnitine carrier protein \\
\hline Q9TEE8 & Cytochrome c oxidase subunit 3 \\
\hline Q3KR86 & MICOS complex subunit Mic60 \\
\hline D3ZS75 & Ndufc1 \\
\hline P63031 & Mitochondrial pyruvate carrier 1 \\
\hline D4A7N1 & MICOS complex subunit Mic25 \\
\hline Q2TA68 & Dynamin-like 120 kDa protein, mitochondrial \\
\hline Q8CFD0 & Sideroflexin-5 \\
\hline Q80W89 & NADH dehydrogenase [ubiquinone] 1 alpha subcomplex subunit 11 \\
\hline P32089 & Tricarboxylate transport protein, mitochondrial \\
\hline В0К020 & CDGSH iron-sulfur domain-containing protein 1 \\
\hline G3V6D3 & ATP synthase subunit beta \\
\hline B2RYK4 & Similar to RIKEN cDNA 1200007B05 \\
\hline
\end{tabular}




\section{Curriculum Vitae}

\section{PERSONAL INFORMATION}

Name

Adress

Email

Nationality

Date of birth

Place of birth
Momchil Nikolaev Ninov

Immanuel-Kant-Str. 32, 37083 Göttingen

mninov@mpibpc.mpg.de

Bulgarian

$11^{\text {th }}$ February 1986

Pleven, Bulgaria

\section{EDUCATION}

$2011-2015$

Max Planck Institute For Biophysical Chemistry

PhD in Department of Neurobiology (Supervisor Prof. Dr. Reinhard Jahn)

Thesis: Biochemical characterization of presynaptic membrane protein complexes

$2009-2011$

\section{Georg August University Göttingen}

International Max Planck Research School in Molecular Biology

Master thesis at Weizmann Institute of Science, Rehovot (Israel):

EGF-induced microRNA turnover (Supervisor Prof. Dr. Yosef Yarden)

$2005-2009$

Sofia University “St. Kliment Ohridsky”

Bachlor of Science in Organic and Bioorganic Chemistry, Faculty of Chemistry and Pharmacy

$2000-2005$

Foreign Language High School, Pleven, Bulgaria

Neue Oberschule High School, Braunschweig, Germany 


\section{CONFERENCES AND MEETINGS}

European Synapse Meeting (Balaton Lake, Hungary)

SynSYS Consortium meetings (Paris and Rome)

Horizons in Molecular Biology (2011, 2012, 2013, 2014)

\section{AWARDS AND SCHOLARSHIPS}

$2010-2011$

Scholarship by Verein zur Förderung der molekularen Biowissenschaften e.V, Germany and Max Planck Society

2010

Membership at American Chemical Society

2009

Winner in an open student competition and excellence scholarship holder of V. I. Vernadsky Foundation, Russia

$2009-2010$

Scholarship by the German Academic Exchange Service (DAAD)

$2009-2010$

Scholarship holder of the Vernadsky Foundation, Russia

2008

Erasmus Scholarship, 6 months at the University of Saarland, Germany

2007 Young researcher “Alma Mater” Prize by the Sofia University "St. Kl. Ohridsky” for High Scientific Achievements in Chemistry

$2005-2009$ Scholarship for Academic Excellence, Sofia University "St. Kliment Ohridsky”, Sofia, Bulgaria

2005 Award of the Department of General and Inorganic Chemistry

\section{PUBLICATIONS}

Chiono V., Gentile P., Boccafoschi F., Carmgnola I, Ninov M., Georgieva V, Georgiev G., Ciardelli G. Photoactive chitosan switching on bone-like apatite deposition. Biomacromolecules.2010 Feb 8;11(2):309-15 (PMID: 20085315) 